\title{
Technology Adoption, Productivity, Efficiency, and Risk Exposure in the Ethiopian Small Farm Sector
}

\author{
Dissertation \\ to obtain the doctoral degree \\ in the International Ph.D. Program for Agricultural Sciences in Goettingen (IPAG) \\ at the Faculty of Agricultural Sciences, \\ Georg-August-University Goettingen, Germany
}

\author{
presented by \\ Zewdu Ayalew Abro \\ born in Gorarba, Ethiopia
}

Göttingen, July 2018 
D7

Name of supervisor: Prof. Dr. Matin Qaim

Name of co-supervisor: Prof. Dr. Meike Wollni

Name of co-supervisor: Prof. Dr. Bernhard Brümmer

Date of dissertation: 20.07 .2018 


\section{Summary}

Poverty and food insecurity are key global challenges. In the history of agriculture, advances in technology have contributed to increased food supply. Particularly, the green revolution has brought remarkable productivity growth in developing countries. Over the last six decades, the productivity of staple crops - such as maize, rice and wheat - has more than doubled. This in turn has increased food supply, calorie availability, and lowered food and feed prices. However, the green revolution was not sustainable because of the accompanying environmental problems that caused soil and water pollution, loss of biodiversity, greenhouse gas emissions and eventually human health problems. Since the green revolution targeted irrigated and high potential areas, many poor people living in marginal areas were also left behind.

Additional growth in agricultural productivity is required to reduce poverty, food and nutrition insecurity, and to meet the future demand for agricultural products. Goal two of the UN Sustainable Development Goals targets doubling productivity between 2015 and 2030 through sustainable agricultural intensification. Sustainable intensification necessitates the use of technologies and practices that increase productivity while enhancing resilience of farmers and their farming systems to climate change. Being promoted as climate-smart agriculture, the technologies and practices should enable maintaining healthy soils for crop nutrition, promoting biodiversity, containing diseases, pests and weeds, and improving efficiency of water use, and they are often context specific. Many empirical studies have attempted to identify appropriate technologies and practices for various farming systems. In this dissertation, we contribute to this body of literature by analyzing the productivity, efficiency, and risk implications of farmers' tillage and seed choice practices. The analysis builds on two representative panel household datasets from the small farm sector in Ethiopia. The dissertation consists of three essays addressing distinct research objectives.

Conservation agriculture in general and reduced tillage in particular is gaining attention as one component of climate-smart agriculture. However, farmers in many developing countries still practice intensive tillage since reduced tillage is largely unknown to them. The economic implications of intensive tillage practices are not yet sufficiently studied even though this is crucial for designing sustainable tillage policy and promotion of conservation agriculture. In Essay 1, we analyze the impact of farmers' intensive tillage practices on wheat productivity and farmers' risk exposure. To the best of our knowledge, this research is the first that documents the impact of intensive tillage practices on farmers' risk exposure in developing countries. Furthermore, previous 
studies on conservation agriculture treat non-adopters of reduced tillage as a homogeneous group. Nevertheless, farmers who practice intensive tillage are more likely to be heterogeneous. Our data provide us with an opportunity to understand the heterogeneous effects of various intensities of tillage. In order to control for selection bias associated with the choice of intensity of tillage, we estimate a flexible moment-based production function using an endogenous switching regression treatment effects model. We find that higher intensities of tillage are associated with higher productivity than lower intensities of tillage. Our findings also show that exposure to risk is lower in higher intensities of tillage and that the estimated risk premium, which is the amount risk averse farmers are willing to pay to avoid risk, is the lowest at higher intensities of tillage. We conclude that farmers use tillage as a strategy to increase productivity and minimize production risks. This suggests that the opportunity costs of switching to reduced tillage are rather high unless farmers are supported by appropriate incentive schemes.

Reducing production losses associated with crop diseases is one of the key objectives of climatesmart agriculture, and rust diseases are one of the major wheat production threats worldwide. The importance of breeding for disease resistance using locally adapted and preferred germplasms are well understood in theory. However, the performance of improved disease resistant varieties in farmers' fields has rarely been quantified. While the productivity effects of improved varieties are well studied, most studies do not distinguish between different varietal traits such as rust resistance traits. In Essay 2, we evaluate the effects of using rust-resistant varieties on wheat productivity. We compare improved varieties that are resistant to stripe rust with improved susceptible and traditional susceptible varieties. Our production function estimates show that improved resistant varieties are more productive than traditional varieties. Furthermore, the productivity gains of improved resistant varieties are higher than improved susceptible varieties. Under drought and other abiotic stresses, our results further show that improved varieties - with and without resistance to yellow rust performed notably worse than traditional varieties. We observe that breeders were able to successfully combine rust-resistance traits with high yield traits. However, the poor performance of improved varieties during droughts and other stresses may indicate that improved varieties are not well adapted to farmers' production conditions. The policy implication is that sustainable adoption depends on the success of breeding to not only improve disease resistance and yield traits but also to improve drought tolerance and other production stresses in the same varieties.

Even though high yielding improved varieties provide higher productivity on average, farmers may sub-optimally use improved varieties because they may not always use genetically pure quality seeds of the improved varieties. An important reason for sub-optimal use of improved varieties is 
the seed recycling practices of farmers in many developing countries. While the impacts of new improved varieties on productivity and efficiency are well documented, the productivity and efficiency effects of fresh and recycled seeds have rarely been studied. In Essay 3, we analyze the impact of using fresh seeds, compared to using recycled seeds from the previous harvest, on both land productivity and efficiency of maize farmers. Given the slow varietal turnover rate and seed recycling practices of farmers in many developing countries, quantifying the benefits of using fresh seeds can help to shed light on how to design strategies of attaining higher productivity in an efficient way without introducing new improved varieties. We estimate random effects production functions in an endogenous switching regression treatment effects model. We find that farmers who used fresh seeds are not only more productive but also more efficient. The observed gains in productivity and efficiency indicate that promoting fresh seeds can potentially contribute to food security. Despite the productivity and efficiency gains, our results further show the presence of significant inefficiency in inputs use. Closing farmers' inefficiency may need a concerted effort in designing policy instruments that promote input use efficiency.

Overall, the three essays show that farmers' tillage and seed choice practices are heterogeneous, often varying across plots of the same household. Speeding up widespread adoption of climatesmart agriculture technologies needs to consider these heterogeneous practices and their implications for productivity, efficiency, and production risk. Climate-smart agricultural policies may need to promote modern biotechnology tools for breeding improved varieties responsive to reduced tillage, adapted to the local soil and climatic conditions, and consumption preferences. 


\section{Acknowledgements}

First of all, I would like to thank my supervisor Prof. Dr. Matin Qaim for providing me the chance to join his research group as a doctoral researcher. I also thank Prof. Qaim for his guidance and feedback since the inception of my research proposal in early 2013. I would like to thank Prof. Dr. Meike Wollni and Prof. Dr. Bernard Brümmer for agreeing to be members of the examination committee. Many thanks to Ilona Hoepfner for her kind professional support throughout my studies.

I would like to thank the International Maize and Wheat Improvement Center (CIMMYT) for making available the datasets used in this dissertation. Special thanks go to Dr. Olaf Erenstein, the Director of CIMMYT's Socio-Economics Program, for encouraging me to explore the CIMMYT datasets. The three papers in this dissertation are joint works with other researchers. I would like to thank Dr. Bethelhem Legesse Debela, Dr. Moti Jaleta and Dr. Hailemariam Teklewold for their collaboration and contribution. I gratefully acknowledge the German Academic Exchange Service (DAAD) for financing my studies. Special thanks go to Mr. Michael Hillenblink and Ms. Lena Leumer for their professional support on matters related to my stipend at the DAAD.

Life would have been difficult without my colleagues at the Chair of International Food Economics and Rural Development. It is an honor to be part of this dynamic research group. I would like to thank everybody for their support and interactions throughout my studies (Andrea, Anika, Christoph, Daniel, Dennis, Esther, Eva, Haruna, Jonida, Kathrin, Kenneth, Kibrom, Lisa Jäckering, Lisa Straussberger, Makaiko, Marco, Nadjia, Priscilla, Rosina, Stefan, Sylvester, Theda, and Vijesh). Special thanks go to Anika, Christoph and Kibrom for their comments and suggestions on the earlier draft of the dissertation.

Dr. Camilla Andersson, Dr. Bamlaku Alamirew Alemu and Dr. Gebeyehu Manie Fetene have been on my side since the inception of my studies providing me with invaluable support. Thank you all! I would also like to thank Dr. Kelemework Geleta Gebeyehu and Zewdie Adane Mariami for their friendship. Last but not least, my special thanks go to my sisters Alem, Almaz, Aziza, Meseret and Roza, and my brother Isaiase for taking care of our family. 


\section{Dedication}

To my father Ato Ayalew Abro Shibeshi, my mother Woyzero Mulu Yesuf Adem, and my grandmother Woyzero Lakech Meshesha Hussien. They are important personalities in my life who have given me a generous gift, education!

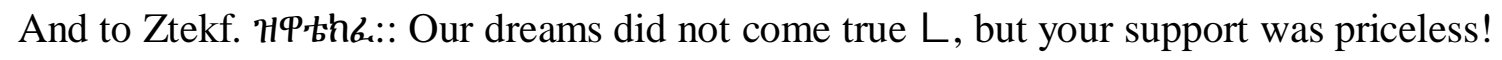




\section{Table of Contents}

Summary

Acknowledgements ......................................................................................................................................iv

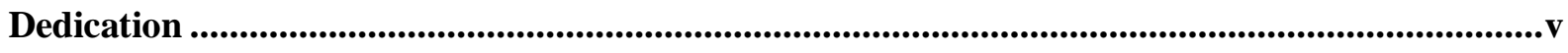

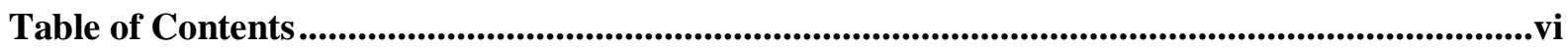

List of Tables............................................................................................................................................ viii

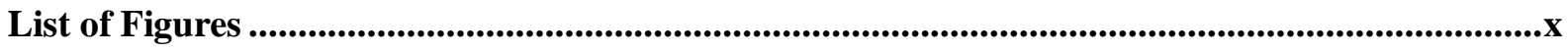

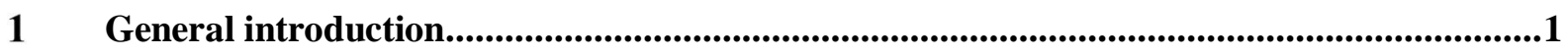

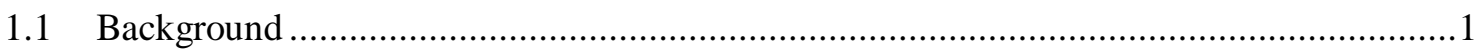

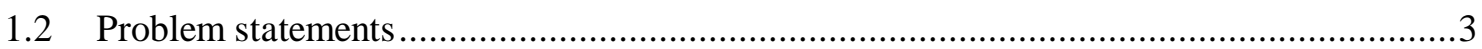

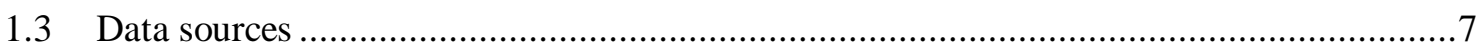

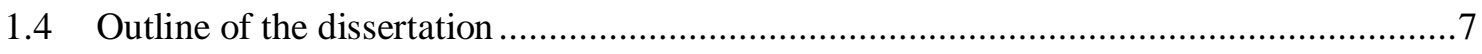

2 Does intensive tillage enhance productivity and reduce risk exposure? Panel data evidence from smallholders' agriculture in Ethiopia ..............................................................................................8

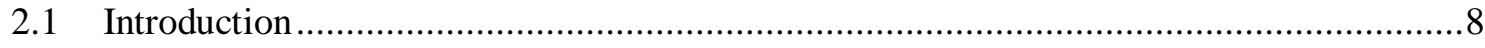

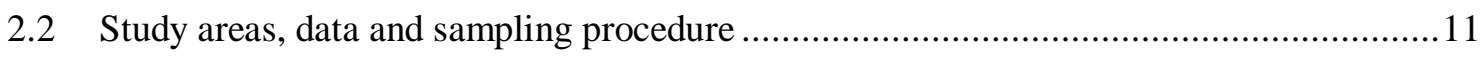

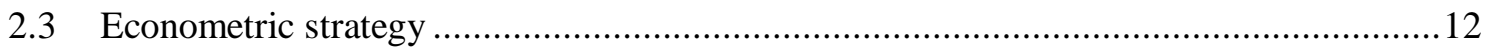

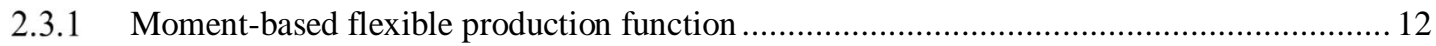

2.3.2 The endogenous switching regression model.................................................................... 13

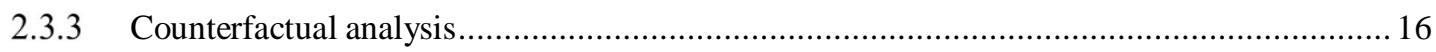

2.3.4 The impact of intensity of tillage on the cost of risk .......................................................... 17

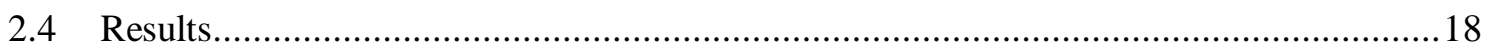

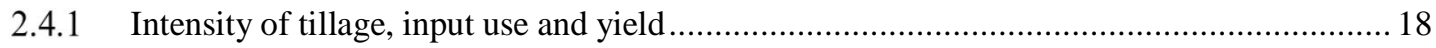

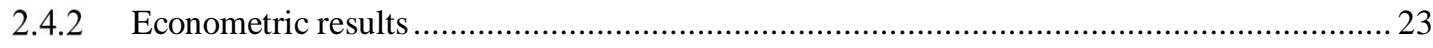

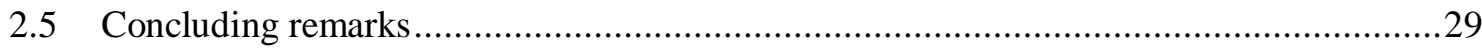

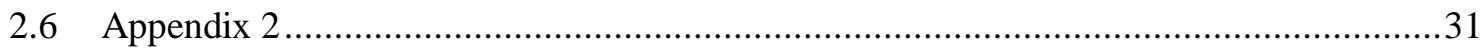

$3 \quad$ Yield effects of rust-resistant wheat varieties in Ethiopia...................................................47 


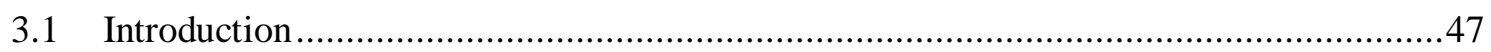

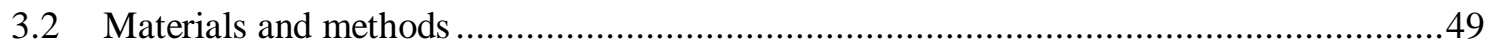

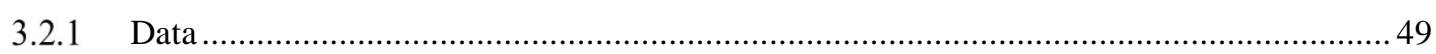

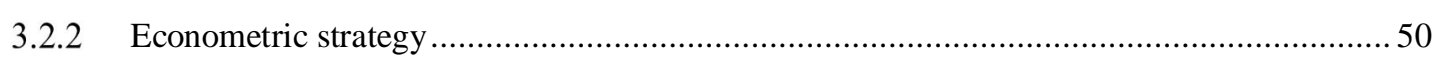

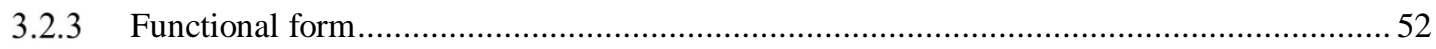

3.2.4 Testing for local adaptation of improved varieties ............................................................5 53

3.2.5 Accounting for possible selection bias ........................................................................ 53

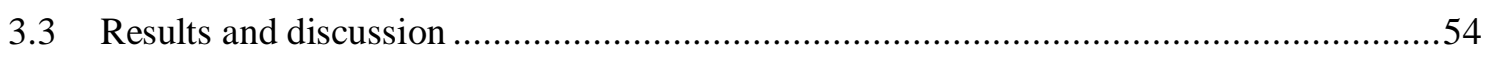

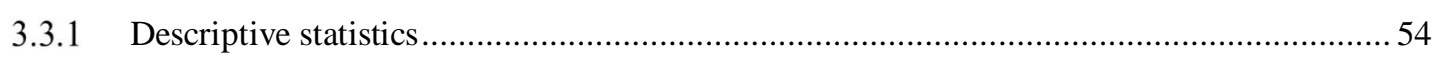

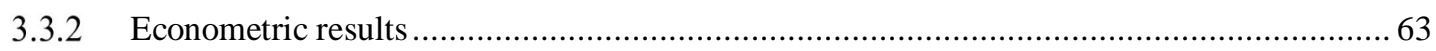

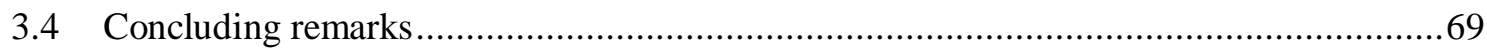

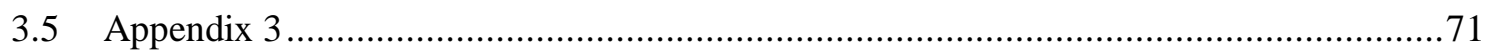

4 The impact of using fresh seeds on land productivity and efficiency: evidence from smallholder agriculture in Ethiopia ........................................................................................................................................75

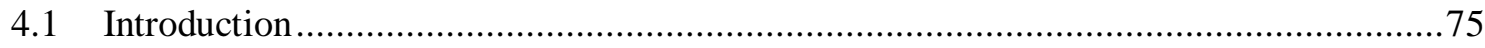

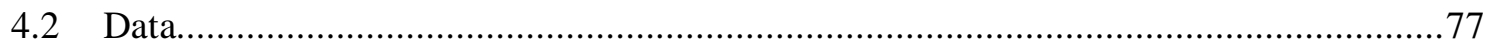

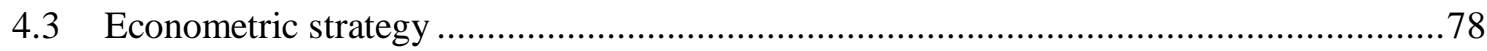

4.3.1 Endogenous switching random effects production function …………………................. 79

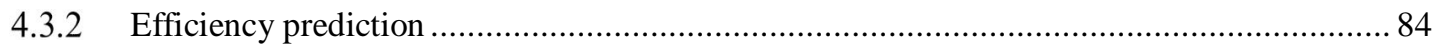

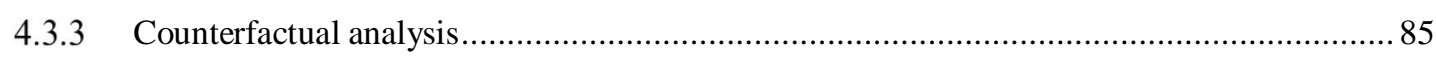

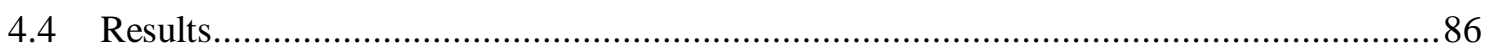

4.4.1 Patterns of maize seed use, production stresses, inputs use, and land productivity ................86

4.4.2 The impact of using fresh seeds on land productivity and efficiency …….............................93

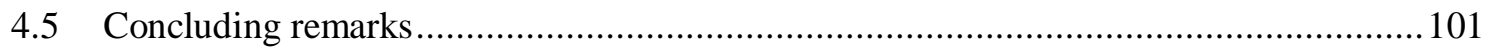

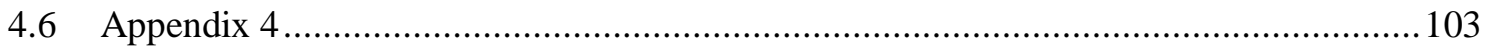

$5 \quad$ General conclusion...........................................................................................................119

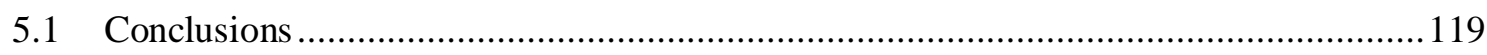

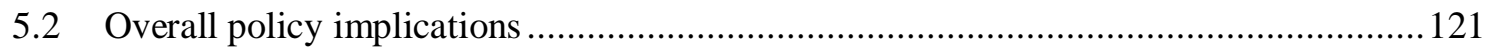

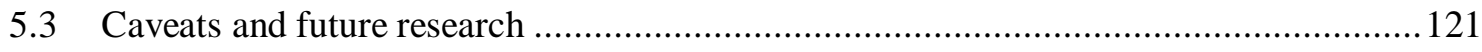

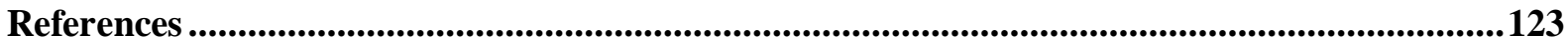




\section{List of Tables}

Table 2.1. Frequency of tillage (2009/10-2013/14) (\%)

Table 2.2. Transition matrix: change in frequency of tillage between 2009/10 and 2013/14 (\%). 20

Table 2.3. Inputs use and intensity of tillage (2009/10-2013/14)

Table 2.4. Average treatment effects on the treated (ATTs) on yield and risk exposure (variance and skewness).

Table 2.5. Summary statistics, descriptions and measurements for the variables used in the regressions (2009/10-2013/14).

Table 2.6. The selection equation, random effects ordered logit model (REOLM).

Table 2.7. Results of the endogenous switching regressions (logarithms of yield ( $\mathrm{kg} / \mathrm{ha}$ ) by intensity of tillage).

Table 2.8. Results of the endogenous switching regressions: the dependent variables are risk exposure (variances by intensity of tillage).

Table 2.9. Results of the endogenous switching regressions: the dependent variables are risk exposure (skewness by intensity of tillage).

Table 2.10. Average treatment effects on the treated (ATTs) on yield and risk exposure (variance and skewness) by three rainfall regimes.

Table 2.11. Average treatment effects on the treated (ATTs): net return to land (Birr/ha) and risk exposure (variance and skewness)

Table 3.1. Description and measurement of variables used in the analysis. 55

Table 3.2. Importance of wheat for sample households. 56

Table 3.3. Plot level incidence of various abiotic and biotic factors. 56

Table 3.4. Intensity of input use. 60

Table 3.5. Model diagnostics 64 
Table 3.6. Determinants of wheat yield (different model specifications).

Table 3.7. Role of interactions between types of varieties and production stress in explaining wheat yield. 68

Table 3.8. List of improved wheat varieties and levels of stripe rust resistance. 71

Table 3.9. Input interaction terms and district dummies from wheat yield model. 72

Table 4.1. Descriptions and summary statistics of variables. 82

Table 4.2. Maize seed purchase constraints 91

Table 4.3. Incidence of production stresses by seed type (\%). 91

Table 4.4. Inputs' use by seed type. 93

Table 4.5. The impact of fresh seeds on land productivity..... 94

Table 4.6. The impact of using fresh seeds on efficiency. 98

Table 4.7. The multinomial logit selection model for seeds use. 103

Table 4.8. The random effects switching regressions. 106

Table 4.9. Average treatment effects on the treated and untreated using the variants of the exogenous switching regressions (land productivity).

Table 4.10. Average treatment effects on the treated and untreated using the variants of the exogenous switching regressions (efficiency) 112

Table 4.11. Impact of using fresh seeds on log of land productivity $(\mathrm{kg} / \mathrm{ha})$ based on the endogenous switching regression model.

Table 4.12. The impact of fresh seeds on net return to land (Birr/ha). 116 


\section{List of Figures}

Figure 2.1. Wheat yield distributions by frequency of tillage and survey year........................ 21

Figure 2.2. The impact intensity of tillage on costs of risk. ................................................ 28

Figure 2.3. The impact intensity of tillage on costs of risk: net return to land and risk exposure

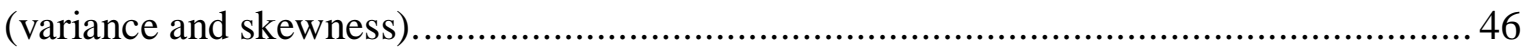

Figure 3.1. Percentage of wheat plots by type of variety. ................................................. 57

Figure 3.2. Mean wheat yields on sample plots and experimental stations $(\mathrm{kg} / \mathrm{ha}) . \ldots \ldots \ldots \ldots \ldots \ldots . . . . .58$

Figure 3.3. Distribution of wheat yield by type of variety...............................................5 59

Figure 3.4. Plot characteristics and input use by type of wheat variety................................... 63

Figure 3.5. Plot level adoption of varieties by agroecology (both survey rounds)..................... 74

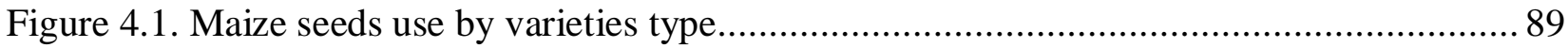

Figure 4.2. Percentage of maize area cultivated by the age of improved varieties..................... 90

Figure 4.3. Distributions of land productivity by seed type (2009/10-2012/13) ...................... 92

Figure 4.4. Distributions of predicted value of land productivity $(\mathrm{kg} / \mathrm{ha})$ in actual and counterfactual

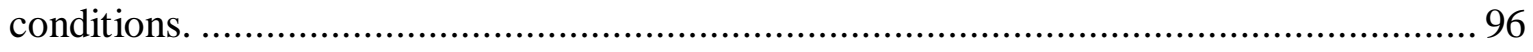

Figure 4.5. Distributions of actual estimated efficiency of farming households by seed type...... 97

Figure 4.6. Distributions of efficiency of farming households in the actual and counterfactual conditions.

Figure 4.7. Distributions of predicted log of land productivity $(\mathrm{kg} / \mathrm{ha})$ in actual and counterfactual

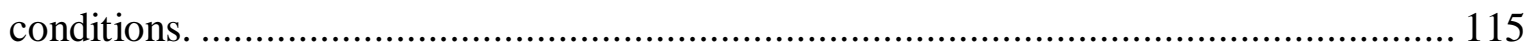

Figure 4.8. Distributions of predicted value of net return to land (Birr/ha) in actual and counterfactual conditions. 


\section{General introduction}

\subsection{Background}

Globally, poverty and food insecurity are formidable challenges. Estimates show that 766 million people lived below the $\$ 1.90$ per day poverty line (World Bank, 2017), 688 million people were severely food insecure, and 815 million were undernourished in 2016 (FAO, 2017). The world population is estimated to grow by $33 \%$ until 2050, which will require cereal production to increase by $60 \%$ between 2007 and 2050 in order to meet the growing demand for food (Conforti, 2011). At the same time, the agricultural sector is threatened by climate change. Unless adaptation and mitigation measures are implemented, climate change will adversely affect agricultural production. By 2050 , it is likely that most places will be hotter by $1-3^{\circ} \mathrm{C}$, which may reduce the yield of major crops by at least 5\% (Jaggard et al., 2010).

Throughout the history of agriculture, advances in technology have led to increased food supply (Boserup, 2007; Qaim, 2016). Particularly, the green revolution has brought impressive productivity growth in developing countries of Asia. Productivity of staple crops such as maize, rice, and wheat more than doubled and overall food supply increased by $12-13 \%$ in developing countries between 1960 and 1990. Without the green revolution, world food and feed prices would have been about $35-65 \%$ higher, and calorie availability would have been lower by 11-13\% (Evenson and Gollin, 2003; Gollin et al., 2005; Pingali, 2012). Despite these remarkable successes, it is argued that the green revolution was not sustainable because of the accompanying environmental problems that have caused severe soil and water pollution, loss of biodiversity, and greenhouse gas emissions and eventually human health problems (FAO, 2013; Gollin et al., 2005; Lee et al., 2006; Pingali, 2012; Tilman et al., 2002; World Bank, 2012). Many poor people who live in marginal areas were left behind because the green revolution targeted irrigated and high-potential rain-fed areas (IFPRI, 2002). It bypassed many of the sub-Saharan African countries where the majority of poor people live today (Pingali, 2012).

Sustainable agricultural intensification is a fundamental step towards producing enough food without harming the environment (Barrett et al., 2017; FAO, 2018; IFAD, 2016; UN, 2015). Goal two of the UN Sustainable Development Goals targets doubling productivity of the small farm sector between 2015 and 2030 by promoting sustainable production practices. Since 2009, the 
existing sustainable production technologies and practices are being promoted as climate-smart agriculture (CSA). CSA integrates economic, social, and environmental dimensions of sustainable agricultural development. The objectives of CSA include food and nutrition security for all people through increased productivity and incomes and to improve farmers' resilience and adaptation to climate change. CSA should maintain and improve soil fertility, reduce greenhouse gas emissions, promote crop biodiversity, reduce the incidence of pests, diseases and weeds, and enable efficient management of water (FAO, 2013, 2018). The suitability of various CSA technologies and practices depends on many conditions that can vary across agroecological zones (Lee et al., 2006; Wainaina et al., 2017). The context specificity of CSA calls for empirical research relevant to various agroecological zones. Many studies have attempted to identify appropriate technologies and practices in various farming systems (El-Shater et al., 2016; Jaleta et al., 2016; Kassie et al., 2015b; Krishna and Veettil, 2014; Wainaina et al., 2016, 2017).

One of the sustainable production practices promoted as CSA is conservation agriculture, which is defined as a cultivation system based on three principles: minimal soil disturbance (zero, minimum or reduced tillage), proper crop residue management, and maintaining crop biodiversity using crop rotations (Hobbs et al., 2008). In particular, reduced tillage is gaining attention in the climate change debate, yet it is not common in many production contexts where farmers still practice intensive tillage (Andersson and D'Souza, 2014; Teklewold and Mekonnen, 2017). While the agronomic benefits of intensive tillage are well-understood (Hobbs et al., 2008; Sime et al., 2015; Temesgen et al., 2008), its economic implications at the farm level are not yet sufficiently studied.

Besides reduced tillage, the adoption of high yielding improved varieties and high quality seeds is promoted as CSA. Seed choice is crucial as an ex ante risk management strategy to minimize losses due to production shocks and to improve productivity (FAO, 2013, 2018; Fisher et al., 2015; Shiferaw et al., 2011, 2014b). A large body of literature on seed choice exists (Evenson and Gollin, 2003; Feder et al., 1985; Gollin et al., 2005; Pingali, 2012; Walker and Alwang, 2015), in which adoption is often defined as a binary variable, indicating if farmers adopt improved varieties or not. However, in reality, farmers' seed choice is more complex because there are many kinds of varieties of the same crop with various traits (Glover et al., 2016; Sumberg, 2016). Farmers often cultivate several varieties of the same crop spreading across various plots. Furthermore, farmers may suboptimally use improved varieties because they may not always use genetically pure seeds of improved varieties (Abate et al., 2015; Alemu and Bishaw, 2015; Fisher et al., 2015; Sisay et al., 2017). In fact, in many developing countries, seed recycling is a common practice among farmers, which affects the quality of seeds. This implies that the commonly used binary indicator of adoption 
ignores important elements of seed choice regarding the heterogeneity of varieties with different traits and seed characteristics. Understanding the implication of farmers' heterogeneous seed choice practices is crucial to design appropriate seed policies that consider farmers' diverse preferences, ecological and socioeconomic conditions.

The dissertation addresses the implications of small-scale farmers' production practices in light of promoting climate-smart agriculture in three essays. Essay 1 focuses on the productivity and risk implication of heterogeneous intensive tillage practices. Essay 2 sheds light on the productivity effects of improved rust disease resistant varieties in comparison to disease susceptible high yielding improved varieties, and varieties with a good adaptation to the production environment but with no such traits. Essay 3 looks at productivity and efficiency effects of using fresh seeds in comparison to recycled seeds.

\subsection{Problem statements}

In the history of agriculture, tillage evolved as a distinctive farming technology (Boserup, 2007) and has many agronomic benefits. First, tillage suppresses weeds (Boomsma et al., 2010; Erkossa et al., 2006; Guan et al., 2015; Sime et al., 2015; Temesgen et al., 2008; Weiner et al., 2001). Low density of weeds reduces the competition for available soil nutrients and the amount of labor needed for weeding activities. Second, tillage disturbs the growth cycle of diseases that exist in the soil and plant debris, which reduces the incidence of pests and diseases (Bailey, 1996; Bockus and Shroyer, 1998; Krupinsky et al., 2007). Third, tillage can increase soil moisture by increasing the water infiltration rate (Blevins and Frye, 1993; Guan et al., 2015; Sime et al., 2015; Temesgen et al., 2008; Wang et al., 2002). Fourth, tillage softens the soil and allows the preparation of a fine seedbed, which facilitates uniform seed germination. Uniform seed germination in turn increases the density of the plant and suppresses weeds (Hobbs et al., 2008; Mouazen et al., 2007; Weiner et al., 2001). These agronomic benefits underscore the use of intensive tillage as an ex-ante risk management strategy in order to reduce potential production risks induced by various stresses such as diseases and weeds.

Proponents of conservation agriculture, on the other hand, argue that reduced tillage saves labor and energy costs of intensive tillage while minimizing environmental footprints. Reduced tillage could also increase agricultural productivity by replenishing soil organic matter. This in turn improves carbon sequestration and reduces greenhouse gas emissions (Hobbs et al., 2008). In drought prone 
areas, soil disturbance through tillage may lead to loss of organic matter and moisture evaporation, which may increase the chance of crop failure (Hobbs et al., 2008; Kassam et al., 2009). Many empirical studies find that adopters of reduced tillage have a higher productivity and income than non-adopters (El-Shater et al., 2016; Erenstein et al., 2008; Jaleta et al., 2016; Kassie et al., 2015b; Krishna and Veettil, 2014; Teklewold et al., 2013b). Due to the potential productivity gains and ecological benefits shown by empirical studies in developing countries, the development community promotes the adoption of reduced tillage. However, adoption remains quite low and even dis-adoption has been reported (Andersson and D'Souza, 2014; Brown et al., 2017; Lalani et al., 2016; Pedzisa et al., 2015). Low adoption might be explained by the absence of locally adapted reduced tillage technologies (e.g., zero tillage seeders), lack of farmers' exposure to the technologies, and high initial investment costs (e.g., herbicides to suppress weeds) (El-Shater et al., 2016; Loss et al., 2015). Furthermore, no substitutes exist for competing end uses of crop residues, which is one of the complementary practices of reduced tillage. This may make reduced tillage less attractive to smallholder farmers (Jaleta et al., 2015). Especially, in sub-Saharan Africa, several studies argue that reduced tillage may not deliver the expected benefits to smallholder farmers (Giller et al., 2009, 2011; Halbrendt et al., 2014; Tessema et al., 2015).

In order to understand the reason for low adoption rates of reduced tillage, it is fundamental to study farmers' motivation for intensive tillage practices. However, the impact of different tillage intensities on productivity and income are hardly understood. Analyzing the crop level impact of various intensities of tillage remains crucial to document the productivity and production risk (e.g. crop failure) implication of tillage because various crops may respond differently to tillage practices. In the context of the small farm sector in developing countries, the only such study we are aware of is Teklewold and Mekonnen (2017) who analyze the impact of tillage intensities on income derived from cereal cultivation in Ethiopia. However, the study does not address the impact of intensive tillage practices on farmers' risk exposure. Studying the risk implication of tillage is important because the benefits of tillage are associated with reducing the incidence of weeds, pests, and diseases. We address these research gaps in Essay 1 by analyzing the impact of intensive tillage practices on productivity and risk exposure in wheat production.

As mentioned in Section 1.2, reducing production losses that might arise because of diseases is one of the key objectives of CSA. Worldwide, wheat production is threatened by frequent outbreaks of rust diseases, which cause estimated production losses of 15-20\% (FAO, 2014; Oerke, 2006). Since wheat accounts for a sizeable share of the global calories and protein consumed (Shiferaw et al., 2013), production losses may affect food security of producing farmers and consumers of wheat. 
Reducing losses is thus key to meet future food demand and reduce food insecurity (Hertel, 2015; Savary et al., 2017).

Improved rust disease resistant varieties could help to reduce production losses (Savary et al., 2017; Velu and Singh, 2013). These varieties have a disease resistant gene that could fight disease pathogens when outbreaks occur. They could also substitute fungicides, contributing to ecological sustainability (Dixon et al., 2006; Savary et al., 2006, 2012; Stuthman et al., 2007; Velu and Singh, 2013). Furthermore, the rust disease resistant varieties have high yielding traits that increase productivity (Gebre-Mariam et al., 1991; Savary et al., 2017; Velu and Singh, 2013).

Nonetheless, breeding improved varieties for disease resistance is challenging. Resistance traits have to be introduced to locally adapted and preferred varieties. The advantages through reducing production losses due to diseases could be offset by disadvantages resulting from the use of germplasm that is not well adapted to soil and climatic conditions (Krishna et al., 2016b; Qaim et al., 2006; Smale et al., 1998). Lack of local adaptation may in turn affect farmers' willingness to adopt rust disease resistant varieties. The importance of using locally adapted and preferred germplasms for breeding is well understood in theory, but the performance of improved disease resistant varieties has rarely been examined in empirical research at farm-level. Even though several studies analyze productivity effects of improved varieties, these studies do not distinguish between different varietal traits (Di Falco et al., 2007; Matuschke et al., 2007; Mazid et al., 2015; Teklewold et al., 2013a; Walker and Alwang, 2015). Our objective in Essay 2 is therefore to address this research gap by quantifying productivity gains from improved rust resistant varieties in relation to susceptible improved and traditional varieties, and the productivity response of these varieties to various production stresses in wheat production.

As mentioned above, CSA promotes high quality improved varieties, but farmers may suboptimally use these varieties. One important indicator of seed quality is whether farmers use fresh seeds or recycled seeds, which is the focus of Essay 3 (Spielman and Smale, 2017). Fresh seeds from seed producers are genetically pure and enable farmers to keep the productivity advantage of varieties when these varieties were initially released by breeders (Morris et al., 1999; Spielman and Smale, 2017). They might also be more responsive to external inputs and better withstand stresses, thus increasing productivity and input use efficiency (Byerlee, 1996; Fisher et al., 2015; Gollin et al., 2005). The productivity and efficiency gains of fresh seeds may in turn contribute to food security even without introducing new improved varieties. 
Although seed recycling leads to the deterioration of important genetic traits of seeds, it is a common practice in many developing countries (Morris et al., 1999; Shiferaw et al., 2014b). While avoiding the additional costs of purchasing fresh seeds is likely to be the main reason, seed selfsufficiency and stable yields across seasons are other important reasons for recycling seeds (Japhether et al., 2006; Morris et al., 1999; Sisay et al., 2017; Spielman and Smale, 2017). Stable yields of recycled seeds may enable farmers to have a reasonable expectation about the productivity of their fields. Farmers may also avoid delays on the arrival of fresh seeds by using recycled seeds, which may enable them to exploit the available soil moisture by planting on time.

There are two strands of literature on improved varieties adoption. The first strand focuses on the impact of improved varieties on land productivity (Amare et al., 2012; Bezu et al., 2014; Evenson and Gollin, 2003; Khonje et al., 2015; Manda et al., 2016; Teklewold et al., 2013b; Walker and Alwang, 2015; Zeng et al., 2015). Most of these studies underline the responsiveness of improved varieties to external inputs, but give little attention to the impact of improved varieties on farmers' efficiency. This strand of literature relies on estimating average production functions that do not account for efficiency. This is equivalent to assuming that all farmers are equally efficient (Coelli et al., 2005; Kumbhakar et al., 2015), but efficiency could explain part of the variation in land productivity among farmers. Failure to account for land productivity differences resulting from efficiency differences among farmers may lead to over- or underestimation of the benefits of seed choice.

The second strand of the literature focuses on farmers' efficiency. Some of the available studies on efficiency assume that farmers use homogenous seeds (Dhungana et al., 2004; Kalirajan, 1991; Kalirajan and Shand, 2001). This assumption however might be disputed because of farmers' seed recycling practices as documented in several studies (Evenson and Gollin, 2003; Walker and Alwang, 2015). Other studies on efficiency do not address seed recycling practices of farmers at all (Alene and Hassan, 2006; Battese et al., 2017; Xu and Jeffrey, 1998). Neglecting the role of heterogeneity of seed types when evaluating the impact of seed choice on productivity and efficiency could lead to misleading policy conclusions.

From the two strands of the literature, we see that the main focus of previous studies is varietal decisions, which is the replacement of one variety by another (mostly a new one). Surprisingly, no rigorous studies exist on the impact of using fresh seeds, in comparison to recycled seeds, on both land productivity and efficiency. Focusing either only on land productivity or efficiency may overor underestimate the potential benefits of seed choice. These research gaps may impede designing 
policies that account for farmers seed preferences, socioeconomic, and agroecological conditions. In Essay 3, we address these gaps by studying the impact of using fresh seeds, relative to recycled seeds, on both land productivity and efficiency using detailed classification of maize seeds used by smallholder farmers.

\subsection{Data sources}

The data for the dissertation comes from two separate household surveys conducted by the International Maize and Wheat Improvement Center (CIMMYT) and the Ethiopian Institute of Agricultural Research (EIAR) in 2010 and 2013. In order to address the research objectives for Essay 1 and Essay 2, we use two rounds of panel household survey data (2,096 households) collected from wheat producing districts in Ethiopia. For Essay 3, we exploited two rounds of panel household survey data (2,468 households) collected from maize producing districts in Ethiopia. Both datasets are representative of the major wheat and maize producing districts and were collected through face-to-face interviews with farmers, conducted by well-trained enumerators in local languages. Information on household-level socioeconomic and demographic factors, community characteristics, volume of production, varieties and seeds, and production constraints were collected for a census of all plots cultivated by each household.

\subsection{Outline of the dissertation}

The remainder of this dissertation is organized as follows. In Chapter 2, we present Essay 1. Essay 2 can be found in Chapter 3 and Chapter 4 contains Essay 3. Chapter 5 provides conclusions, policy implications, caveats and some suggestions for future research. 


\section{Does intensive tillage enhance productivity and reduce risk exposure? Panel data evidence from smallholders' agriculture in Ethiopia ${ }^{1}$}

\subsection{Introduction}

Tillage is one of the most important innovations in our history to offset deteriorating natural soil fertility (Boserup, 2007; Hobbs et al., 2008). Agronomic studies show that intensive tillage practices have four main benefits. First, tillage suppresses already germinated weeds, and it initiates new weed germination. Suppressing weeds helps crops to use the available soil nutrients without competition (Boomsma et al., 2010; Erkossa et al., 2006; Guan et al., 2015; Sime et al., 2015; Temesgen et al., 2008; Weiner et al., 2001). Low density of weeds saves additional labor spent in weeding activities. Second, as plant debris is mixed with the soil through tillage, the incidence of foliar diseases that may survive from previous infections could decline (Bailey, 1996; Bockus and Shroyer, 1998; Krupinsky et al., 2007). Third, intensive tillage could increase soil moisture by increasing water infiltration rate (Blevins and Frye, 1993; Guan et al., 2015; Sime et al., 2015; Temesgen et al., 2008; Wang et al., 2002). Last but not the least, by softening the soil and allowing the preparation of fine seedbed, tillage facilitates uniform seed germination. Uniform seed germination in turn increases the density of the plant and suppresses weeds (Hobbs et al., 2008; Mouazen et al., 2007; Weiner et al., 2001). Consequently, intensive tillage serves as an ex-ante risk management strategy in order to reduce potential production risks induced by various stresses such as diseases and weeds.

However, the conservation agriculture $(\mathrm{CA})^{2}$ literature shows that intensive tillage practices disturb the biological functions of soil microorganisms and its diversity leading to loss of soil organic

\footnotetext{
${ }^{1}$ This chapter is published as Abro, Z. A., Jaleta, M., and Teklewold, H. 'Does Intensive Tillage Enhance Productivity and Reduce Risk Exposure? Panel Data Evidence from Smallholders' Agriculture in Ethiopia'. Journal of Agricultural Economics, (2018). Available at https://doi.org/10.1111/1477-9552.12262. ZAA designed the research, analyzed the data, and wrote the first draft of the paper. MJ collected the data. MJ and HT commented on the data analysis and contributed to writing the paper.

${ }^{2} \mathrm{CA}$ has three main components: minimum soil disturbance, crop rotation and intercropping, and crop residue management (Hobbs et al., 2008). In order to draw sound conclusion about the impact of tillage on yield and production risk, these factors need to be controlled. The findings we present in this paper are robust to differences in practicing crop rotation and residue management.
} 
matter (Hobbs et al., 2008; Kassam et al., 2009; Lal, 2001). Soil organic matter provides not only the necessary nutrients for crop growth but also stabilizes soil structure. Tillage induced loss of soil organic matter thus leads to lower soil fertility (Kassam et al., 2009). Furthermore, in drought prone areas, intensive tillage practices may lead to soil moisture evaporation, increasing the chance of crop failures (Kassam et al., 2009; Piggin et al., 2015; Shiferaw et al., 2014a). Despite such negative effects, intensive tillage is widely practiced in many developing countries (Giller et al., 2009; Grabowski et al., 2016; Lalani et al., 2016; Stevenson et al., 2014).

In this chapter, our goal is to analyze the impact of intensive tillage practices on productivity and risk exposure of wheat farmers. We use two rounds of panel data collected in Ethiopia. Ethiopia is an interesting case study because intensive tillage practices remain the dominant method of seedbed preparation, and reduced tillage is rarely practiced (Jaleta et al., 2016). Furthermore, the majority of farmers have a deep historical connection with the plough (Aune et al., 2001; McCann, 1995). It is thus important to understand farmers' motivation behind their strong attachment with the millennia old intensive ox-plough tillage system. This tillage system is under pressure because of its implications for soil degradation (Aune et al., 2001). Introduction of sustainable tillage practices is a challenge to policy makers. By shedding light on the opportunity costs of switching to reduced tillage, our study should help identify policy instruments that consider the trade-offs between the biophysical, economic and risk effects as well as the needs and preferences of smallholder farmers in Ethiopia and elsewhere with similar tillage systems.

Many studies find that the introduction of reduced tillage has brought significant productivity and income gains in maize production (Jaleta et al., 2016; Kassie et al., 2015b; Teklewold et al., 2013a). Similar findings were also reported for wheat (El-Shater et al., 2016; Erenstein et al., 2008; Krishna et al., 2016a; Krishna and Veettil, 2014). In South Asia, for example, a review of the literature by Krishna et al. (2016) reveals that farm level benefits (yield ${ }^{3}$ and low costs of production) of reduced tillage in wheat production are higher than for conventional tillage. In addition to the reported yield gains and reduced costs of production, other studies on both crops show that adoption of reduced tillage has lower downside risk exposure than conventional tillage (Aryal et al., 2016; Kassie et al., 2015a; Magnan et al., 2011; Ngwira et al., 2013; Sommer et al., 2011). Regardless of agronomic differences (e.g., grain size and weed management) in maize and wheat, findings of studies in both

\footnotetext{
${ }^{3}$ In this dissertation, quantity produced in kg per hectare (yield), productivity, and land productivity tell the same thing and we use the three terms interchangeably.
} 
crops underscore that reduced tillage is important for the protection of farmers from livelihood failures.

Despite the documented positive impacts, studies from developed countries show that farmers may not adopt reduced tillage because they are averse to risk (Gandorfer et al., 2011; Meyer-Aurich et al., 2009; Tew et al., 1986; Williams et al., 1990). In developing countries, particularly in SubSaharan Africa, there is skepticism about the effectiveness of reduced tillage (Giller et al., 2009, 2011; Halbrendt et al., 2014; Tessema et al., 2015). As a policy response, various payment schemes are used to encourage farmers' adoption of reduced tillage in the USA and European Union (Claassen et al., 2008; Kertész and Madarász, 2014; Power, 2010; Ribaudo et al., 2010). In developing countries, there seems an implicit assumption that the documented benefits of reduced tillage are sufficient incentive for its widespread adoption. But dis-adoption of donor-supported CA interventions, including reduced tillage, has been reported (Andersson and D'Souza, 2014; Brown et al., 2017; Lalani et al., 2016; Pedzisa et al., 2015). Low or non-adoption of reduced tillage is also associated with lack or absence of locally adapted reduced tillage technologies (e.g., zero tillage seeders) and service providers, lack of farmers' exposure to the technologies, and high initial investment costs (El-Shater et al., 2016; Loss et al., 2015). As a result, most farmers continue practicing intensive tillage (Andersson and D’Souza, 2014; Teklewold and Mekonnen, 2017).

Thus far, most studies focus on reduced tillage, and there is lack of evidence on the risk and productivity implications of intensive tillage practices in smallholder family farms in developing countries. In moisture stressed areas of the Nile Basin of Ethiopia, Teklewold and Mekonnen (2017) find that reduced tillage has the potential to increase farm income from major cereals. On the other hand, they show that higher tillage intensities increase farm income in higher rainfall areas. Our study is a contribution to this literature by studying the productivity impact of intensive tillage practices using a different dataset for a single crop. Given that various crops may respond differently to tillage practices, analyzing crop level impact of various intensities of tillage is important. Furthermore, to the best of our knowledge, this research is the first that documents the impact of intensive tillage practices on farmers' risk exposure in developing countries. Finally, previous studies of reduced tillage treat non-adopters as an homogeneous group. Nevertheless, farmers who practice some form of tillage (either oxen or tractor based) are more likely to be heterogeneous (Teklewold and Mekonnen, 2017). Our data provide us with an opportunity to understand the heterogeneous effects of various intensities of tillage. Heterogeneous effects of tillage practices may imply that farmers' tillage decisions are influenced by unobserved factors (e.g., managerial skills). 
In order to handle selection bias stemming from unobserved heterogeneity, we estimate a flexible moment-based production function using endogenous switching regression treatment effects model.

The rest of this chapter is structured as follows. In Section 2.2, we briefly discuss the study areas, the data and sampling procedure. Section 2.3 describes the econometric methods and we present the results in Section 2.4. Section 2.5 concludes.

\subsection{Study areas, data and sampling procedure}

We use household survey data collected by the International Maize and Wheat Improvement Center (CIMMYT) and the Ethiopian Institute of Agricultural Research (EIAR). Wheat production is rainfed in Ethiopia. Rainfall in the survey areas were 1,200 mm and 1,207 mm in 2009/10 and 2013/14, respectively (Fick and Hijmans, 2017). The majority of the survey areas (more than 90\%) are at least 2,000 meters above sea level. The survey is representative of the main wheat producing zones of Ethiopia, and was collected in two rounds (Tolemariam et al., 2016). The survey covers 2009/10 and 2013/14 harvesting seasons. In the first step, 148 major wheat-growing districts that passed the minimum 2000 ha wheat area per district threshold were purposely selected. In these districts, after taking account of differences in agro-ecologies, 120 peasant associations (PA), the smallest administrative unit, were then randomly selected. Finally, well-trained teams of enumerators interviewed 15 to 18 households in each PA, leading to 2,096 households in the sample. Most of these households were also interviewed in the second round of the survey.

The survey instrument was a structured questionnaire. Detailed plot and household characteristics were collected. Among these, the key variables of interest include plot characteristics such as slope, color and fertility of the soil, the presence of production stresses (e.g., drought), and plot size. Besides, data were collected on detailed farm management practices such as crop rotation, residue management, use of improved varieties, and manure application. Farmers provided information on quantity of production, expenses on fertilizers and agrochemicals, amount of labor days and oxen days spent for each plot. Furthermore, characteristics of the head of the household such as education, age, sex, number of (non) relatives he/she relies on within and outside the village, and his/her confidence on government officials and extension workers. Other household level variables include number of extension contacts per year, and whether the household received food relief from the government. 
The dataset has close to 6,000 wheat plots in both rounds. We drop extreme observations below the 1st or above the 99th percentile of the yield distribution (Abdul-Salam and Phimister, 2016). We use 5,891 plots from 1,928 households in our regressions. Among the 1928 households, 1,420 exist in both rounds while 508 households were either only in 2009/10 or 2013/14 round. The unbalanced data show that some households did not produce wheat in one of the two survey years.

\subsection{Econometric strategy}

Our objective is to estimate the impact of intensity of tillage on both productivity and risk exposure. In this chapter, productivity is measured by the quantity of production per hectare (yield). Risk exposure is measured by the second central moment (variance) and third central moment (skewness) of the error distribution of yield after controlling for differences in inputs, household and plot characteristics. We proxy our main variable of interest, the intensity of tillage, by the frequency of tillage for each plot. This proxy may not reflect differences in the strength of the oxen draft power and the quality of other farming equipment (particularly the traditional plough). However, these quality differences are more likely to be time invariant since farmers are less likely to change these factors over a short period so that our econometric method should handle such potential heterogeneities. In what follows, we first discuss the procedures we follow for the estimation of the mean yield function, variance, and the skewness of the error distributions. Next, we discuss the econometric methods and how the results are interpreted.

\subsubsection{Moment-based flexible production function}

We disentangle the impact of intensity of tillage on mean yield, variance and skewness using a flexible moment-based production function proposed by Antle (1983). The flexible moment-based production function divides the variation in yield into two parts. First, differences in inputs and other observable characteristics explain part of the variation in yield, which is the mean effect of the explanatory variables on yield. Second, the unexplained variation of yield (the error distribution) is modelled as an economic structure reflecting the riskiness of agricultural production (Antle, 1983; Asche and Tveterås, 1999; Just and Pope, 1978). The error distribution of the yield function provides relevant information to analyze farmers' risk exposure. Skewness measures the extent of farmers' downside risk exposure (e.g., crop failure) by distinguishing unexpected bad and good events, but the variance does not (Di Falco and Chavas, 2009; Di Falco and Veronesi, 2014). Despite 
this disadvantage of the variance, we use both variance and skewness as a measures of risk exposure. Using both measures helps to understand the total cost of risk.

Following Di Falco and Veronesi (2014), we assume a continuous and twice differentiable production function $y=g(\boldsymbol{x}, v)$ where y is yield, $\boldsymbol{x}$ is a vector of explanatory variables and $v$ is a random variable representing risks associated with random shocks (e.g., rainfall and temperature). The probability distribution of $g(x, v)$ is given by

$$
g(\boldsymbol{x}, v)=f_{1}\left(\boldsymbol{x}, \beta_{1}\right)+u
$$

where $f_{1}\left(\boldsymbol{x}, \beta_{1}\right)=E[g(\boldsymbol{x}, v)]$ is the mean of $g(\boldsymbol{x}, v)$ and $\boldsymbol{u}=g(\boldsymbol{x}, v)-f_{1}\left(\boldsymbol{x}, \beta_{1}\right)$ is a heteroskedastic and non-symmetric random variable. The variance and the skewness is given by

$$
E\left\{\left[g(\boldsymbol{x}, v)-f_{1}\left(\boldsymbol{x}, \beta_{1}\right)\right]^{m} \mid \boldsymbol{x}\right\}=f_{m}\left(\boldsymbol{x}, \beta_{1}\right)
$$

where $m=2,3$ is the second and the third central moments of the error distribution representing variance and skewness, respectively. We first test whether the distribution of $u$ is heteroskedastic and non-symmetric, which is a precondition for the variance and skewness analysis. The null hypotheses of constant variance and symmetric distribution are rejected at $10 \%$ level of significance or below for most of the models (see Table 2.7 in Appendix 2). We then estimate the mean function $f_{1}\left(x, \beta_{1}\right)$, the variance $f_{2}\left(\boldsymbol{x}, \beta_{1}\right)$, and the skewness $f_{3}\left(\boldsymbol{x}, \beta_{1}\right)$.

\subsubsection{The endogenous switching regression model}

Farmers' choice of tillage may be dependent on the benefit they get from a specific intensity of tillage, given the information they have about their plots and their resource endowments. But all the factors that motivate the farmers to choose a specific intensity of tillage may not be observed, which creates a selection problem. For example, farmers may have unobserved private information about the quality of the land, and failing to account for such unobserved factors may introduce estimation bias (Kassie et al., 2015b). Endogeneity may also arise because some of the explanatory variables 
(e.g., plot characteristics such as slope) may influence both the choice of the intensity of tillage and the outcome variables, yield and risk exposure (Alene and Manyong, 2007).

The other important issue to consider in our estimation is that intensive tillage practices may affect the productivity of inputs. For instance, a well-prepared seedbed through intensive tillage may suppress weeds. Low weed density in turn may increase the productivity of labor because higher yield could be achieved with a reduced amount of weeding labor. In order to take this in to account, we could introduce non-linearity to the intensity of tillage by estimating a linear model and introducing quadratic and interaction terms with inputs. This approach is not convenient in the sense that we need to instrument not only the intensity of tillage and the quadratic term of the intensity of tillage but also the interaction terms between inputs and intensity of tillage. Furthermore, we are not interested on the coefficients of the explanatory variables per se. Rather, we want to establish a counterfactual framework in order to compare the impact of each intensity of tillage with a counterfactual outcome had the plots that were ploughed at higher intensities of tillage were ploughed at a lower intensity of tillage. For these reasons, we use the endogenous switching regression model (ESR) which is a convenient econometric method of obtaining counterfactual outcomes by estimating separate production functions for each intensity of tillage. The ESR helps us to control for endogeneity problems while allowing a complete interactions between the explanatory variables (including inputs) and intensity of tillage (Alene and Manyong, 2007; Kabunga et al., 2012; Kassie et al., 2010).

We estimate the ESR in $\operatorname{six}^{4}$ regimes as follows (Di Falco and Veronesi, 2014; Kassie et al., 2010). ${ }^{5}$

$$
Y_{I T}=\beta_{I T} \boldsymbol{X}_{I T}+\rho_{I T} \boldsymbol{P}_{I T}+\vartheta_{I T} \boldsymbol{H}+\tau_{I T} T+\pi_{I T} \boldsymbol{D}+\theta_{I T} \overline{\boldsymbol{M}}_{I T}+\sigma_{I T} \hat{\lambda}_{I T}+\varepsilon_{I T},
$$

where IT $=2,3,4,5,6$ and 7 or more as the intensity of tillage. $Y$ is logarithm of yield and $\boldsymbol{X}$ represents expenses on fertilizers and agrochemicals, labour days, and oxen days, all in logarithms. Since several farmers used zero amounts of fertilizers and other agrochemicals, we follow Battese (1997): after taking logarithms, undefined values are replaced by zero, and additional dummy variables are

\footnotetext{
${ }^{4} \mathrm{Few}$ plots that were ploughed less than 2 times and more than 7 times are clubbed to intensities of tillage 2 and 7 times, respectively.

${ }^{5} \mathrm{We}$ avoid notational cluttering by suppressing the subscripts referring to plot $i$, household $j$, and time $t$.
} 
added to indicate zero quantities of particular inputs. $\boldsymbol{P}$ is a vector of plot characteristics, farm management practices (e.g., crop residue retention), and production stresses (e.g., drought). $\boldsymbol{H}$ is a vector of household level variables (e.g., education, age and sex of the head), whether the household receives food relief from the government, social status (measured by the number of people that the farmers know inside and outside the village) and whether the farmers are confident on the skills of the extension workers and government officials. $T$ is a time dummy that takes a value of 1 for 2013/14 and 0 for 2009/10. $\boldsymbol{D}$ is a vector of dummies of agro-ecology that controls for differences in weather patterns and other unobserved characteristics of each agro-ecology. $\varepsilon_{I T}=u_{j}+e_{i j t}$ represents composed error terms of unobserved heterogeneity $\left(u_{j}\right)$ for household $j$ and the usual error terms of plot $i$ in household $j$ and year $t$. The $\beta, \rho, \vartheta, \tau, \pi, \theta$, and $\sigma$ are parameters to be estimated.

Equation (2.3) could be estimated using either fixed or random effects estimator. We choose to estimate all of the equations in (2.3) using random effects for two reasons. First, our data show that the cross-sectional variation is consistently higher than the within variation for both the dependent and independent variables. In such situations, the random effects estimator is more efficient than the fixed effects because it uses both the cross-sectional and the variation of the variables overtime. Second, if we use the fixed effects estimator, we would lose a sizable 508 observations that produced wheat only either in $2009 / 10$ or $2013 / 14$. Unlike the fixed effects estimator however, the random effects model hinges on a strong assumption that unobserved heterogeneity (e.g., innate ability and unobserved quality differences in oxen power) are independent of the explanatory variables. In order to avoid incorrect inference from biased estimated coefficients because of endogeneity (correlations between the explanatory variables and time invariant unobserved heterogeneity), we use the Mundlak's fixed effects, which is represented by $\overline{\boldsymbol{M}}$ in equation (2.3). In the Mundlak's fixed effects, we assume that the time invariant unobserved heterogeneity $\left(u_{j}\right)$ is a linear function of the averages of the time and plot varying explanatory variables $(\overline{\boldsymbol{M}}), u_{j}=\boldsymbol{\theta} \overline{\boldsymbol{M}}+$ $\gamma_{j}$ with $\gamma_{j} \sim I I D\left(0, \sigma^{2}\right)$, where $E\left(\gamma_{j} \mid \bar{M}\right)=0$ and $\boldsymbol{\theta}$ is the corresponding vector of coefficients, and $\gamma_{j}$ is a normally distributed error term uncorrelated with $\overline{\boldsymbol{M}}$ (Di Falco and Veronesi, 2014; Mundlak, 1978).

In equation (2.3), the $\hat{\lambda}$ s are selection correction terms, and they are defined as 


$$
\hat{\lambda}_{I T}=\sum_{I T \neq r}^{M} \delta_{I T}\left[\frac{\hat{P}_{I T} \ln \hat{P}_{I T}}{1-\hat{P}_{I T}}+\ln \hat{P}_{r}\right]
$$

$\hat{P}_{r}$ is the probability of choosing the $r$ th intensity of tillage (Bourguignon et al., 2006; Dubin and McFadden, 1984). The probabilities are estimated using random effects ordered logit model (REOLM). $\delta_{I T}$ is the correlation coefficient between the error terms of the REOLM and the regime switching equations $(2.3), \varepsilon_{I T}$.

For model identification, in addition to the non-linear selection terms, $\hat{\lambda}$, we use an exclusion restriction that correlates with intensity of tillage but not with yield or risk exposure (Di Falco et al., 2011). We use the Peasants' association (PA), the smallest administrative unit, median frequency of tillage as an exclusion restriction. Since individuals belonging to the same group tend to be similar in behavior (Angrist, 2014; Manski, 1993), we hypothesize that the PA's tillage practices may tend to shape a farmer's practice in a particular plot. Thus, the PA's median frequency of tillage is more likely to be correlated with the frequency of tillage for a given plot, but should not affect a given plot's yield directly. Covariate shocks such as changes in weather patterns could affect both the intensity of tillage, and yield and risk exposure. ${ }^{6}$ We control for the various shocks and fixed effects of agro-ecology in both the REOLM and second stage regressions. Therefore, the median frequency of tillage could pick up inherent differences in production potentials and profitability of tillage choice stemming from unobserved factors. A falsification test, following Di Falco et al. (2011), shows that the exclusion restriction is statistically valid for fifteen of the eighteen equations (see Appendix 2, Tables 2.7-2.9).

\subsubsection{Counterfactual analysis}

Our main objective is to estimate the treatment effects of increasing the intensity of tillage on yield and risk exposure (variance and skewness). Selection-corrected predictions of the counterfactual yield and risk exposure are obtained from equation (2.3) (Bourguignon et al., 2006). The counterfactual outcome is defined as the expected wheat yield and risk exposure of higher tillage intensities $(3,4,5,6,7$ or more) that would have been obtained if the returns (coefficients) on their characteristics $\left(\boldsymbol{X}_{I T}\right)$ had been the same as the returns (coefficients) on the characteristics $\left(\boldsymbol{X}_{I T}\right)$ of the reduced tillage intensities ( $\mathrm{IT}=2$ ). We obtain the actual conditional expectations in the sample

\footnotetext{
${ }^{6} \mathrm{We}$ regressed the median frequency of tillage against various shocks, and we confirm the two are correlated.
} 
and the conditional expectations for the counterfactual outcome using equations (2.4a) and (2.4b), respectively, as follows.

$E\left(Y_{I T} \mid I T=i\right)=\beta_{I T} \boldsymbol{X}_{I T}+\sigma_{I T} \hat{\lambda}_{I T}, i=3,4,5,6,7$ or more,

$E\left(Y_{2} \mid I T=i\right)=\beta_{2} X_{I T}+\sigma_{2} \hat{\lambda}_{I T}, i=3,4,5,6,7$ or more,

All the right hand side variables in equations (2.3) are subsumed in $\mathbf{X}$ in equations (2.4a-2.4b). The average treatment effects on the treated (ATTs) for both yield and risk exposure (variance and skewness) are calculated using equation (2.5) (Di Falco and Veronesi, 2014).

$\mathrm{ATTs}=E\left(Y_{I T} \mid I T=i\right)-E\left(\mathrm{Y}_{2} \mid I T=i\right)=\left(\beta_{I T}-\beta_{2}\right) \boldsymbol{X}_{I T}+\left(\sigma_{I T}-\sigma_{2}\right) \hat{\lambda}_{I T}$,

where IT=3,4,5,6,7 or more. Positive ATTs for yield show that the chosen intensity of tillage increases farmers' yield relative to the counterfactual outcome. Similarly, when the ATTs of the skewness are positive, higher intensities of tillage reduces downside risk exposure. On the contrary, when the ATTs of the variance are positive, it indicates that higher intensities of tillage tend to increase variance of yield and vice versa.

\subsubsection{The impact of intensity of tillage on the cost of risk}

Tillage is an ex-ante risk management strategy used by farmers in order to minimize production risks that may arise due to high incidence of diseases and weeds, among other benefits. We estimate the cost of risk to each intensity of tillage and the counterfactual outcome using a quantile-based approach developed by Kim et al. (2014) and used in empirical applications by Kassie et al. (2015b). The quantile-based approach represents the risk-preference of the decision maker by the Constant Relative Risk-Aversion (CRRA) utility function: $U(Q)=\left(Q^{1-b}\right) /(1-b)$, where $Q>0$ is yield 
and $b>0$ is the relative risk aversion coefficient. The cost of risk is measured by the risk premium (R) using equation (2.6) (Kassie et al., 2015b; Kim et al., 2014).

$$
\begin{aligned}
R \approx 0.5 *[F( & \left.\left.b_{k}\right)-F\left(b_{k-1}\right)\right] \\
& *\left\{\frac{b\left(m_{k 1}\right)^{-b-1}}{\sum_{i=1}^{k}\left\{\left[F\left(b_{k}\right)-F\left(b_{k-1}\right)\right] *\left(m_{i 1}\right)^{-b}\right\}} * m_{k 2}+\left[b\left(M_{1}\right)^{-1}\right] *\left[m_{k 1}-M_{1}\right]^{2}\right\} \\
& +(1 / 6) *\left[F\left(b_{k}\right)-F\left(b_{k-1}\right)\right] \\
& *\left\{-\frac{b(1+b)\left(m_{k 1}\right)^{-b-2}}{\sum_{i=1}^{k}\left\{\left[F\left(b_{k}\right)-F\left(b_{k-1}\right)\right] *\left(m_{i 1}\right)^{-b}\right\}} * m_{k 3}-\left[b(1+b)\left(M_{1}\right)^{-2}\right]\right. \\
& \left.*\left[m_{k 1}-M_{1}\right]^{3}\right\}
\end{aligned}
$$

where $m_{k 1}, m_{k 2}$, and $m_{k 3}$ are the partial mean, variance and skewness of yield distributions in quantile $k$, respectively; $F\left(b_{k}\right)-F\left(b_{k-1}\right)$ is the probability of each partial central moment in quantile $k ; M_{1}$ is the overall all central moment of the distribution of yield in quantile $k$. The cost of risk $R$ is computed for each quantile by using the predicted values of yield, variance and skewness for both the actual and counterfactual conditions in equation (2.4a) and equation (2.4b), respectively.

\subsection{Results}

\subsubsection{Intensity of tillage, input use and yield}

In this subsection, we present the intensity of tillage practices, input use and its correlation with yield. The summary statistics, definitions and measurements for all the explanatory variables used in our regressions are presented in Appendix 2, Table 2.5. In Table 2.1, we show that $83 \%$ of the plots were ploughed between 3 to 5 times, which is within the recommended frequency of tillage by the Ethiopian extension system (MOA, 2014). For the rest of $17 \%$ of the plots, farmers ploughed 
below or above the recommended intensity of tillage. Nearly $5 \%$ of the plots were ploughed 2 or fewer times, and the majority of these (4\%) were ploughed twice. Plots that were ploughed 6 times were approximately $8 \%$. For another $5 \%$ of the plots, farmers plough 7 or more times. Since the number of no-till ${ }^{7}$ plots (28) and plots that were ploughed once (19) were very small, they were categorized with plots that were ploughed twice. ${ }^{8}$ Similarly, the number of plots that were ploughed more than 7 times were only 75 , and they were categorized with plots that were ploughed 7 times. ${ }^{9}$

Table 2.1. Frequency of tillage (2009/10-2013/14) (\%).

\begin{tabular}{ccc}
\hline Frequency of tillage & Number of plots & \% \\
\hline 2 & 307 & 5.1 \\
3 & 1,648 & 27.6 \\
4 & 2,083 & 34.8 \\
5 & 1,205 & 20.2 \\
6 & 455 & 7.6 \\
7 or more & 283 & 4.7 \\
\hline Total & 5,981 & 100 \\
\hline
\end{tabular}

The households' tillage practices may vary from time to time. This is shown in Table 2.2 using a transition matrix. We calculate the household level transition matrix by using the plot level frequencies of tillage for each round. The diagonal cells of Table 2.2 show the percentage of households who do not change the frequency of tillage across rounds. At the frequency of tillage

\footnotetext{
${ }^{7}$ The no-till plots are not strictly zero tillage plots as it is defined in the conservation agriculture literature. Farmers reported that 17 of the 28 no-till plots have a steep slope while they reported that the fertility of the soil is poor in 20 of the 28 no-till plots. These plots are no-till plots perhaps because the topography of the plot is not convenient for ploughing. They also do not use any mechanized form of farming methods (e.g., zero-tillage seeders). Farmers may use hoes for sowing and ploughing is not needed.

${ }^{8}$ Having a separate category for no till plots remain important if there are enough observations. When we group the notill plots and plots that were ploughed once with those plots that were ploughed twice, the grouping may hide potential differences in yield and risk exposure. We used a joint $\mathrm{F}$ test for this case. First, we created two dummy variables: if the plots are no-till plots and 0 otherwise (NOTILL), and if the plots were ploughed once and 0 otherwise (ONETILL). Next, we run a regression by taking yield as a dependent variable, and NOTILL, ONETILL and other factors in equation (2.3) as explanatory variables. After controlling for confounding factors, the coefficients of NOTILL and ONETILL are not jointly significant $(\mathrm{F}$ test: $\mathrm{Chi}$ squared $=2.81$ and $\mathrm{p}$-value $=0.25)$ showing that there is no yield difference between the no-till, plots that were ploughed once, and the plots that were ploughed twice. We conclude that we do not face a serious problem of hiding potential heterogeneities by grouping these plots. However, the coefficient of NOTILL is negative and significant at $10 \%$ indicating that the yield of no-till plots tend to be lower than plots that were ploughed twice. We also undertook the same regression taking our measures of risk exposure (skewness and variance) as dependent variables. The results show that NOTILL and ONETILL are not statistically significant, individually and jointly.

${ }^{9}$ Following the approach in footnote 8 , yield and downside risk are not significant ( $\mathrm{F}$ test: Chi squared $=0.34$ and $\mathrm{p}$ value $=0.84$ ) between plots that were ploughed 7 times and 8 or more times.
} 
equals 4 or below, the majority of the households choice of the frequency of tillage remains identical over the two years. But when the frequency of tillage is 5 or above, the percentage of households who chose identical frequency of tillage over the two years is below $40 \%$.

Table 2.2. Transition matrix: change in frequency of tillage between 2009/10 and 2013/14 (\%).

\begin{tabular}{ccccccccc}
\hline \multirow{2}{*}{ Frequency of tillage } & \multicolumn{7}{c}{$\mathbf{2 0 1 3 / 1 4}$} \\
\cline { 3 - 9 } & 2 & 3 & 4 & 5 & 6 & 7 or more & Total \\
\hline \multirow{4}{*}{$\mathbf{2 0 0 9 / 1 0}$} & 2 & 49.1 & 37.7 & 11.3 & 0.0 & 0.0 & 1.9 & 100 \\
& 3 & 7.4 & 58.6 & 28.6 & 3.4 & 1.4 & 0.6 & 100 \\
& 4 & 1.9 & 25.0 & 55.3 & 15.4 & 1.9 & 0.6 & 100 \\
& 5 & 0.7 & 8.8 & 41.2 & 38.5 & 9.5 & 1.4 & 100 \\
& 6 & 0.7 & 3.4 & 19.7 & 43.5 & 19.1 & 13.6 & 100 \\
\hline
\end{tabular}

In Table 2.2, the cells to the right of the diagonal indicate that the households increase tillage frequency between 2009/10 and 2013/14. The values to the left of the diagonal show that households' frequency of tillage decline across rounds. Most of the changes in households' choice of tillage frequency is to the left of the diagonal showing a reduction in the frequency of tillage across years. A small proportion of the households increased their frequency of tillage. Irrespective of increasing or decreasing the frequency of tillage, we do not observe a significant jump in the choice of the frequency of tillage to an extremely high or low intensity of tillage. Rather the majority of the households tend to increase or decrease the intensity of tillage to the next higher or lower tillage intensity. Even though the transition matrix hides potential heterogeneities across plots within a household, it gives an insight that most households have changed the frequency of tillage over our time period.

In Figure 2.1, we present a scatter plot depicting the correlation between the frequency of tillage and yield. As Figure 2.1 shows, we observe that yield and frequency of tillage are positively correlated indicating that yield tends to increase with frequency of tillage. However, the relationship shown in Figure 2.1 does not control for differences in inputs and other confounding factors that may explain part of the variation in yield. 


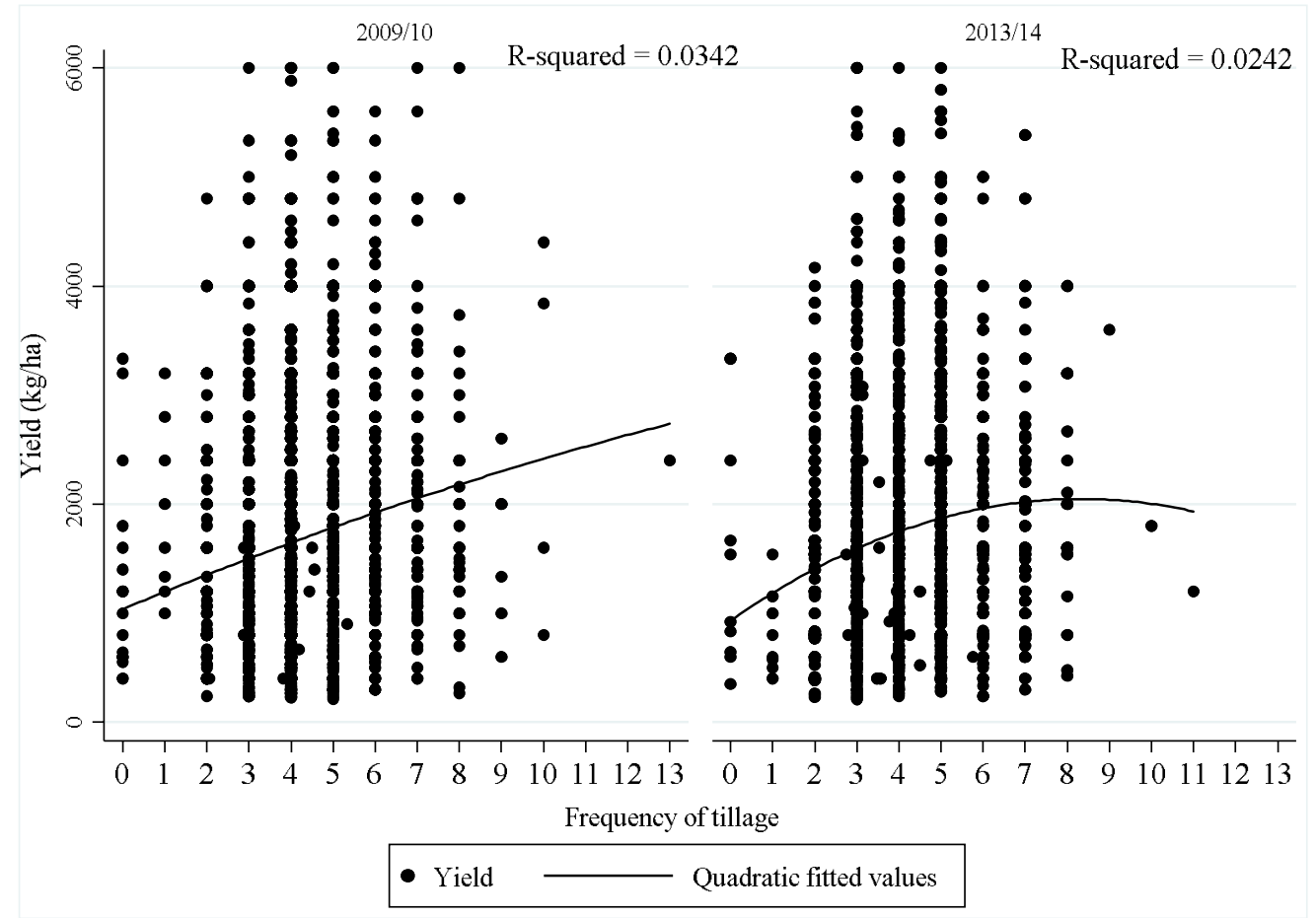

Figure 2.1. Wheat yield distributions by frequency of tillage and survey year.

In Table 2.3, we show average input use by the frequency of tillage. As expected, the use of oxen increases with the frequency of tillage. However, the labor requirement declines as the frequency of tillage increases, reflecting the decline in the need to control for weeds. The quantity of labor for weeding is low at higher frequencies of tillage suggesting that farmers might be able to control weeds by increasing tillage or by increasing use of herbicides. We are unable to identify if the cost of agrochemicals at a higher frequency of tillage is driven by uses of herbicides, fungicides or pesticides because we do not have accurate data for each. Using information about the previous season's crop for each of the wheat plots, we show that higher intensities of tillage are associated with lower labor days spent for weed control regardless of the status of crop rotation. Despite the fact that strategic choice of crop rotations may help to control for weeds, our data show that the mean labor days spent on weeding tends to be low in plots that did not use crop rotation. 
Table 2.3. Inputs use and intensity of tillage (2009/10-2013/14).

\begin{tabular}{|c|c|c|c|c|c|c|c|}
\hline \multirow[b]{2}{*}{ Inputs } & \multicolumn{6}{|c|}{ Frequency of tillage } & \multirow[b]{2}{*}{ Overall average } \\
\hline & 2 & 3 & 4 & 5 & 6 & 7 or more & \\
\hline \multirow[t]{2}{*}{ Oxen power (days/ha) } & 14.4 & $19.0 * * *$ & $23.7 * * *$ & $28.1 * * *$ & $33.3 * * *$ & $37.6 * * *$ & 24.2 \\
\hline & $(7.4)$ & $(9.1)$ & $(9.9)$ & $(11.6)$ & $(14.8)$ & $(14.9)$ & $(12.0)$ \\
\hline \multirow[t]{2}{*}{ Labor (days/ha) } & 103.4 & $111.2 *$ & $92.4 * *$ & $78.5 * * *$ & $82.8 * * *$ & $89.2 * *$ & 94.5 \\
\hline & $(87.1)$ & $(85.0)$ & $(79.1)$ & $(59.3)$ & $(47.5)$ & $(65.1)$ & $(76.0)$ \\
\hline \multirow[t]{2}{*}{ Labor for land preparation (days/ha) } & 15.4 & $15.4 * * *$ & $18.3 * * *$ & $21.4 * * *$ & $26.3 * * *$ & $28.2 * * *$ & 19.1 \\
\hline & $(19.2)$ & $(11.1)$ & $(10.0)$ & $(14.0)$ & $(18.5)$ & $(16.5)$ & $(13.4)$ \\
\hline \multirow[t]{2}{*}{ No rotation in the plot } & 16.4 & 14.7 & 17.1 & 19.7 & $27.2 * * *$ & $28.7 * *$ & 17.6 \\
\hline & $(23.7)$ & $(9.0)$ & $(8.2)$ & $(17.3)$ & $(32.3)$ & $(13.4)$ & $(14.5)$ \\
\hline \multirow[t]{2}{*}{ Legume rotation in the plot } & 10.4 & $15.1 * * *$ & $18.9 * * *$ & $22.9 * * *$ & $26.7 * * *$ & $26.3 * * *$ & 17.6 \\
\hline & $(6.1)$ & $(11.7)$ & $(11.0)$ & $(15.5)$ & $(18.8)$ & $(21.3)$ & $(12.6)$ \\
\hline \multirow[t]{2}{*}{ Other cereals rotation in the plot } & 20.7 & $15.9 * * *$ & $18.4^{*}$ & 21.5 & $26.0 * * *$ & $28.5 * * *$ & 20.1 \\
\hline & $(25.0)$ & $(11.4)$ & $(10.1)$ & $(12.6)$ & $(15.0)$ & $(16.5)$ & $(13.3)$ \\
\hline \multirow[t]{2}{*}{ Labor for weed control (days/ha) } & 34.2 & 37.2 & $24.8 * * *$ & $16.1 * * *$ & $15.0 * * *$ & $14.6 * * *$ & 25.7 \\
\hline & $(37.7)$ & $(44.0)$ & $(39.6)$ & $(24.7)$ & $(21.2)$ & $(19.8)$ & $(37.4)$ \\
\hline \multirow[t]{2}{*}{ No rotation in the plot } & 28.6 & $40.3 * *$ & 25.5 & $12.3 * * *$ & $8.7 * * *$ & $10.8^{*}$ & 26.6 \\
\hline & $(35.1)$ & $(41.1)$ & $(38.0)$ & $(26.4)$ & $(10.8)$ & $(14.7)$ & $(37.5)$ \\
\hline \multirow[t]{2}{*}{ Legume rotation in the plot } & 35.3 & $43.1 *$ & 32.0 & $20.7 * * *$ & $19.4 * *$ & 19.9 & 34.2 \\
\hline & $(34.5)$ & $(47.4)$ & $(51.1)$ & $(30.9)$ & $(23.9)$ & $(35.8)$ & $(45.9)$ \\
\hline \multirow[t]{2}{*}{ Other cereals rotation in the plot } & 35.1 & 32.2 & $21.3^{* * *}$ & $15.9 * * *$ & $15.6^{* * *}$ & $15.6^{* * *}$ & 22.0 \\
\hline & $(42.0)$ & $(42.0)$ & $(32.9)$ & $(22.3)$ & $(22.0)$ & $(18.8)$ & $(32.6)$ \\
\hline \multirow[t]{2}{*}{ Expenses on fertilizers (Birr/ha) ${ }^{\mathbf{a}}$} & 578.2 & $697.8 * * *$ & $829.0 * * *$ & $830.8 * * *$ & $931.1 * * *$ & $995.9 * * *$ & 796.0 \\
\hline & $(691.8)$ & $(687.1)$ & $(724.6)$ & $(621.5)$ & $(649.9)$ & (711.4) & $(692.9)$ \\
\hline \multirow[t]{2}{*}{ Expenses on agrochemicals (Birr/ha) ${ }^{\mathbf{a}}$} & 9.5 & $25.6 * * *$ & $39.2 * * *$ & $55.6 * * *$ & $50.7 * * *$ & $57.5^{* * *}$ & 39.0 \\
\hline & $(24.2)$ & $(59.9)$ & $(60.8)$ & $(70.1)$ & $(51.4)$ & $(61.3)$ & $(62.0)$ \\
\hline
\end{tabular}
deflated by zone level price index. 
Table 2.3 further show that higher frequency of tillage is associated with high expenses on fertilizers and agrochemicals. This may reflect that those who plough at a higher frequency are wealthier with a better command of important inputs to invest in their plots. However, the standard deviation reveals that the variability of fertilizers and agrochemicals expenses are high showing the existence of strong heterogeneity in input use. The heterogeneity in input use may indicate that the responsiveness of inputs to yield may differ depending on the choice of tillage frequency. In the next subsection, we present our empirical results after controlling for these potential heterogeneities by allowing the inputs and other explanatory variables to have a differential effect on yield for each intensity of tillage.

\subsubsection{Econometric results}

Our primary interest is to quantify the impact of intensity of tillage on yield and risk exposure. As a result, we do not discuss the coefficients of each of the models in detail. The estimation results are provided in Appendix 2, Tables 2.6-2.9. In the rest of this subsection, we present the average treatment effects on the treated (ATTs) and the cost of risk measured by the risk premium.

\subsubsection{Impact of intensities of tillage on yield and risk exposure}

In Table 2.4, we present the ATTs of yield and measures of risk exposure (variance and skewness). The rows indicate the intensity of tillage that are used as a treatment. We report the actual expected yield, variance, and skewness of the error distribution of yield observed in the sample in columns A, D and G, respectively. The counterfactual expected yield, variance, and skewness are reported in columns B, E, and $\mathrm{H}$ of Table 2.4, respectively. The ATTs are estimated using the formula in equation (2.5). Column $\mathrm{C}$ of Table 2.4 shows the ATTs on yield while columns F and I show the ATTs on risk exposure. 
Table 2.4. Average treatment effects on the treated (ATTs) on yield and risk exposure (variance and skewness).

\begin{tabular}{|c|c|c|c|c|c|c|c|c|c|}
\hline \multirow[b]{2}{*}{$\begin{array}{l}\text { Intensity of } \\
\text { tillage (IT) }\end{array}$} & \multicolumn{3}{|c|}{ Yield } & \multicolumn{6}{|c|}{ Risk exposure } \\
\hline & $\begin{array}{l}\text { Actual } \\
\text { expected } \\
\text { yield }\end{array}$ & $\begin{array}{l}\text { Counterfactual } \\
\text { expected yield }\end{array}$ & $\mathbf{A T T s}=\mathrm{A}-\mathrm{B}$ & $\begin{array}{c}\text { Actual } \\
\text { expected } \\
\text { variance }\end{array}$ & $\begin{array}{l}\text { Counterfactual } \\
\text { expected variance }\end{array}$ & ATTs $=D-E$ & $\begin{array}{c}\text { Actual } \\
\text { expected } \\
\text { skewness }\end{array}$ & $\begin{array}{c}\text { Counterfactual } \\
\text { expected skewness }\end{array}$ & ATTs $=\mathbf{G}-\mathbf{H}$ \\
\hline & $\mathbf{A}$ & B & C & D & $\mathbf{E}$ & $\mathbf{F}$ & G & $\mathbf{H}$ & I \\
\hline \multirow[t]{2}{*}{3} & 1296.7 & 1341.3 & $-44.6 * *$ & 0.263 & 0.294 & $-0.031 * * *$ & -0.028 & -0.049 & $0.021 * * *$ \\
\hline & (11.3) & $(16.8)$ & $(20.3)$ & $(0.002)$ & $(0.004)$ & $(0.005)$ & $(0.002)$ & $(0.004)$ & $(0.009)$ \\
\hline \multirow[t]{2}{*}{4} & 1521.4 & 1438.3 & $83.1 * * *$ & 0.241 & 0.294 & $-0.054 * * *$ & -0.028 & -0.068 & $0.040 * * *$ \\
\hline & (12.0) & $(16.2)$ & $(20.1)$ & $(0.002)$ & $(0.004)$ & $(0.005)$ & $(0.001)$ & $(0.004)$ & $(0.004)$ \\
\hline \multirow[t]{2}{*}{5} & 1686.8 & 1408.1 & $278.7 * * *$ & 0.224 & 0.299 & $-0.075 * * *$ & -0.055 & -0.092 & $0.037 * * *$ \\
\hline & $(17.1)$ & $(21.1)$ & $(27.1)$ & $(0.003)$ & $(0.006)$ & $(0.007)$ & $(0.003)$ & $(0.005)$ & $(0.005)$ \\
\hline \multirow[t]{2}{*}{6} & 1703.2 & 1473.8 & $229.4 * * *$ & 0.277 & 0.261 & 0.016 & -0.065 & -0.096 & $0.031 * *$ \\
\hline & $(26.3)$ & $(32.8)$ & $(42.1)$ & $(0.009)$ & $(0.009)$ & $(0.013)$ & $(0.010)$ & $(0.008)$ & $(0.012)$ \\
\hline \multirow[t]{2}{*}{7 or more } & 1852.0 & 1433.5 & $418.6 * * *$ & 0.188 & 0.258 & $-0.069 * * *$ & -0.026 & -0.119 & $0.094 * * *$ \\
\hline & $(40.8)$ & $(43.2)$ & $(59.4)$ & $(0.008)$ & $(0.011)$ & $(0.014)$ & $(0.005)$ & $(0.010)$ & $(0.011)$ \\
\hline
\end{tabular}

Notes: (i) *** $\mathrm{p}<0.01, * * \mathrm{p}<0.05,{ }^{*} \mathrm{p}<0.1$. (ii) standard errors are in parenthesis. (ii) negative (positive) values of the skewness indicate downside (upside) risk. 
The ATTs for yield measures the average yield a farmer could obtain by increasing the intensity of tillage in comparison to the counterfactual outcome. As column C of Table 2.4 shows, all but one of the tillage intensities show an increase in yield in comparison to the counterfactual outcome. On average, ploughing 4 times increases yield by $83 \mathrm{~kg}$. The increase in yield is even higher if the farmers plough their plots 5 times leading to an average yield gain of $279 \mathrm{~kg}$. Ploughing 6 times increases yield by $229 \mathrm{~kg}$. The results show farmers obtain the highest yield when the intensity of tillage is 7 or more (419 kg). Since ploughing 3 times reduces yield by $45 \mathrm{~kg}$, farmers may be able to increase yield by increasing the intensity of tillage. This result is consistent with Teklewold and Mekonen (2017) who show that increasing the intensity of tillage increases net farm income in the Nile Basin of Ethiopia. Even though the method of ploughing is different, similar high expected returns from conventional tillage are reported in the USA and Germany (Gandorfer et al., 2011; Meyer-Aurich et al., 2009; Williams et al., 1990).

Our measures of risk exposure are the variance and skewness of the error distribution of yield. In column F of Table 2.4, almost all of the ATTs are negative showing that higher intensities of tillage are variance reducing. Negative values of the skewness is evidence of downside risk exposure whereas positive values indicate evidence of upside risk. Columns $\mathrm{G}$ and $\mathrm{H}$ of Table 2.4 show that both the actual and the counterfactual skewness values are negative indicating that farmers are likely to face downside risk. The positive ATTs for the skewness reveals that farmers' downside risk exposure tends to decline as the intensity of tillage increases (Column I, Table 2.4).

Studies show that reducing the intensity of tillage are beneficial in moisture stress areas because minimum soil disturbance helps to preserve moisture (Kassie et al., 2010, 2015b; Teklewold and Mekonnen, 2017). We check the sensitivity of our results presented in Table 2.4 to differences in rainfall patterns by splitting the data into three: low, medium and high rainfall areas. ${ }^{\mathbf{1 0}}$ The results are presented in Appendix 2, Table 2.10. Regardless of rainfall patterns, our results consistently show higher yield and lower risk exposure at higher intensities of tillage.

Finally, it is also worth noting that reducing tillage may reduce the costs of production, which may lead to a net income benefits to the farmers (Giller et al., 2009; Jaleta et al., 2016; Krishna et al., 2016a). We have analyzed the impact of increasing intensities of tillage on farmers' returns to land net of variable costs of production. The ATTs for net return to land (Birr/ha), variance and skewness of its error distribution are reported in Appendix 2, Table 2.11. At higher intensities of tillage, the

\footnotetext{
${ }^{10}$ The data source for the rainfall is Fick and Hijmans (2017).
} 
results reveal that farmers' net return to land is higher and downside risk exposure is lower, consistent with the results presented above. However, the variance of net return to land tends to increase when the intensities of tillage are five and more.

\subsubsection{Impact of intensity of tillage on the cost of risk}

We estimate the cost of risk using a quantile-based approach using equation (2.6) above. We divide the distributions of yield, variance and skewness obtained from equations (2.4a) and (2.4b) into two quantiles. ${ }^{11}$ We use the lowest quantile in order to estimate the cost of risk because unfavorable risks are located at the lower tail of the distributions. Following Kassie et al. (2015b) and Kim et al. (2014), we give various estimated cost of risk at different levels of Constant Relative Risk-Aversion (CRRA) preferences ( 0.5 to 3 ) for both the counterfactual outcome and each intensities of tillage.

The results are reported in Figure 2.2.

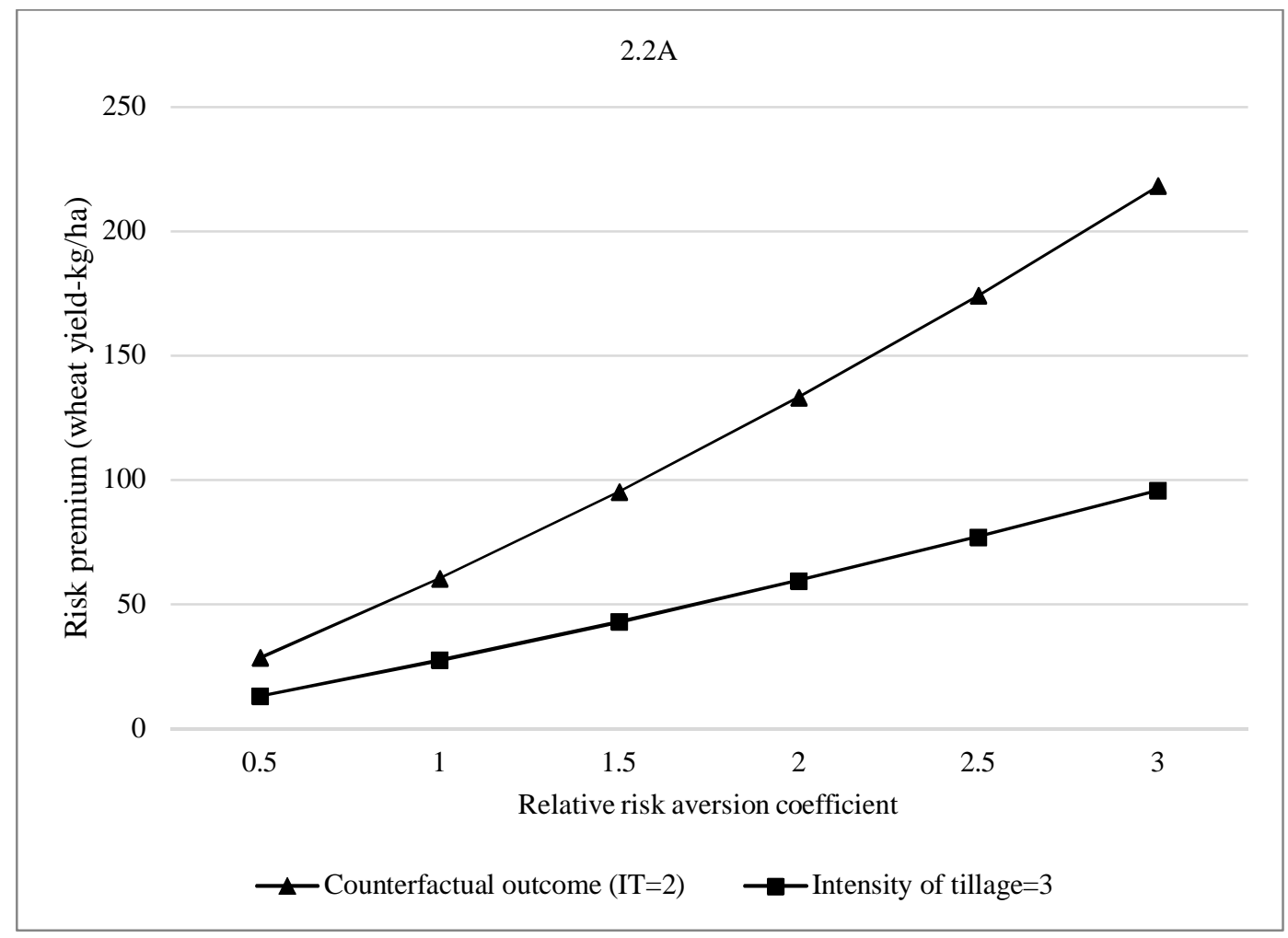

\footnotetext{
${ }^{11}$ In order to understand the sensitivity of our results to a different quantile, we divided the distributions of the yield, variance and skewness in equations (2.4a and 2.4b) into 4 equal parts and estimated the cost of risk. Even though the number of observations in each quantile drops, the conclusion we draw about the cost of risk remain the same.
} 

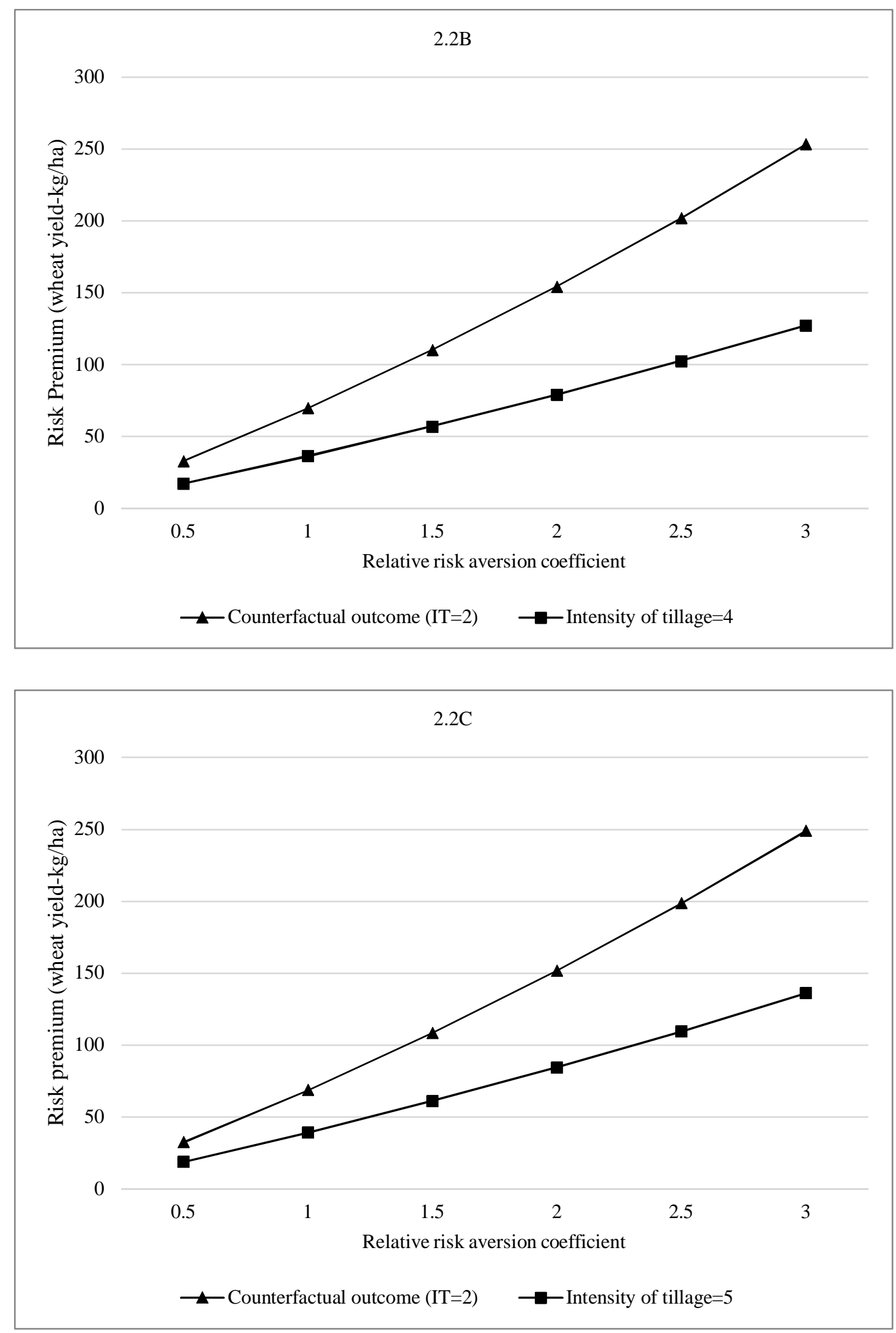

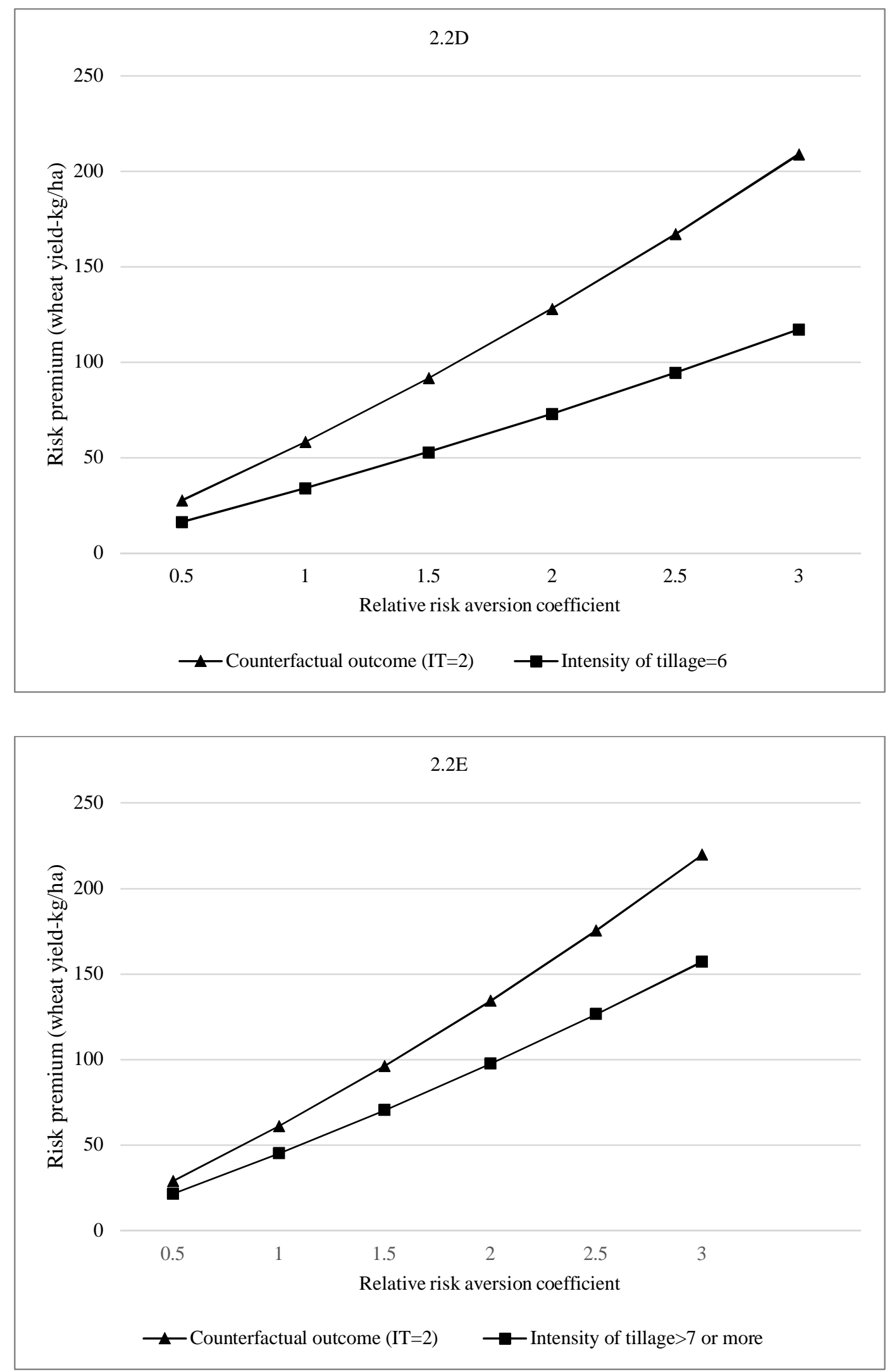

Figure 2.2. The impact intensity of tillage on costs of risk. 
Figure 2.2 shows that the cost of risk is the lowest at higher intensities of tillage. As the relative risk aversion coefficient increases, the cost of risk tends to rise reflecting the fact that risk averse farmers are willing to avoid risk at a higher cost. Figure 2.2 further reveals that the vertical distance between the counterfactual outcome and each intensity of tillage is greatest at intensities of tillage 3 and 4 , suggesting that farmers obtain the greatest reduction in the cost of risk for plots that were ploughed 3 and 4 times. After the 4th intensity of tillage, in comparison to the counterfactual outcome, the contribution of an additional round of tillage to a reduction in the cost of risk tends to decline. We also find qualitatively similar results when net return to land (Birr/ha) and its variance and skewness are used as outcome variables (see Appendix 2, Figure 2.3).

\subsection{Concluding remarks}

In many developing countries, tilling the land is the most common practice. Tillage provides various services to the famers such as facilitating uniform and easy seed germination, suppressing weeds, increasing the soils' water infiltration rate, and reducing the incidence of various diseases. However, intensive tillage practices may lead to soil degradation by increasing soil erosion and disturbing soil microorganisms beneficial to the soil ecosystem. Agricultural scientists, international organizations and national governments promote reduced tillage as a solution to mitigate the negative impact of soil degradation. The farm level impacts of reduced tillage have been widely studied. However, there is limited research on the productivity and risk implications of intensive tillage practices in developing countries where many farmers practice intensive tillage.

We study the impact of intensity of tillage practices on productivity and risk exposure in major wheat producing zones of Ethiopia. Understanding the potential gains and losses from intensive tillage practices in the farmers' fields is crucial in order to promote sustainable intensification practices that considers the needs of smallholder farmers. We estimate a flexible moment-based production function using endogenous switching regression treatment effects model. Our results show that high intensities of tillage are generally associated not only with higher yields but also with lower risk exposure. Our findings strongly suggest that farmers use tillage as a strategy to increase productivity and minimize production risks. Our results further show that the cost of risk is the lowest at the higher intensities of tillage.

Under the current circumstances of wheat farmers in Ethiopia, high intensity tillage seems to be important. Even though intensive tillage exacerbates soil erosion, the net effect tends to be positive, 
high expected yield and low risk exposure. Findings of impact assessments on reduced tillage interventions in many countries show that reduced tillage has the potential to improve productivity and livelihood of rural households. The findings of the studies on reduced tillage differ from our findings perhaps because the potential nonlinear effects of various intensities of tillage for nonadopters of reduced tillage were not controlled in these studies.

In the literature, there is a consensus that the full benefits of reduced tillage are realized only after many years. As our results show, there is a short-term opportunity cost of switching to reduced tillage. Promoting reduced tillage should be accompanied with incentive schemes that could potentially compensate yield losses and production risks. However, detailed crop and agroecological specific studies are required because the impact of intensive tillage practices might be crop and context specific. In situations where adequate number of observations with no-till are in the sample, future studies which use similar approaches to ours will need to make a distinction between no-till and reduced tillage. Further research might be also required to identify the impact of intensive tillage on yield and risk under varying rainfall conditions, and controlling for the effects of sowing date and the history of tillage in specific plots. 


\subsection{Appendix 2}

Table 2.5. Summary statistics, descriptions and measurements for the variables used in the regressions (2009/10-2013/14).

\begin{tabular}{|c|c|c|c|c|c|c|c|}
\hline \multirow[b]{2}{*}{ Variables } & \multirow[b]{2}{*}{ Descriptions and measurement } & \multicolumn{2}{|c|}{$2009 / 10$} & \multicolumn{2}{|c|}{$2013 / 14$} & \multicolumn{2}{|c|}{ Overall } \\
\hline & & Mean & SD & Mean & SD & Mean & SD \\
\hline \multicolumn{8}{|c|}{ Dependent variables } \\
\hline Yield & Yield (kg/ha) & 1670.7 & 1009.3 & $1728.7 * *$ & 1023.8 & $1,698.7$ & $1,016.6$ \\
\hline Net return & Net return to land (Birr/ha) ${ }^{\mathbf{a}}$ & 6513.0 & 6593.5 & 6460.6 & 6271.9 & 6487.8 & 6440.2 \\
\hline Tillage & Frequency of tillage (number) & 4.2 & 1.3 & $4.0 * * *$ & 1.2 & 4.1 & 1.2 \\
\hline \multicolumn{8}{|l|}{ Inputs } \\
\hline Oxen days & Oxen power (days/ha) & 23.6 & 12.6 & $24.8 * * *$ & 11.3 & 24.2 & 12.0 \\
\hline Labor & Total labor (days/ha) & 98.6 & 83.1 & $90.0 * * *$ & 67.2 & 94.5 & 76.0 \\
\hline Fertilizer & Real expenses on fertilizer (Birr/ha) & 698.3 & 696.8 & $901.2 * * *$ & 673.0 & 796.0 & 692.9 \\
\hline Agrochemicals & Real expenses on agrochemicals (Birr/ha) & 32.3 & 47.4 & $46.2 * * *$ & 74.0 & 39.0 & 62.0 \\
\hline Rented & 1 if the plot was rented in, 0 otherwise & 0.23 & & 0.25 & & 0.24 & \\
\hline Machine & 1 if the farmer used machinery in the plot, 0 otherwise & 0.08 & & $0.13 * * *$ & & 0.11 & \\
\hline \multicolumn{8}{|c|}{ Plot characteristics } \\
\hline Plot size & Plot size (ha) & 0.41 & 0.37 & $0.38 * * *$ & 0.30 & 0.40 & 0.34 \\
\hline Distance & Plot distance from home (walking minutes) & 18.9 & 27.5 & $17.5 * *$ & 24.2 & 18.2 & 26.0 \\
\hline No rotation & 1 if crops were not rotated, 0 otherwise & 0.15 & & $0.18 * * *$ & & 0.17 & \\
\hline Legume rotation & 1 if rotation with legumes, 0 otherwise & 0.24 & & 0.25 & & 0.24 & \\
\hline $\begin{array}{l}\text { Other cereals } \\
\text { Rotation }\end{array}$ & 1 if rotation with other cereals, 0 otherwise & 0.61 & & $0.57 * * *$ & & 0.59 & \\
\hline Residue & 1 if crop residue left on the plot, 0 otherwise & 0.31 & & $0.05 * * *$ & & 0.18 & \\
\hline Manure & 1 if the farmer applied manure in the plot, 0 otherwise & 0.19 & & $0.17 *$ & & 0.18 & \\
\hline LV & 1 if local varieties were used in the plot, 0 otherwise & 0.05 & & $0.19 * * *$ & & 0.12 & \\
\hline IS & 1 if improved rust susceptible varieties were used in the plot, 0 otherwise & 0.46 & & $0.27 * * *$ & & 0.37 & \\
\hline IR & 1 if improved rust resistant varieties were used in the plot, 0 otherwise & 0.19 & & $0.47 * * *$ & & 0.32 & \\
\hline $\mathrm{OV}$ & 1 if other improved varieties were used in the plot, 0 otherwise & 0.30 & & $0.08 * * *$ & & 0.19 & \\
\hline Flat & 1 if the slope of the plot is flat, 0 otherwise & 0.64 & & $0.68 * * *$ & & 0.66 & \\
\hline Medium slope & 1 if the slope of the plot is medium, 0 otherwise & 0.31 & & $0.27 * * *$ & & 0.29 & \\
\hline Steep & 1 if the slope of the plot is steep, 0 otherwise & 0.05 & & 0.05 & & 0.05 & \\
\hline Shallow & 1 if the depth of the soil is shallow, 0 otherwise & 0.14 & & 0.14 & & 0.14 & \\
\hline Medium depth & 1 if the depth of the soil is medium, 0 otherwise & 0.26 & & 0.27 & & 0.26 & \\
\hline Deep & 1 if the depth of the soil is deep, 0 otherwise & 0.61 & & 0.60 & & 0.60 & \\
\hline
\end{tabular}




\begin{tabular}{|c|c|c|c|c|c|c|c|}
\hline \multirow[b]{2}{*}{ Variables } & \multirow[b]{2}{*}{ Descriptions and measurement } & \multicolumn{2}{|c|}{$2009 / 10$} & \multicolumn{2}{|c|}{$2013 / 14$} & \multicolumn{2}{|c|}{ Overall } \\
\hline & & Mean & SD & Mean & SD & Mean & SD \\
\hline Black & 1 if the color of the soil is black, 0 otherwise & 0.44 & & 0.46 & & 0.45 & \\
\hline Brown & 1 if the color of the soil is brown, 0 otherwise & 0.22 & & $0.18 * * *$ & & 0.20 & \\
\hline Red & 1 if the color of the soil is red, 0 otherwise & 0.27 & & 0.28 & & 0.28 & \\
\hline Grey & 1 if the color of the soil is grey and others, 0 otherwise & 0.06 & & $0.08 * * *$ & & 0.07 & \\
\hline \multicolumn{8}{|c|}{ Production tresses } \\
\hline Pests & 1 if the farmer faced incidence of pests in the plot, 0 otherwise & 0.02 & & $0.01 * * *$ & & 0.02 & \\
\hline Diseases & 1 if the farmer faced incidence of wheat diseases in the plot, 0 otherwise & 0.12 & & $0.18 * * *$ & & 0.15 & \\
\hline Drought & 1 if the farmer faced incidence of drought in the plot, 0 otherwise & 0.07 & & $0.01 * * *$ & & 0.04 & \\
\hline Waterlogging & 1 if the farmer faced incidence of waterlogging in the plot, 0 otherwise & 0.04 & & $0.05 * * *$ & & 0.05 & \\
\hline Abiotic stress & 1 if the farmer faced incidence of other abiotic stresses (e.g., frost), 0 otherwise & 0.09 & & 0.10 & & 0.10 & \\
\hline \multicolumn{8}{|c|}{ Household level explanatory variables } \\
\hline Male & 1 if sex of the household head is, 0 if female & 0.96 & & $0.94 * *$ & & 0.95 & \\
\hline Age & Age of the head of the household (years) & 43.7 & 11.7 & $46.9 * * *$ & 12.2 & 45.3 & 12.2 \\
\hline Illiterate & 1 if the head of the household is illiterate, 0 otherwise & 0.44 & & $0.48 * *$ & & 0.46 & \\
\hline School $>=2$ and $<6$ & 1 if the head of the household attended school between two and six years, 0 otherwise & 0.38 & & $0.33 * *$ & & 0.36 & \\
\hline School $>=6$ & 1 if the head of the household completed more than six years of schooling, 0 otherwise & 0.18 & & 0.19 & & 0.18 & \\
\hline Oxen & 1 if the household owns two or more oxen, 0 otherwise & 0.72 & & 0.72 & & 0.72 & \\
\hline Household size & Household size & 6.8 & 2.4 & 6.7 & 2.3 & 6.7 & 2.4 \\
\hline Training & The farmer took training on minimum tillage and climate change adaptation, 0 otherwise & 0.12 & & 0.09 & & 0.11 & \\
\hline Plots & Number of total plots cultivated by the household & 7.8 & 3.3 & $8.0 * *$ & 3.4 & 7.9 & 3.4 \\
\hline Ext contact & Number of extension contacts (days/year) & 45.6 & 51.3 & $40.0 * * *$ & 31.6 & 42.93 & 43.0 \\
\hline Distanceh & Distance to herbicide markets (walking minutes) & 73.1 & 57.9 & $61.4 * * *$ & 50.2 & 67.1 & 54.7 \\
\hline Kinship & Number of relatives and nonrelatives a household relies on & 25.6 & 41.1 & $35.5 * * *$ & 64.2 & 30.4 & 53.7 \\
\hline Aid relief & 1 if the household received drought or aid relief, 0 otherwise & 0.05 & & $0.01 * * *$ & & 0.03 & \\
\hline Confidence & 1 if the head of the household is confident on the skill of the officials and extension workers & 0.54 & & $0.59 * * *$ & & 0.57 & \\
\hline \multicolumn{8}{|c|}{ 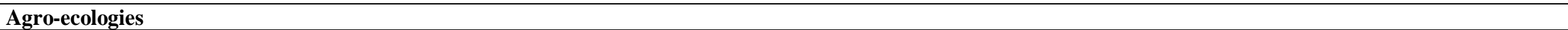 } \\
\hline $\mathrm{H} 2$ & 1 if tepid to cool humid mid-highlands, 0 otherwise & & & & & 0.17 & \\
\hline $\mathrm{H} 3$ & 1 if cold to very cold humid sub-afro alpine, 0 otherwise & & & & & 0.02 & \\
\hline M1 & 1 if hot to warm moist lowlands, 0 otherwise & & & & & 0.03 & \\
\hline M2 & 1 if tepid to cool moist mid-highlands, 0 otherwise & & & & & 0.30 & \\
\hline SA2 & 1 if tepid to cool semi-arid mid-highlands, 0 otherwise & & & & & 0.01 & \\
\hline SH1 & 1 if hot to warm sub-humid lowlands, 0 otherwise & & & & & 0.04 & \\
\hline $\mathrm{SH} 2$ & 1 if tepid to cool sub-humid mid highlands, 0 otherwise & & & & & 0.14 & \\
\hline SM2 & 1 if tepid to cool sub-moist mid highlands, 0 otherwise & & & & & 0.28 & \\
\hline
\end{tabular}


Table 2.6. The selection equation, random effects ordered logit model (REOLM).

\begin{tabular}{|c|c|}
\hline Explanatory variables & Coef/se \\
\hline Plot size & $\begin{array}{c}0.605 * * * \\
(0.134)\end{array}$ \\
\hline Medium slope $^{\mathbf{a}}$ & $\begin{array}{c}-0.149 \\
(0.092)\end{array}$ \\
\hline Steep & $\begin{array}{c}-0.194 \\
(0.196)\end{array}$ \\
\hline Medium depth ${ }^{\mathbf{b}}$ & $\begin{array}{l}-0.016 \\
(0.140)\end{array}$ \\
\hline Deep & $\begin{array}{c}0.049 \\
(0.146)\end{array}$ \\
\hline Brown $^{c}$ & $\begin{array}{c}-0.112 \\
(0.129)\end{array}$ \\
\hline Red & $\begin{array}{c}-0.092 \\
(0.114)\end{array}$ \\
\hline Grey & $\begin{array}{c}-0.041 \\
(0.175)\end{array}$ \\
\hline Rented & $\begin{array}{c}-0.085 \\
(0.085)\end{array}$ \\
\hline Machine & $\begin{array}{c}-0.188 \\
(0.268)\end{array}$ \\
\hline Distance & $\begin{array}{c}-0.003 \\
(0.002)\end{array}$ \\
\hline Legume rotation $^{\mathbf{d}}$ & $\begin{array}{c}0.086 \\
(0.120)\end{array}$ \\
\hline Other cereals rotation & $\begin{array}{l}0.205^{*} \\
(0.106)\end{array}$ \\
\hline Residue & $\begin{array}{l}-0.126 \\
(0.156)\end{array}$ \\
\hline Pests & $\begin{array}{c}0.409 \\
(0.338)\end{array}$ \\
\hline Diseases & $\begin{array}{c}0.184 \\
(0.133)\end{array}$ \\
\hline Drought & $\begin{array}{c}0.302 \\
(0.266)\end{array}$ \\
\hline Waterlogging & $\begin{array}{l}-0.005 \\
(0.209)\end{array}$ \\
\hline Abiotic stress & $\begin{array}{c}0.049 \\
(0.177)\end{array}$ \\
\hline Male & $\begin{array}{c}0.662 \\
(0.478)\end{array}$ \\
\hline Age & $\begin{array}{c}0.002 \\
(0.017)\end{array}$ \\
\hline School $>=2$ and $<6^{\mathrm{e}}$ & $\begin{array}{c}0.331 \\
(0.270)\end{array}$ \\
\hline School $>=6$ & $\begin{array}{c}0.584 \\
(0.446)\end{array}$ \\
\hline Household size & $\begin{array}{c}0.058 \\
(0.060)\end{array}$ \\
\hline Training & $\begin{array}{c}0.157 \\
(0.228)\end{array}$ \\
\hline Oxen & $\begin{array}{c}0.344 * * * \\
(0.130)\end{array}$ \\
\hline Plots & $\begin{array}{c}-0.053 * \\
(0.031)\end{array}$ \\
\hline Distanceh & $\begin{array}{l}0.002 * \\
(0.001)\end{array}$ \\
\hline Ext contact & $\begin{array}{c}0.004 * * \\
(0.002)\end{array}$ \\
\hline Kinship & $0.002 *$ \\
\hline
\end{tabular}


Aid relief

Confidence

Survey year $(2013 / 14=1)$

$-0.146$

(0.137)

$-0.168$

(0.102)

PA median frequency of tillage

Cut point 1

Cut point 2

Cut point 3

Cut point 4

Cut point 4

Cut point 5

$17.497 * * *$

(0.770)

Panel level variance component of the error term, $\mathrm{u}$

$3.143 * * *$

Wald test statistic for significance of the instrument

Log pseudo likelihood

Wald test

Agro-ecology controlled

Yes

Mundlak's fixed effects controlled

Yes

Number of plots

5,981

Number of households

1,928

Notes: (i) $* * * \mathrm{p}<0.01, * * \mathrm{p}<0.05, * \mathrm{p}<0.1$. (ii) clustered standard errors are in parenthesis. (iii) base category:, ${ }^{\mathrm{a}}$ flat slops, ${ }^{\mathbf{b}}$ shallow depth, ${ }^{\mathbf{c}}$ black soil, ${ }^{\mathbf{d}}$ plots not rotated, ${ }^{\mathbf{e}}$ the head of the household is illiterate. 
Table 2.7. Results of the endogenous switching regressions (logarithms of yield (kg/ha) by intensity of tillage).

\begin{tabular}{|c|c|c|c|c|c|c|}
\hline \multirow[b]{3}{*}{ Explanatory variables } & \multicolumn{6}{|c|}{ Logarithm of yield $(\mathrm{kg} / \mathrm{ha})^{\mathrm{g}}$} \\
\hline & 2 & 3 & 4 & 5 & 6 & 7 or more \\
\hline & Coef/se & Coef/se & Coef/se & Coef/se & Coef/se & Coef/se \\
\hline \multicolumn{7}{|l|}{ Inputs and tenure status } \\
\hline \multirow[t]{2}{*}{ Labor, $\log$} & 0.153 & $0.191 * * *$ & $0.158 * * *$ & $0.167 * * *$ & 0.040 & 0.007 \\
\hline & $(0.111)$ & $(0.035)$ & $(0.027)$ & $(0.054)$ & $(0.104)$ & $(0.156)$ \\
\hline \multirow[t]{2}{*}{ Fertilizer, log } & 0.141 & $0.200 * * *$ & $0.221 * * *$ & $0.206^{* * *}$ & $0.195 * * *$ & $0.256^{* * *}$ \\
\hline & $(0.106)$ & $(0.031)$ & $(0.025)$ & $(0.034)$ & $(0.057)$ & $(0.078)$ \\
\hline \multirow[t]{2}{*}{ Agrochemicals, log } & -0.339 & $0.071^{*}$ & $0.071 * * *$ & $0.071 * * *$ & -0.003 & $0.168 * *$ \\
\hline & $(0.321)$ & $(0.038)$ & $(0.020)$ & $(0.024)$ & $(0.062)$ & $(0.083)$ \\
\hline \multirow[t]{2}{*}{ Oxen days, log } & -0.111 & 0.067 & 0.052 & $0.112 *$ & -0.008 & 0.120 \\
\hline & $(0.142)$ & $(0.052)$ & $(0.040)$ & $(0.062)$ & $(0.104)$ & $(0.189)$ \\
\hline \multirow[t]{2}{*}{ machine } & 1.211 & $0.402 * * *$ & $0.331 * * *$ & $0.299 * * *$ & 0.380 & 0.659 \\
\hline & $(0.876)$ & $(0.095)$ & $(0.073)$ & $(0.074)$ & $(0.375)$ & $(0.534)$ \\
\hline \multirow[t]{2}{*}{ rented } & $-0.247 * *$ & -0.031 & -0.010 & -0.013 & -0.042 & 0.004 \\
\hline & $(0.116)$ & $(0.035)$ & $(0.031)$ & $(0.041)$ & $(0.067)$ & $(0.109)$ \\
\hline \multicolumn{7}{|l|}{ Plot characteristics } \\
\hline \multirow[t]{2}{*}{ plot size } & -0.169 & -0.121 & $-0.186 * * *$ & -0.054 & -0.129 & -0.124 \\
\hline & $(0.366)$ & $(0.085)$ & $(0.053)$ & $(0.064)$ & $(0.116)$ & $(0.222)$ \\
\hline \multirow[t]{2}{*}{ medium slope ${ }^{a}$} & -0.162 & -0.010 & -0.005 & 0.012 & -0.107 & -0.160 \\
\hline & $(0.143)$ & $(0.036)$ & $(0.030)$ & $(0.043)$ & $(0.103)$ & $(0.146)$ \\
\hline \multirow[t]{2}{*}{ steep } & 0.185 & -0.028 & -0.030 & -0.041 & $-0.262 *$ & 0.078 \\
\hline & $(0.306)$ & $(0.068)$ & $(0.079)$ & $(0.082)$ & $(0.146)$ & $(0.338)$ \\
\hline \multirow[t]{2}{*}{ medium depth ${ }^{\mathbf{b}}$} & -0.149 & 0.040 & 0.051 & 0.040 & $0.347 * *$ & 0.218 \\
\hline & $(0.170)$ & $(0.043)$ & $(0.044)$ & $(0.069)$ & $(0.150)$ & $(0.185)$ \\
\hline \multirow[t]{2}{*}{ deep } & -0.076 & $0.094^{*}$ & 0.045 & $0.177 * *$ & $0.241 *$ & $0.329 *$ \\
\hline & $(0.168)$ & $(0.048)$ & $(0.048)$ & $(0.070)$ & $(0.128)$ & $(0.187)$ \\
\hline \multirow[t]{2}{*}{ brown $^{c}$} & 0.250 & 0.022 & -0.045 & 0.045 & 0.161 & -0.079 \\
\hline & $(0.226)$ & $(0.043)$ & $(0.042)$ & $(0.063)$ & $(0.115)$ & $(0.180)$ \\
\hline \multirow[t]{2}{*}{ red } & -0.109 & -0.001 & -0.038 & $0.139 * *$ & 0.108 & 0.087 \\
\hline & $(0.264)$ & $(0.039)$ & $(0.045)$ & $(0.069)$ & $(0.115)$ & $(0.177)$ \\
\hline \multirow[t]{2}{*}{ gray } & -0.278 & $0.116^{*}$ & -0.007 & -0.053 & -0.170 & -0.073 \\
\hline & $(0.443)$ & $(0.064)$ & $(0.056)$ & $(0.080)$ & $(0.185)$ & $(0.237)$ \\
\hline legume rotation ${ }^{\mathbf{d}}$ & -0.190 & -0.017 & 0.050 & 0.054 & 0.174 & -0.170 \\
\hline
\end{tabular}




\begin{tabular}{|c|c|c|c|c|c|c|}
\hline \multirow[b]{3}{*}{ Explanatory variables } & \multicolumn{6}{|c|}{ Logarithm of yield $(\mathrm{kg} / \mathrm{ha})^{\mathrm{g}}$} \\
\hline & 2 & 3 & 4 & 5 & 6 & 7 or more \\
\hline & Coef/se & Coef/se & Coef/se & Coef/se & Coef/se & Coef/se \\
\hline \multirow{3}{*}{ other cereals rotation } & $(0.193)$ & $(0.042)$ & $(0.042)$ & $(0.052)$ & $(0.128)$ & $(0.270)$ \\
\hline & -0.029 & $-0.069 *$ & 0.008 & -0.006 & 0.055 & -0.163 \\
\hline & $(0.173)$ & $(0.041)$ & $(0.037)$ & $(0.044)$ & $(0.103)$ & $(0.176)$ \\
\hline \multirow[t]{2}{*}{ residue } & -0.161 & -0.021 & $0.119 * * *$ & -0.025 & -0.213 & -0.081 \\
\hline & $(0.198)$ & $(0.075)$ & $(0.046)$ & $(0.073)$ & $(0.135)$ & $(0.177)$ \\
\hline \multirow[t]{2}{*}{ manure } & -0.031 & 0.043 & $0.119 * * *$ & $0.102 *$ & -0.056 & 0.098 \\
\hline & $(0.140)$ & $(0.043)$ & $(0.038)$ & $(0.054)$ & $(0.100)$ & $(0.190)$ \\
\hline \multirow[t]{2}{*}{$I^{\mathrm{e}}$} & -0.102 & 0.076 & $0.103^{* *}$ & 0.012 & -0.161 & -0.003 \\
\hline & $(0.144)$ & $(0.051)$ & $(0.052)$ & $(0.066)$ & $(0.124)$ & $(0.218)$ \\
\hline \multirow[t]{2}{*}{ IR } & 0.083 & $0.137 * *$ & $0.088^{*}$ & 0.052 & -0.065 & -0.204 \\
\hline & $(0.156)$ & $(0.053)$ & $(0.052)$ & $(0.064)$ & $(0.110)$ & $(0.252)$ \\
\hline \multirow[t]{2}{*}{$\mathrm{OV}$} & -0.019 & $0.095^{*}$ & 0.075 & 0.079 & 0.030 & 0.129 \\
\hline & $(0.169)$ & $(0.056)$ & $(0.054)$ & $(0.077)$ & $(0.153)$ & $(0.228)$ \\
\hline \multicolumn{7}{|l|}{ Production stresses } \\
\hline \multirow[t]{2}{*}{ pests } & $-0.766^{* * *}$ & -0.115 & -0.054 & $-0.303^{*}$ & $-0.542 * *$ & 0.132 \\
\hline & $(0.286)$ & $(0.165)$ & $(0.111)$ & $(0.177)$ & $(0.221)$ & $(0.502)$ \\
\hline \multirow[t]{2}{*}{ drought } & -1.135 & $-0.224 * *$ & $-0.322 * * *$ & $-0.401 * * *$ & -0.264 & 0.107 \\
\hline & (1.219) & $(0.087)$ & $(0.076)$ & $(0.106)$ & $(0.235)$ & $(0.715)$ \\
\hline \multirow[t]{2}{*}{ waterlogging } & -0.400 & $-0.284 * * *$ & $-0.335^{* * *}$ & -0.162 & $-0.611 * * *$ & -0.063 \\
\hline & $(0.268)$ & $(0.067)$ & $(0.074)$ & $(0.101)$ & $(0.222)$ & $(0.441)$ \\
\hline \multirow[t]{2}{*}{ abiotic stress } & -0.229 & $-0.257 * * *$ & $-0.366 * * *$ & $-0.280 * *$ & -0.010 & -0.270 \\
\hline & $(0.190)$ & $(0.058)$ & $(0.052)$ & $(0.112)$ & $(0.237)$ & $(0.398)$ \\
\hline \multicolumn{7}{|c|}{ Household level explanatory variables and model statistics } \\
\hline \multirow[t]{2}{*}{ male } & -0.158 & 0.005 & 0.066 & $0.422 *$ & 0.066 & -0.355 \\
\hline & $(0.712)$ & $(0.262)$ & $(0.190)$ & $(0.241)$ & $(0.372)$ & $(0.895)$ \\
\hline \multirow[t]{2}{*}{ age } & $-0.039 *$ & -0.007 & -0.003 & -0.007 & -0.006 & 0.013 \\
\hline & $(0.023)$ & $(0.010)$ & $(0.005)$ & $(0.010)$ & $(0.017)$ & $(0.019)$ \\
\hline \multirow[t]{2}{*}{ school $>=2$ and $<6^{f}$} & 0.428 & -0.072 & 0.003 & 0.190 & 0.042 & -0.029 \\
\hline & $(0.305)$ & $(0.102)$ & $(0.077)$ & $(0.121)$ & $(0.203)$ & $(0.317)$ \\
\hline \multirow[t]{2}{*}{ School $>=6$} & 0.294 & 0.051 & -0.019 & 0.032 & -0.165 & -0.045 \\
\hline & $(0.756)$ & $(0.218)$ & $(0.167)$ & $(0.172)$ & $(0.291)$ & $(0.391)$ \\
\hline ext contact & 0.001 & -0.001 & -0.000 & 0.000 & 0.000 & 0.001 \\
\hline
\end{tabular}


Logarithm of yield $(\mathrm{kg} / \mathrm{ha})^{\mathrm{g}}$

Explanatory variables

\begin{tabular}{|c|c|c|c|c|c|}
\hline 2 & 3 & 4 & 5 & 6 & 7 or more \\
\hline Coef/se & Coef/se & Coef/se & Coef/se & Coef/se & Coef/se \\
\hline$(0.002)$ & $(0.001)$ & $(0.000)$ & $(0.001)$ & $(0.001)$ & $(0.001)$ \\
\hline-0.002 & -0.000 & -0.000 & 0.000 & -0.002 & -0.001 \\
\hline$(0.002)$ & $(0.001)$ & $(0.000)$ & $(0.000)$ & $(0.001)$ & $(0.003)$ \\
\hline$-0.840 * * *$ & -0.234 & -0.213 & 0.035 & -0.497 & -0.130 \\
\hline$(0.247)$ & $(0.150)$ & (0.169) & $(0.137)$ & $(0.408)$ & $(0.695)$ \\
\hline $0.268^{*}$ & 0.069 & 0.011 & $0.205^{* * *}$ & 0.059 & 0.165 \\
\hline$(0.162)$ & $(0.056)$ & (0.044) & $(0.059)$ & $(0.119)$ & $(0.165)$ \\
\hline-0.008 & 0.050 & -0.022 & -0.031 & $-0.192 * *$ & -0.115 \\
\hline$(0.143)$ & $(0.049)$ & $(0.034)$ & $(0.054)$ & $(0.091)$ & $(0.150)$ \\
\hline Yes & Yes & Yes & Yes & Yes & Yes \\
\hline Yes & Yes & Yes & Yes & Yes & Yes \\
\hline Yes & Yes & Yes & Yes & Yes & Yes \\
\hline-0.076 & 0.063 & $0.720 * * *$ & $-0.569 * *$ & -0.546 & -0.242 \\
\hline$(0.261)$ & $(0.165)$ & $(0.230)$ & $(0.284)$ & $(0.395)$ & $(0.304)$ \\
\hline $6.531 * * *$ & $4.723 * * *$ & $4.179 * * *$ & $5.392 * * *$ & $6.010 * * *$ & $5.794 * * *$ \\
\hline$(1.643)$ & $(0.381)$ & $(0.304)$ & $(0.367)$ & $(0.904)$ & $(1.216)$ \\
\hline 307 & 1,648 & 2,083 & 1,205 & 455 & 283 \\
\hline 161 & 734 & 972 & 625 & 267 & 157 \\
\hline $383.84 * * *$ & $692.57 * * *$ & $1044.67 * * *$ & $631.65 * * *$ & $228.98 * * *$ & $154.03 * * *$ \\
\hline-0.077 & -0.222 & -0.218 & -0.535 & -0.493 & -0.345 \\
\hline 33.770 & $69.680 * * *$ & $67.410 * * *$ & $50.810 *$ & $47.220 *$ & $51.620 * *$ \\
\hline 0.32 & 0.18 & $27.8 * * *$ & $4.57 * * *$ & 1.32 & $2.73 *$ \\
\hline 0.08 & 0.18 & $18.320 * * *$ & 2.58 & 0.53 & 0.120 \\
\hline
\end{tabular}

Falsification test: the instrument is not significant

0.120

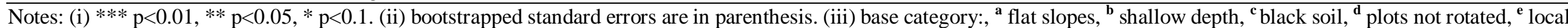
varieties, ${ }^{\mathbf{f}}$ the head of the household is illiterate. (iv) ${ }^{\mathbf{g}}<=2,3,4,5,6$ and $>=7$ refer plots that were ploughed 2 or fewer, $3,4,5,6$, and 7 or more times, respectively. 
Table 2.8. Results of the endogenous switching regressions: the dependent variables are risk exposure (variances by intensity of tillage).

\begin{tabular}{|c|c|c|c|c|c|c|}
\hline \multirow[b]{3}{*}{ Explanatory variables } & \multicolumn{6}{|c|}{ Risk exposure (variance) ${ }^{g}$} \\
\hline & 2 & 3 & 4 & 5 & 6 & 7 or more \\
\hline & Coef/se & Coef/se & Coef/se & Coef/se & Coef/se & Coef/se \\
\hline \multicolumn{7}{|l|}{ Inputs and tenure status } \\
\hline Labor, $\log$ & $\begin{array}{l}-0.032 \\
(0.062)\end{array}$ & $\begin{array}{c}0.004 \\
(0.022)\end{array}$ & $\begin{array}{c}0.029 \\
(0.021)\end{array}$ & $\begin{array}{c}0.020 \\
(0.044)\end{array}$ & $\begin{array}{l}-0.080 \\
(0.083)\end{array}$ & $\begin{array}{c}0.009 \\
(0.064)\end{array}$ \\
\hline Fertilizer, log & $\begin{array}{c}0.043 \\
(0.061)\end{array}$ & $\begin{array}{l}-0.031 \\
(0.020)\end{array}$ & $\begin{array}{c}-0.067 * * * \\
(0.017)\end{array}$ & $\begin{array}{l}-0.011 \\
(0.022)\end{array}$ & $\begin{array}{l}-0.001 \\
(0.046)\end{array}$ & $\begin{array}{l}-0.005 \\
(0.040)\end{array}$ \\
\hline Agrochemicals, log & $\begin{array}{c}0.085 \\
(0.130)\end{array}$ & $\begin{array}{l}-0.021 \\
(0.022)\end{array}$ & $\begin{array}{c}0.002 \\
(0.013)\end{array}$ & $\begin{array}{c}0.004 \\
(0.019)\end{array}$ & $\begin{array}{c}0.115^{* *} \\
(0.050)\end{array}$ & $\begin{array}{l}-0.026 \\
(0.042)\end{array}$ \\
\hline Oxen days, log & $\begin{array}{c}0.102 \\
(0.076)\end{array}$ & $\begin{array}{l}0.062 * \\
(0.035)\end{array}$ & $\begin{array}{l}-0.024 \\
(0.029)\end{array}$ & $\begin{array}{l}-0.046 \\
(0.049)\end{array}$ & $\begin{array}{c}0.046 \\
(0.070)\end{array}$ & $\begin{array}{c}0.041 \\
(0.108)\end{array}$ \\
\hline machine & $\begin{array}{l}-0.312 \\
(0.401)\end{array}$ & $\begin{array}{c}0.080 \\
(0.060)\end{array}$ & $\begin{array}{c}0.025 \\
(0.050)\end{array}$ & $\begin{array}{c}0.032 \\
(0.053)\end{array}$ & $\begin{array}{l}-0.375 \\
(0.395)\end{array}$ & $\begin{array}{l}-0.067 \\
(0.220)\end{array}$ \\
\hline rented & $\begin{array}{c}0.082 \\
(0.069) \\
\end{array}$ & $\begin{array}{c}-0.062 * * \\
(0.027) \\
\end{array}$ & $\begin{array}{l}-0.019 \\
(0.026) \\
\end{array}$ & $\begin{array}{l}-0.033 \\
(0.032) \\
\end{array}$ & $\begin{array}{l}-0.027 \\
(0.044) \\
\end{array}$ & $\begin{array}{l}-0.009 \\
(0.062) \\
\end{array}$ \\
\hline \multicolumn{7}{|l|}{ Plot characteristics } \\
\hline plot size & $\begin{array}{c}0.196 \\
(0.151)\end{array}$ & $\begin{array}{c}-0.096^{*} \\
(0.055)\end{array}$ & $\begin{array}{c}0.033 \\
(0.035)\end{array}$ & $\begin{array}{l}-0.051 \\
(0.050)\end{array}$ & $\begin{array}{l}0.210 * * \\
(0.100)\end{array}$ & $\begin{array}{l}-0.091 \\
(0.091)\end{array}$ \\
\hline medium slope ${ }^{a}$ & $\begin{array}{l}-0.050 \\
(0.070)\end{array}$ & $\begin{array}{l}0.041 * \\
(0.024)\end{array}$ & $\begin{array}{l}-0.015 \\
(0.023)\end{array}$ & $\begin{array}{l}-0.019 \\
(0.033)\end{array}$ & $\begin{array}{l}-0.029 \\
(0.077)\end{array}$ & $\begin{array}{l}-0.008 \\
(0.070)\end{array}$ \\
\hline steep & $\begin{array}{l}-0.147 \\
(0.202)\end{array}$ & $\begin{array}{c}0.045 \\
(0.044)\end{array}$ & $\begin{array}{c}0.002 \\
(0.061)\end{array}$ & $\begin{array}{l}-0.093 \\
(0.076)\end{array}$ & $\begin{array}{c}0.120 \\
(0.113)\end{array}$ & $\begin{array}{l}-0.157 \\
(0.194)\end{array}$ \\
\hline medium depth ${ }^{\mathbf{b}}$ & $\begin{array}{l}-0.036 \\
(0.102)\end{array}$ & $\begin{array}{l}-0.017 \\
(0.036)\end{array}$ & $\begin{array}{l}-0.038 \\
(0.038)\end{array}$ & $\begin{array}{l}-0.040 \\
(0.051)\end{array}$ & $\begin{array}{l}-0.024 \\
(0.113)\end{array}$ & $\begin{array}{l}-0.128 \\
(0.088)\end{array}$ \\
\hline deep & $\begin{array}{l}-0.074 \\
(0.104)\end{array}$ & $\begin{array}{l}-0.034 \\
(0.041)\end{array}$ & $\begin{array}{l}-0.017 \\
(0.034)\end{array}$ & $\begin{array}{c}0.001 \\
(0.048)\end{array}$ & $\begin{array}{c}0.007 \\
(0.110)\end{array}$ & $\begin{array}{l}-0.068 \\
(0.103)\end{array}$ \\
\hline brown $^{\mathbf{c}}$ & $\begin{array}{l}-0.017 \\
(0.104)\end{array}$ & $\begin{array}{l}-0.044 \\
(0.032)\end{array}$ & $\begin{array}{c}0.002 \\
(0.033)\end{array}$ & $\begin{array}{l}-0.046 \\
(0.050)\end{array}$ & $\begin{array}{c}0.015 \\
(0.081)\end{array}$ & $\begin{array}{c}0.019 \\
(0.109)\end{array}$ \\
\hline red & $\begin{array}{l}-0.028 \\
(0.100)\end{array}$ & $\begin{array}{l}-0.018 \\
(0.029)\end{array}$ & $\begin{array}{l}-0.005 \\
(0.031)\end{array}$ & $\begin{array}{l}-0.030 \\
(0.063)\end{array}$ & $\begin{array}{l}-0.072 \\
(0.085)\end{array}$ & $\begin{array}{l}-0.040 \\
(0.097)\end{array}$ \\
\hline gray & $\begin{array}{c}0.160 \\
(0.209)\end{array}$ & $\begin{array}{c}0.028 \\
(0.045)\end{array}$ & $\begin{array}{c}0.061 \\
(0.042)\end{array}$ & $\begin{array}{c}0.010 \\
(0.063)\end{array}$ & $\begin{array}{c}0.005 \\
(0.106)\end{array}$ & $\begin{array}{l}-0.101 \\
(0.126)\end{array}$ \\
\hline legume rotation ${ }^{\mathbf{d}}$ & $\begin{array}{c}0.048 \\
(0.107)\end{array}$ & $\begin{array}{c}0.007 \\
(0.033)\end{array}$ & $\begin{array}{c}0.010 \\
(0.028)\end{array}$ & $\begin{array}{l}-0.059 \\
(0.041)\end{array}$ & $\begin{array}{l}-0.119 \\
(0.152)\end{array}$ & $\begin{array}{c}0.136 \\
(0.159)\end{array}$ \\
\hline other cereals rotation & $\begin{array}{c}0.061 \\
(0.084)\end{array}$ & $\begin{array}{c}0.037 \\
(0.026)\end{array}$ & $\begin{array}{c}0.013 \\
(0.025)\end{array}$ & $\begin{array}{l}-0.047 \\
(0.044)\end{array}$ & $\begin{array}{l}-0.135 \\
(0.143)\end{array}$ & $\begin{array}{l}-0.000 \\
(0.085)\end{array}$ \\
\hline residue & $\begin{array}{c}0.019 \\
(0.114)\end{array}$ & $\begin{array}{c}0.025 \\
(0.057)\end{array}$ & $\begin{array}{c}0.039 \\
(0.036)\end{array}$ & $\begin{array}{c}0.058 \\
(0.058)\end{array}$ & $\begin{array}{l}-0.087 \\
(0.098)\end{array}$ & $\begin{array}{l}-0.033 \\
(0.115)\end{array}$ \\
\hline manure & $\begin{array}{c}0.104 \\
(0.079)\end{array}$ & $\begin{array}{c}0.007 \\
(0.031)\end{array}$ & $\begin{array}{l}-0.035 \\
(0.027)\end{array}$ & $\begin{array}{l}-0.033 \\
(0.033)\end{array}$ & $\begin{array}{c}0.028 \\
(0.063)\end{array}$ & $\begin{array}{l}-0.010 \\
(0.102)\end{array}$ \\
\hline $\mathrm{IS}^{\mathrm{e}}$ & $\begin{array}{l}-0.095 \\
(0.078)\end{array}$ & $\begin{array}{l}-0.015 \\
(0.040)\end{array}$ & $\begin{array}{c}-0.081 * * \\
(0.041)\end{array}$ & $\begin{array}{l}-0.001 \\
(0.052)\end{array}$ & $\begin{array}{c}0.140 \\
(0.102)\end{array}$ & $\begin{array}{c}0.147 \\
(0.111)\end{array}$ \\
\hline IR & $\begin{array}{l}-0.008 \\
(0.089)\end{array}$ & $\begin{array}{l}-0.006 \\
(0.044)\end{array}$ & $\begin{array}{c}-0.070 * \\
(0.041)\end{array}$ & $\begin{array}{c}0.012 \\
(0.050)\end{array}$ & $\begin{array}{c}0.114 \\
(0.087)\end{array}$ & $\begin{array}{c}0.162 \\
(0.152)\end{array}$ \\
\hline OV & $\begin{array}{l}-0.067 \\
(0.106) \\
\end{array}$ & $\begin{array}{l}-0.049 \\
(0.041) \\
\end{array}$ & $\begin{array}{l}-0.061 \\
(0.042) \\
\end{array}$ & $\begin{array}{l}-0.022 \\
(0.060) \\
\end{array}$ & $\begin{array}{c}0.135 \\
(0.108) \\
\end{array}$ & $\begin{array}{l}-0.012 \\
(0.121) \\
\end{array}$ \\
\hline \multicolumn{7}{|l|}{ Production stresses } \\
\hline pests & $\begin{array}{l}-0.048 \\
(0.135)\end{array}$ & $\begin{array}{l}-0.058 \\
(0.128)\end{array}$ & $\begin{array}{l}-0.081 \\
(0.081)\end{array}$ & $\begin{array}{c}0.063 \\
(0.131)\end{array}$ & $\begin{array}{c}0.174 \\
(0.208)\end{array}$ & $\begin{array}{c}0.027 \\
(0.272)\end{array}$ \\
\hline drought & $\begin{array}{c}0.546 \\
(0.501)\end{array}$ & $\begin{array}{l}-0.064 \\
(0.064)\end{array}$ & $\begin{array}{l}-0.011 \\
(0.057)\end{array}$ & $\begin{array}{c}0.005 \\
(0.081)\end{array}$ & $\begin{array}{c}0.076 \\
(0.175)\end{array}$ & $\begin{array}{l}-0.199 \\
(0.355)\end{array}$ \\
\hline
\end{tabular}




\begin{tabular}{|c|c|c|c|c|c|c|}
\hline \multirow[b]{3}{*}{ Explanatory variables } & \multicolumn{6}{|c|}{ Risk exposure (variance) ${ }^{g}$} \\
\hline & 2 & 3 & 4 & 5 & 6 & 7 or more \\
\hline & Coef/se & Coef/se & Coef/se & Coef/se & Coef/se & Coef/se \\
\hline \multirow[t]{2}{*}{ waterlogging } & $0.240^{*}$ & -0.008 & -0.017 & -0.017 & 0.156 & 0.094 \\
\hline & $(0.128)$ & $(0.049)$ & $(0.056)$ & $(0.087)$ & $(0.136)$ & $(0.143)$ \\
\hline \multirow[t]{2}{*}{ abiotic stress } & 0.143 & 0.046 & 0.033 & $0.231 * * *$ & -0.095 & 0.103 \\
\hline & $(0.112)$ & $(0.042)$ & $(0.039)$ & $(0.077)$ & $(0.136)$ & $(0.149)$ \\
\hline \multicolumn{7}{|c|}{ Household level explanatory variables and model statistics } \\
\hline \multirow[t]{2}{*}{ male } & -0.099 & 0.122 & 0.088 & -0.259 & 0.054 & -0.151 \\
\hline & $(0.294)$ & $(0.147)$ & $(0.137)$ & $(0.167)$ & $(0.247)$ & $(0.435)$ \\
\hline \multirow[t]{2}{*}{ age } & 0.018 & 0.001 & -0.005 & 0.005 & -0.008 & -0.013 \\
\hline & $(0.012)$ & $(0.004)$ & $(0.003)$ & $(0.009)$ & $(0.011)$ & $(0.008)$ \\
\hline \multirow[t]{2}{*}{ school $>=2$ and $<6^{\mathrm{f}}$} & 0.031 & -0.081 & -0.003 & -0.085 & 0.128 & -0.069 \\
\hline & $(0.171)$ & $(0.073)$ & $(0.052)$ & (0.089) & $(0.138)$ & $(0.153)$ \\
\hline \multirow[t]{2}{*}{ School $>=6$} & -0.066 & 0.049 & -0.030 & -0.001 & -0.021 & -0.084 \\
\hline & $(0.336)$ & $(0.105)$ & (0.116) & $(0.127)$ & $(0.203)$ & $(0.220)$ \\
\hline \multirow[t]{2}{*}{ ext contact } & -0.000 & -0.000 & -0.000 & 0.000 & 0.001 & 0.000 \\
\hline & $(0.001)$ & $(0.000)$ & $(0.000)$ & $(0.000)$ & $(0.001)$ & $(0.001)$ \\
\hline \multirow[t]{2}{*}{ Kinship } & 0.000 & -0.000 & 0.000 & -0.000 & -0.000 & -0.001 \\
\hline & $(0.001)$ & $(0.000)$ & $(0.000)$ & $(0.000)$ & $(0.001)$ & $(0.002)$ \\
\hline \multirow[t]{2}{*}{ aid relief } & 0.016 & 0.011 & 0.121 & 0.020 & 0.176 & -0.279 \\
\hline & $(0.128)$ & $(0.110)$ & $(0.121)$ & $(0.088)$ & $(0.202)$ & $(0.442)$ \\
\hline \multirow[t]{2}{*}{ confidence } & -0.023 & -0.013 & -0.037 & 0.055 & 0.083 & 0.022 \\
\hline & $(0.091)$ & $(0.035)$ & $(0.030)$ & $(0.036)$ & $(0.077)$ & (0.084) \\
\hline \multirow[t]{2}{*}{ Survey year $(2013 / 14=1)$} & -0.020 & -0.030 & 0.026 & -0.045 & 0.015 & 0.021 \\
\hline & $(0.072)$ & $(0.029)$ & $(0.021)$ & $(0.044)$ & $(0.088)$ & $(0.080)$ \\
\hline Battese (1997) dummies & Yes & Yes & Yes & Yes & Yes & Yes \\
\hline Mundlak's fixed effects & Yes & Yes & Yes & Yes & Yes & Yes \\
\hline Agroecological fixed effects & Yes & Yes & Yes & Yes & Yes & Yes \\
\hline \multirow[t]{2}{*}{ Selection correction terms (lamba) } & -0.024 & $0.279^{*}$ & -0.191 & -0.048 & 0.389 & 0.158 \\
\hline & $(0.137)$ & $(0.148)$ & $(0.139)$ & $(0.184)$ & $(0.306)$ & $(0.149)$ \\
\hline \multirow[t]{2}{*}{ Constant } & -0.662 & 0.273 & $0.766 * * *$ & 0.065 & -0.929 & -0.110 \\
\hline & $(0.712)$ & $(0.256)$ & $(0.193)$ & $(0.273)$ & $(0.639)$ & $(0.560)$ \\
\hline Number of plots & 307 & 1,648 & 2,083 & 1,205 & 455 & 283 \\
\hline Number of households & 161 & 734 & 972 & 625 & 267 & 157 \\
\hline Wald test & $132.23 * * *$ & 89.75 & $102.94 * * *$ & 81.09 & 62.66 & 40.53 \\
\hline
\end{tabular}

Other tests and indicators

\begin{tabular}{lllllll}
\hline Falsification test: the instrument is not significant & 0.960 & 0.150 & 0.100 & 0.380 & 0.050 & 0.030
\end{tabular} Notes: (i) ${ }^{* * *} \mathrm{p}<0.01, * * \mathrm{p}<0.05,{ }^{*} \mathrm{p}<0.1$. (ii) bootstrapped standard errors are in parenthesis. (iii) base category:, ${ }^{\mathbf{a}}$ flat slops, ${ }^{\mathbf{b}}$ shallow depth, ${ }^{\mathbf{c}}$ black soil, ${ }^{\mathbf{d}}$ plots not rotated, ${ }^{\mathbf{e}}$ local varieties, ${ }^{\mathbf{f}}$ the head of the household is illiterate. (iv) ${ }^{\mathbf{g}}$ $\langle=2,3,4,5,6$ and $\rangle=7$ refer plots that were ploughed 2 or fewer, $3,4,5,6$, and 7 or more times, respectively. 
Table 2.9. Results of the endogenous switching regressions: the dependent variables are risk exposure (skewness by intensity of tillage).

\begin{tabular}{|c|c|c|c|c|c|c|}
\hline \multirow[b]{3}{*}{ Explanatory variables } & \multicolumn{6}{|c|}{ Risk exposure (skewness) ${ }^{g}$} \\
\hline & 2 & 3 & 4 & 5 & 6 & 7 or more \\
\hline & Coef/se & Coef/se & Coef/se & Coef/se & Coef/se & Coef/se \\
\hline \multicolumn{7}{|l|}{ Inputs and tenure status } \\
\hline \multirow[t]{2}{*}{ Labor, $\log$} & -0.009 & 0.029 & 0.012 & -0.017 & 0.036 & 0.021 \\
\hline & $(0.089)$ & $(0.029)$ & $(0.024)$ & $(0.066)$ & $(0.151)$ & $(0.091)$ \\
\hline \multirow[t]{2}{*}{ Fertilizer, $\log$} & -0.023 & -0.015 & -0.005 & -0.010 & -0.010 & -0.001 \\
\hline & $(0.087)$ & $(0.027)$ & $(0.025)$ & $(0.032)$ & $(0.082)$ & $(0.048)$ \\
\hline \multirow[t]{2}{*}{ Agrochemicals, log } & -0.017 & -0.008 & 0.007 & 0.001 & -0.022 & 0.013 \\
\hline & $(0.214)$ & $(0.032)$ & $(0.017)$ & $(0.024)$ & $(0.099)$ & $(0.052)$ \\
\hline \multirow[t]{2}{*}{ Oxen days, log } & -0.070 & -0.042 & -0.011 & -0.018 & 0.051 & -0.063 \\
\hline & $(0.100)$ & $(0.048)$ & $(0.038)$ & $(0.061)$ & $(0.109)$ & $(0.143)$ \\
\hline \multirow[t]{2}{*}{ machine } & 0.121 & 0.028 & -0.015 & -0.024 & 0.411 & 0.151 \\
\hline & $(0.601)$ & $(0.066)$ & $(0.055)$ & $(0.070)$ & $(0.474)$ & $(0.381)$ \\
\hline \multirow[t]{2}{*}{ rented } & -0.069 & 0.012 & -0.004 & 0.028 & 0.048 & 0.060 \\
\hline & $(0.076)$ & $(0.035)$ & $(0.034)$ & $(0.044)$ & $(0.063)$ & $(0.085)$ \\
\hline \multicolumn{7}{|l|}{ Plot characteristics } \\
\hline \multirow[t]{2}{*}{ plot size } & 0.044 & 0.064 & 0.002 & 0.051 & -0.122 & -0.020 \\
\hline & $(0.330)$ & $(0.069)$ & $(0.043)$ & $(0.068)$ & $(0.147)$ & $(0.118)$ \\
\hline \multirow[t]{2}{*}{ medium slope $^{\mathbf{a}}$} & 0.024 & $-0.054 *$ & 0.018 & 0.041 & -0.071 & -0.024 \\
\hline & $(0.095)$ & $(0.032)$ & $(0.030)$ & $(0.048)$ & $(0.110)$ & $(0.097)$ \\
\hline \multirow[t]{2}{*}{ steep } & -0.175 & -0.013 & -0.022 & 0.051 & -0.148 & -0.036 \\
\hline & $(0.269)$ & $(0.051)$ & $(0.091)$ & $(0.113)$ & $(0.148)$ & $(0.247)$ \\
\hline \multirow[t]{2}{*}{ medium depth ${ }^{\mathbf{b}}$} & -0.083 & -0.025 & -0.022 & 0.049 & 0.163 & 0.065 \\
\hline & $(0.135)$ & $(0.042)$ & $(0.054)$ & $(0.072)$ & $(0.170)$ & $(0.115)$ \\
\hline \multirow[t]{2}{*}{ deep } & -0.111 & -0.023 & 0.039 & 0.044 & 0.116 & 0.061 \\
\hline & $(0.135)$ & $(0.052)$ & $(0.054)$ & $(0.065)$ & $(0.164)$ & $(0.125)$ \\
\hline \multirow[t]{2}{*}{ brown $^{c}$} & 0.057 & 0.057 & 0.002 & 0.112 & 0.095 & -0.049 \\
\hline & $(0.165)$ & $(0.038)$ & $(0.045)$ & $(0.073)$ & $(0.129)$ & $(0.133)$ \\
\hline \multirow[t]{2}{*}{ red } & 0.212 & 0.003 & 0.028 & 0.024 & 0.070 & 0.007 \\
\hline & $(0.284)$ & $(0.036)$ & $(0.041)$ & $(0.086)$ & $(0.128)$ & $(0.134)$ \\
\hline \multirow[t]{2}{*}{ gray } & 0.251 & 0.008 & -0.010 & -0.011 & 0.005 & -0.034 \\
\hline & $(0.310)$ & $(0.056)$ & $(0.050)$ & $(0.083)$ & $(0.173)$ & $(0.142)$ \\
\hline \multirow[t]{2}{*}{ legume rotation ${ }^{\mathbf{d}}$} & 0.143 & 0.019 & 0.000 & 0.089 & 0.235 & -0.160 \\
\hline & $(0.246)$ & $(0.040)$ & $(0.037)$ & $(0.066)$ & $(0.276)$ & $(0.191)$ \\
\hline \multirow[t]{2}{*}{ other cereals rotation } & 0.108 & -0.005 & 0.007 & 0.066 & 0.252 & -0.039 \\
\hline & $(0.186)$ & $(0.035)$ & $(0.035)$ & $(0.072)$ & $(0.295)$ & $(0.092)$ \\
\hline residue & -0.048 & -0.062 & 0.010 & -0.070 & -0.042 & 0.084 \\
\hline & $(0.155)$ & $(0.090)$ & $(0.045)$ & $(0.080)$ & $(0.150)$ & $(0.126)$ \\
\hline manure & 0.033 & -0.032 & -0.005 & 0.042 & -0.004 & 0.067 \\
\hline & $(0.095)$ & $(0.045)$ & $(0.038)$ & $(0.046)$ & $(0.104)$ & $(0.135)$ \\
\hline $\mathrm{IS}^{\mathrm{e}}$ & -0.075 & 0.000 & -0.024 & -0.003 & 0.125 & -0.074 \\
\hline & $(0.105)$ & $(0.053)$ & $(0.050)$ & $(0.075)$ & $(0.152)$ & $(0.154)$ \\
\hline IR & -0.123 & -0.008 & -0.041 & 0.014 & 0.103 & -0.157 \\
\hline & $(0.118)$ & $(0.058)$ & $(0.052)$ & $(0.068)$ & $(0.144)$ & $(0.228)$ \\
\hline OV & -0.121 & -0.018 & 0.015 & 0.082 & 0.024 & -0.001 \\
\hline & $(0.139)$ & $(0.053)$ & $(0.048)$ & $(0.084)$ & $(0.154)$ & $(0.154)$ \\
\hline Production stresses & & & & & & \\
\hline pests & 0.109 & $0.258 * *$ & -0.019 & 0.021 & -0.348 & -0.004 \\
\hline & $(0.253)$ & $(0.131)$ & $(0.088)$ & $(0.134)$ & $(0.281)$ & $(0.295)$ \\
\hline drought & -0.115 & 0.002 & 0.026 & 0.106 & -0.011 & 0.122 \\
\hline
\end{tabular}




\begin{tabular}{|c|c|c|c|c|c|c|}
\hline \multirow[b]{3}{*}{ Explanatory variables } & \multicolumn{6}{|c|}{ Risk exposure (skewness) $^{g}$} \\
\hline & \multirow{2}{*}{$\frac{2}{\text { Coef/se }}$} & \multirow{2}{*}{$\begin{array}{c}3 \\
\text { Coef/se }\end{array}$} & \multirow{2}{*}{$\begin{array}{c}4 \\
\text { Coef/se }\end{array}$} & \multirow{2}{*}{$\begin{array}{c}5 \\
\text { Coef/se }\end{array}$} & \multirow{2}{*}{$\begin{array}{c}6 \\
\text { Coef/se }\end{array}$} & \multirow{2}{*}{$\begin{array}{c}7 \text { or more } \\
\text { Coef/se }\end{array}$} \\
\hline & & & & & & \\
\hline & $(0.663)$ & $(0.088)$ & $(0.064)$ & $(0.111)$ & $(0.214)$ & $(0.426)$ \\
\hline \multirow[t]{2}{*}{ waterlogging } & -0.108 & 0.023 & 0.022 & 0.165 & 0.131 & 0.137 \\
\hline & $(0.170)$ & $(0.062)$ & $(0.065)$ & $(0.102)$ & $(0.232)$ & $(0.252)$ \\
\hline \multirow[t]{2}{*}{ abiotic stress } & -0.044 & 0.017 & 0.060 & -0.059 & -0.061 & -0.096 \\
\hline & $(0.156)$ & $(0.044)$ & $(0.051)$ & $(0.126)$ & $(0.274)$ & $(0.188)$ \\
\hline \multicolumn{7}{|c|}{ Household level explanatory variables and model statistics } \\
\hline \multirow[t]{2}{*}{ male } & -0.232 & -0.127 & -0.198 & 0.117 & -0.246 & 0.209 \\
\hline & $(0.523)$ & $(0.257)$ & $(0.167)$ & $(0.194)$ & $(0.373)$ & $(0.559)$ \\
\hline \multirow[t]{2}{*}{ age } & 0.008 & 0.002 & 0.001 & 0.003 & -0.013 & 0.010 \\
\hline & $(0.017)$ & $(0.009)$ & $(0.005)$ & $(0.014)$ & $(0.018)$ & $(0.011)$ \\
\hline \multirow[t]{2}{*}{ school $>=2$ and $<6^{\mathrm{f}}$} & -0.157 & -0.014 & 0.032 & 0.005 & -0.113 & 0.093 \\
\hline & $(0.275)$ & $(0.086)$ & $(0.067)$ & $(0.100)$ & $(0.230)$ & $(0.165)$ \\
\hline \multirow[t]{2}{*}{ School $>=6$} & 0.052 & 0.127 & 0.074 & -0.126 & -0.064 & 0.114 \\
\hline & $(0.575)$ & $(0.158)$ & $(0.152)$ & $(0.144)$ & $(0.340)$ & $(0.214)$ \\
\hline \multirow[t]{2}{*}{ ext contact } & -0.000 & -0.000 & -0.000 & 0.000 & -0.001 & -0.000 \\
\hline & $(0.002)$ & $(0.001)$ & $(0.000)$ & $(0.001)$ & $(0.001)$ & $(0.001)$ \\
\hline \multirow[t]{2}{*}{ Kinship } & -0.000 & -0.000 & 0.000 & 0.000 & -0.000 & 0.002 \\
\hline & $(0.002)$ & $(0.001)$ & $(0.000)$ & $(0.000)$ & $(0.001)$ & $(0.002)$ \\
\hline \multirow[t]{2}{*}{ aid relief } & -0.031 & -0.014 & 0.120 & 0.043 & 0.097 & 0.020 \\
\hline & $(0.160)$ & $(0.138)$ & $(0.197)$ & $(0.104)$ & $(0.336)$ & $(0.504)$ \\
\hline \multirow[t]{2}{*}{ confidence } & 0.110 & 0.055 & -0.028 & -0.031 & -0.001 & -0.049 \\
\hline & $(0.121)$ & $(0.053)$ & $(0.041)$ & $(0.052)$ & $(0.131)$ & $(0.122)$ \\
\hline \multirow[t]{2}{*}{ Survey year (2013/14=1) } & 0.023 & -0.022 & -0.001 & 0.029 & -0.069 & -0.031 \\
\hline & $(0.098)$ & $(0.042)$ & $(0.027)$ & $(0.066)$ & $(0.149)$ & $(0.104)$ \\
\hline Battese (1997) dummies & Yes & Yes & Yes & Yes & Yes & Yes \\
\hline Mundlak's fixed effects & Yes & Yes & Yes & Yes & Yes & Yes \\
\hline Agroecological fixed effects & Yes & Yes & Yes & Yes & Yes & Yes \\
\hline \multirow[t]{2}{*}{ Selection correction terms (lamba) } & -0.026 & -0.230 & 0.126 & -0.006 & -0.402 & -0.020 \\
\hline & $(0.199)$ & $(0.258)$ & $(0.191)$ & $(0.267)$ & $(0.547)$ & $(0.199)$ \\
\hline \multirow[t]{2}{*}{ Constant } & 0.140 & 0.048 & -0.031 & 0.005 & 0.759 & 0.211 \\
\hline & $(1.062)$ & $(0.375)$ & $(0.269)$ & $(0.436)$ & $(1.106)$ & $(0.704)$ \\
\hline Number of plots & 307 & 1,648 & 2,083 & 1,205 & 455 & 283 \\
\hline Number of households & 161 & 734 & 972 & 625 & 267 & 157 \\
\hline Wald test & 7.950 & 27.310 & 29.080 & 24.210 & 10.710 & 11.350 \\
\hline
\end{tabular}

\begin{tabular}{lllllll}
\hline Falsification test: the instrument is not significant & 0.000 & 0.000 & $13.040^{* * * *}$ & $4.320^{* *}$ & 0.030 & 0.240
\end{tabular}

Notes: (i) $* * * \mathrm{p}<0.01, * * \mathrm{p}<0.05,{ }^{*} \mathrm{p}<0.1$. (ii) bootstrapped standard errors are in parenthesis. (iii) base category:, ${ }^{\mathrm{a}}$ flat slops, ${ }^{\mathbf{b}}$ shallow depth, ${ }^{\mathbf{c}}$ black soil, ${ }^{\mathbf{d}}$ plots not rotated, ${ }^{\mathbf{e}}$ local varieties, ${ }^{\mathbf{f}}$ the head of the household is illiterate. (iv) ${ }^{\mathbf{g}}$ $<=2,3,4,5,6$ and $>=7$ refer plots that were ploughed 2 or fewer, $3,4,5,6$, and 7 or more times, respectively. 
Table 2.10. Average treatment effects on the treated (ATTs) on yield and risk exposure (variance and skewness) by three rainfall regimes.

\begin{tabular}{|c|c|c|c|c|c|c|c|c|c|c|}
\hline \multirow{3}{*}{$\begin{array}{l}\text { Intensity of } \\
\text { tillage (IT) }\end{array}$} & \multicolumn{3}{|c|}{ Yield } & \multirow{3}{*}{$\begin{array}{l}\text { Actual } \\
\text { expected } \\
\text { variance } \\
\text { D }\end{array}$} & \multirow[b]{2}{*}{$\begin{array}{l}\text { Counterfactual } \\
\text { expected variance }\end{array}$} & \multirow[b]{2}{*}{$\begin{array}{l}\text { ATTs=D- } \\
\mathbf{E}\end{array}$} & \multirow[b]{2}{*}{$\begin{array}{l}\text { Actual } \\
\text { expected } \\
\text { skewness }\end{array}$} & \multicolumn{2}{|l|}{ Risk exposure } & \multirow{3}{*}{ Rainfall regimes } \\
\hline & $\begin{array}{c}\text { Actual } \\
\text { expected } \\
\text { yield }\end{array}$ & $\begin{array}{l}\text { Counterfactual } \\
\text { expected yield }\end{array}$ & ATTs $=\mathrm{A}-\mathrm{B}$ & & & & & $\begin{array}{l}\text { Counterfactual } \\
\text { expected } \\
\text { skewness }\end{array}$ & ATTs $=\mathrm{G}-\mathrm{H}$ & \\
\hline & A & $\mathbf{B}$ & $\mathbf{C}$ & & $\mathbf{E}$ & $\mathbf{F}$ & $\mathbf{G}$ & $\mathbf{H}$ & I & \\
\hline \multirow[t]{2}{*}{3} & 1431.2 & 1456.1 & -25.0 & 0.269 & 0.275 & -0.007 & -0.035 & -0.055 & $0.019 * * *$ & \\
\hline & $(20.7)$ & $(31.1)$ & $(37.3)$ & $(0.004)$ & $(0.008)$ & (0.009) & $(0.004)$ & $(0.007)$ & $(0.007)$ & \\
\hline \multirow[t]{2}{*}{4} & 1681.9 & 1567.9 & $113.9 * * *$ & 0.237 & 0.273 & $-0.036 * * *$ & -0.038 & -0.065 & $0.028 * * *$ & \\
\hline & $(20.7)$ & (29.9) & (36.4) & $(0.003)$ & $(0.008)$ & $(0.009)$ & $(0.002)$ & $(0.007)$ & $(0.007)$ & \\
\hline \multirow[t]{2}{*}{5} & 1846.9 & 1519.1 & $327.8 * * *$ & 0.195 & 0.265 & $-0.070 * * *$ & -0.057 & -0.089 & $0.031 * * *$ & low \\
\hline & $(33.7)$ & $(39.2)$ & $(51.7)$ & $(0.006)$ & $(0.010)$ & $(0.012)$ & $(0.004)$ & $(0.008)$ & $(0.009)$ & \\
\hline \multirow[t]{2}{*}{6} & 1848.4 & 1559.8 & $288.6 * * *$ & 0.212 & 0.225 & -0.013 & -0.040 & -0.079 & 0.039 & \\
\hline & $(57.9)$ & $(70.0)$ & $(90.8)$ & $(0.018)$ & $(0.023)$ & $(0.029)$ & $(0.019)$ & $(0.016)$ & $(0.024)$ & \\
\hline 7 or more & $\begin{array}{l}1675.0 \\
(95.1) \\
\end{array}$ & $\begin{array}{l}1477.2 \\
(127.2) \\
\end{array}$ & $\begin{array}{c}197.8 \\
(158.8) \\
\end{array}$ & $\begin{array}{c}0.188 \\
(0.016) \\
\end{array}$ & $\begin{array}{c}0.247 \\
(0.022) \\
\end{array}$ & $\begin{array}{c}-0.059 * * \\
(0.027) \\
\end{array}$ & $\begin{array}{l}-0.023 \\
(0.013) \\
\end{array}$ & $\begin{array}{l}-0.105 \\
(0.023) \\
\end{array}$ & $\begin{array}{c}0.082 * * * \\
(0.026)\end{array}$ & \\
\hline \multirow[t]{2}{*}{3} & 1193.1 & 1224.6 & -31.5 & 0.259 & 0.309 & $-0.051 * * *$ & -0.016 & -0.053 & $0.038 * * *$ & \\
\hline & $(15.4)$ & $(21.8)$ & $(26.7)$ & $(0.003)$ & $(0.007)$ & $(0.008)$ & $(0.004)$ & $(0.006)$ & $(0.007)$ & \\
\hline \multirow[t]{2}{*}{4} & 1467.2 & 1367.8 & $99.4 * * *$ & 0.244 & 0.327 & $-0.083 * * *$ & -0.023 & -0.099 & $0.076 * * *$ & \\
\hline & $(18.3)$ & (24.9) & (30.9) & $(0.003)$ & $(0.007)$ & $(0.008)$ & $(0.002)$ & $(0.006)$ & $(0.007)$ & \\
\hline \multirow[t]{2}{*}{5} & 1641.2 & 1375.6 & $265.7 * * *$ & 0.240 & 0.349 & $-0.109 * * *$ & -0.059 & -0.094 & $0.034 * * *$ & medium \\
\hline & $(26.8)$ & $(37.5)$ & $(46.1)$ & $(0.005)$ & $(0.011)$ & $(0.012)$ & $(0.005)$ & $(0.008)$ & $(0.009)$ & \\
\hline \multirow[t]{2}{*}{6} & 1588.8 & 1367.9 & $220.9 * * *$ & 0.307 & 0.285 & 0.022 & -0.075 & -0.097 & 0.02 & \\
\hline & $(36.1)$ & $(53.4)$ & (64.4) & $(0.016)$ & $(0.015)$ & $(0.022)$ & $(0.017)$ & $(0.012)$ & $(0.021)$ & \\
\hline \multirow[t]{2}{*}{7 or more } & 2002.3 & 1256.3 & $746.1 * * *$ & 0.216 & 0.303 & $-0.087 * * *$ & -0.022 & -0.063 & $0.041 *$ & \\
\hline & $(90.8)$ & $(72.3)$ & $(116.1)$ & $(0.016)$ & (0.019) & $(0.024)$ & $(0.011)$ & $(0.021)$ & $(0.024)$ & \\
\hline \multirow[t]{2}{*}{3} & 1270.9 & 1364.8 & $-93.9 * *$ & 0.263 & 0.294 & $-0.031 * * *$ & -0.039 & -0.037 & -0.002 & \\
\hline & (21.9) & (36.4) & $(42.5)$ & $(0.005)$ & (0.009) & $(0.010)$ & $(0.005)$ & $(0.008)$ & (0.009) & \\
\hline \multirow[t]{2}{*}{4} & 1405.7 & 1371.6 & 33.9 & 0.241 & 0.279 & $-0.039 * * *$ & -0.023 & -0.039 & $0.016^{* *}$ & \\
\hline & (21.6) & $(28.1)$ & $(35.5)$ & $(0.003)$ & $(0.007)$ & $(0.008)$ & $(0.002)$ & $(0.007)$ & $(0.007)$ & \\
\hline \multirow[t]{2}{*}{5} & 1577.4 & 1332.9 & $244.5 * * *$ & 0.235 & 0.286 & $-0.051 * * *$ & -0.051 & -0.094 & $0.043 * * *$ & high \\
\hline & $(25.5)$ & (32.4) & (41.2) & $(0.005)$ & (0.009) & $(0.010)$ & $(0.004)$ & $(0.008)$ & $(0.009)$ & \\
\hline \multirow[t]{2}{*}{6} & 1712.1 & 1507.8 & $204.3 * * *$ & 0.278 & 0.255 & $0.023 * * *$ & -0.071 & -0.105 & $0.034 *$ & \\
\hline & $(43.0)$ & $(50.7)$ & (66.3) & $(0.014)$ & $(0.013)$ & (0.019) & $(0.015)$ & $(0.012)$ & (0.019) & \\
\hline \multirow[t]{2}{*}{7 or more } & 1844.2 & 1501.4 & $342.7 * * *$ & 0.171 & 0.234 & $-0.063 * * *$ & -0.028 & -0.151 & $0.122 * * *$ & \\
\hline & $(49.7)$ & $(54.4)$ & $(73.7)$ & $(0.011)$ & $(0.017)$ & $(0.021)$ & $(0.007)$ & $(0.012)$ & $(0.014)$ & \\
\hline
\end{tabular}

Notes: (i) $* * * \mathrm{p}<0.01, * * \mathrm{p}<0.05, * \mathrm{p}<0.1$. (ii) standard errors are in parenthesis. (iii) negative(positive) value of the skewness indicate downside (upside) risk. 
Table 2.11. Average treatment effects on the treated (ATTs): net return to land (Birr/ha) and risk exposure (variance and skewness).

\begin{tabular}{|c|c|c|c|c|c|c|c|c|c|}
\hline \multirow{3}{*}{$\begin{array}{l}\text { Intensity of } \\
\text { tillage (IT) }\end{array}$} & \multicolumn{3}{|c|}{ Net return to land } & \multirow[b]{2}{*}{$\begin{array}{c}\text { Actual } \\
\text { expected } \\
\text { variance } \\
\end{array}$} & \multirow[b]{2}{*}{$\begin{array}{c}\text { Counterfactual } \\
\text { expected skewness }\end{array}$} & \multirow[b]{2}{*}{$\begin{array}{c}\text { ATTs=D- } \\
\text { E }\end{array}$} & \multicolumn{3}{|c|}{ Risk exposure } \\
\hline & $\begin{array}{c}\text { Actual } \\
\text { expected net } \\
\text { return to land } \\
\end{array}$ & $\begin{array}{c}\text { Counterfactual } \\
\text { expected net return to } \\
\text { land } \\
\end{array}$ & $\mathbf{A T T s}=\mathrm{A}-\mathrm{B}$ & & & & $\begin{array}{c}\text { Actual } \\
\text { expected } \\
\text { skewness } \\
\end{array}$ & $\begin{array}{c}\text { Counterfactual } \\
\text { expected skewness }\end{array}$ & ATTs $=\mathrm{G}-\mathrm{H}$ \\
\hline & $\mathbf{A}$ & B & $\mathbf{C}$ & D & $\mathbf{E}$ & $\mathbf{F}$ & $\mathbf{G}$ & $\mathbf{H}$ & I \\
\hline \multirow[t]{2}{*}{3} & 5428.6 & 5322.3 & 106.3 & 0.303 & 0.329 & $-0.026 * * *$ & 0.213 & -0.006 & $0.220 * * *$ \\
\hline & $(70.9)$ & (118.3) & $(138.0)$ & $(0.005)$ & $(0.007)$ & $(0.009)$ & $(0.009)$ & $(0.013)$ & $(0.015)$ \\
\hline \multirow[t]{2}{*}{4} & 6525.8 & 4837.7 & $1688.1 * * *$ & 0.321 & 0.309 & 0.012 & 0.209 & -0.100 & $0.309 * * *$ \\
\hline & $(65.2)$ & (109.5) & (127.5) & $(0.005)$ & $(0.006)$ & $(0.008)$ & $(0.006)$ & $(0.012)$ & $(0.014)$ \\
\hline \multirow[t]{2}{*}{5} & 7220.4 & 3891.4 & $3329.0 * * *$ & 0.306 & 0.277 & $0.029 * * *$ & 0.123 & -0.268 & $0.391 * * *$ \\
\hline & (101.5) & (144.6) & (176.6) & $(0.006)$ & $(0.009)$ & $(0.011)$ & $(0.005)$ & $(0.016)$ & $(0.017)$ \\
\hline \multirow[t]{2}{*}{6} & 7089.9 & 3456.5 & $3633.4 * * *$ & 0.354 & 0.252 & $0.101 * * *$ & 0.142 & -0.363 & $0.506 * * *$ \\
\hline & $(161.7)$ & $(223.0)$ & $(275.5)$ & $(0.016)$ & $(0.015)$ & $(0.022)$ & $(0.014)$ & $(0.026)$ & $(0.029)$ \\
\hline \multirow[t]{2}{*}{7 or more } & 7649.0 & 3159.6 & $4489.4 * * *$ & 0.354 & 0.223 & $0.13 * * *$ & 0.072 & -0.408 & $0.480 * * *$ \\
\hline & $(243.8)$ & $(281.0)$ & $(372.1)$ & $(0.023)$ & $(0.017)$ & $(0.028)$ & $(0.014)$ & $(0.033)$ & $(0.036)$ \\
\hline
\end{tabular}

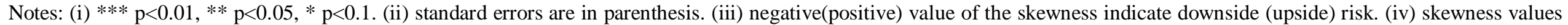
are rescaled by dividing by $1,000,000,000,000$ while the variance values are rescaled by dividing it by 100,000,000. 

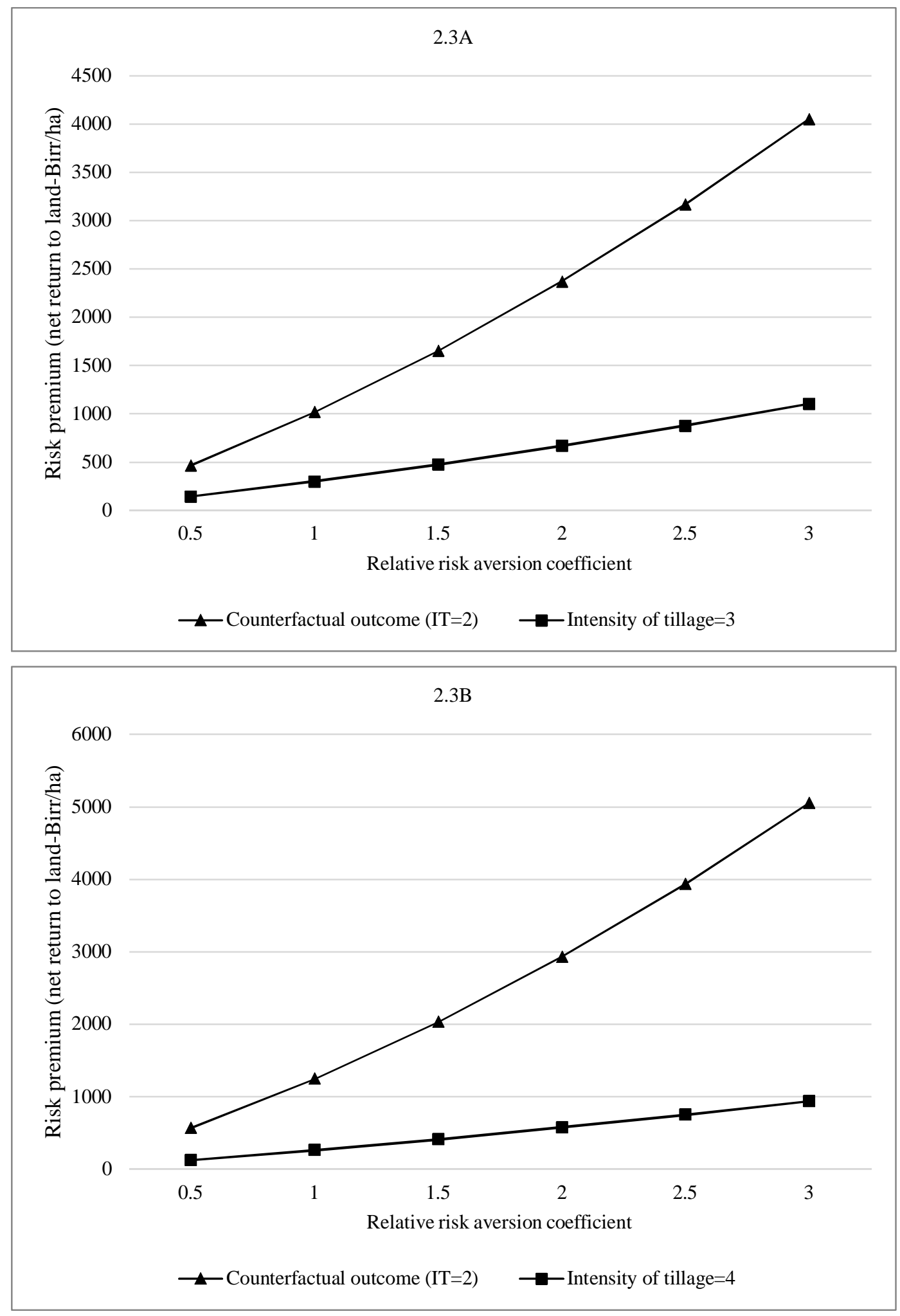

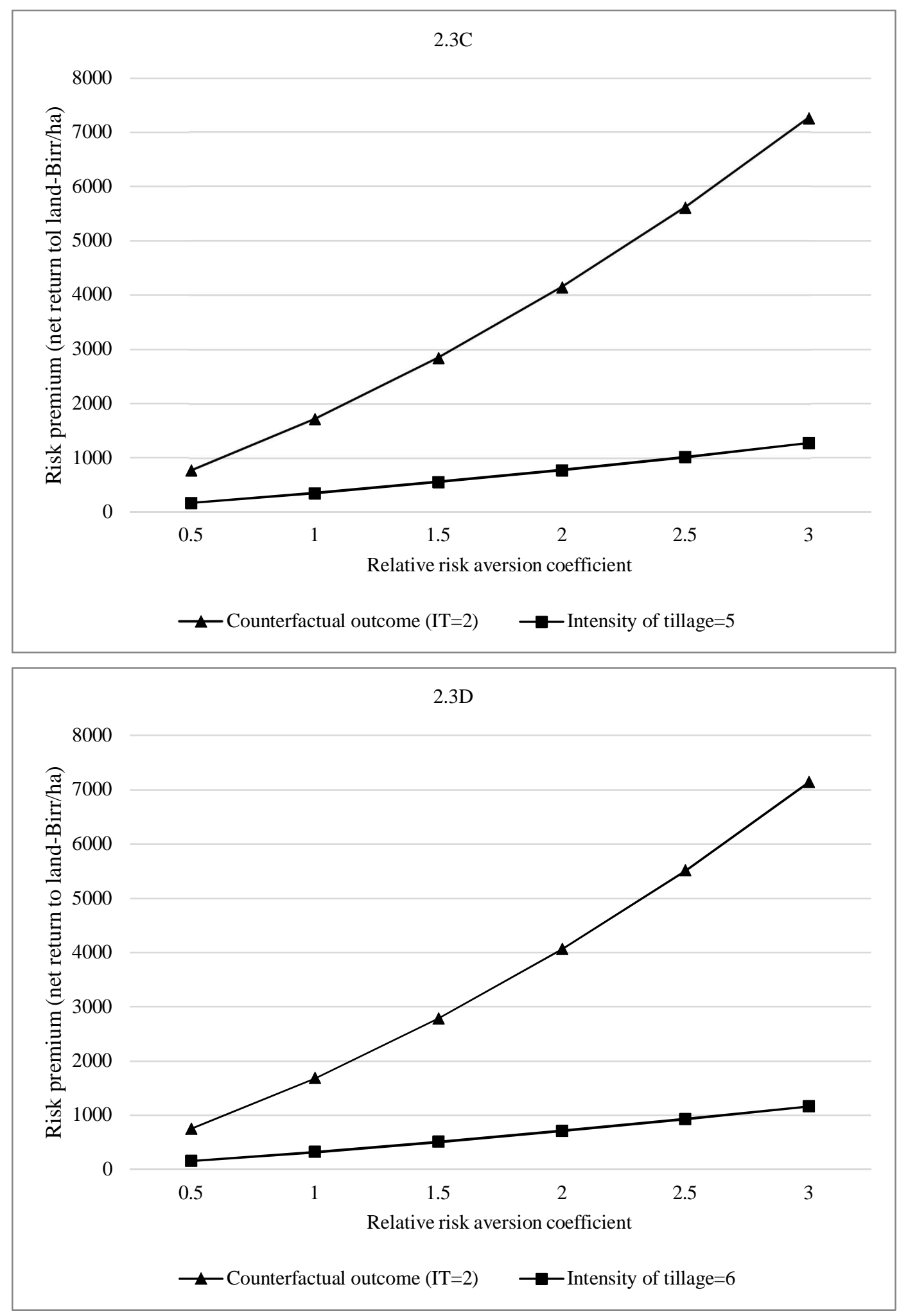


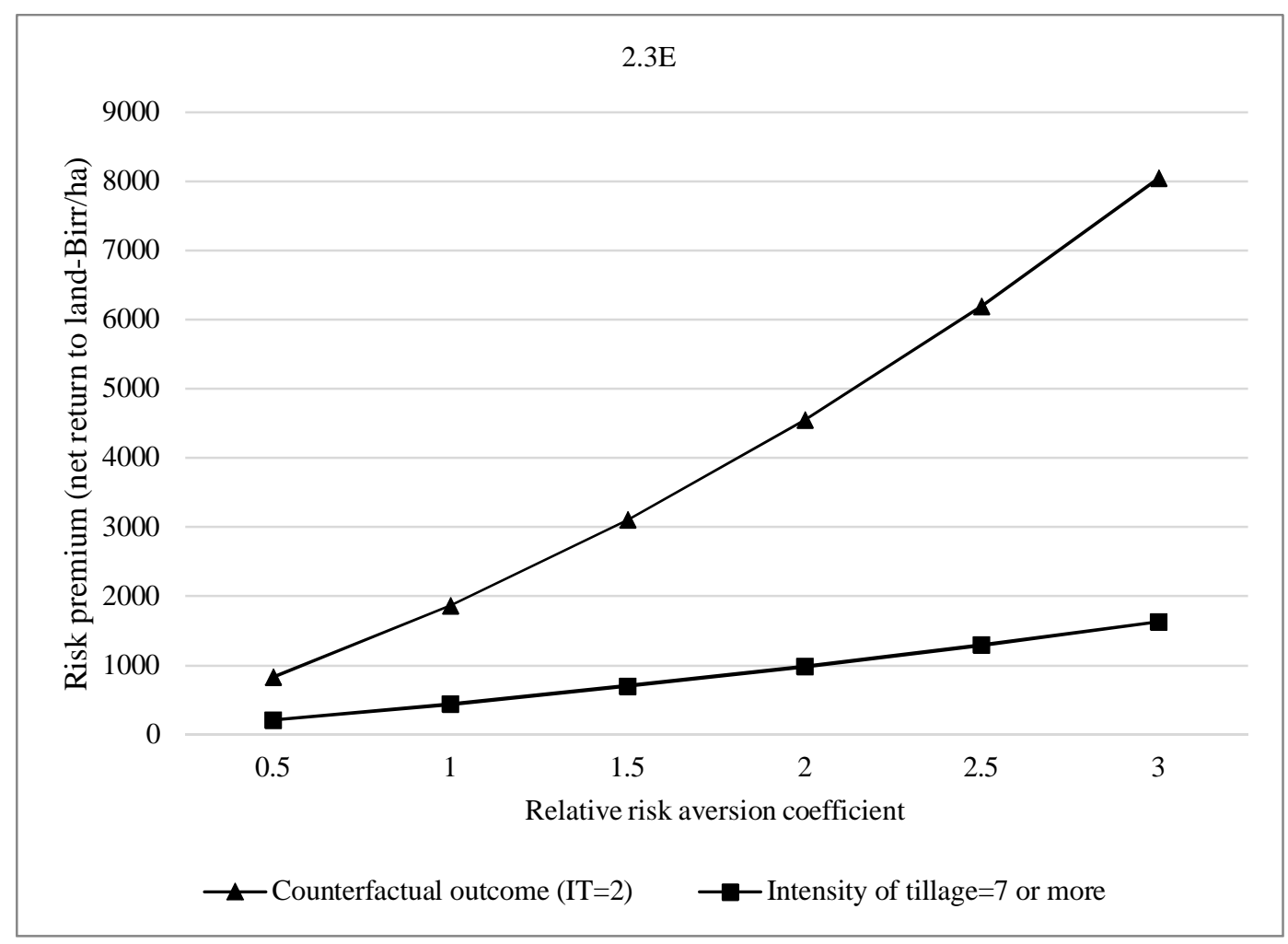

Figure 2.3. The impact intensity of tillage on costs of risk: net return to land and risk exposure (variance and skewness). 


\section{Yield effects of rust-resistant wheat varieties in Ethiopia ${ }^{12}$}

\subsection{Introduction}

Plant pests and diseases cause considerable crop losses in worldwide agriculture (Oerke, 2006; Strange and Scott, 2005; Savary et al., 2012; Savary et al., 2017). In many regions, crop losses caused by insects, fungi, bacteria, viruses, and other pathogens are estimated at 15-20\% on average; during acute epidemics actual losses can be much higher (Oerke, 2006; FAO, 2014). Plant genetic improvement through breeding can help to reduce such losses without having to increase the use of chemical pesticides (Dixon et al., 2006; Savary et al., 2006, 2012; Stuthman et al., 2007; Velu and Singh, 2013). Reducing crop losses and thus sustainably increasing effective yield is key for meeting future food demand (Hertel, 2015; Kassie et al., 2015; Savary et al., 2017).

However, breeding plants for resistance is a complex and enduring process. Evolving pest and pathogen populations can overcome existing plant genetic resistance so that there is continuous need to identify and develop new resistance mechanisms. Furthermore, pest and disease resistance traits have to be introduced to locally adapted and preferred varieties. Otherwise, advantages through lower crop losses from pests and diseases could be canceled out by disadvantages resulting from the use of germplasm not well adapted to soil and climatic conditions or quality preferences in a particular context (Krishna et al., 2016b; Qaim et al., 2006; Smale et al., 1998). Lack of local adaptation may in turn affect the willingness of farmers to adopt new pest- and disease-resistant varieties.

While such linkages are well understood in theory, they have rarely been examined in empirical research with data from farmers' fields. Many studies on the adoption of improved crop varieties have evaluated yield effects in general, yet without differentiating between different crop traits and varietal characteristics (Di Falco et al., 2007; Matuschke et al., 2007; Mazid et al., 2015; Teklewold et al., 2013a; Walker and Alwang, 2015). We contribute to this literature by unpacking yield

\footnotetext{
${ }^{12}$ This chapter is published as Abro, Z. A., Jaleta, M., and Qaim, M. 'Yield effects of rust-resistant wheat varieties in Ethiopia'. Food Security, vol. 9(6) (2017) PP. 1343-1357. ZAA designed the research, analyzed the data, and wrote the paper. MJ collected the data. MJ and MQ commented on the data analysis and contributed to writing the paper.
} 
differentials of three varietal traits: disease resistance, yield potential, and adaptation to local abiotic stresses. Specifically, using data from a panel survey of wheat farmers in Ethiopia we compare yields of improved resistant varieties with and without disease resistance and yields of traditional varieties. The results could help to better understand whether crop improvement programs have succeeded in developing and disseminating varieties that are well adapted to biotic and abiotic stresses of local relevance.

Wheat is one of the most important food security crops in the world, accounting for a sizeable share of the global calories and protein consumed (Shiferaw et al., 2013). The importance of wheat in Africa is also increasing. Wheat is affected by various diseases, the most important of which are rusts caused by fungal pathogens. There are different types of wheat rust with multiple races (Chen et al., 2014; Morgounov et al., 2012; Velu and Singh, 2013). The most common rusts are stem rust (Puccinia graminis $f$. sp. tritici), leaf rust (Puccinia triticina), and stripe rust (or yellow rust) (Puccinia striiformis $f$. sp. tritici). The Ug99 pathotype of stem rust was recently detected in East Africa (Chaves et al., 2013). While Ug99 has caused considerable damage in Kenya, in Ethiopia significant yield losses through Ug99 were not reported until very recently (Olivera et al., 2015). Over the last 10 years, stripe rust was much more damaging in Ethiopia (ICARDA, 2013; Olivera et al., 2015; Yami et al., 2012). Hence, our analysis focuses on stripe rust. In what follows, we use the term "stripe rust-resistant" or "rust-resistant" varieties for wheat cultivars that show high or at least moderate levels of resistance to stripe rust. Such rust-resistant varieties have been promoted by Ethiopia's extension service since 2010 (Olivera et al., 2015; Yami et al., 2012). According to our data, stripe rust-resistant varieties are now grown on about half of the total wheat area in Ethiopia. We are not aware of previous research that has evaluated the yield performance of these resistant varieties in farmers' fields.

The data used in this study were collected in Ethiopia in two rounds, namely in 2009/10 and 2013/14. We develop and estimate plot-level production functions, including farmers' varietal choices as explanatory variables while controlling for other inputs and for farm, farmer, and regional characteristics. We also include interaction terms between varietal traits and various production stresses, in order to gain a better understanding of the performance of improved and traditional varieties under local conditions. The panel structure of the data, with variation in the adoption of different types of varieties over time, help to reduce issues of selection bias that are commonplace in studies with observational data (Krishna et al., 2016). The next section introduces the data and the econometric strategy in more detail. Then, results are presented and discussed before the last section concludes. 


\subsection{Materials and methods}

\subsubsection{Data}

We use data from a panel survey of smallholder farmers in Ethiopia that were collected in two rounds by the International Maize and Wheat Improvement Center (CIMMYT) and the Ethiopian Institute of Agricultural Research (EIAR). The purpose of this survey was to document wheat variety adoption dynamics in Ethiopia (Tolemariam et al., 2016). The two survey rounds cover the 2009/10 and 2013/14 agricultural seasons. In the sampling frame, 148 major wheat-growing districts of Ethiopia were purposively selected. Within these districts, peasant's associations (communities) were randomly selected. Within each selected peasant's association, 15 to 18 households were randomly selected, leading to 2,096 households in the sample. Most of these households were interviewed in both survey rounds. The sample is representative of farmers in major wheat-growing areas of Ethiopia.

The structured questionnaire for the survey was developed by CIMMYT scientists in Ethiopia together with EIAR colleagues and field officers. The questionnaire was pre-tested in a pilot survey before it was finalized. The actual survey data were collected through face-to-face interviews with farmers conducted by well-trained enumerators in local languages. A wide range of farm and farmer characteristics and variables describing the broader socioeconomic context were elicited. In both survey rounds, detailed data for all plots cultivated by sample farmers were also collected.

The pooled data include over 20,000 plots, out of which 6,001 were grown with wheat. For the wheat plots, farmers were asked to report the types and quantities of inputs used and the output harvested during the particular season. Farmers were also asked to specify the wheat variety used in each plot. For the analysis, we differentiate between traditional and improved varieties. Traditional varieties are mostly of the durum type, whereas improved varieties are bread wheat. All traditional varieties are susceptible to stripe rust (Gebre-Mariam et al., 1991). For the improved varieties, we further differentiate between varieties that are either resistant or susceptible to stripe rust. Farmers reported 34 different improved varieties. The resistance classification is based on the available literature and additional discussions with experts from EIAR, as shown in Table 3.8 in Appendix 3. Overall, we consider and compare three types of varieties, namely (i) traditional 
varieties susceptible to stripe rust, (ii) improved varieties susceptible to stripe rust, and (iii) improved varieties resistant to stripe rust. ${ }^{\mathbf{1 3}}$

Farmers were also asked whether or not they had experienced particular production stresses for each plot during the particular season. These were closed-ended questions, meaning that a set of biotic (pests and diseases) and abiotic (e.g., drought) stress factors were specified in the questionnaire. As yield losses due to particular stress factors are difficult to estimate for farmers, the response options for each stress were simply "yes" or "no". The list of stress factors included was developed after a thorough review of the major wheat production problems in the country. Pre-testing of the questionnaire helped to use classifications that farmers could easily distinguish. Closed-ended questions are easier to use than open-ended questions in the statistical analysis. However, in addition to the pre-defined stress factors, other stresses mentioned by farmers were recorded and coded during data processing.

Unfortunately, out of the 6001 total wheat plot observations, we are only able to use 4,751 for the statistical analysis. A sizeable number of plot observations $(1,132)$ had to be dropped because the official name of the wheat variety grown was not known and could not be found out, even after further investigation. Without knowing the official name, we could not reliably verify whether the variety is resistant or susceptible to stripe rust. Dropping these observations may mean that the sample is not fully representative of wheat farming in Ethiopia anymore. In addition, we dropped 106 extreme yield observations: recent research showed that observations below the 1st or above the 99th percentile of the yield distribution may affect the results in unexpected ways (Abdul-Salam and Phimister, 2016; Aguilar et al., 2015). Finally, we had to drop 12 observations with missing data for some of the other variables of interest.

\subsubsection{Econometric strategy}

Large bodies of literature exist on the estimation of yield losses resulting from crop diseases. One literature strand focuses on the estimation of actual yield losses using field experiments, regression approaches, simulation models, and other tools (Cooke et al., 2006; James, 1974; Savary et al., 2006, 2012). Another literature strand analyzes potential yield losses and losses avoided by breeding disease-resistant varieties (Lantican et al., 2016; Marasas et al., 2003, 2004; Mather et al., 2003; Smale et al., 1998). Some of the latter studies also go beyond reporting percentage yield losses (or

\footnotetext{
${ }^{13}$ As we will see in Chapter 4, the issue of using seed recycling will be important. Seed recycling is a common practice among wheat farmers. In our sample, $78 \%$ of the farmers used recycled seeds while the rest $22 \%$ used fresh seeds.
} 
losses avoided) and calculate benefit-cost ratios, which is useful for research priority setting (Pardey et al., 2006). However, whenever yield losses (or avoided losses leading to effective yield gains) are estimated from data collected in farmers' plots, outside of controlled experimental settings, it is important to account for possible confounding factors, such as differences in input use, soil quality, farmers' management ability etc.

In this study, we analyze yield losses that farmers can avoid by using wheat varieties that are resistant to stripe rust. In particular, we analyze the yield of improved rust-resistant wheat varieties in comparison to the yield of improved susceptible and traditional susceptible varieties after controlling for input use, plot characteristics, and other contextual variables. We estimate a production function of the following type:

$Y_{i j t}=\alpha+\beta_{1} I R_{i j t}+\beta_{2} I S_{i j t}+\delta \boldsymbol{S}_{i j t}+\gamma \boldsymbol{X}_{i j t}+\rho \boldsymbol{F}_{i j t}+\vartheta \boldsymbol{H}_{j t}+\pi \boldsymbol{D}_{j}+\tau T_{t}+\varepsilon_{i j t}$

where $Y_{i j t}$ is wheat yield on plot $i$ of farm household $j$ in year $t$, and $I R_{i j t}$ and $I S_{i j t}$ are two dummy variables representing the use of improved resistant and improved susceptible varieties, respectively (referring to stripe rust). The coefficients $\beta_{1}$ and $\beta_{2}$ compare yield levels of these two improved types of varieties with those of traditional susceptible varieties. Since improved varieties are generally higher yielding than traditional varieties, we expect positive and significant coefficients for $\beta_{1}$ and $\beta_{2}$.

When researchers breed for rust resistance, the objective is to develop new varieties with yield levels at least as high as those of susceptible varieties (Gebre-Mariam et al., 1991). We expect positive yield effects of rust-resistant varieties in years with high rust infection (because of lower crop damage with resistant varieties), whereas the difference may be small or non-existent in years with low rust infection. We have the advantage of being able to compare yields of improved wheat varieties with and without the rust resistance traits. If $\beta_{1}$ is greater than $\beta_{2}$, the resistance traits help to reduce crop losses and increase effective yields. The difference between $\beta_{1}$ and $\beta_{2}$ is an indication of the yield loss that would have occurred had the resistant varieties not been developed and adopted (Marasas et al., 2003). 
The other variables in equation (3.1) control for possible confounding factors. $\boldsymbol{S}_{i j t}$ is a vector of dummy variables representing the incidence of different production stresses (e.g., diseases, drought, and other abiotic stresses), $\boldsymbol{X}_{i j t}$ is a vector of other production inputs, such as labor, fertilizer, and pesticides, and $\boldsymbol{F}_{i j t}$ is a vector of plot-level controls, such as plot size, soil quality, and slope of the land. $\boldsymbol{H}_{j t}$ is a vector of household-level characteristics, such as farmers' age and education, and $\boldsymbol{D}_{j}$ is a vector of district dummy variables to control for differences in unobserved regional factors (e.g., infrastructure, rainfall, agroecological potential). $T_{t}$ is a time dummy variable that takes a value of one for the second survey round 2013/14, with 2009/10 as the reference. $\varepsilon_{i j t}=u_{j}+e_{i j t}$, where $u_{j}$ is the unobserved heterogeneity for farm household $j$, and $e_{i j t}$ is the random error term. As many farm household have more than one wheat plot, we need to account for the possibility that the error term is heteroskedastic. This could lead to incorrect standard errors of the coefficient estimates. To avoid bias, we use a procedure to estimate standard errors that are cluster-corrected at the farm household level (Greene, 2012).

\subsubsection{Functional form}

The technical relationship between inputs and outputs in a production function tends to be nonlinear; higher input use usually leads to higher yield, but with decreasing marginal effects. The most commonly used functional forms in production function analysis are the Cobb-Douglas and the translog, both of which use logarithms of the input and output variables (Coelli et al., 2005). The translog function is more flexible, as it does not impose restrictions on the substitutability between different inputs. Which of the two functions is more appropriate in a particular context can be tested. In our case, the statistical test rejects the null hypothesis that the more restrictive Cobb-Douglas function fits the data well (test results are shown below), so we use the translog specification to estimate the production function in equation (3.1).

One problem with log-transforming inputs and output is that several farmers used zero quantities of certain inputs. As the logarithm of zero is not defined, these observations would be lost if not dealt with specifically. We use the method proposed by (Battese, 1997)) to handle zero input quantities: after taking logs, undefined values are replaced by zero, and additional dummy variables are added to indicate zero quantities of particular inputs. Battese (1997) showed that this method leads to consistent production function estimates. 


\subsubsection{Testing for local adaptation of improved varieties}

In equation (3.1), we only included dummy variables for the improved varieties with and without stripe rust resistance to look at simple yield effects. To gain a better understanding of whether improved varieties are well adapted to different types of local production stresses, we estimate another set of production function models with interaction terms as follows:

$Y_{i j t}=\alpha+\beta_{1} I R_{i j t}+\beta_{2} I S_{i j t}+\varphi\left(I R_{i j t} \times \boldsymbol{S}_{i j t}\right)+\omega\left(I S_{i j t} \times \boldsymbol{S}_{i j t}\right)+\cdots+\varepsilon_{i j t}$

Other control variables are included as in equation (3.1), but not shown in equation (3.2) for brevity. To illustrate the interpretation of the coefficients of the interactions between production stresses $\left(\boldsymbol{S}_{i j t}\right)$ and the improved varieties $\left(I R_{i j t}\right.$ and $\left.I S_{i j t}\right)$, we use the incidence of drought as an example. In equation (3.2), $\beta_{1}$ alone indicates the yield effect of rust-resistant varieties in situations with no drought, whereas $\varphi$ shows whether rust-resistant varieties perform better or worse than local varieties under drought conditions. A negative coefficient $\varphi$ would indicate that rust-resistant varieties perform worse under drought. This could happen when the rust-resistance traits were not integrated into germplasm that is well adapted to drought situations. Such lack of local adaptation would discourage the adoption of rust-resistant varieties in drought-prone locations. In addition to drought, $\boldsymbol{S}_{i j t}$ can also represent other production stresses.

\subsubsection{Accounting for possible selection bias}

The models in equations (3.1) and (3.2) involve panel data and can be estimated with either random effects (RE) or fixed effects (FE) estimators (Greene, 2012). The RE estimator is more efficient but can lead to bias when there is unobserved heterogeneity that is jointly correlated with any of the explanatory variables and the outcome variable. For instance, farmers who adopt certain types of varieties may systematically differ from non-adopters (Alemu and Bishaw, 2015; Barrett et al., 2004; Mather et al., 2003). Such systematic and unobserved heterogeneity between adopters and non-adopters would be a typical case of selection bias. The FE estimator builds on differencing within households over time so that time-invariant unobserved heterogeneity is canceled out. This is a neat way of reducing selection bias. However, for robust estimation the FE estimator requires sufficient variation over time for all variables of interest. If the variation over time is small, an 
alternative to the standard FE estimator can be used, as proposed by Mundlak (1978). We employ the random effects model with the Mundlak FE version, rewriting equation (3.1) as follows:

$Y_{i j t}=\alpha+\beta_{1} I R_{i j t}+\beta_{2} I S_{i j t}+\delta \boldsymbol{S}_{i j t}+\gamma \boldsymbol{X}_{i j t}+\rho \boldsymbol{F}_{i j t}+\vartheta \boldsymbol{H}_{j t}+\pi \boldsymbol{D}_{j}+\tau T_{t}+\theta \overline{\boldsymbol{M}}_{i j t}+\varepsilon_{i j t}$

where $\overline{\boldsymbol{M}}_{i j t}$ is a vector of cluster means of all time-varying observations. Mundlak's FE estimator controls for unobserved heterogeneity that may correlate with the explanatory variables in equation (3.3) (Di Falco and Veronesi, 2014; Mundlak, 1978). If the estimated parameters $\theta$ are jointly zero, unobserved heterogeneity does not cause bias, so that the RE estimator can be used. Testing for the significance of $\theta$ is an alternative to the Hausman test (Greene, 2012; Rabe-Hesketh and Skrondal, 2012).

\subsection{Results and discussion}

\subsubsection{Descriptive statistics}

Table 3.1 shows a list of variables used in the analysis with explanations and units of measurement. Table 3.2 characterizes the role that wheat production plays in sample farm households. The total average cultivated area per farm household is around 2 ha, out of which one-third is cultivated with wheat. Wheat accounts for over $40 \%$ of the total value of production (approximately 8,500 Birr or 446 US\$ in both survey years). 
Table 3.1. Description and measurement of variables used in the analysis.

\begin{tabular}{ll}
\hline Variables & Description and measurement \\
$\begin{array}{l}\text { Dependent variable } \\
\text { Types of wheat varieties }\end{array}$ & Quantity of wheat output per hectare (kg/ha) \\
TS (traditional susceptible) & 1 if traditional varieties susceptible to stripe rust were used; 0 otherwise \\
IS (improved susceptible) & 1 if improved varieties susceptible to stripe rust were used; 0 otherwise \\
IR (improved resistant) & 1 if improved varieties resistant to stripe rust were used, 0 otherwise \\
Input use & Expenses on fertilizer (Birr/ha), log transformed \\
Fertilizer & Expenses on herbicide (Birr/ha), log transformed \\
Herbicide & Oxen days per hectare, log transformed \\
Oxen days & Labor days per hectare, log transformed \\
Labor & Quantity of manure(kg/ha), log transformed \\
Manure & 1 if fungicides or insecticides were used, 0 otherwise \\
Pesticide & Plot level biotic and abiotic shocks \\
& 1 if there was an incidence of drought; 0 otherwise \\
$\begin{array}{l}\text { Drought } \\
\text { Other abiotic }\end{array}$ & 1 if there was an incidence of waterlogging, frost, or hailstorm; 0 otherwise \\
Diseases & 1 if there was an incidence of wheat diseases; 0 otherwise \\
Any stress & 1 if there was an incidence of any production stress; 0 otherwise \\
Other plot level characteristics & \\
plot size & Size of plot (ha) \\
Good soil & 1 if the soil is of good quality, according to farmer; 0 otherwise \\
Medium soil & 1 if the soil is of medium quality, according to farmer; 0 otherwise \\
Poor soil & 1 if the soil is of poor quality, according to farmer; 0 otherwise \\
Flat slope & 1 if the plot was flat sloped; 0 otherwise \\
Medium slope & 1 if the plot was medium sloped; 0 otherwise \\
Steep slope & 1 if the plot was steep sloped; 0 otherwise \\
Farmer characteristics & \\
Age & Age of the farmer (household head) in years \\
Male & 1 if the farmer (household head) is male; 0 if female \\
Education & Years of schooling of the farmer (household head) \\
Survey round & 1 if the observation if from the $2013 / 14$ survey round; 0 if $2009 / 10$ \\
Year & \\
&
\end{tabular}


Table 3.2. Importance of wheat for sample households.

\begin{tabular}{|c|c|c|}
\hline \multirow{2}{*}{ Variables } & 2009/10 & 2013/14 \\
\hline & Mean/SD & Mean/SD \\
\hline \multirow[t]{2}{*}{ Total crop area cultivated by the household (ha) } & 2.11 & 2.45 \\
\hline & $(1.77)$ & $(2.02)$ \\
\hline \multirow[t]{2}{*}{ Total wheat area cultivated by the household (ha) } & 0.74 & 0.70 \\
\hline & $(0.88)$ & $(0.71)$ \\
\hline \multirow[t]{2}{*}{ Share of wheat area to total area cultivated (\%) } & 36 & 31 \\
\hline & (21) & (19) \\
\hline \multirow[t]{2}{*}{ Share of wheat to total value of crop production (\%) } & 44 & 43 \\
\hline & (26) & (26) \\
\hline \multirow[t]{2}{*}{ Value of total crop production (Birr) ${ }^{\mathbf{a}}$} & 15,649 & 14,633 \\
\hline & $(18,235)$ & $(21,114)$ \\
\hline \multirow[t]{2}{*}{ Value of wheat production (Birr) ${ }^{\mathbf{a}}$} & 8,638 & 8,312 \\
\hline & $(13,616)$ & $(13,506)$ \\
\hline Number of household observations & 2069 & 1921 \\
\hline
\end{tabular}

a The official exchange rate was 1 US $\$=19.05$ Birr in 2013. Monetary values are expressed in real terms for easier comparison across survey rounds.

Wheat is affected by various production stresses, with significant temporal and spatial variation. According to farmers' own statements, $8 \%$ of the wheat plots were affected by drought in 2009/10 as shown in Table 3.3. In 2013/14, the share of drought-affected plots was only 1\%. Other abiotic stresses, such as waterlogging, frost, or hailstorms affected around 9-10\% of the plots in both seasons. Wheat diseases, including stripe rust and other disease problems, were reported in $13 \%$ and $20 \%$ of the plots in 2009/10 and 2013/14, respectively. While wheat rust problems have increased in Ethiopia in recent years, both survey rounds refer to seasons with moderate rust infection levels. Plot level incidence of various abiotic and biotic stresses.

Table 3.3. Plot level incidence of various abiotic and biotic factors.

\begin{tabular}{lcccc}
\hline Type of stress & Number of plots & Both rounds & $2009 / 10$ & $2013 / 14$ \\
\hline Drought & 4751 & 0.04 & 0.08 & 0.01 \\
Other abiotic $^{\mathrm{e}}$ & 4751 & 0.09 & 0.09 & 0.10 \\
Diseases & 4751 & 0.17 & 0.13 & 0.20 \\
\hline
\end{tabular}

Notes: ${ }^{\text {a }}$ Other abiotic stresses include waterlogging, frost, and hailstorm.

Figure 3.1 shows the adoption of different types of wheat varieties over the two survey rounds (Figure 3.5 in Appendix 3 differentiates by agroecology). The use of traditional varieties is limited. In $2009 / 10$, only $7 \%$ of all wheat plots were grown with traditional varieties. Strikingly, however, this share had increased to $20 \%$ in $2013 / 14$. This increase in the use of traditional varieties suggests that not all farmers were satisfied with the performance of improved varieties in previous years, possibly due to the role of biotic and abiotic stress factors. Among the improved varieties, in 
2009/10 most were susceptible to stripe rust. By 2013/14, the share of improved varieties with resistance to stripe rust had increased to $51 \%$. The increased adoption of rust-resistant varieties reflects intensified promotion efforts by various organizations in Ethiopia as a response to recent rust epidemics in East Africa (Olivera et al., 2015; Tolemariam et al., 2016; Yami et al., 2012).

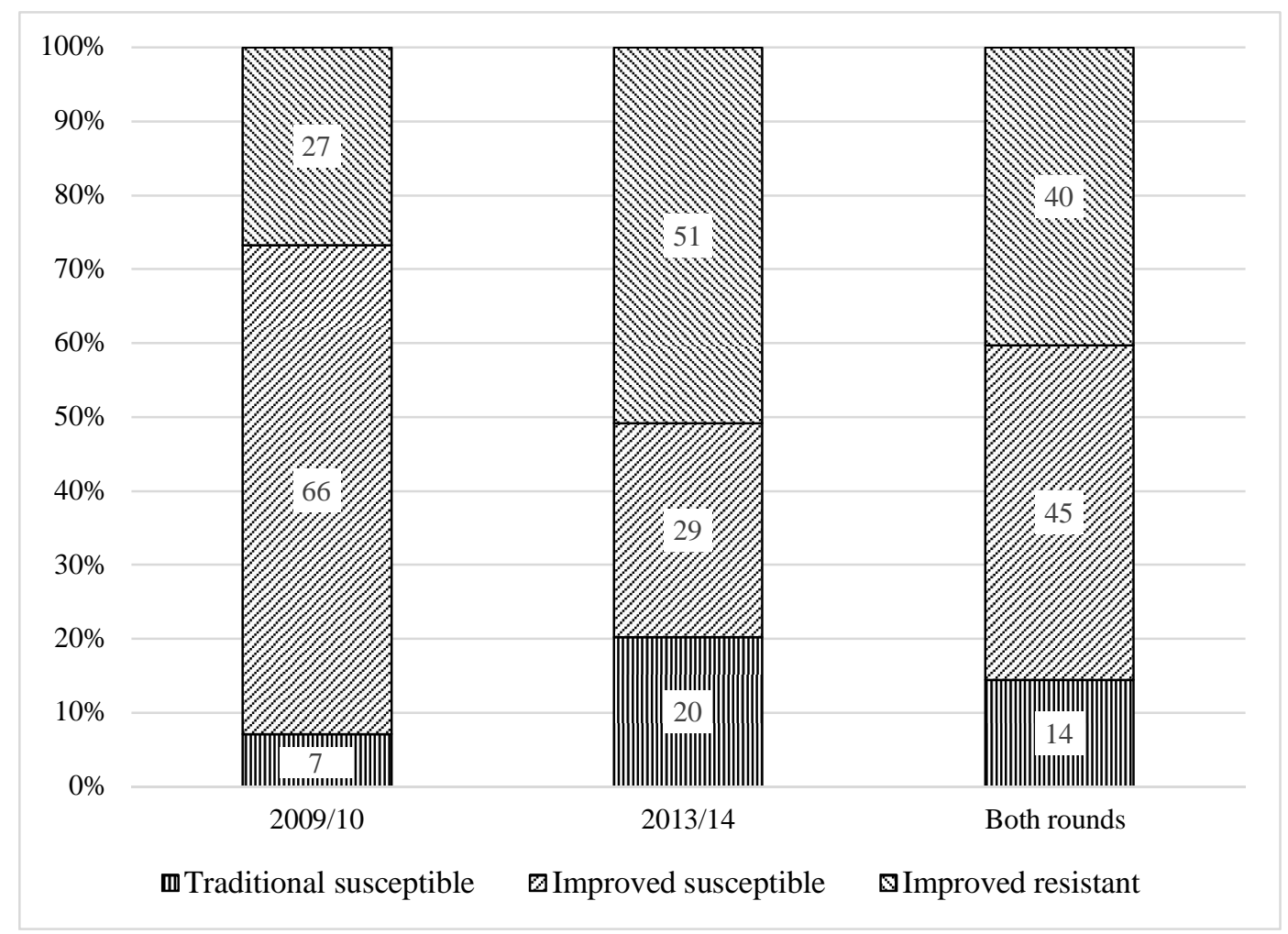

Figure 3.1. Percentage of wheat plots by type of variety. 


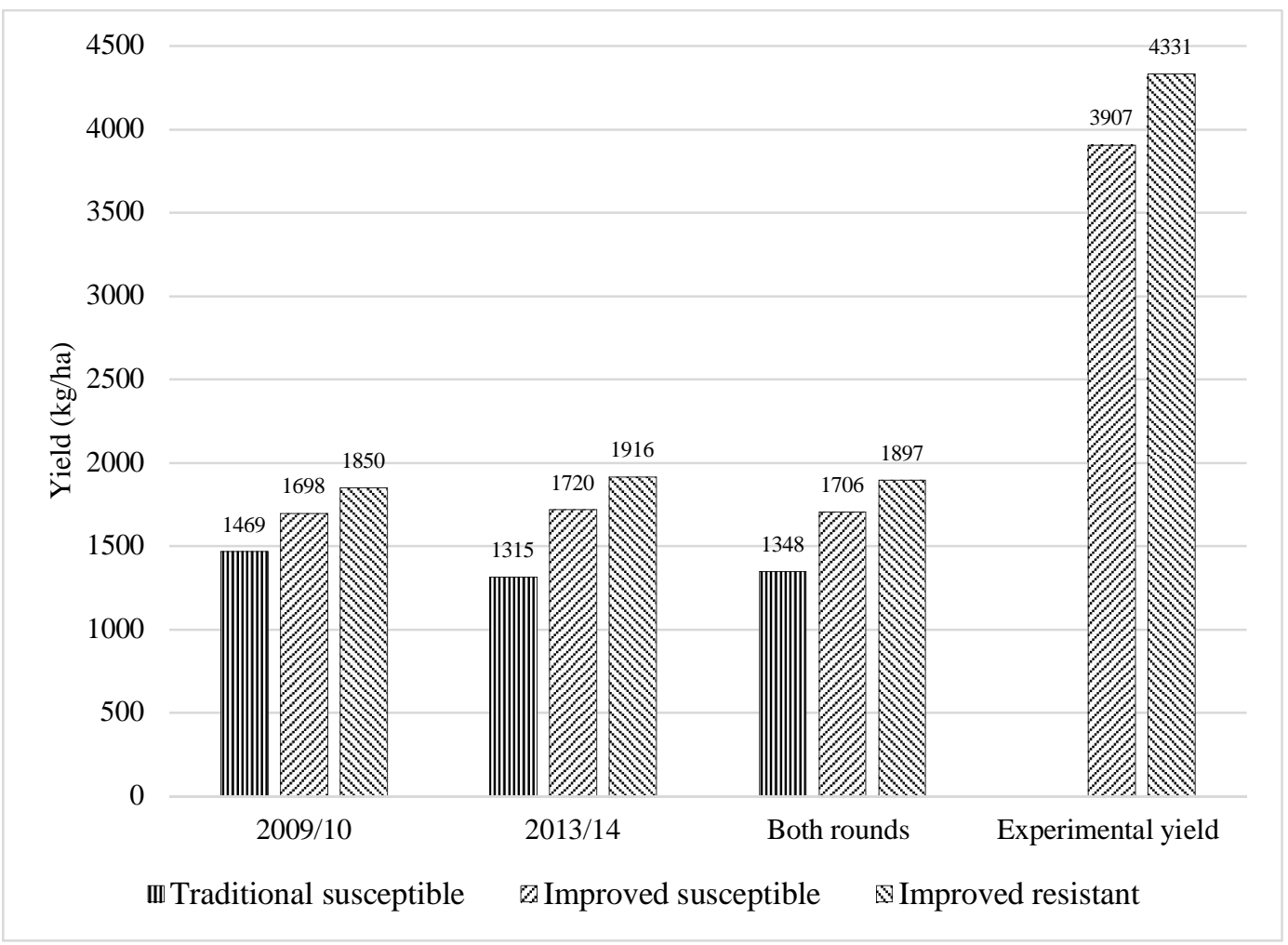

Figure 3.2. Mean wheat yields on sample plots and experimental stations $(\mathrm{kg} / \mathrm{ha})$. Note: Experimental yields are average values obtained from various sources listed in Table 3.8 in Appendix 3.

Figure 3.2 shows aggregate mean wheat yields obtained by farmers, differentiating by type of variety grown. Traditional varieties consistently have the lowest average yields, whereas improved rust-resistant varieties have the highest average yields. Yields in our survey are lower than the national average of $2200 \mathrm{~kg}$ reported by ECSA (2015). Differences may possibly be due to different methods used in yield estimations. While our data are based on farmers' statements, ECSA (2015) uses actual crop cuts. It is possible that farmers underestimate yields, or that the crop cut method overestimates the actual harvest obtained by farmers. Discrepancies between yield data obtained with different methods were also reported in other studies (Sapkota et al., 2016). Regardless of the method used, average wheat yields obtained by farmers are much lower than those on experimental stations in Ethiopia (Figure 3.2). One reason is that experimental stations are often located in areas with good soil quality and water availability. Furthermore, due to various constraints farmers often use lower than recommended quantities of fertilizer and other inputs (Bellon, 2006; Getnet et al., 2016; Gollin et al., 2005).

Figure 3.3 depicts density functions of wheat yield by type of variety. Improved susceptible varieties dominate the distribution of traditional varieties, while improved resistant varieties dominate both other distributions. This pattern is observed consistently for both survey rounds. In line with the 
literature, the yields are not normally distributed but positively skewed to the left, suggesting that more than half of the farmers have below average yields (Ramirez et al., 2003).

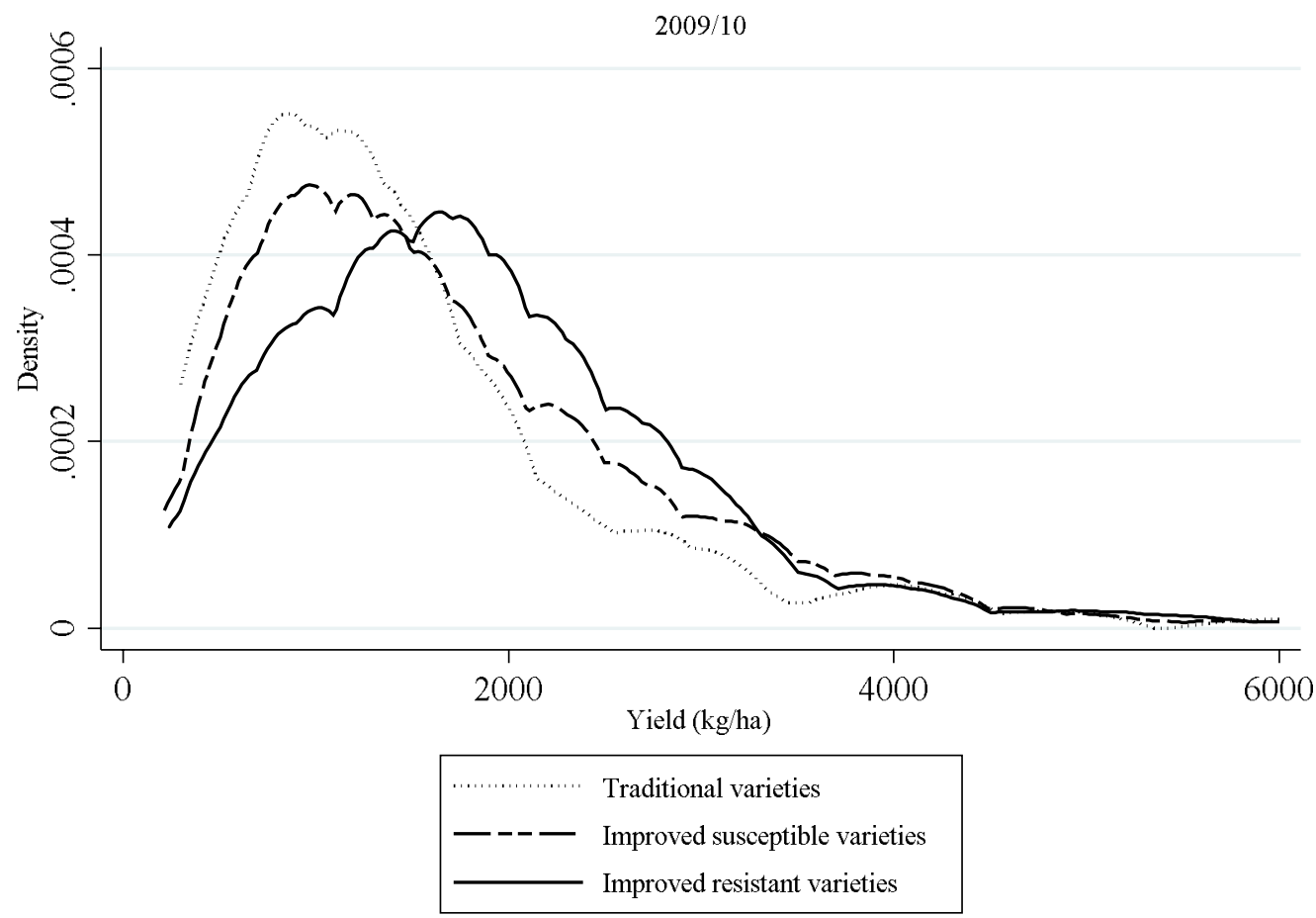

$2013 / 14$

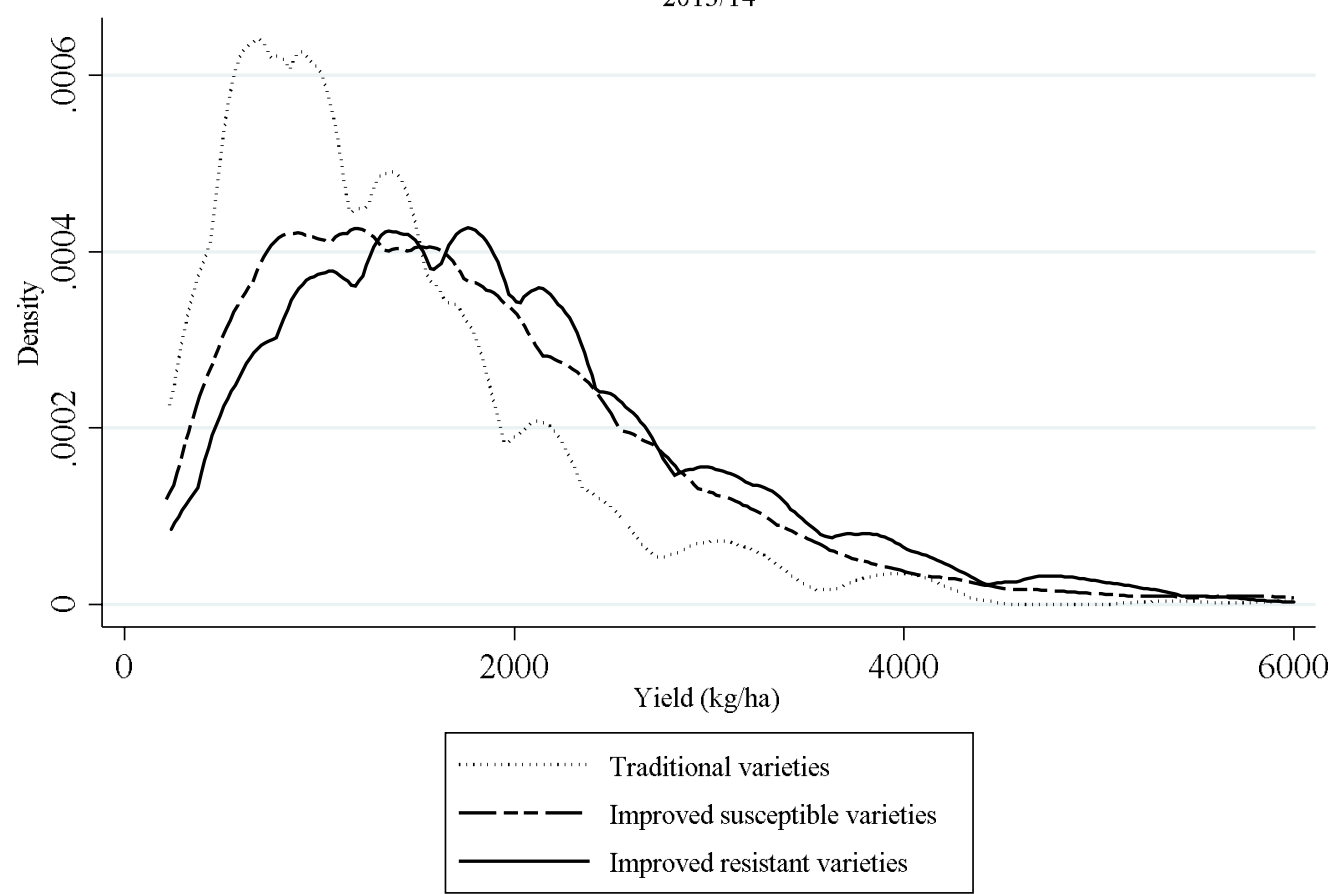

Figure 3.3. Distribution of wheat yield by type of variety. 
Table 3.4 reports the intensity of input use. For fertilizers and herbicides, different types of products are used (e.g., DAP, urea fertilizer), so we express them in monetary terms. Farmers reported that they had used fertilizer in more than $80 \%$ of their wheat plots. However, the intensity of fertilizer use shows significant variation. Table 3.4 also shows that wheat is grown in a very labor-intensive way in Ethiopia, with an average of 89 labor days and 24 oxen days per ha and season.

Table 3.4. Intensity of input use.

\begin{tabular}{|c|c|c|c|}
\hline \multirow{2}{*}{ Inputs } & Both rounds & $2009 / 10$ & $2013 / 14$ \\
\hline & Mean/SD & Mean/SD & Mean/SD \\
\hline Fertilizer use (\% of plots) & 84 & 80 & 88 \\
\hline \multirow[t]{2}{*}{ Fertilizer (expenses) } & 847 & 762 & 914 \\
\hline & $(685)$ & $(687)$ & $(676)$ \\
\hline Herbicide use (\% of plots) & 60 & 62 & 59 \\
\hline \multirow[t]{2}{*}{ Herbicide (expenses) } & 39 & 33 & 42 \\
\hline & $(57)$ & (43) & (66) \\
\hline \multirow[t]{2}{*}{ Oxen days } & 24 & 24 & 25 \\
\hline & (12) & (13) & (11) \\
\hline \multirow[t]{2}{*}{ Labor days } & 89 & 91 & 88 \\
\hline & (68) & (69) & (66) \\
\hline Manure use (\% of plots) & 17 & 18 & 17 \\
\hline \multirow[t]{2}{*}{ Manure $(\mathrm{kg})$} & 284 & 308 & 265 \\
\hline & $(900)$ & $(976)$ & $(837)$ \\
\hline Pesticide use (\% of plots) & 4 & 3 & 4 \\
\hline Number of plots & 4,751 & 2,096 & 2,655 \\
\hline
\end{tabular}

Notes: Expenses are expressed in Birr/ha. The official exchange rate was 1 US $\$=19.05$ Birr in 2013. Monetary values are expressed in real terms for easier comparison across survey rounds. For other details of variable definitions, see Table 3.1.

Figure 3.4 shows input use by type of wheat variety. On average, improved varieties are grown on somewhat larger plots than traditional varieties. Also the intensity of input use seems to differ across varietal types. Farmers with improved wheat varieties tend to spend more on fertilizers and herbicides. On the other hand, farmers with improved rust-resistant varieties use less manure and less labor. The differences in input use underline the importance of controlling for possible confounding factors when analyzing yield effects of different types of wheat varieties. 

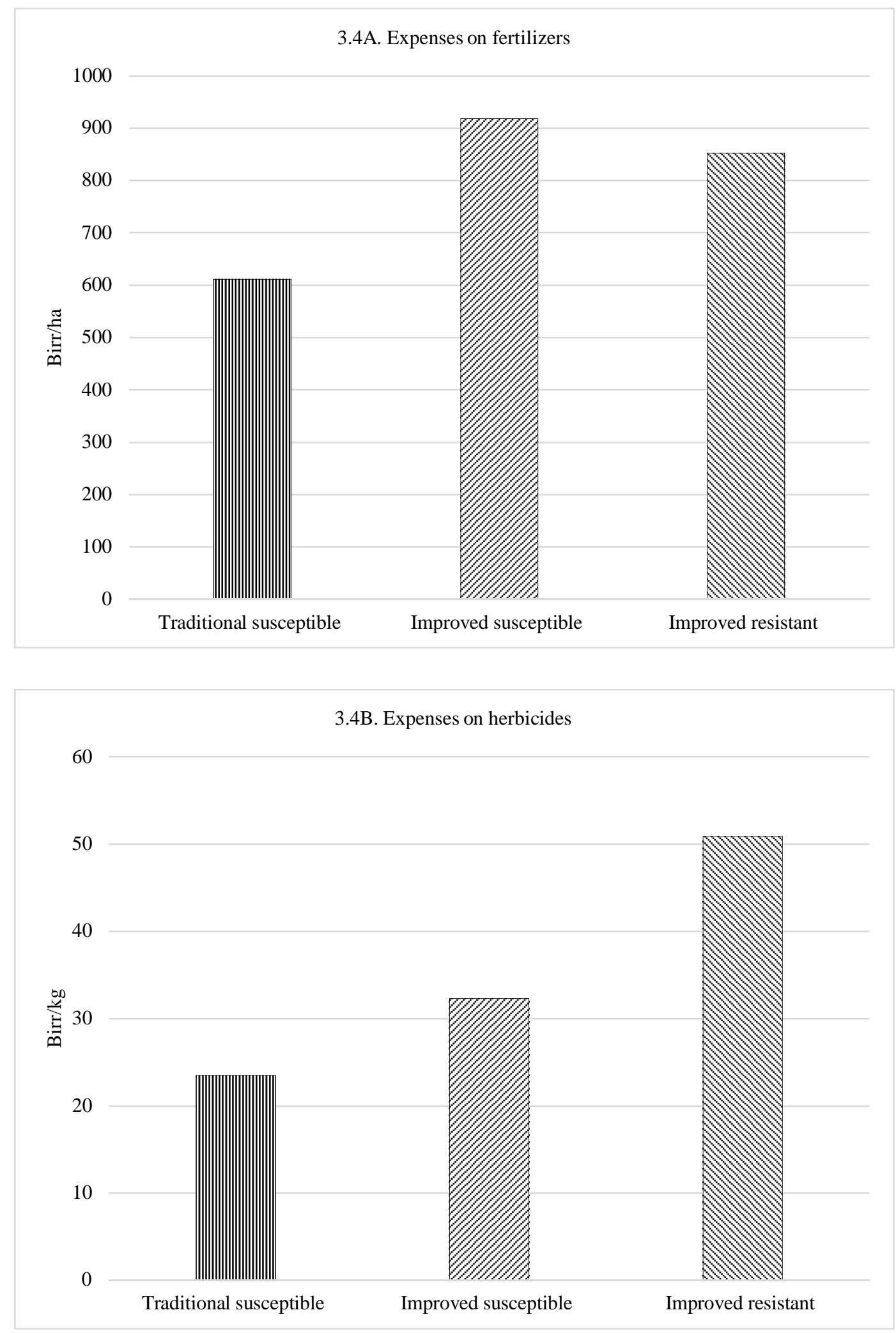


\subsection{Quantity of labor}

120

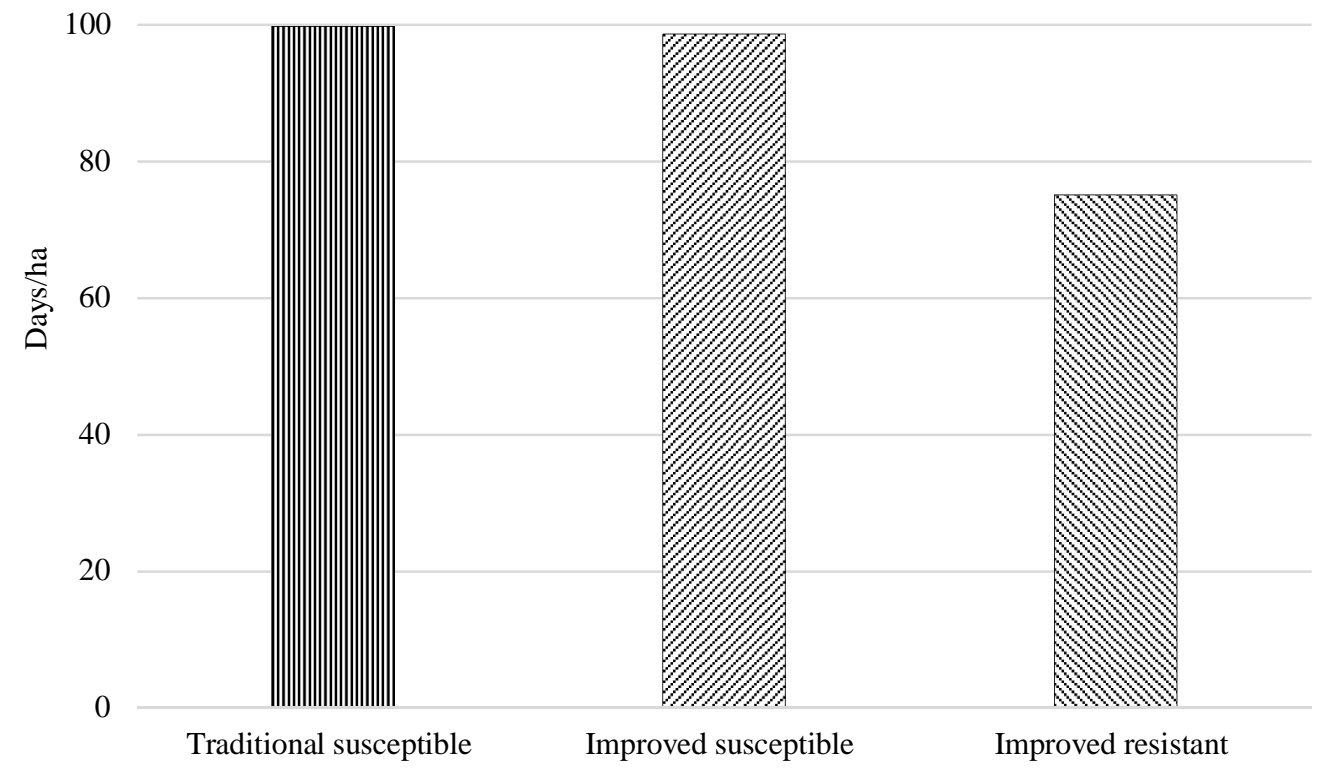

3.4D. Plot size

0.5

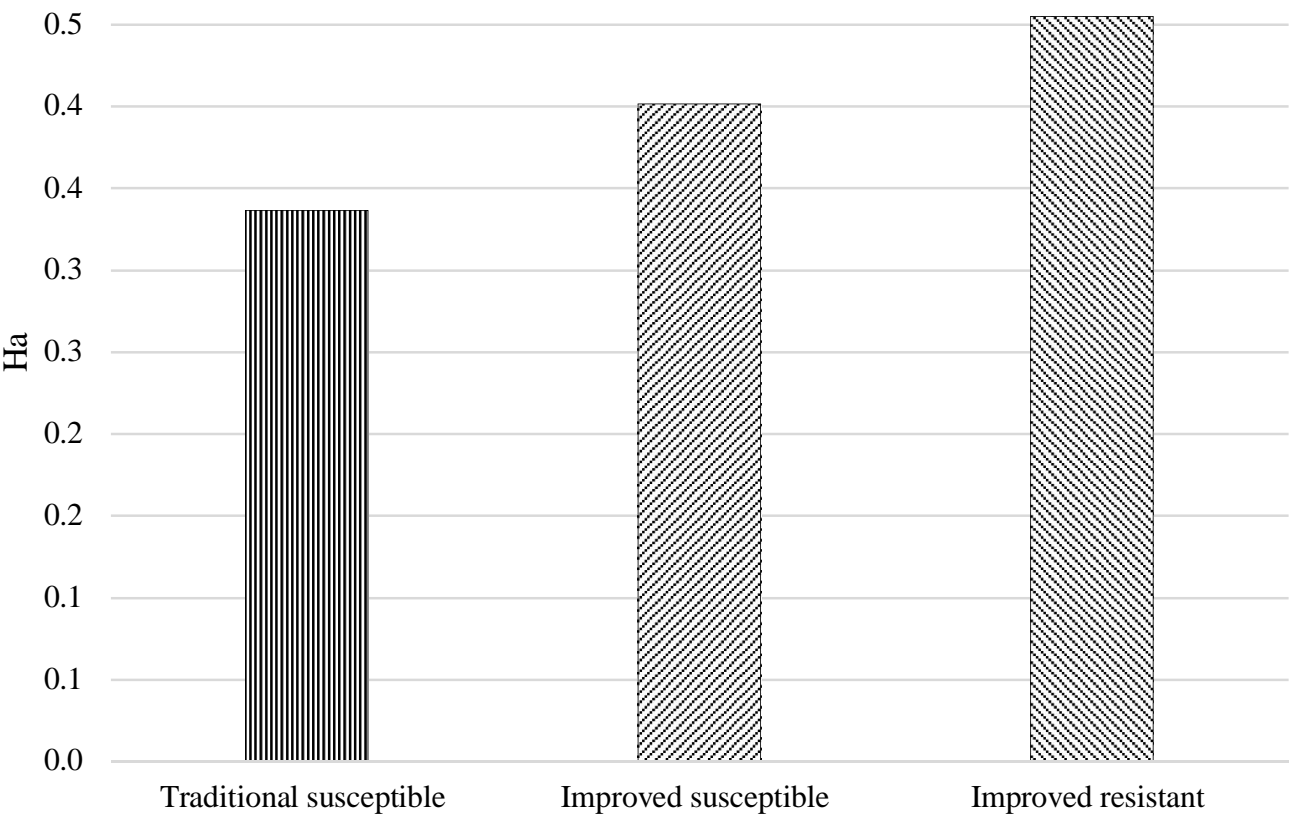




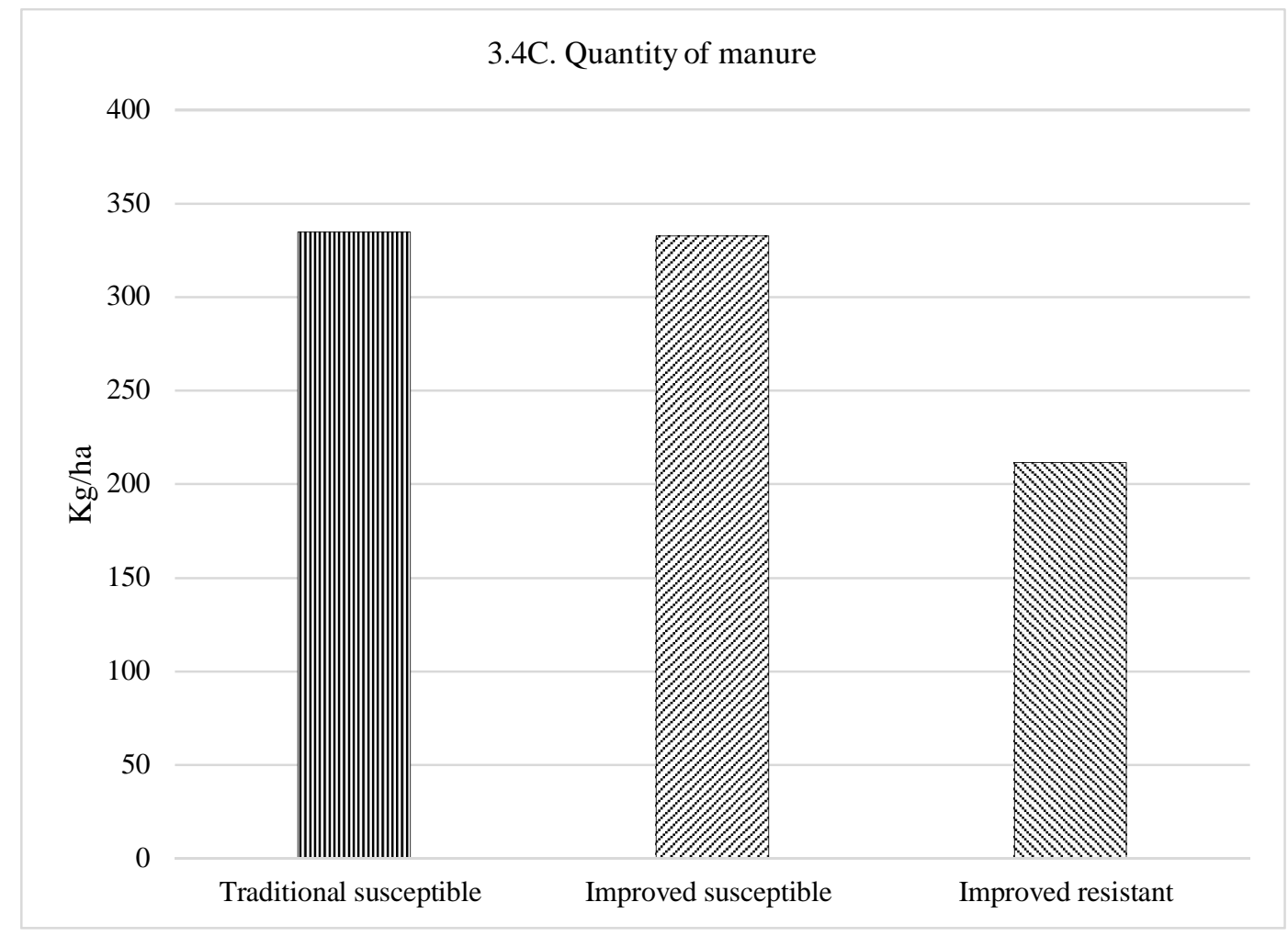

Figure 3.4. Plot characteristics and input use by type of wheat variety.

\subsubsection{Econometric results}

Before looking at the production function estimates, we discuss the statistical tests that we carried out for functional form and possible selection bias. The test results shown in Table 3.5 refer to the models explained above in equations (3.1) and (3.3). The first test relates to functional form. Our null hypothesis is that the coefficients of the input interaction terms in the translog production function are jointly insignificant. In that case, the Cobb-Douglas functional form would be appropriate. However, the test rejects this null hypothesis, so we conclude that the more flexible translog functional form with input interaction terms is appropriate to use. The second test relates to the role of unobserved heterogeneity among farmers, which could lead to selection bias. The null hypothesis is that the $\theta$ coefficients for the Mundlak fixed effects are jointly zero. This null hypothesis cannot be rejected. We conclude that the normal RE estimator can be used to obtain unbiased results. 
Table 3.5. Model diagnostics.

\begin{tabular}{lcccc} 
Null hypothesis & $\begin{array}{c}\text { Chi squared test } \\
\text { statistic }\end{array}$ & $\begin{array}{c}\text { Degrees of } \\
\text { freedom }\end{array}$ & $\begin{array}{c}\text { Chi squared critical } \\
\text { value }\end{array}$ & $\begin{array}{c}\text { p- } \\
\text { value }\end{array}$ \\
\hline $\begin{array}{l}\text { Cobb-Douglas function fits the data } \\
\begin{array}{l}\text { Mundlak's fixed effects are jointly } \\
\text { zero }\end{array}\end{array}$ & 71.75 & 15 & 24.996 & 0.000 \\
\end{tabular}

The translog production function estimates are shown in Table 3.6. For brevity, the coefficients of the input interaction terms and district dummy variables are not shown in Table 3.6. These additional coefficients are shown in Table 3.9 in Appendix 3. The coefficients of the district dummies in Table 3.9 suggest that there are significant regional differences in yield, even after controlling for inputs and other plot and farmer characteristics. These differences may be due to agroecological factors. In all models in Table 3.6, the inputs are mean centered, so the coefficients can be interpreted directly as elasticities at sample means. The elasticity is the percentage change in yield for a $1 \%$ change in a particular input.

In model (1) of Table 3.6, we only include inputs and other control variables. We control for neither the variety dummies nor dummies for production stresses. As can be seen, all input coefficients have the expected positive signs, and most of them are statistically significant. These estimates suggest that wheat farmers can obtain higher yields by further increasing their input intensity. The highest input elasticity is observed for chemical fertilizer: a $1 \%$ increase in the use of fertilizer increases yield by $0.3 \%$ on average.

The results of model (1) further suggest that higher yields are obtained on smaller plots, which may be related to a higher share of family labor on small farms. Due to different incentives, family labor is often more productive than hired labor. A negative correlation between farm/plot size and yield has also been shown in other studies (Barrett et al., 2010; Carletto et al., 2013; Kilic et al., 2017; Sen, 1966). Plots managed by households with better-educated household heads have higher yields. On the other hand, the sex of the household head does not seem to influence yield after controlling for plot characteristics and input use. In terms of land characteristics, lower yields are obtained on land with steep slopes than on flat land. Less favorable land is also associated with lower wheat yields, as one would expect.

In Model (2) of Table 3.6, we include a dummy variable for the incidence of wheat diseases as an additional control variable. As mentioned, the most relevant disease is stripe rust, but other diseases are also included. The coefficient for this variable suggests that stripe rust and other diseases have 
caused yield damage of $19 \%$. Note that this is not the average loss for the entire sample, but only refers to those fields where farmers reported disease incidence during the respective years. For comparison, during the 2010 stripe rust outbreak in Syria, yield declines of 20-70\% were reported, depending on infection levels in a particular region (ICARDA, 2011). Also in Ethiopia, yield losses through stripe rust of more than 20\% were reported for particular years (Alemu et al., 2015; Bishaw et al., 2014; Denbel et al., 2013; Hailu and Fininsa, 2007; Tadesse et al., 2010; Zerihun et al., 2012). Against this background, the $19 \%$ loss derived from our data on plots with disease incidence are relatively low. But it should be mentioned that overall stripe rust levels were not particularly high in the two years covered by the survey.

In model (3) of Table 3.6, we include the two dummy variables for improved varieties with and without resistance to stripe rust. The estimates suggest that improved resistant varieties outperform traditional varieties that are susceptible to stripe rust. Compared to traditional varieties, growing improved resistant varieties increases yield by $8 \%$ on average. It can be expected that yield gains of resistant varieties will still be higher in locations with high rust infection levels. One way to analyze this further would be to interact the variable for resistant varieties with rust infection levels. Unfortunately, this is not possible with our farmer-reported disease incidence variable, because this variable is endogenous: when farmers have adopted rust-resistant varieties they naturally observe lower disease problems in their own plots.

Model (3) further suggests that the yield gain of improved susceptible varieties is 6\%. The difference between improved resistant and improved susceptible varieties is $2 \%$. The $2 \%$ extra yield gain is the percentage that would have been lost if resistant varieties had not been adopted. That this difference is small (and statistically not significant) should not surprise given that there was no major rust epidemic in the two seasons covered by the survey. It seems that breeders were successful in terms of avoiding a yield penalty when introducing the rust resistance traits into improved germplasm. Such a penalty could potentially occur if rust resistance was negatively correlated with other plant traits that influence yield.

In model (4) of Table 3.6, we additionally introduce an interaction term between rust-resistant varieties and the year dummy variable. The positive and significant coefficient of this interaction term suggests that the yield gains of rust-resistant varieties were higher in 2013/14 than in 2009/10. This difference between years suggests that there is temporal variation in disease infection levels. In seasons with severe rust infection, the benefits of resistant varieties are likely much larger. 
In model (5), we include two dummy variables for different types of abiotic stresses, one for drought and the other for shocks such as waterlogging, frost, and hailstorms combined. Both variables have large negative coefficients, suggesting that abiotic stresses can reduce wheat yield significantly; each type of shock reduces yield by more than $30 \%$. Hence, the attractiveness and performance of improved and disease-resistant varieties will also depend on their adaptation to common abiotic stresses. This is further analyzed in the following. 
Table 3.6. Determinants of wheat yield (different model specifications).

\begin{tabular}{|c|c|c|c|c|c|}
\hline \multirow{2}{*}{ Explanatory variables } & Model (1) & Model (2) & Model (3) & Model (4) & Model (5) \\
\hline & Coeff/se & Coeff/se & Coeff/se & Coeff/se & Coeff/se \\
\hline \multirow[t]{2}{*}{ IR (improved resistant) ${ }^{\mathbf{a}}$} & & & $0.080 * * *$ & 0.019 & $0.070 * * *$ \\
\hline & & & $(0.027)$ & $(0.037)$ & $(0.027)$ \\
\hline \multirow[t]{2}{*}{ IS (improved susceptible) ${ }^{\mathbf{a}}$} & & & $0.059 * *$ & 0.044 & $0.046^{*}$ \\
\hline & & & $(0.028)$ & $(0.028)$ & $(0.027)$ \\
\hline \multirow[t]{2}{*}{ IR $x$ year } & & & & $0.081 * *$ & \\
\hline & & & & $(0.036)$ & \\
\hline \multirow[t]{2}{*}{ Drought } & & & & & $-0.328 * * *$ \\
\hline & & & & & $(0.061)$ \\
\hline \multirow[t]{2}{*}{ Other abiotic } & & & & & $-0.332 * * *$ \\
\hline & & & & & $(0.042)$ \\
\hline \multirow[t]{2}{*}{ Diseases } & & $-0.188 * * *$ & & & \\
\hline & & $(0.029)$ & & & \\
\hline \multirow[t]{2}{*}{ Fertilizer } & $0.229 * * *$ & $0.226 * * *$ & $0.226 * * *$ & $0.224 * * *$ & $0.227 * * *$ \\
\hline & $(0.020)$ & $(0.020)$ & $(0.020)$ & $(0.020)$ & $(0.019)$ \\
\hline \multirow[t]{2}{*}{ Herbicide } & $0.074 * * *$ & $0.079 * * *$ & $0.075 * * *$ & $0.072 * * *$ & $0.077 * * *$ \\
\hline & $(0.020)$ & $(0.019)$ & $(0.020)$ & $(0.020)$ & $(0.019)$ \\
\hline \multirow[t]{2}{*}{ Oxen days } & 0.047 & 0.036 & 0.049 & 0.049 & 0.043 \\
\hline & $(0.044)$ & $(0.044)$ & $(0.044)$ & $(0.044)$ & $(0.044)$ \\
\hline \multirow[t]{2}{*}{ Labor } & $0.094 * * *$ & $0.104 * * *$ & $0.095^{* * *}$ & $0.096^{* * *}$ & $0.090 * *$ \\
\hline & $(0.036)$ & $(0.036)$ & $(0.036)$ & $(0.036)$ & $(0.035)$ \\
\hline \multirow[t]{2}{*}{ Manure } & $0.057 * *$ & $0.054 * *$ & $0.056 * *$ & $0.058 * *$ & $0.053 * *$ \\
\hline & $(0.024)$ & $(0.024)$ & $(0.024)$ & $(0.024)$ & $(0.023)$ \\
\hline \multirow[t]{2}{*}{ Pesticide } & 0.093 & 0.116 & 0.092 & 0.099 & 0.078 \\
\hline & $(0.075)$ & $(0.071)$ & $(0.074)$ & $(0.073)$ & $(0.074)$ \\
\hline \multirow[t]{2}{*}{ Plot size } & $-0.127 * * *$ & $-0.127 * * *$ & $-0.128 * * *$ & $-0.126 * * *$ & $-0.117 * * *$ \\
\hline & $(0.039)$ & $(0.039)$ & $(0.039)$ & $(0.040)$ & $(0.036)$ \\
\hline \multirow[t]{2}{*}{ Medium soil $^{\mathbf{b}}$} & $-0.039 *$ & $-0.036^{*}$ & $-0.038^{*}$ & $-0.037^{*}$ & -0.026 \\
\hline & $(0.022)$ & $(0.022)$ & $(0.022)$ & $(0.022)$ & $(0.021)$ \\
\hline \multirow[t]{2}{*}{ Poor soil ${ }^{\mathbf{b}}$} & $-0.082 * *$ & $-0.076^{* *}$ & $-0.083 * *$ & $-0.082 * *$ & $-0.071 * *$ \\
\hline & $(0.035)$ & $(0.035)$ & $(0.035)$ & $(0.034)$ & $(0.033)$ \\
\hline \multirow[t]{2}{*}{ Medium slope ${ }^{\mathbf{c}}$} & -0.035 & -0.022 & -0.035 & -0.034 & $-0.038^{*}$ \\
\hline & $(0.023)$ & $(0.023)$ & $(0.023)$ & $(0.023)$ & $(0.022)$ \\
\hline \multirow[t]{2}{*}{ Steep slope ${ }^{\mathbf{c}}$} & $-0.108 * *$ & $-0.093 * *$ & $-0.106 * *$ & $-0.110 * *$ & $-0.120 * * *$ \\
\hline & $(0.046)$ & $(0.045)$ & $(0.046)$ & $(0.045)$ & $(0.046)$ \\
\hline \multirow[t]{2}{*}{ Age } & $-0.003 * * *$ & $-0.003 * * *$ & $-0.003 * * *$ & $-0.003 * * *$ & $-0.003 * * *$ \\
\hline & $(0.001)$ & $(0.001)$ & $(0.001)$ & $(0.001)$ & $(0.001)$ \\
\hline \multirow[t]{2}{*}{ Male } & 0.026 & 0.022 & 0.027 & 0.028 & 0.026 \\
\hline & $(0.040)$ & $(0.040)$ & $(0.040)$ & $(0.040)$ & $(0.039)$ \\
\hline \multirow[t]{2}{*}{ Education } & $0.015 * * *$ & $0.014 * * *$ & $0.015 * * *$ & $0.015^{* * *}$ & $0.014 * * *$ \\
\hline & $(0.003)$ & $(0.003)$ & $(0.003)$ & $(0.003)$ & $(0.003)$ \\
\hline \multirow[t]{2}{*}{ Year } & -0.008 & 0.005 & -0.006 & -0.037 & -0.025 \\
\hline & $(0.020)$ & $(0.020)$ & $(0.020)$ & $(0.025)$ & $(0.020)$ \\
\hline \multirow[t]{2}{*}{ Constant } & $-0.529 * * *$ & $-0.471 * *$ & $-0.590 * * *$ & $-0.559 * * *$ & $-0.568 * * *$ \\
\hline & $(0.203)$ & $(0.203)$ & $(0.203)$ & $(0.203)$ & $(0.200)$ \\
\hline
\end{tabular}

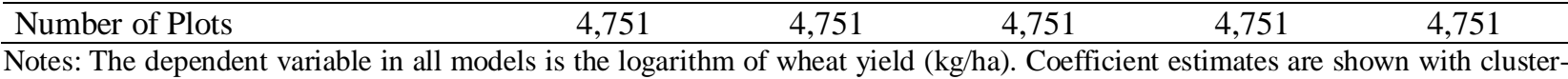
corrected standard errors in parentheses. For variable definitions, see Table 3.1. Dummies to correct for zero input use, input interaction terms, and district dummies are included in all models but not shown here for brevity (see Table 3.9 in Appendix 3). ${ }^{a}$ The base category are traditional varieties. ${ }^{\mathrm{b}}$ The base category is good soil. ${ }^{\mathrm{c}}$ The base category is flat slope. $* * * \mathrm{p}<0.01 ; * * \mathrm{p}<0.05$; $* \mathrm{p}<0.1$. 
In Table 3.7, we present results of models with interaction terms between the types of varieties and different production stresses (see equation 3.2). In each model, we also control directly for the same stress factors so we can interpret the coefficients of the interaction terms as the yield performance of improved varieties in comparison to local varieties in situations of abiotic stress.

Table 3.7. Role of interactions between types of varieties and production stress in explaining wheat yield.

\begin{tabular}{|c|c|c|c|}
\hline & Model (6) & Model (7) & Model (8) \\
\hline & Coeff/se & Coeff/se & Coeff/se \\
\hline IR (improved resistant) & $\begin{array}{c}0.076 * * * \\
(0.027)\end{array}$ & $\begin{array}{c}0.076 * * * \\
(0.028)\end{array}$ & $\begin{array}{c}0.104 * * * \\
(0.029)\end{array}$ \\
\hline IS (improved susceptible) & $\begin{array}{c}0.055^{* *} * \\
(0.028)\end{array}$ & $\begin{array}{l}0.054^{*} \\
(0.029)\end{array}$ & $\begin{array}{c}0.091 * * * \\
(0.031)\end{array}$ \\
\hline Drought & $\begin{array}{l}-0.124 \\
(0.148)\end{array}$ & $\begin{array}{c}-0.329 * * * \\
(0.061)\end{array}$ & \\
\hline Abiotic stress & $\begin{array}{c}-0.332 * * * \\
(0.041)\end{array}$ & $\begin{array}{c}-0.292 * * * \\
(0.075)\end{array}$ & \\
\hline Any stress & & & $\begin{array}{c}-0.217 * * * \\
(0.051)\end{array}$ \\
\hline \multicolumn{4}{|l|}{ Interaction terms } \\
\hline IR x drought & $\begin{array}{l}-0.195 \\
(0.155)\end{array}$ & & \\
\hline IS $x$ drought & $\begin{array}{c}-0.246 * \\
(0.145)\end{array}$ & & \\
\hline IR $x$ abiotic stress & & $\begin{array}{l}-0.039 \\
(0.084)\end{array}$ & \\
\hline IS $\mathrm{x}$ abiotic stress & & $\begin{array}{c}-0.055 \\
(0.078)\end{array}$ & \\
\hline IR $x$ any stress & & & $\begin{array}{c}-0.122 * * \\
(0.055)\end{array}$ \\
\hline IS $x$ any stress & & & $\begin{array}{l}-0.084 \\
(0.053)\end{array}$ \\
\hline Constant & $\begin{array}{c}-0.574 * * * \\
(0.201)\end{array}$ & $\begin{array}{c}-0.575 * * * \\
(0.201)\end{array}$ & $\begin{array}{c}-0.528 * * * \\
(0.200)\end{array}$ \\
\hline Number of plots & 4,751 & 4,751 & 4,751 \\
\hline
\end{tabular}

Notes: The dependent variable in all models is the logarithm of wheat yield (kg/ha). Coefficient estimates are shown with clustercorrected standard errors in parentheses. Only the main variables of interest are shown. Other included variables are the same as those in model (1) of Table 3.6. *** $p<0.01 ; * * p<0.05 ; * p<0.1$.

In model (6) of Table 3.7, we focus on drought situations. In model (7), we look at other abiotic stresses, whereas in model (8), we combine all stresses together in one dummy variable. All interaction terms have a negative sign, but some of the coefficients are statistically insignificant. The statistical insignificance of the coefficients is due to the small number of farmers reporting 
production stresses and a certain degree of collinearity that is common when including variables directly and as interaction terms. Nevertheless, some of the negative interaction term coefficients are quite large in magnitude, suggesting that improved varieties - with and without stripe rust resistance - perform notably worse under abiotic stress than traditional varieties. At the same time, especially in model (8), the coefficients of the variety dummies themselves increase in comparison to results in Table 3.6, where these interaction terms were not included.

These results suggest that the improved wheat varieties commonly grown in Ethiopia are yield increasing under favorable production conditions, but not perfectly adapted to drought and other relevant abiotic stresses. The inferior performance of improved varieties under abiotic stress and the growing frequency of weather extremes through climate change may also explain why many farmers recently switched back to growing traditional varieties, as observed in the second round of the survey (see Figure 3.1). The dis-adoption of improved varieties is associated with lower average productivity, as traditional varieties perform worse than improved varieties when there are no extreme production stresses. Combining high yield potential with disease resistance, as successfully done for improved rust-resistant varieties, is one important step towards developing better-adapted high-yielding varieties. Further adding higher tolerance to drought and other abiotic stresses remains an important future challenge for wheat breeding programs.

\subsection{Concluding remarks}

In developing country agriculture, sizeable crop losses due to a wide range of pests and diseases occur. Breeding crops for pest and disease resistance is a sustainable way to reduce such losses without having to increase the use of chemical pesticides. However, in order to make resistant varieties attractive for farmers and really increase effective yields, pest and disease resistance traits have to be combined with other important crop traits such as high yield potential and tolerance to drought and other abiotic stresses. Previous research on the impact of improved crop varieties has mostly looked at yield effects in general, without differentiating between different varietal traits and characteristics. In this study, we have used panel data from wheat farmers in Ethiopia to analyze yield effects of varieties that are resistant to stripe rust. In particular, we have compared yields of improved rust-resistant wheat varieties with yields of improved susceptible and traditional susceptible varieties. 
Production function estimates suggest that the adoption of improved rust-resistant varieties has raised yields by $8 \%$ in comparison to traditional susceptible varieties. Improved susceptible varieties have $6 \%$ higher average yields than traditional varieties, after controlling for other factors. The yield difference between improved resistant and improved susceptible varieties is relatively small, which is largely because the survey data were collected in seasons with only moderate stripe rust infection levels. While wheat rust problems have increased recently in Ethiopia and other countries of East Africa, the survey does not cover seasons with severe stripe rust outbreaks. Rustresistant varieties perform equally well or better than other improved varieties in years with low or moderate rust infection. The above average performance of the rust-resistant improved varieties, relative to the improved susceptible varieties, indicates that breeders were able to combine rustresistance traits with high yield potential successfully. In years with higher rust infection, resistant varieties will likely outperform improved susceptible varieties.

We have also analyzed the performance of improved wheat varieties in plots where abiotic production stresses (e.g., drought, waterlogging) affect yield by using interaction terms. Under abiotic production stresses, improved varieties - with and without stripe rust resistance - perform notably worse than traditional varieties. In other words, the improved wheat varieties commonly grown in Ethiopia are not perfectly adapted to drought and other unfavorable weather conditions. This - together with the fact that the frequency of weather extremes is rising with climate change may explain why many farmers in Ethiopia recently switched back to growing traditional varieties. In order to foster sustainable adoption, traits of high yield potential, disease resistance, grain quality, and tolerance to drought and other abiotic stresses need to be combined in the same varieties. This is a challenge for breeders not only because some of these traits may be negatively correlated in available genetic pools, but also because pathogens evolve so that searching for new plant resistance mechanisms remains a continuous task. Modern biotechnology, including new tools for genome editing, may help to overcome some of the complexities involved.

Our results may contribute to further tailoring breeding programs to the needs of smallholder farmers. Yet, more conceptual and empirical research is needed to better understand the linkages between different types of varietal traits, evolving environmental, climatic, and socioeconomic conditions, farmers' technology adoption behavior, and impacts of technologies on agricultural productivity. 


\subsection{Appendix 3}

Table 3.8. List of improved wheat varieties and levels of stripe rust resistance.

\begin{tabular}{|c|c|c|c|c|}
\hline Variety name & $\begin{array}{l}\text { Level of stripe rust } \\
\text { resistance }\end{array}$ & $\begin{array}{l}\begin{array}{l}\text { Frequency of plots } \\
(\%)\end{array} \\
\end{array}$ & $\begin{array}{l}\text { Year } \\
\text { released }\end{array}$ & $\begin{array}{l}\text { Sources of information for stripe rust } \\
\text { resistance }\end{array}$ \\
\hline Kubsa & Susceptible & 32.18 & 1994 & Alemu et al. (2015) \\
\hline Digelu & Resistant & 19.09 & 2005 & Alemu et al. (2015) \\
\hline Galema & Susceptible & 8.66 & 1995 & Yami et al. (2012) \\
\hline Dashen & Susceptible & 8.34 & 1984 & Bishaw et al. (2014) \\
\hline Pavon & Resistant & 4.58 & 1982 & Yami et al. (2012) \\
\hline Tusie & Resistant & 4.38 & 1997 & Yami et al. (2012) \\
\hline $\begin{array}{l}\text { Dakeba } \\
\text { (Picaflor) }\end{array}$ & Resistant & 4.06 & 2010 & http://wheatatlas.org/ug99 \\
\hline Mada-Walabu & Resistant & 3.91 & 2000 & Alemu et al. (2015) \\
\hline $\begin{array}{l}\text { Dande'a } \\
\text { (Danphe) }\end{array}$ & Resistant & 3.76 & 2010 & http://wheatatlas.org/ug99 \\
\hline ET-13 & Resistant & 3.59 & 1981 & Yami et al. (2012) \\
\hline Enkoye & Susceptible & 1.94 & 1974 & Bishaw et al. (2014) \\
\hline Simba & Resistant & 1.25 & 2000 & Communication with experts from EIAR \\
\hline Wabe & Susceptible & 1.06 & 1994 & Hailu and Fininsa (2017) \\
\hline Hawii & Resistant & 1.06 & 2000 & Yami et al. (2012) \\
\hline Sof-Oumer & Resistant & 0.39 & 2000 & Alemu et al. (2015) \\
\hline Dure & Resistant & 0.39 & 2001 & Alemu et al. (2015) \\
\hline Millennium & Susceptible & 0.37 & 2007 & Alemu et al. (2015) \\
\hline Kulilit/Kulkulit & Resistant & 0.25 & 2009 & Zerihun et al. (2012) \\
\hline Shina & Susceptible & 0.25 & 1999 & Communication with experts from EIAR \\
\hline Menzie & Resistant & 0.07 & 2007 & Zerihun et al. (2012) \\
\hline K6295-4A & Resistant & 0.07 & 1980 & Yami et al. (2012) \\
\hline Sirbo & Resistant & 0.05 & 2001 & Tadesse et al. (2010) \\
\hline Wetera & Susceptible & 0.05 & 2000 & Communication with experts from EIAR \\
\hline Doddota & Susceptible & 0.05 & 2001 & Communication with experts from EIAR \\
\hline Bobitcho & Resistant & 0.05 & 2002 & Communication with experts from EIAR \\
\hline Bollo & Susceptible & 0.02 & 2009 & Zerihun et al. (2012) \\
\hline KGB-01 & Resistant & 0.02 & 1980 & Yami et al. (2012) \\
\hline Obsa & Resistant & 0.02 & 2006 & Communication with experts from EIAR \\
\hline Magala & Susceptible & 0.02 & 1997 & Communication with experts from EIAR \\
\hline Tay & Resistant & 0.02 & 2005 & Communication with experts from EIAR \\
\hline Gasay & Resistant & 0.02 & 2007 & Communication with experts from EIAR \\
\hline
\end{tabular}


Table 3.9. Input interaction terms and district dummies from wheat yield model.

\begin{tabular}{|c|c|c|c|}
\hline Explanatory variables & Coeff/se & Explanatory variables & Coeff/se \\
\hline $0.5 * \log$ of cost of fertilizer squared (fert) & $\begin{array}{c}0.070^{* * * *} \\
(0.024)\end{array}$ & Hitosa (yes=1) & $\begin{array}{c}0.685 * * * \\
(0.101)\end{array}$ \\
\hline $0.5 * \log$ of cost of herbicide squared (herb) & $\begin{array}{c}0.048 \text { *** } \\
(0.018)\end{array}$ & Limuna Bilbilo (yes=1) & $\begin{array}{c}0.584 * * * \\
(0.102)\end{array}$ \\
\hline $0.5 * \log$ of oxen days squared (oxen) & $\begin{array}{l}-0.017 \\
(0.054)\end{array}$ & Munesa (yes=1) & $\begin{array}{c}0.606 * * * * \\
(0.101)\end{array}$ \\
\hline $0.5 *$ labor days squared (labor) & $\begin{array}{c}0.159 * * * \\
(0.029)\end{array}$ & Seru (yes=1) & $\begin{array}{c}0.044 \\
(0.119)\end{array}$ \\
\hline $0.5^{*}$ quantity of manure squared (manure) & $\begin{array}{c}0.022 \\
(0.017)\end{array}$ & Shirka $($ yes $=1)$ & $\begin{array}{c}0.383^{* * * *} \\
(0.100)\end{array}$ \\
\hline $\log$ fert $x \log$ herb & $\begin{array}{l}-0.002 \\
(0.002)\end{array}$ & Sude $($ yes $=1)$ & $\begin{array}{c}0.185 \\
(0.114)\end{array}$ \\
\hline $\log$ fert $x \log$ oxen & $\begin{array}{l}-0.008 \\
(0.007)\end{array}$ & Gasera $($ yes $=1)$ & $\begin{array}{c}0.594 * * * \\
(0.121)\end{array}$ \\
\hline $\log$ fert x log labor & $\begin{array}{l}-0.009 \\
(0.006)\end{array}$ & Goba (yes=1) & $\begin{array}{c}0.180 \\
(0.140)\end{array}$ \\
\hline $\log$ fert $x \log$ manure & $\begin{array}{c}0.000 \\
(0.001)\end{array}$ & Adami Tulu Jido Komb (yes=1) & $\begin{array}{c}0.308^{* * * *} \\
(0.114)\end{array}$ \\
\hline $\log$ herb $x \log$ oxen & $\begin{array}{l}-0.008 \\
(0.012)\end{array}$ & Adea (yes=1) & $\begin{array}{c}0.391 * * * \\
(0.091)\end{array}$ \\
\hline $\log$ herb x log labor & $\begin{array}{c}0.002 \\
(0.008)\end{array}$ & Dugda $($ yes $=1)$ & $\begin{array}{l}0.195^{*} \\
(0.113)\end{array}$ \\
\hline $\log$ herb x log manure & $\begin{array}{l}-0.002 \\
(0.002)\end{array}$ & Lomme $($ yes $=1)$ & $\begin{array}{c}0.438^{* * * *} \\
(0.137)\end{array}$ \\
\hline $\log$ oxen $x \log$ labor & $\begin{array}{l}-0.010 \\
(0.027)\end{array}$ & Mulo (yes=1) & $\begin{array}{c}0.029 \\
(0.112)\end{array}$ \\
\hline $\log$ oxen $x \log$ manure & $\begin{array}{c}0.004 \\
(0.007)\end{array}$ & Qercha (yes=1) & $\begin{array}{c}-0.252^{*} \\
(0.131)\end{array}$ \\
\hline $\log$ labor $x \log$ manure & $\begin{array}{l}-0.005 \\
(0.006)\end{array}$ & Uraga (yes=1) & $\begin{array}{c}-0.275^{* *} \\
(0.138)\end{array}$ \\
\hline Cost of fertilizer is zero (yes $=1$ ) & $\begin{array}{l}-0.087 \\
(0.506)\end{array}$ & Dedo (yes=1) & $\begin{array}{l}-0.045 \\
(0.112)\end{array}$ \\
\hline Cost of herbicide is zero (yes $=1$ ) & $\begin{array}{c}0.056 \\
(0.148)\end{array}$ & Kuyu (yes=1) & $\begin{array}{c}-0.263^{* *} \\
(0.115)\end{array}$ \\
\hline Oxen days is zero (yes $=1$ ) & $\begin{array}{c}0.289 \\
(0.234)\end{array}$ & Wuchale (yes=1) & $\begin{array}{l}-0.138 \\
(0.114)\end{array}$ \\
\hline Quanitity of manure is zero (yes $=1$ ) & $\begin{array}{l}-0.001 \\
(0.372)\end{array}$ & Wonchi (yes=1) & $\begin{array}{l}-0.084 \\
(0.116)\end{array}$ \\
\hline Awabel (yes=1) & $\begin{array}{c}0.217 * * \\
(0.108)\end{array}$ & Adaba (yes=1) & $\begin{array}{c}0.240^{* *} \\
(0.106)\end{array}$ \\
\hline Enarj Enawga (yes=1) & $\begin{array}{c}0.075 \\
(0.138)\end{array}$ & Arsi Negele $($ yes $=1)$ & $\begin{array}{c}0.452^{* * * *} \\
(0.098)\end{array}$ \\
\hline Enemay (yes=1) & $\begin{array}{l}0.242^{*} \\
(0.131)\end{array}$ & Dodola $($ yes $=1)$ & $\begin{array}{c}0.517 * * * \\
(0.101)\end{array}$ \\
\hline Goncha Siso Enese (yes=1) & $\begin{array}{l}0.173^{*} \\
(0.094)\end{array}$ & Gedeb Asasa (yes=1) & $\begin{array}{c}0.704 * * * \\
(0.109)\end{array}$ \\
\hline Huletej Enese (yes=1) & $\begin{array}{c}0.068 \\
(0.105)\end{array}$ & Shashemene $($ yes=1) & $\begin{array}{c}0.381 * * * \\
(0.108)\end{array}$ \\
\hline Angolelana Tera (yes=1) & $\begin{array}{l}0.219^{*} \\
(0.112)\end{array}$ & Adea Berga $($ yes=1) & $\begin{array}{l}0.160^{*} \\
(0.096)\end{array}$ \\
\hline Basona Werana (yes=1) & $\begin{array}{c}0.231 * * \\
(0.101)\end{array}$ & Gende Beret (yes=1) & $\begin{array}{c}0.108 \\
(0.114)\end{array}$ \\
\hline Menz Gera Meder (yes=1) & -0.025 & Meskan $($ yes=1) & 0.008 \\
\hline
\end{tabular}




\begin{tabular}{|c|c|c|c|}
\hline Explanatory variables & Coeff/se & Explanatory variables & Coeff/se \\
\hline \multirow{3}{*}{ Menz Mama Meder (yes=1) } & $(0.109)$ & & $(0.126)$ \\
\hline & 0.032 & Sodo $($ yes=1) & $0.248^{* *}$ \\
\hline & $(0.133)$ & & $(0.112)$ \\
\hline \multirow[t]{2}{*}{ Bugna (yes=1) } & $0.388 * * *$ & Soro $($ yes=1) & 0.031 \\
\hline & $(0.125)$ & & $(0.107)$ \\
\hline \multirow[t]{2}{*}{ Meket (yes=1) } & 0.066 & Kedida Gamela (yes $=1$ ) & $-0.374 * * *$ \\
\hline & $(0.117)$ & & $(0.129)$ \\
\hline \multirow[t]{2}{*}{ Kay Gayint (yes=1) } & -0.052 & Hula (yes=1) & -0.157 \\
\hline & $(0.144)$ & & $(0.154)$ \\
\hline \multirow[t]{2}{*}{ Misrak Este $($ yes=1) } & $-0.225^{*}$ & Halaba S/district $($ yes=1) & 0.124 \\
\hline & $(0.129)$ & & $(0.202)$ \\
\hline \multirow[t]{2}{*}{ Debresina (yes=1) } & $-0.291 * * *$ & Yem special $($ yes $=1)$ & $-0.244 * *$ \\
\hline & $(0.095)$ & & $(0.113)$ \\
\hline \multirow[t]{2}{*}{ Delanta $($ yes=1) } & 0.083 & Degua Temben $($ yes=1) & 0.146 \\
\hline & $(0.120)$ & & $(0.171)$ \\
\hline \multirow[t]{2}{*}{ Sayint $($ yes $=1$ ) } & -0.083 & Werei Leke (yes=1) & 0.179 \\
\hline & $(0.101)$ & & $(0.113)$ \\
\hline \multirow[t]{2}{*}{ Were Ilu (yes=1) } & 0.158 & Saese Tsaeda Emba $($ yes $=1)$ & 0.085 \\
\hline & $(0.103)$ & & $(0.107)$ \\
\hline \multirow[t]{2}{*}{ Wogidi (yes=1) } & $-0.267 * *$ & Enderta $($ yes=1) & 0.172 \\
\hline & $(0.114)$ & & $(0.176)$ \\
\hline \multirow[t]{2}{*}{ Bure (yes=1) } & $0.256^{*}$ & Ofla $($ yes=1) & $0.513 * * *$ \\
\hline & $(0.131)$ & & $(0.111)$ \\
\hline \multirow[t]{2}{*}{ Sekela $($ yes=1) } & -0.078 & Dabat (yes=1) & 0.025 \\
\hline & $(0.109$ & & $(0.113)$ \\
\hline \multirow[t]{2}{*}{ Arsi-Robe $($ yes=1) } & 0.021 & & \\
\hline & $(0.106)$ & & \\
\hline
\end{tabular}

Notes: These estimates belong to model (5) in Table 3.6 with the logarithm of wheat yield $(\mathrm{kg} / \mathrm{ha})$ as the dependent variable. Coefficient estimates are shown with cluster-corrected standard errors in parentheses. The base category for the district dummies is Ankasha Guagusa. *** $p<0.01 ; * * p<0.05 ; * p<0$. 


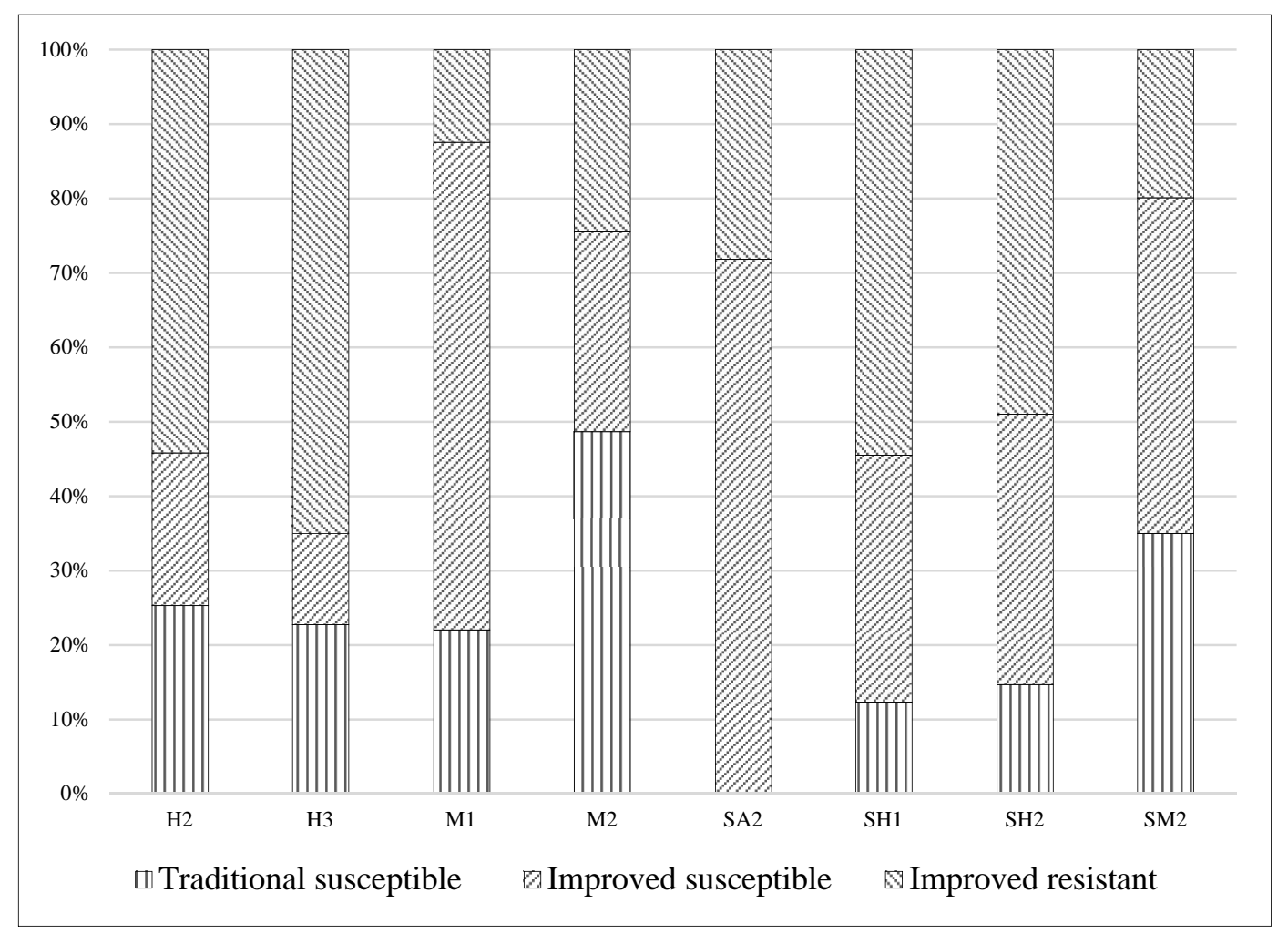

Figure 3.5. Plot level adoption of varieties by agroecology (both survey rounds).

Notes: H2, tepid to cool humid mid-highlands ( $\mathrm{n}=888$ ); H3, cold to very cold humid sub-Afro-Alpine ( $\mathrm{n}=107)$; M1, hot to warm moist lowlands ( $\mathrm{n}=143)$; M2, tepid to cool moist mid-highlands $(\mathrm{n}=1350)$; SA2, tepid to cool semi-arid mid highlands $(\mathrm{n}=62)$; SH1, hot to warm sub-humid lowlands ( $\mathrm{n}=219$ ); $\mathrm{SH}$ 2, tepid to cool sub-humid mid highlands ( $\mathrm{n}=668$ ); SM2, tepid to cool sub-moist mid highlands $(\mathrm{n}=1314)$. 


\section{The impact of using fresh seeds on land productivity and efficiency: evidence from smallholder agriculture in Ethiopia $^{14}$}

\subsection{Introduction}

In smallholders agriculture, farmers use seed choice as a key ex ante risk management strategy to protect production losses from shocks and improving productivity (Fisher et al., 2015; Shiferaw et al., 2011, 2014a). Seed choice could be of varietal replacement or seed replacement decision. Varietal replacement is a decision to shift from using traditional or improved varieties to newly released varieties in order to obtain a new improved genetic material that substantially increase productivity and avoid production losses. Seed replacement decision is either to use fresh seeds or recycled seeds of the same varieties by replanting saved seeds from the previous harvest (Heisey and Brennan, 1991; Morris et al., 1999; Smale et al., 2013; Spielman and Smale, 2017).

Fresh seeds purchased from seed producers are genetically pure seeds with low chance of contamination with weeds, diseases and other foreign matters (Morris et al., 1999). The advantage of using fresh seeds is to keep the productivity advantage of the old varieties when these varieties were initially released by breeders (Spielman and Smale, 2017). Fresh seeds might also be responsive to external inputs and withstand stresses (Byerlee, 1996; Fisher et al., 2015; Gollin et al., 2005). Using fresh seeds may thus make farmers not only productive but also efficient in inputs use, which may in turn contribute to food security even without introducing new improved varieties. However, both productivity and efficiency benefits might not be always obtained. Tradeoffs in productivity and efficiency may prevail. For example, new strains of diseases may overcome the fresh seeds' resistance to diseases that may lead to production losses. Despite the fact that fresh seeds have higher productivity on average, production losses associated with emerging new diseases may make farmers less efficient for a given level of inputs. In such cases, quantifying potential

\footnotetext{
${ }^{14}$ Chapter 4 is a joint work with Bethelhem Legesse Debela (BLD). Zewdu Ayalew Abro and BLD developed the research idea. ZAA analyzed the data and wrote the first draft of the manuscript. BLD commented on the data analysis and contributed to writing the paper. We would like to thank Dr. Menale Kassie for his comments and suggestions when we developed the research ideas.
} 
tradeoffs in land productivity and efficiency helps to tailor policy towards strategies that increase productivity at most efficiency.

The practice of seed recycling, which is common in many developing countries, may lead to changes in genetic composition of the seeds reducing productivity (Morris et al., 1999). However, some studies show that seed recycling, even for hybrid varieties, might be rational because it is found profitable (Japhether et al., 2006; Macharia et al., 2010; Nkonya and Mwangi, 2004; Pixley and Bänziger, 2004; Wanyama et al., 2006). One advantage of using recycled seeds is that it brings stable yields across seasons (Japhether et al., 2006; Morris et al., 1999). Stable yields in turn may mean that farmers have a reasonable expectation about the productivity of their fields so that they can make appropriate investment on inputs. Using saved seeds obtained through seed recycling may also make farmers seed self-sufficient. Seed self-sufficiency may particularly be important in many developing countries where the seed industry is weak and inefficient (Sisay et al., 2017; Spielman and Smale, 2017). By using recycled seeds, farmers may avoid delays on the arrival of fresh seeds, which may enable them to exploit the available soil moisture by planting on time. Consequently, productivity and efficiency of famers may improve, and hence their profitability.

Whether fresh seeds or recycled seeds provide the highest land productivity and efficiency gains is an empirical question. In this chapter, our objective is to analyze the impact of fresh seeds, in comparison to recycled seeds, on land productivity and efficiency in maize producing districts in Ethiopia. Many studies analyze the impact of improved varieties (i.e. farmers' varietal replacement decisions) on land productivity (Amare et al., 2012; Bezu et al., 2014; Kassie et al., 2015b; Khonje et al., 2015; Manda et al., 2016; Suri, 2011; Teklewold et al., 2013b; Zeng et al., 2015). Others studied the impact of improved varieties on efficiency (Alene and Hassan, 2006; Alene and Manyong, 2006; Battese et al., 2017; Dhungana et al., 2004; Kalirajan, 1991; Kalirajan and Shand, 2001; Xu and Jeffrey, 1998). However, no rigorous studies exist on the impact of using fresh seeds on land productivity and efficiency. Our first contribution to the literature is therefore providing rigorous assessment on the productivity and efficiency implications of using fresh seeds relative to recycled seeds. Understanding the productivity and efficiency advantages of fresh seeds and recycled seeds helps policy makers in designing efficient investment strategies on breeding for new improved varieties and seed multiplication of existing varieties.

We also contribute by addressing two important shortcomings of the previous literature on new improved varieties in relation to land productivity and efficiency. First, the previous studies that analyzed the impact of new improved varieties on land productivity implicitly assume that farmers 
are equally efficient (Coelli et al., 2005; Kumbhakar et al., 2015). This is because these studies estimate production functions that do not account for inefficiency. Since part of the variation in land productivity is explained by differences in efficiency, the estimated impact of new improved varieties on land productivity might be over- or underestimated. Second, some of the studies on efficiency assume identical seed technology. That is, they assume farmers use homogenous seed types (Dhungana et al., 2004; Kalirajan, 1991; Kalirajan and Shand, 2001). The identical seed technology assumption might be disputed because of farmers' seed recycling behavior as documented in many studies (Evenson and Gollin, 2003; Walker and Alwang, 2015). Other studies on efficiency do not address seed recycling behavior of farmers (Alene and Hassan, 2006; Battese et al., 2017; Xu and Jeffrey, 1998). If farmers' seed choice behavior is heterogeneous, failure to control for such heterogeneity might bias the estimates of the production function. We estimate the impact of fresh seeds on both land productivity and efficiency simultaneously using endogenous switching random effects production functions. We use a comprehensive panel household survey data. We control for the heterogeneous effects of seed choice using a more detailed classification of maize seeds based on the number of seasons seeds are recycled.

The rest of the chapter is structured as follows. In Section 2, we briefly describe the data. In Section 3, we present the econometric methods while we present the results in Section 4. In Section 5, we make concluding remarks.

\subsection{Data}

We use two rounds of panel household survey data collected by the International Maize and Wheat Improvement Center (CIMMYT) and the Ethiopian Institute of Agricultural Research (EIAR) in 2010 and 2013. ${ }^{15}$ The survey covers the 2009/10 and 2012/13 cropping calendars. It is representative of the major rain fed maize producing districts of Ethiopia. In the first stage of the sampling procedure, 39 districts were purposively selected based on the districts' maize production potential. Sample villages and households were selected using a multistage proportionate random sampling. The number of households interviewed was 2,468. The total number of plots is approximately 30,000 in both rounds. Our analysis focuses on maize production because detailed

\footnotetext{
${ }^{15}$ The data used in this research is funded by MAIZE Consortium Research Program (Maize CRP) and the Australian Centre for International Agricultural Research (ACIAR) through the International Maize and Wheat Improvement Center (CIMMYT)-led Sustainable Intensification of Maize-Legume Cropping Systems for Food Security in Eastern and Southern Africa (SIMLESA) program, and the Adoption Pathways Project. The dataset were accessed as part of the consultancy work by Bethelhem Legesse Debela at CIMMYT under the supervision of Dr. Menale Kassie.
} 
data on seed use for other crops are unavailable. The sample households cultivated 8,189 maize plots (4,305 plots in 2009/10 and 3,884 plots in 2012/13). We drop observations that have missing values for some of the key variables in our analysis. In the end, we use 7,794 plots cultivated by 2,394 households. The data show that $4 \%$ of the households did not produce maize in one of the two rounds.

Using a structured questionnaire, detailed information on household level socioeconomic and demographic factors, community characteristics, volume of production, seeds, and production constraints were collected. Farmers were asked if they have used fresh seeds bought from formal maize seed distributors or they used recycled seeds. If farmers recycle seeds, we have solicited for the number of seasons the seeds were recycled. We classify the recycled seeds into seeds recycled between 1 and 3 seasons (hereafter recycled seeds (1-3 seasons)), and seeds recycled for more than 3 seasons (hereafter recycled seeds ( $>3$ seasons)). This classification is based on the recommended practices of breeders who suggested that the number of seasons seeds recycled is an important indicator for the performance of varieties (Zeng et al., 2015). In our data, farmers reported that seeds of hybrids varieties, open pollinated varieties (OPVs) and traditional varieties were recycled. Throughout our analysis, we control for productivity differences in hybrid varieties, OPVs, and traditional varieties.

\subsection{Econometric strategy}

Our objective is to estimate the land productivity and efficiency implications of using fresh seeds. While the measure of land productivity comes from the data, quantity produced per hectare (yield), we obtain farmers' efficiency indicator from the econometric model. We estimate the production function using a random effects model following recent developments in estimating efficiency using panel data (Greene, 2005a, 2005b; Kumbhakar et al., 2015). Then, we recover an efficiency estimate by using the unobserved heterogeneity indicator of the random effects model. We opt to use this approach to estimate efficiency instead of the commonly used Stochastic Frontier Analysis (SFA) because the predicted land productivity estimates would have been based on the efficient frontier in SFA approach. Hence, results would not show the impact of using fresh seeds on land productivity to the average farmers. Our approach therefore enables us to examine the impact of fresh seeds on land productivity and efficiency on the average farmers as opposed to the efficient farmers. 
The within variation in our data is lower than the between variation in almost all the variables suggesting that random effects is more efficient than fixed effects because it uses the weighted average of the between and within variation in the data. Using fixed effects approach would also mean losing $4 \%$ of our sample that exist only in either of the two survey years. For these two reasons, we estimate the random effects in a switching regression treatment effects approach. Using switching regression approach is justified by the Chow test. We reject the null hypothesis that the coefficients of each group are the same: $F$ statistic $[F(32,6,306)=2.72 ; p$-value $=0.000)$ and $(F(32$, $6,748)=4.44 ; p$-value $=0.000]$. The test results show that seed choice and land productivity have a non-linear relationship. In the next three subsections, we introduce our estimation approach.

\subsubsection{Endogenous switching random effects production function}

As briefly described in Section 2, we have three types of seeds: fresh seeds, recycled seeds (1-3 seasons), and recycled seeds ( $>3$ seasons). We estimate the random effects production function to each seed type in three regimes as specified in equation (4.1a-4.1c). ${ }^{16}$

$$
\begin{aligned}
& \text { Regime 1: } Y_{1}=\boldsymbol{X}_{1} \beta_{1}+\gamma_{1} \hat{\lambda}_{1}+u_{1 j}+\varepsilon_{1 i j} \text { if } A=1 \\
& \text { Regime 2: } Y_{2}=\boldsymbol{X}_{2} \beta_{2}+\gamma_{2} \hat{\lambda}_{2}+u_{2 j}+\varepsilon_{2 i j} \text { if } A=2 \\
& \text { Regime 3: } Y_{3}=\boldsymbol{X}_{3} \beta_{3}+\gamma_{3} \hat{\lambda}_{3}+u_{3 j}+\varepsilon_{3 i j} \text { if } A=3
\end{aligned}
$$

where $A=1,2,3$ indicates fresh seeds, recycled seeds (1-3 seasons), and recycled seeds ( $>3$ seasons), respectively. $Y_{A}$ represents logarithm of land productivity (kg/ha) of plot $i$ and household $j$ at time t. $\boldsymbol{X}_{A}$ is a vector of inputs (labor days, expenses on fertilizers, expenses on other agrochemicals, and quantity of manure $)^{17}$; household level variables (e.g., education, gender, oxen ownership and other assets); plot level characteristics (e.g., slope, color of the soil, crop rotation practices, and the presence of various production stresses); district dummy variables to control for differences in unobserved district level factors that may affect farmers' preferences and a dummy variable for

\footnotetext{
${ }^{16}$ We avoid notational cluttering by suppressing the subscripts referring to plot $i$, household $j$, and time $t$ of the dependent and independent variables.

${ }^{17}$ The inputs are measured in per hectare terms. They are also mean-centered $\left(\log \left(X_{i}-\log \bar{X}\right)\right.$ so that the first order estimated coefficients of the translog production function are interpreted as production elasticities at the sample mean.
} 
survey year controlling for time effects. Farmers did not use fertilizers, manure, and other agrochemicals (herbicide and pesticides) in several plots. When we take the logarithm of these input quantities, the zeros are undefined. We replace undefined values by zero after taking the logarithms, and in order to address potential estimation bias, Battese intercept shifting dummy variables (0 if zero inputs are used, 1 otherwise) is controlled in the regressions (Battese, 1997). The explanatory variables are chosen carefully in order to capture potential heterogeneities across plots and households. The variables used and their descriptions are reported in Table 4.1. Equations (4.1a4.1c) are translog production functions because the coefficients of input interaction terms are significantly different from zero in all equations (see at the bottom of Table 4.8, Appendix 4).

$\gamma_{A}$ and $\beta_{A}$ are parameters to be estimated. $u_{A j}$ represents the time invariant unobserved heterogeneity and $\varepsilon_{A i j}$ refers to random error terms with mean 0 and constant variance for household j. $\varepsilon_{A i j}$ and $u_{A j}$ are assumed not only independent of each other but also independent of $\boldsymbol{X}_{A}$. This assumption is strong because there might be plot-specific unobservables such as missing information regarding land quality (Abro et al., 2018; Kassie et al., 2015b). We relax this assumption by using the Mundlak's fixed effects approach by including the household level averages of all plot-varying observations in equations (4.1a-4.1c). In the Mundlak's approach, the time invariant unobserved heterogeneity $\left(u_{A j}\right)$ is assumed to be a linear function of the averages of plot-varying explanatory variables $(\overline{\boldsymbol{M}}), u_{A j}=\theta \overline{\boldsymbol{M}}+\tau_{j}$ with $\tau_{j} \sim \operatorname{IID}\left(0, \sigma^{2}\right)$, where $E\left(\gamma_{j} \mid \bar{M}\right)=0$ and $\theta$ is the corresponding vector of coefficients, and $\tau_{j}$ is a normally distributed error term uncorrelated with $\overline{\boldsymbol{M}}$ (Di Falco and Veronesi, 2014; Mundlak, 1978).

The Mundlak's fixed effects procedure controls for time invariant unobserved heterogeneity, but it does not address the potential problem of time-varying unobserved factors that may affect seed choice, which is represented by $\hat{\lambda}_{A}$ (Di Falco and Veronesi, 2014; Kassie et al., 2015b). Farmers may not use a certain seed type unless the chosen seeds have gains in productivity. We estimate the land productivity equations of the three seed types by taking observed and unobserved factors that affect seed choice into account. We model the determinants of seed choice $\left(\mathrm{A}_{i j k}\right)$ in plot $i$ of the $j$ th household and seed type $k$ using the multinomial logistic model (MNL). Using the standard procedure of obtaining inverse Mill's ratio, we obtain $\hat{\lambda}_{A}$ from the MNL and include it as explanatory variable in equations (4.1a-4.1c) (Bourguignon et al., 2006; Kassie et al., 2015b; Teklewold et al., 2013b). 
In addition to the non-linear selection terms $\left(\hat{\lambda}_{A}\right)$, estimating equations (4.1a-4.1c) requires exclusion restrictions. The exclusion restrictions should be exogenous explanatory variables that correlate with seed choice and uncorrelated with land productivity (Di Falco et al., 2011). We exclude distance to markets and distance to seed information sources in the production functions in equations (4.1a-4.1c). Distance to markets and information sources were used as exclusion restrictions in many studies (Di Falco et al., 2011; Kassie et al., 2015b; Suri, 2011; Zeng et al., 2015). Zeng et al. (2015) argue that once the intensity of inputs and plot characteristics are controlled for in the production function, distance variables related to market access and information sources may affect land productivity only through seed choice. Following Kassie et al. (2015) and the above-mentioned argument of Zeng et al. (2015), we also exclude variables on farmers' social networks and farmers' perception about the skill of government officials. We expect that farmers' perception on the presence of seed constraints (seed availability, price and quality) affect what kind of seeds they should use in their fields but not actual productivity. We therefore exclude these variables in the production function. In Panel F of Table 4.1, we show the definitions of the excluded variables.

As expected, the excluded variables are jointly different from zero $\left(\chi^{2}(24)=58.73\right.$; $p$-value $\left.=0.001\right)$ in the MNL model (Table 4.7, Appendix 4). Furthermore, a simple falsification test following Di Falco et al. (2011) shows that the exclusion restrictions are not jointly significant in two of the three switching regressions. For the models with recycled seeds (1-3 seasons) and recycled seeds (>3 seasons), the exclusion restrictions are insignificant $\left(\chi^{2}(15)=11.35 ; \mathrm{p}\right.$-value $=0.499$ and $\chi^{2}(15)=17.38 ; \mathrm{p}$-value $=0.121$, respectively) supporting the validity of the instruments. However, the significant falsification test for fresh seeds, $\left(\chi^{2}(15)=48.00\right.$; $p$-value $\left.=0.001\right)$, may indicate that the instruments may tend to affect both seed choice and land productivity. As a robustness check, we estimate two variants of exogenous switching regressions. In the first variant of the exogenous switching regressions, we estimate our models without including the inverse Mill's ratio $(\hat{\lambda})$ in equations (4.1a-4.1c). In the second variant of the exogenous switching regressions, we exclude $\hat{\lambda}$ and include the exclusion restrictions as explanatory variables in equations (4.1a-4.1c). 
Table 4.1. Descriptions and summary statistics of variables.

Panel A: Outcome variables

\begin{tabular}{|c|c|c|c|c|c|}
\hline Yield & Maize yield (kg/ha) & 2346 & 1873 & 4 & 12800 \\
\hline \multicolumn{6}{|l|}{ Panel B: Inputs } \\
\hline Labor & Labor days per hectare & 106 & 70 & 2 & 466 \\
\hline Total labor & Total labor (days) & 35 & 38 & 0 & 1451 \\
\hline Fertilizers & Expenses on fertilizers (Birr/ha) & 1245 & 1672 & 0 & 12423 \\
\hline Used fertilizers & 1 if the farmers used fertilizers in the plot, 0 otherwise & 0.60 & & 0 & 1 \\
\hline Other agrochemicals & Expenses on herbicides and pesticides (Birr/ha) & 19 & 109 & 0 & 3000 \\
\hline Used other agrochemicals & 1 if the farmers used herbicides and pesticides in the plot, 0 otherwise & 0.13 & & 0 & 1 \\
\hline Manure & Quantity of manure $(\mathrm{kg} / \mathrm{ha})$ & 423 & 1014 & 0 & 6410 \\
\hline Used manure & 1 if the farmers used manure in the plot, 0 otherwise & 0.29 & & 0 & 1 \\
\hline Battese fertilizers & 1 if fertilizers were not used in the plot, 0 otherwise & 0.40 & & 0 & 1 \\
\hline Battese other agrochemicals & 1 if other agrochemicals were not used in the plot, 0 otherwise & 0.87 & & 0 & 1 \\
\hline Battese manure & 1 if other manure was not used in the plot, 0 otherwise & 0.71 & & 0 & 1 \\
\hline Hybrids & 1 if the varieties are hybrids, 0 otherwise & 0.64 & & 0 & 1 \\
\hline OPVs & 1 if the varieties are open pollinated varieties, 0 otherwise & 0.06 & & 0 & 1 \\
\hline Unidentified & 1 if the official names of the varieties are unknown, 0 otherwise & 0.09 & & 0 & 1 \\
\hline Locals & 1 if local varieties, 0 otherwise & 0.21 & & 0 & 1 \\
\hline Compost & 1 if compost was used in the plot, 0 otherwise & 0.04 & & 0 & 1 \\
\hline Oxen ownership & 1 if the household owns one or more ploughing oxen, 0 otherwise & 0.83 & & 0 & 1 \\
\hline Intercropping & 1 if intercropping was practiced in the plot, 0 otherwise & 0.15 & & 0 & 1 \\
\hline No rotation & 1 if mono-cropping was practiced, 0 otherwise & 0.66 & & 0 & 1 \\
\hline Legume rotation & 1 if rotating with legumes were practiced, 0 otherwise & 0.06 & & 0 & 1 \\
\hline Cereals rotation & 1 if rotating with cereals were practiced, 0 otherwise & 0.29 & & 0 & 1 \\
\hline Crop residue & 1 if crop residues \& stubble left on the plot, 0 otherwise & 0.22 & & 0 & 1 \\
\hline Own seed & 1 if the farmers used their own seeds, 0 otherwise & 0.37 & & 0 & 1 \\
\hline Flat slope & 1 if the plot is gently sloped (flat), 0 otherwise & 0.68 & & 0 & 1 \\
\hline Medium slope & 1 if the plot is medium sloped, 0 otherwise & 0.28 & & 0 & 1 \\
\hline Steep slope & 1 if the plot is steep sloped, 0 otherwise & 0.04 & & 0 & 1 \\
\hline Shallow & 1 if the depth of the soil is shallow, 0 otherwise & 0.20 & & 0 & 1 \\
\hline Medium depth & 1 if the depth of the soil is medium, 0 otherwise & 0.30 & & 0 & 1 \\
\hline Deep & 1 if the depth of the soil is deep, 0 otherwise & 0.49 & & 0 & 1 \\
\hline Black & 1 if the color of the soil is black, 0 otherwise & 0.26 & & 0 & 1 \\
\hline Brown & 1 if the color of the soil is brown, 0 otherwise & 0.24 & & 0 & 1 \\
\hline Red & 1 if the color of the soil is red, 0 otherwise & 0.41 & & 0 & 1 \\
\hline Gray & 1 if the color of the soil is grey and others, 0 otherwise & 0.09 & & 0 & 1 \\
\hline Good soil fertility & 1 if the fertility of the soil is good, 0 otherwise & 0.50 & & 0 & 1 \\
\hline
\end{tabular}




\begin{tabular}{|c|c|c|c|c|c|}
\hline Variables & Description and measurement & Mean & Std. Dev. & Min & Max \\
\hline Medium soil fertility & 1 if the fertility of the soil is medium, 0 otherwise & 0.43 & & 0 & 1 \\
\hline Poor soil fertility & 1 if the fertility of the soil is poor, 0 otherwise & 0.07 & & 0 & 1 \\
\hline \multicolumn{6}{|c|}{ Panel D: Production stresses } \\
\hline Drought & 1 if the farmer faced incidence of drought in the plot, 0 otherwise & 0.20 & & 0 & 1 \\
\hline Waterlogging & 1 if the farmer faced incidence of waterlogging in the plot, 0 otherwise & 0.02 & & 0 & 1 \\
\hline Abiotic stress & 1 if the farmer faced incidence of other abiotic stresses (e.g., frost), 0 otherwise & 0.02 & & 0 & 1 \\
\hline Pests & 1 if the farmer faced incidence of pests in the plot, 0 otherwise & 0.20 & & 0 & 1 \\
\hline Disease & 1 if the farmer faced incidence of wheat diseases in the plot, 0 otherwise & 0.02 & & 0 & 1 \\
\hline Rented & 1 if the plot was rented in, 0 otherwise & 0.05 & & 0 & 1 \\
\hline Plot size & Plot size (ha) & 0.41 & 0.39 & 0 & 5 \\
\hline Plot distance & Plot distance from home (walking minutes) & 11.10 & 21.72 & 0 & 310 \\
\hline Male & 1 if the sex of the household head is male, 0 if female & 0.94 & & 0 & 1 \\
\hline Age & Age of the head of the household (years) & 43.47 & 12.55 & 20 & 96 \\
\hline Illiterate & 1 if the head of the household is illiterate, 0 otherwise & 0.38 & & 0 & 1 \\
\hline School $>=2 \&<6$ & 1 if the head of the household attended school between two and six years, 0 otherwise & 0.44 & & 0 & 1 \\
\hline School $>=6$ & 1 if the head of the household completed more than six years of schooling, 0 otherwise & 0.17 & & 0 & 1 \\
\hline Training & 1 if farmers received any training in the previous season, 0 otherwise & 0.97 & & 0 & 1 \\
\hline Low asset & 1 if the household is in low asset quartile, 0 otherwise & 0.47 & & 0 & 1 \\
\hline Middle asset & 1 if the household is in middle asset quartile, 0 otherwise & 0.21 & & 0 & 1 \\
\hline High asset & 1 if the household is in high asset quartile, 0 otherwise & 0.32 & & 0 & 1 \\
\hline Survey year & 1 if the survey year is 2013,0 if 2010 & 0.48 & & 0 & 1 \\
\hline \multicolumn{6}{|c|}{ Panel F: Variables used as exclusion restrictions } \\
\hline Distance to seed dealers & Distance to the nearest seed dealer (walking minutes) & 49.13 & 55.46 & 0 & 890 \\
\hline Distance to main market & Distance to the main market (walking minutes) & 95.41 & 77.25 & 0 & 2103 \\
\hline Distance to ag ext office & Distance to the nearest extension office (walking minutes) & 30.19 & 29.27 & 0 & 303 \\
\hline Distance to fert dealers & Distance to the nearest fertilizer dealers (walking minutes) & 48.94 & 57.76 & 0 & 1201 \\
\hline Distance to coops & Distance to the nearest cooperatives (walking minutes) & 48.69 & 49.74 & 0 & 640 \\
\hline Leadership & 1 if friends or relatives in leadership position in or outside the village, 0 otherwise & 0.55 & & 0 & 1 \\
\hline Kinship & Number of relatives and non-relatives the head of the household relies on & 30.73 & 49.71 & 0 & 930 \\
\hline No of traders & Number of traders the farmers know & 5.45 & 7.21 & 0 & 198 \\
\hline Confidence & 1 if the head of the household is confident of the skills of government officials, 0 otherwise & 0.69 & & 0 & 1 \\
\hline Seed not available on time & 1 if the head of the household thinks that on-time availability of seeds was a seed access constraint, 0 otherwise & 0.52 & & 0 & 1 \\
\hline High seed price & 1 if the head of the household thinks that seed prices was a seed access constraint, 0 otherwise & 0.79 & & 0 & 1 \\
\hline Low seed quality & 1 if the head of the household thinks that low seed quality was a seed access constraint, 0 otherwise & 0.47 & & 0 & 1 \\
\hline
\end{tabular}




\subsubsection{Efficiency prediction}

Panel data models use the time invariant unobserved heterogeneity $\left(\widehat{u}_{\jmath}\right)$ in order to drive measures of efficiency (Carey, 2000; Greene, 2005a, 2005b; Johnes, 2006; Kumbhakar et al., 2015). The efficiency measure is technical efficiency, which shows the extent of farmers' level of efficiency in producing a maximum output given a certain quantity of inputs. In estimating the models, we assume time invariant efficiency because the panel structure of our data is only at the household level. Estimating time varying efficiency model requires plot level panel data. That said, significant efficiency differences might not be expected between 2009/10 and 2012/13. One may also argue that $\widehat{u_{\jmath}}$ may carry not only inefficiency but also household specific heterogeneity (Greene, 2005b). In order to account for this, we control for as many important explanatory variables as possible so that heterogeneities other than inefficiency across households are minimized. We also expect that heterogeneities may not be high since production activities are undertaken in an open space where each farmer has a great deal of information about what the neighbors do. Thus, treating $\widehat{u_{j}}$ as a measure of inefficiency may not be a strong assumption. We estimate the time invariant unobserved heterogeneity $\left(\widehat{u}_{j}\right)$ using the best linear unbiased predictor (BLUP) (Kumbhakar et al., 2015; RabeHesketh and Skrondal, 2012) as shown in equation (4.2).

$$
\widehat{u_{J}}=\left\{\frac{n_{j} \widehat{\sigma}_{u}^{2}}{\hat{\sigma}_{\varepsilon}^{2}+n_{j} \widehat{\sigma}_{u}^{2}}\right\} \frac{\sum_{i}\left(y_{i j}-\hat{y}_{i j}\right)}{n_{j}}
$$

where $\hat{\sigma}_{u}^{2}$ is the estimated variance of the unobserved time invariant heterogeneity $\left(\widehat{u}_{\jmath}\right)$ of household $j$ and $\hat{\sigma}_{\varepsilon}^{2}$ is the estimated variance for the plot level residual error terms $\left(\varepsilon_{A i j}\right)$ of plot $i$ and household $j . n_{j}$ is the number of plots within household $j . \hat{y}_{i j}$ is the predicted value of land productivity of plot $i$ and household $j$. Using $\widehat{u_{j}}$, we calculate the efficiency of farmers $\left(T E_{j}\right)$ using equation (3) (Carey, 2000; Johnes, 2006; Kumbhakar et al., 2015).

$$
\widehat{T E}_{J}=e^{-\left(\max \left(\widehat{u_{J}}\right)-\widehat{u_{J}}\right)}
$$




\subsubsection{Counterfactual analysis}

After controlling for the effects of potential selection bias and explanatory variables, we obtain the actual sample and counterfactual conditional expectations for both land productivity and efficiency using equations (4.4a-4.4g) (Di Falco and Veronesi, 2014).

$$
\begin{aligned}
& E\left(Y_{1} \mid A=1\right)=\beta_{1} \boldsymbol{X}_{1}+\gamma_{1} \hat{\lambda}_{1} \\
& E\left(Y_{2} \mid A=2\right)=\beta_{2} \boldsymbol{X}_{2}+\gamma_{2} \hat{\lambda}_{2} \\
& E\left(Y_{3} \mid A=3\right)=\beta_{3} \boldsymbol{X}_{3}+\gamma_{3} \hat{\lambda}_{3} \\
& E\left(Y_{2} \mid A=1\right)=\beta_{2} \boldsymbol{X}_{1}+\gamma_{2} \hat{\lambda}_{1} \\
& E\left(Y_{3} \mid A=1\right)=\beta_{3} \boldsymbol{X}_{1}+\gamma_{3} \hat{\lambda}_{1} \\
& E\left(Y_{1} \mid A=2\right)=\beta_{1} \boldsymbol{X}_{2}+\gamma_{1} \hat{\lambda}_{2} \\
& E\left(Y_{1} \mid A=3\right)=\beta_{1} \boldsymbol{X}_{3}+\gamma_{1} \hat{\lambda}_{3}
\end{aligned}
$$

Equations (4.4a-4.4c) are the expected outcomes observed in the sample. Equations (4.4d-4.4e) are the expected counterfactual outcomes had the farmers who used recycled seeds in their plots had used fresh seeds. Equations (4.4f-4.4g) are the expected counterfactual outcomes had the farmers who used fresh seeds in their plots had used recycled seeds. All the other variables are as defined in equations (4.1a-4.1c).

The average treatment effects on the treated (ATTs) and the average treatment effects on the untreated (ATUs) are estimated in equations (4.5a-4.5b) and (4.5c-4.5d), respectively.

$$
\begin{aligned}
& \operatorname{ATT}_{1}=E\left(Y_{1} \mid A=1\right)-E\left(Y_{2} \mid A=1\right)=\left(\beta_{1}-\beta_{2}\right) X_{1}+\left(\gamma_{1}-\gamma_{2}\right) \hat{\lambda}_{1} \\
& \operatorname{ATT}_{2}=E\left(Y_{1} \mid A=1\right)-E\left(Y_{3} \mid A=1\right)=\left(\beta_{1}-\beta_{3}\right) \boldsymbol{X}_{1}+\left(\gamma_{1}-\gamma_{3}\right) \hat{\lambda}_{1} \\
& \mathrm{ATU}_{1}=E\left(Y_{1} \mid A=2\right)-E\left(Y_{2} \mid A=2\right)=\left(\beta_{1}-\beta_{2}\right) \boldsymbol{X}_{2}+\left(\gamma_{1}-\gamma_{2}\right) \hat{\lambda}_{2}
\end{aligned}
$$




$$
\mathrm{ATU}_{2}=E\left(Y_{1} \mid A=3\right)-E\left(Y_{3} \mid A=3\right)=\left(\beta_{1}-\beta_{3}\right) \boldsymbol{X}_{3}+\left(\gamma_{1}-\gamma_{3}\right) \hat{\lambda}_{3}
$$

In equations (4.5a-4.5b), $\mathrm{ATT}_{1}$ and $\mathrm{ATT}_{2}$ represent land productivity and efficiency effects of using fresh seeds based on counterfactual outcomes using recycled seeds (1-3 seasons), and recycled seeds (>3 seasons), respectively. Positive values indicate that using fresh seeds improve land productivity and efficiency. Likewise, in equations (4.5c), ATU 1 shows the returns on land productivity and efficiency that farmers would have obtained had farmers decided to use fresh seeds instead of recycled seeds (1-3 seasons). In equations (4.5d), $\mathrm{ATU}_{2}$ shows the returns on land productivity and efficiency that farmers would have obtained had farmers decided to use fresh seeds instead of recycled seeds ( $>3$ seasons).

Finally, it might be important to analyze the net return that farmers obtain from using fresh seeds with the counterfactual outcomes of the two groups of recycled seeds. Using the methodology outlined above, we estimate the impact of using fresh seeds on net return to land (Birr/ha). The net return to land is obtained by subtracting variable costs (seeds, fertilizers, other agrochemicals, and labor) on the estimated value of maize residue and revenue from quantity of maize produced.

\subsection{Results}

In this section, we discuss the findings of the study. In the first subsection, we discuss descriptive statistics of key variables of interest. In the second subsection, we report the ATTs and ATUs.

\subsubsection{Patterns of maize seed use, production stresses, inputs use, and land productivity}

The patterns of farmers' maize seeds and varieties use are reported in Figure 4.1. When we say varieties, we mean hybrids, OPVs and traditional varieties the farmers use. Seeds' use indicates whether farmers use fresh seeds or recycled seeds of the varieties. Figure 4.1A shows that farmers used fresh seeds in $69 \%$ of their plots in both rounds. In $18 \%$ of their plots, farmers used recycled seeds (1-3 seasons). In the remaining $13 \%$ of the plots, farmers used recycled seeds (> 3 seasons). Across survey rounds, Figure 4.1A also suggests that fresh seeds use increased from 59\% in 2009/10 to $81 \%$ in 2012/13. Between 2009/10 and 2012/13, use of recycled seeds (1-3 seasons) declined from $15 \%$ to $10 \%$. Similarly, between $2009 / 10$ and $2012 / 13$, the use of recycled seeds ( $>3$ seasons) 
declined from $27 \%$ to $9 \%$. The 20 percentage points increase in fresh seeds use across the two survey rounds may indicate the success of the Ethiopian agricultural extension system in promoting fresh seeds (Abate et al., 2015; Husmann, 2015; Shiferaw et al., 2013; Sisay et al., 2017).

In Figure 4.1B, we disaggregate the seeds by varieties type. Hybrid varieties dominate maize production. Hybrid varieties constitute $77 \%$ of the plots under fresh seeds in both rounds consistent with adoption levels in other studies (Abate et al., 2017). Among the recycled seeds (1-3 seasons), $46 \%$ of them are hybrid varieties. Among the recycled seeds (>3 seasons), hybrid varieties constitute $26 \%$. Interestingly, $15 \%$ of the fresh seeds are traditional varieties. Farmers' action on replacing seeds of traditional varieties by fresh seeds show that using fresh seeds is not limited to improved varieties but also 'tired' traditional varieties through continuous use. However, the largest proportion of traditional varieties are recycled seeds. Despite the fact that the highest proportion of fresh seeds are hybrid varieties, Figures 4.1C and 4.1D reveal that using fresh hybrid varieties has declined by 11 percentage points from $83 \%$ in 2009/10 to $72 \%$ in 2012/13.

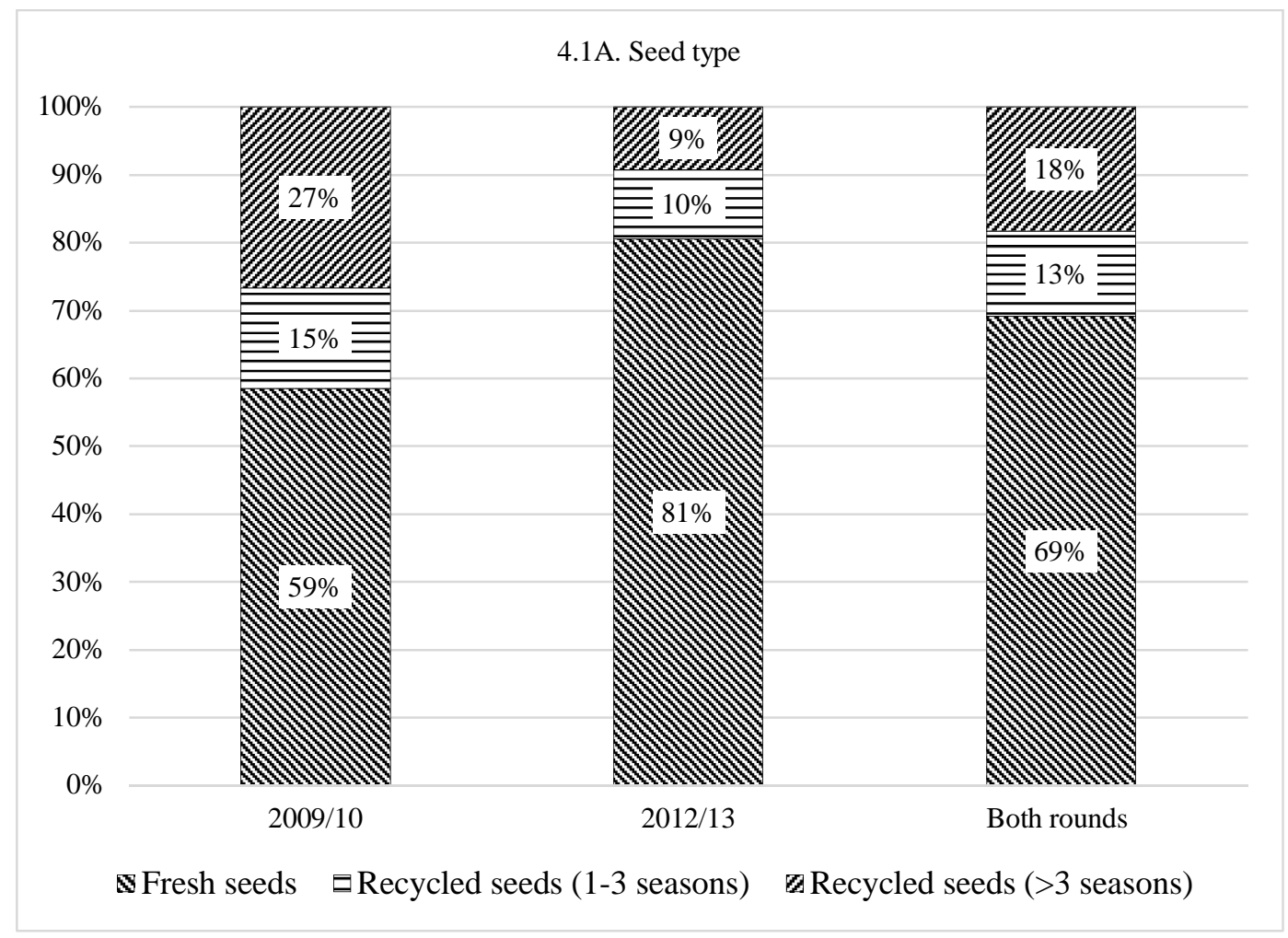


4.1B. Seed type by varieties type: both rounds

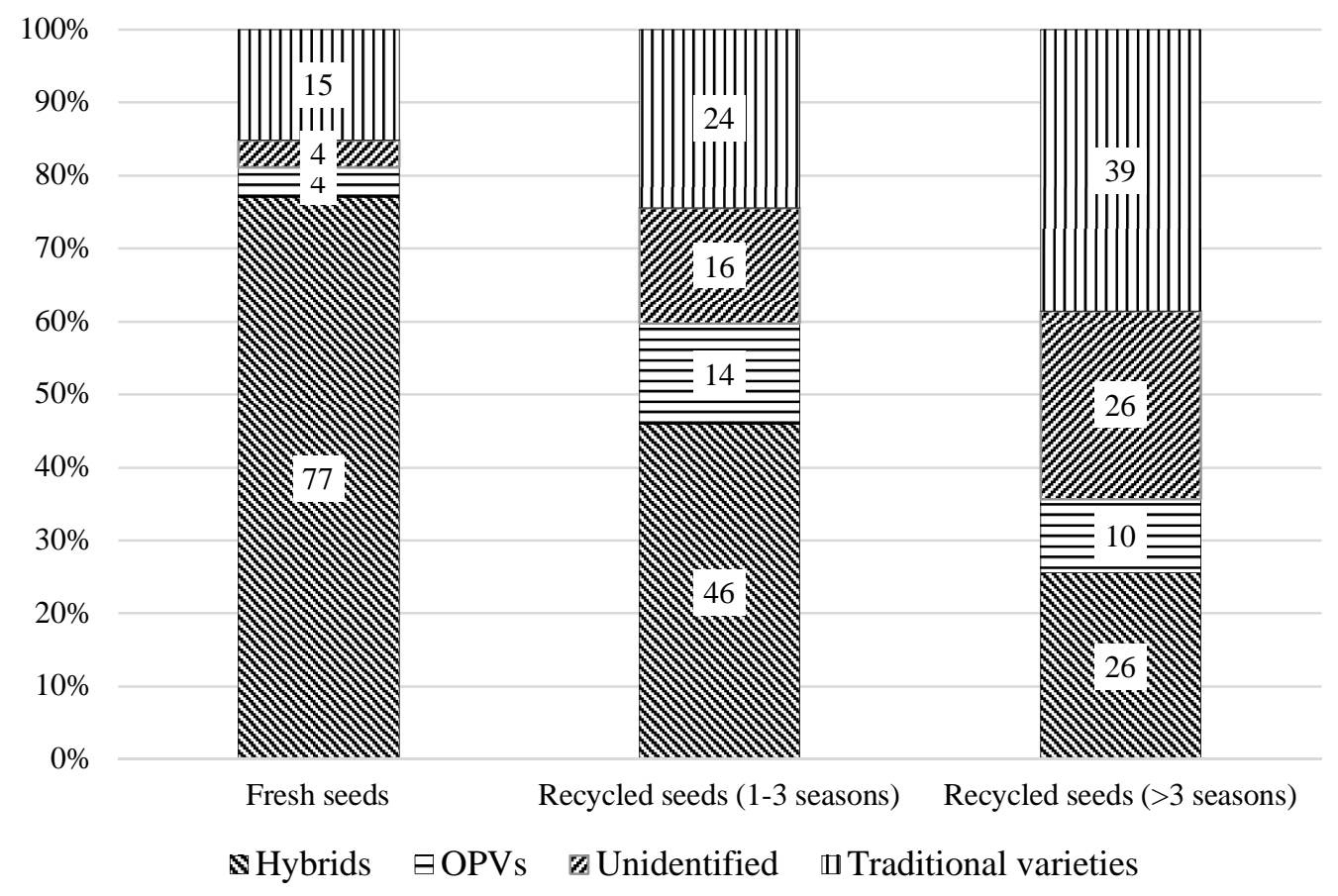

4.1C. Seed type by varieties type:2009/10

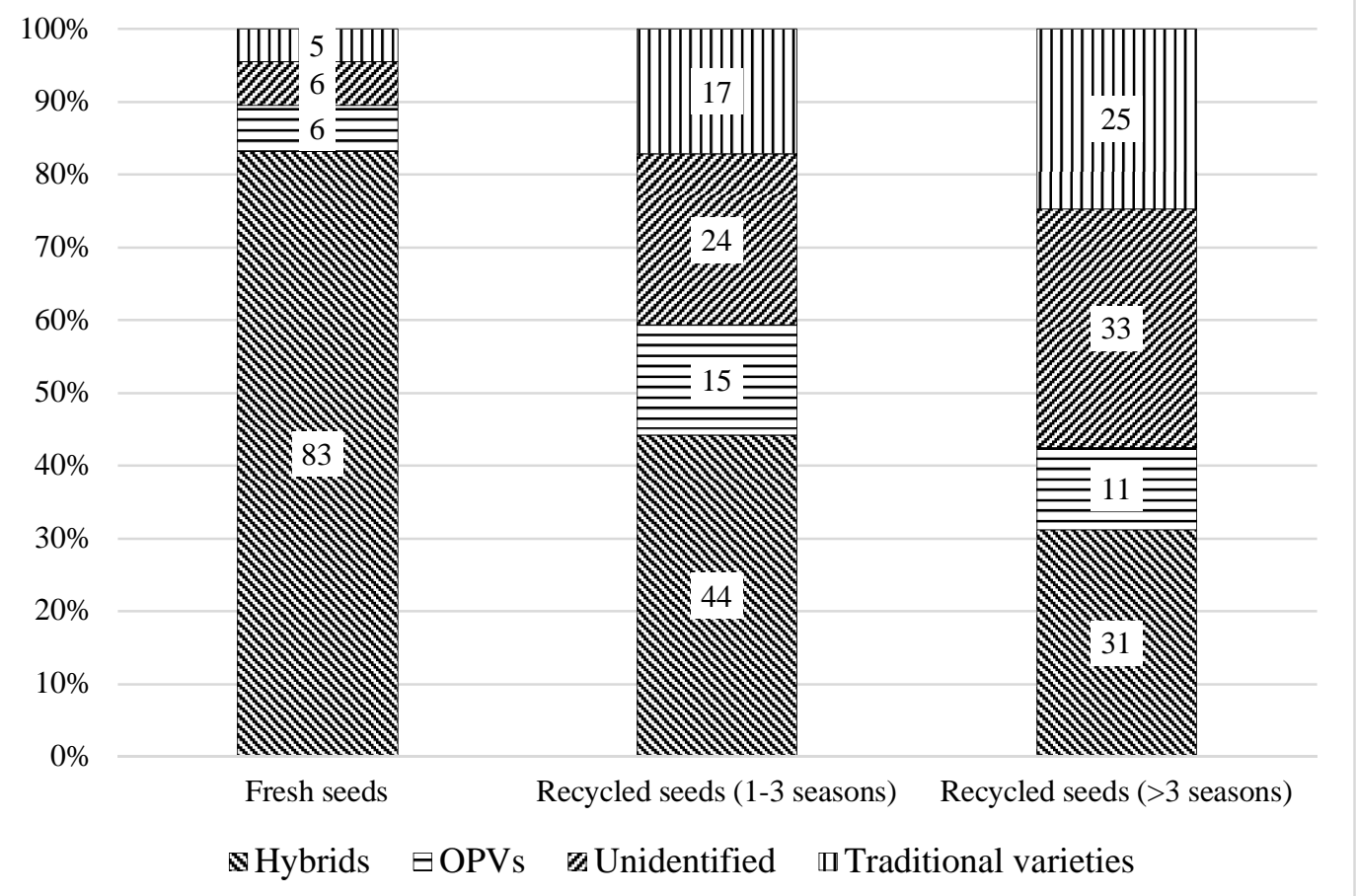




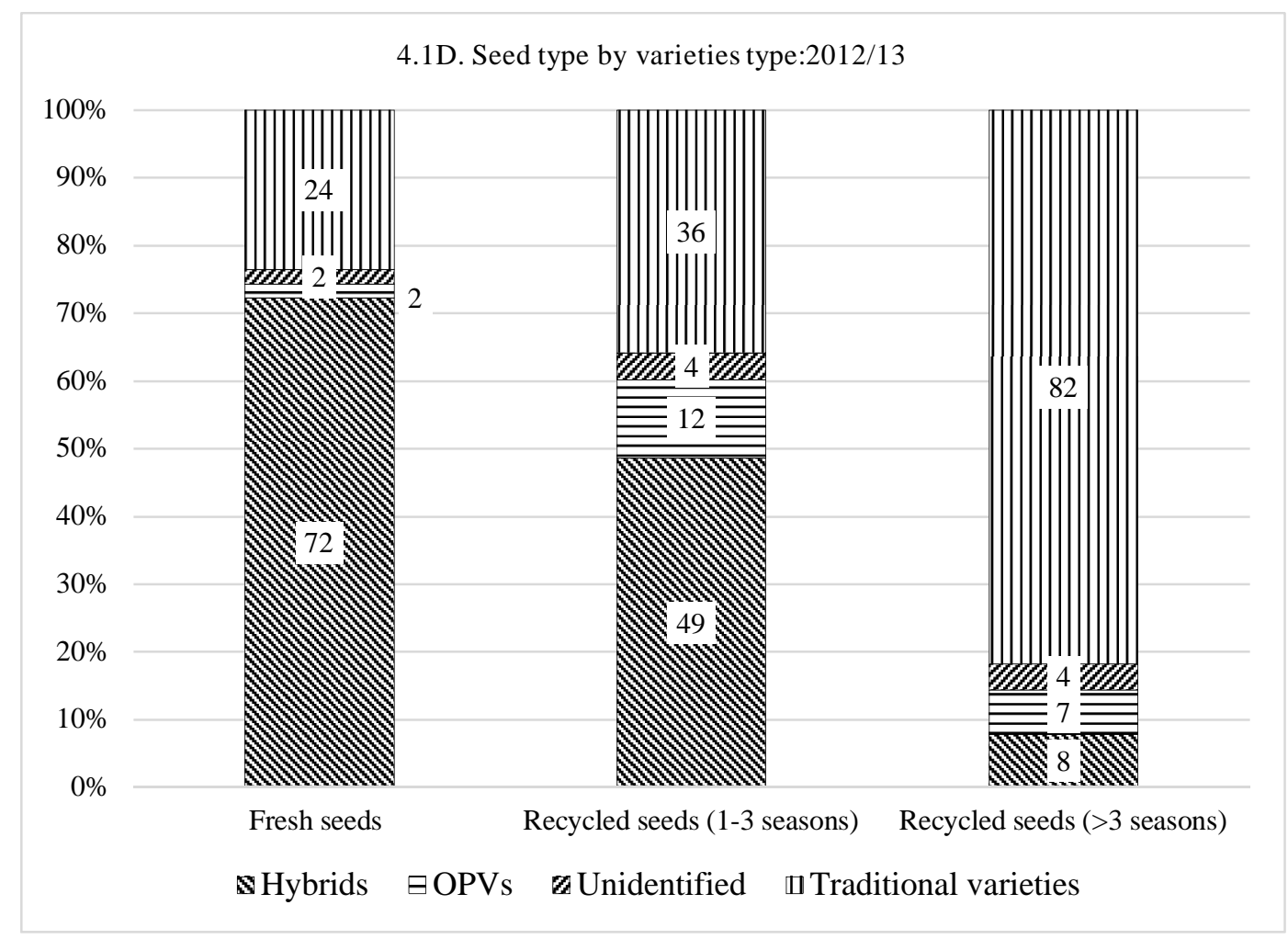

Figure 4.1. Maize seeds use by varieties type

Note: the unidentified are those varieties used by farmers, but their official name is unknown.

Figure 4.2 also reveals that the average age of the varieties is close to 15 years. Farmers grew varieties of 14 years of age and above in nearly $75 \%$ the cultivated maize area while they used recently released varieties ( $<=5$ years) only in $9 \%$ of the cultivated land. This shows that varietal turnover rate is extremely slow. The decline in fresh seed use across the two survey rounds and the slow varietal turnover rate might be attributed to several factors including unavailability of seeds, high price of seeds, low quality of purchased seeds or a combination of these constraints. 


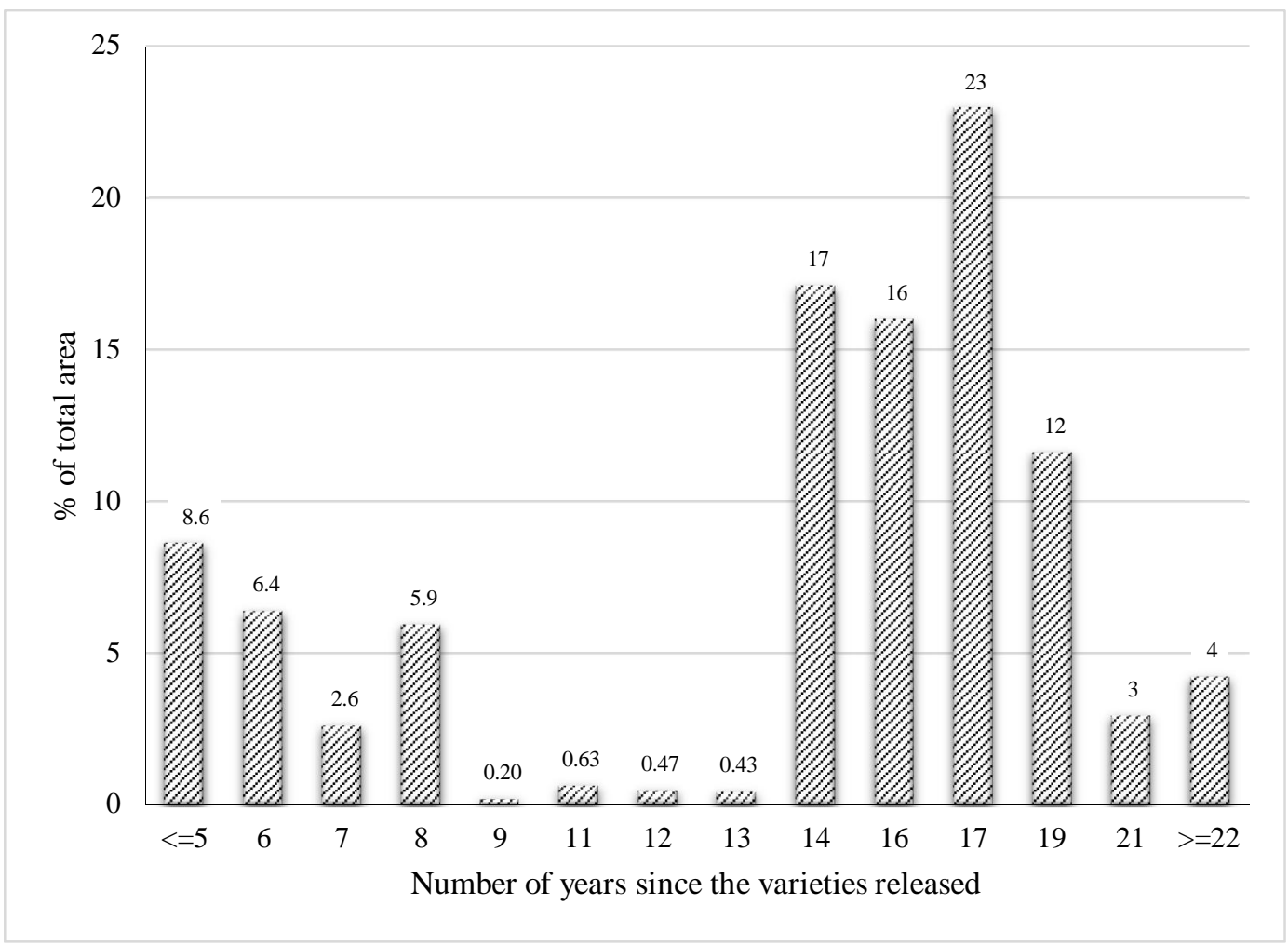

Figure 4.2. Percentage of maize area cultivated by the age of improved varieties.

In Table 4.2, we present constraints farmers face when they purchase seeds. Our data show that $77 \%$ of the farmers reported high price of seeds as a constraint. The price of fresh seeds from 19 to $23 \mathrm{Birr} / \mathrm{kg}, 9$ to $13 \mathrm{Birr} / \mathrm{kg}$, and 5 to $11 \mathrm{Birr} / \mathrm{kg}$ for hybrid, OPVs, and traditional varieties between $2009 / 10$ and 2012/13, respectively. For the same period, relative to the rise in price of seeds, the average price of maize seems to stagnate at $2.30 \mathrm{birr} / \mathrm{kg}$. In addition, $42 \%$ of the farmers reported that obtaining quality seeds were a constraint. The farmers' seed quality assessment reported is subjective, but the presence of counterfeit seeds in the market is reported in Uganda (Bold et al., 2017) and Ethiopia (Sisay et al., 2017). For example, Bold et al. (2017) reported that laboratory experiment of maize seeds randomly collected from the seed market in Uganda is estimated to contain less than $50 \%$ authentic seeds.

Almost half of the farmers reported that seeds were not available on time in the market. Half of the farmers believe that the market provided less quality seed at an expensive price. Furthermore, 25\% of the households reported that they think that all the three problems (seed quality, high price, and on time unavailability) were constraints. Across survey rounds, high price of seeds continued to be a constraint for many farmers while those who reported low seed quality, on time unavailability and a combination of the constraints dropped. In general, the farmers' report on seed price, quality and 
availability is consistent with other previous researches who reported similar constraints in seed adoption in Ethiopia and elsewhere (Abate et al., 2015; Fisher et al., 2015; Husmann, 2015).

Table 4.2. Maize seed purchase constraints.

\begin{tabular}{lccc}
\hline & \multicolumn{3}{c}{ Percentage of households } \\
\cline { 2 - 4 } Constraints & $2009 / 10$ & $2012 / 13$ & Both rounds \\
\hline 1 if high seed price, 0 otherwise & 74 & 79 & 77 \\
1 if low seed quality, 0 otherwise & 43 & 40 & 42 \\
1 if seed not available on time, 0 otherwise & 61 & 41 & 52 \\
1 if high price and low quality of seed, otherwise & 51 & 44 & 48 \\
1 if high-price-low-quality-not available on time, Otherwise & 30 & 21 & 25 \\
\hline
\end{tabular}

Farmers' seed choice might be mediated by their expectation on production stresses that limit the productivity and efficiency of rural households. The last column of Table 4.3 shows that $20 \%$ of the plots were affected by drought while the incidence of pests were observed in nearly $20 \%$ of the plots. According to farmers' report, the incidence of diseases, waterlogging and other abiotic stresses (e.g., frost and hailstorm) were not high. Of the plots that used fresh seeds, farmers reported that $16 \%$ of them faced the incidence of drought. Nearly $17 \%$ of the plots with fresh seeds faced the incidence of pests. The incidence of production stresses tends to be low for plots with recycled seeds.

Table 4.3. Incidence of production stresses by seed type (\%).

\begin{tabular}{lcccc}
\hline Production stresses & $\begin{array}{c}\text { Fresh } \\
\text { seeds }\end{array}$ & $\begin{array}{c}\text { Recycled seeds (1-3 } \\
\text { seasons) }\end{array}$ & $\begin{array}{c}\text { Recycled seeds (>3 } \\
\text { seasons) }\end{array}$ & Total \\
\hline 1 if drought, 0 otherwise & 15.78 & 2.18 & 2.18 & 20.14 \\
1 if pests, 0 otherwise & 16.56 & 2.14 & 2.16 & 19.86 \\
1 if diseases, 0 otherwise & 1.59 & 0.32 & 0.50 & 2.40 \\
1 if waterlogging, 0 otherwise & 1.01 & 0.23 & 0.27 & 1.51 \\
1 if other abiotic stresses, 0 otherwise & 1.13 & 0.30 & 0.72 & 2.14 \\
\hline
\end{tabular}

Note: the percentages given are weighted by the total number of plots in each seed type.

Figure 4.3 shows the distribution of productivity $(\mathrm{kg} / \mathrm{ha})$ disaggregated by the type of seeds. Fresh seeds have a yield advantage over recycled seeds. Recycling seeds ( $>3$ seasons) is associated with lower land productivity throughout the distribution. On average, maize productivity is 2651,1720 and $1627 \mathrm{~kg} / \mathrm{ha}$ for fresh seeds, for recycled seeds (1-3 seasons), and recycled seeds (> 3 seasons), 
respectively. Nevertheless, we do not control for differences in input use that may drive land productivity across the three seeds type in Figure 4.3.

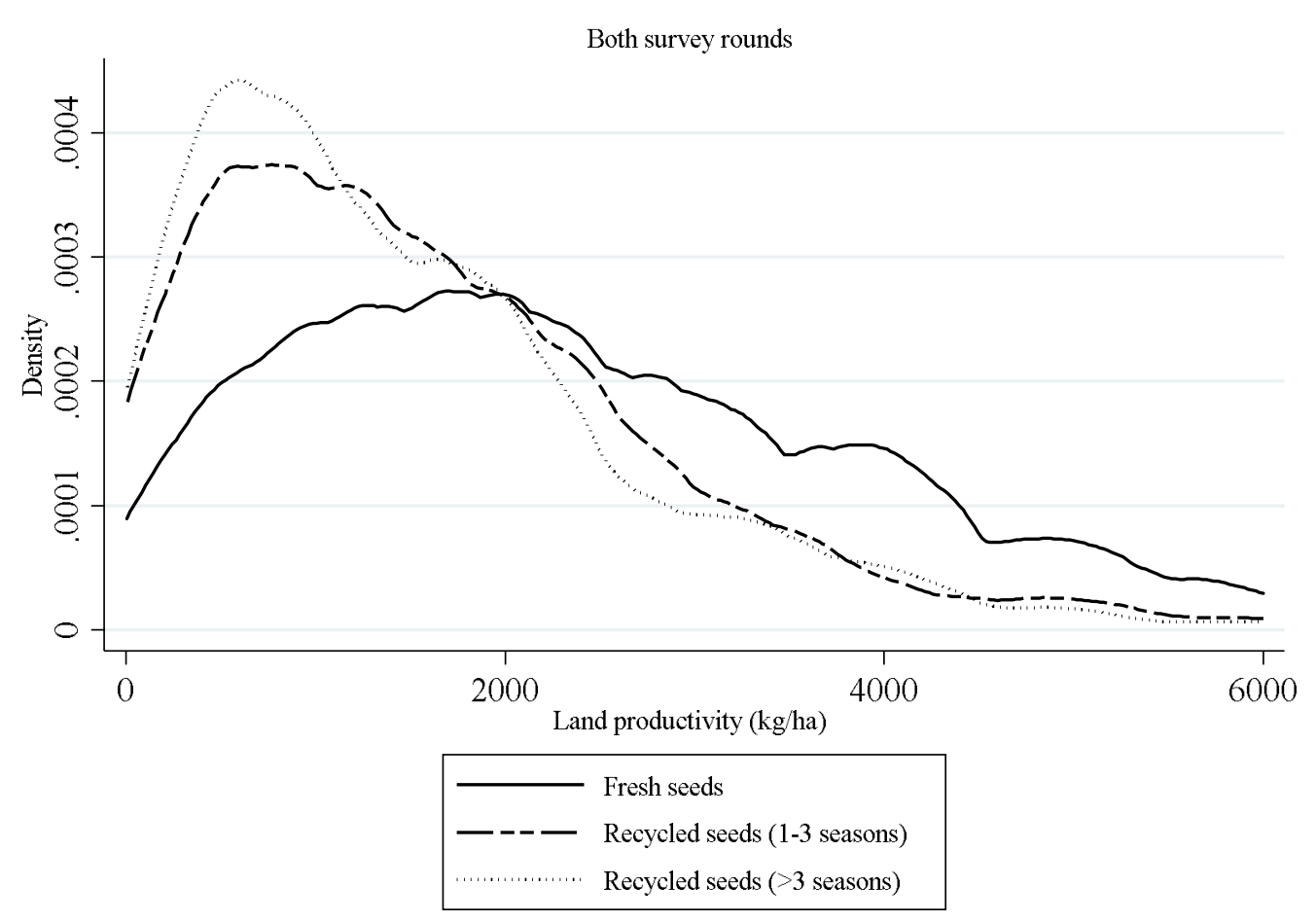

Figure 4.3. Distributions of land productivity by seed type (2009/10-2012/13).

Input use by seed type is reported in Table 4.4. We observe no noticeable difference in labor use by seed type. The intensity of manure is lower in fresh seeds than the recycled seeds. However, farmers spend more on fertilizers and other agrochemicals for plots with fresh seeds than recycled seeds. In the next subsection, we report the impact of seed choice on land productivity and efficiency after controlling for the effect of inputs, production stresses, differences in plot characteristics and other confounding factors. 
Table 4.4. Inputs' use by seed type.

\begin{tabular}{lccc}
\hline Inputs & Fresh seeds & Recycled seeds (1-3 seasons) & Recycled seeds ( $>3$ seasons) \\
\hline Expenses on fertilizers (Birr/ha) & 2206 & $1376^{* * *}$ & $1317^{* * *}$ \\
Other agrochemicals (birr/ha) & 166 & $81^{* * *}$ & $92^{* * *}$ \\
Total labor (days/ha) & 107 & 103 & 107 \\
Manure (kg/ha) & 1461 & $1688^{* * *}$ & 1525 \\
\hline Notes: (i). The estimated values in Table 4.4 exclude zeros. (ii) *** $\mathrm{p}<0.01, * * \mathrm{p}<0.05, * \mathrm{p}<0.1$.
\end{tabular}

\subsubsection{The impact of using fresh seeds on land productivity and efficiency}

In this sub-section, we present the key findings of the estimation results. The multinomial selection model and the switching regressions are presented in Table 4.7 and Table 4.8 in Appendix 4, respectively. Tables 4.9-4.10 of appendix 4 show the ATTs and ATUs for the two exogenous regression models used as robustness checks. The results show no noticeable differences in terms of the conclusion we draw. In the rest of this subsection, we present the results of the endogenous switching regressions.

In Table 4.5, we present the ATTs and ATUs estimated using equations (4.5a-4.5d). The results reveal that significant gains in land productivity are observed when farmers use fresh seeds. In comparison to the counterfactual outcomes based on the recycled seeds (1-3 seasons), fresh seeds increase land productivity by $168 \mathrm{~kg} / \mathrm{ha}$. In the same way, fresh seeds has a $571 \mathrm{~kg} / \mathrm{ha}$ higher land productivity than the counterfactual outcome based on recycled seeds (>3 seasons) (Table 4.5). These results are in line with the expectation of the Ethiopian extension system, which is promoting fresh seeds (Abate et al., 2015). The ATUs in Table 4.5 further show that farmers would have increased their productivity between 32 to $135 \mathrm{~kg} / \mathrm{ha}$ had farmers who used recycled seeds in their plots had decided to use fresh seeds. 
Table 4.5. The impact of fresh seeds on land productivity.

\begin{tabular}{|c|c|}
\hline Expected outcomes & Land Productivity (kg/ha) \\
\hline \multirow[t]{2}{*}{ Fresh seeds $(\mathrm{A})$} & 2130.12 \\
\hline & $(13.59)$ \\
\hline \multirow[t]{2}{*}{ Recycled seeds (1-3 seasons) (B) } & 1372.38 \\
\hline & $(27.58)$ \\
\hline \multirow[t]{2}{*}{ Recycled seeds (> 3 seasons) (C) } & 1264.85 \\
\hline & $(19.66)$ \\
\hline \multirow[t]{2}{*}{ Had farmers who used recycled seeds ( $1-3$ seasons) had used fresh seeds (D) } & 1962.17 \\
\hline & $(15.55)$ \\
\hline \multirow[t]{2}{*}{ Had farmers who used recycled seeds ( $>3$ seasons) had used fresh seeds $(E)$} & 1558.80 \\
\hline & $(13.89)$ \\
\hline \multirow[t]{2}{*}{ Had farmers who used fresh seeds had used recycled seeds (1-3 seasons) (F) } & 1507.68 \\
\hline & $(25.97)$ \\
\hline \multirow[t]{2}{*}{ Had farmers who used fresh seeds had used recycled seeds (>3 seasons) $(G)$} & 1297.00 \\
\hline & $(18.90)$ \\
\hline \multirow[t]{2}{*}{$\mathrm{ATT}_{1}(\mathrm{~A}-\mathrm{D})$} & $167.95 * * *$ \\
\hline & $(20.65)$ \\
\hline \multirow[t]{2}{*}{$\mathrm{ATT}_{2}(\mathrm{~A}-\mathrm{E})$} & $571.32 * * *$ \\
\hline & (19.43) \\
\hline \multirow[t]{2}{*}{$\mathrm{ATU}_{1}(\mathrm{~F}-\mathrm{B})$} & $135.30 * * *$ \\
\hline & (37.88) \\
\hline \multirow[t]{2}{*}{$\mathrm{ATU}_{2}(\mathrm{G}-\mathrm{C})$} & 32.14 \\
\hline & $(27.27)$ \\
\hline
\end{tabular}

Notes: (i) $* * \mathrm{p}<0.005$, *** $\mathrm{p}<0.01$. (ii) standard errors in brackets. (ii) Since the dependent variable, land productivity, was modeled in logarithm, converting the predicted logarithm of land productivity into levels may lead to inaccuracies (Kabunga et al., 2012). We also reported the ATTs and ATUs using the predicted logarithm of land productivity in Table 4.11 and Figure 4.7 in Appendix 4.

The distribution of the predicted values of land productivity under the actual and counterfactual conditions are shown in Figure 4.4. Figure 4.4A depicts that the counterfactual outcomes indicated by the broken lines are to the left of the actual outcomes along the distribution of land productivity. This confirms that using fresh seeds benefits almost everybody who used it. Figures 4.4B and 4.4C further show that most of the farmers would have had higher land productivity had they decided to use fresh seeds instead of recycled seeds. 

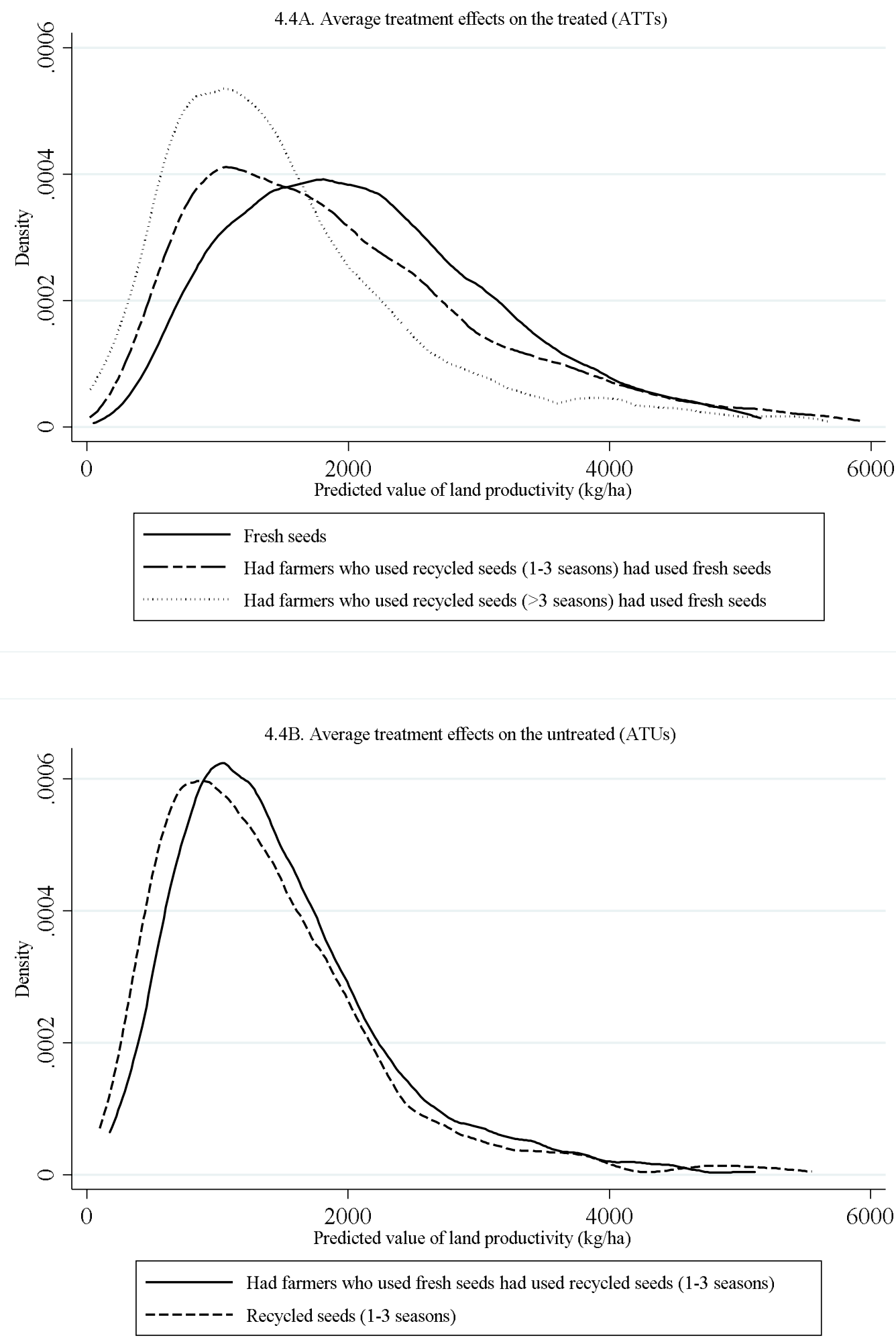


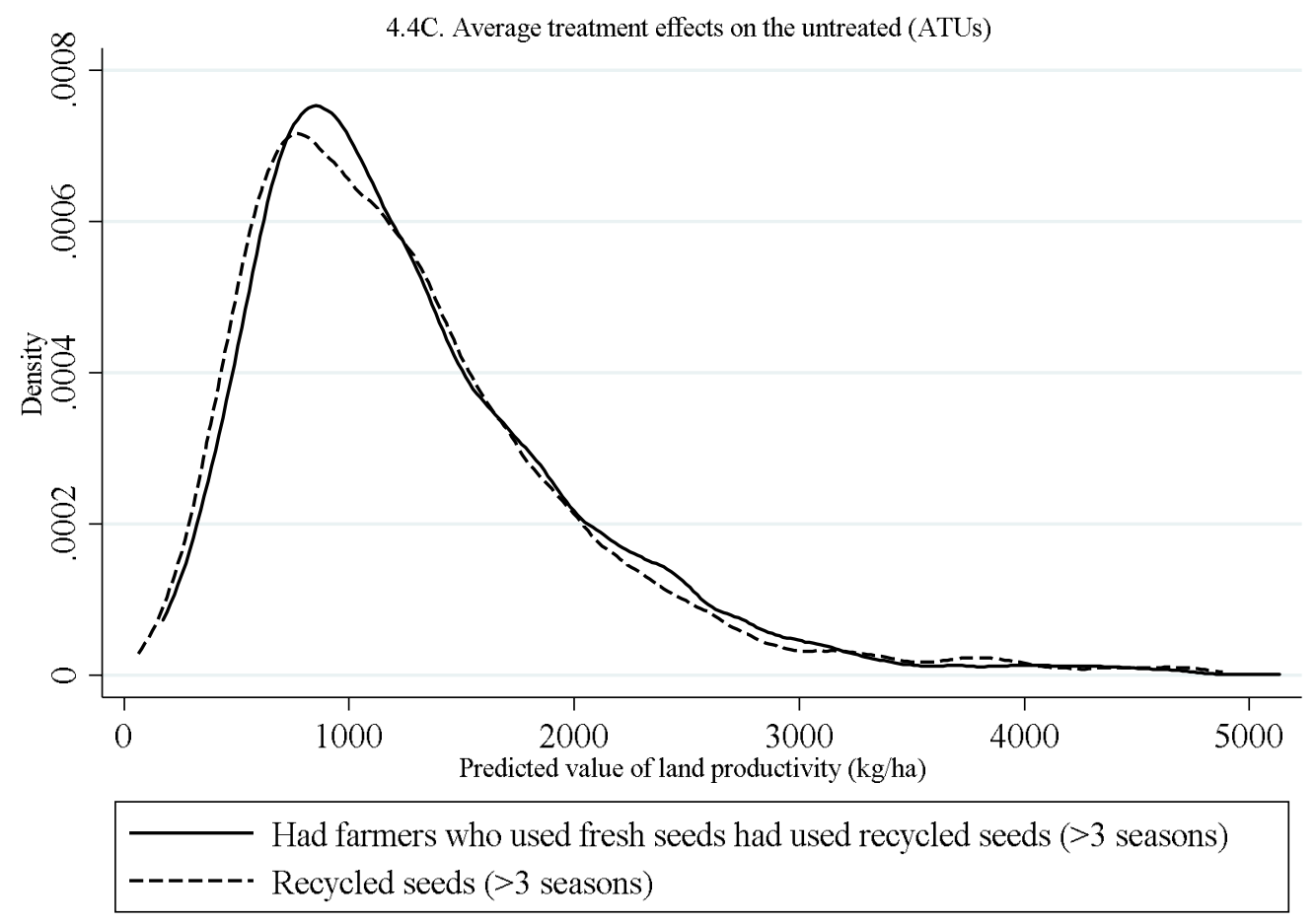

Figure 4.4. Distributions of predicted value of land productivity $(\mathrm{kg} / \mathrm{ha})$ in actual and counterfactual conditions.

The distribution of the estimated efficiency of farming households by seed type is reported in Figure 4.5. The distribution of efficiency for fresh seeds is to the right of the distribution of the two types of recycled seeds in most cases indicating that households tend to be more efficient when they use fresh seeds. Given the existing production technology, our results show that farming households are approximately $61 \%$ efficient when they use fresh seeds. The farming households are $58 \%$ and $56 \%$ efficient when they use recycled seeds (1-3 seasons), and recycled seeds ( $>3$ seasons), respectively. In other words, depending on the seed type, the households' level of inefficiency ranges from $39 \%$ to $44 \%$ showing a high potential to increase productivity by improving farmers' inputs use efficiency. Previous studies in maize production in Ethiopia documented the presence of high inefficiency (22\% to 37\%) (Alene and Hassan, 2006; Alene and Manyong, 2006). Meta-analysis of efficiency estimates on African agriculture also found that the level average inefficiency was $32 \%$ (Ogundari, 2014). Regardless of the magnitudes, our results agree with the previous studies that smallholder farmers are inefficient in inputs use. 


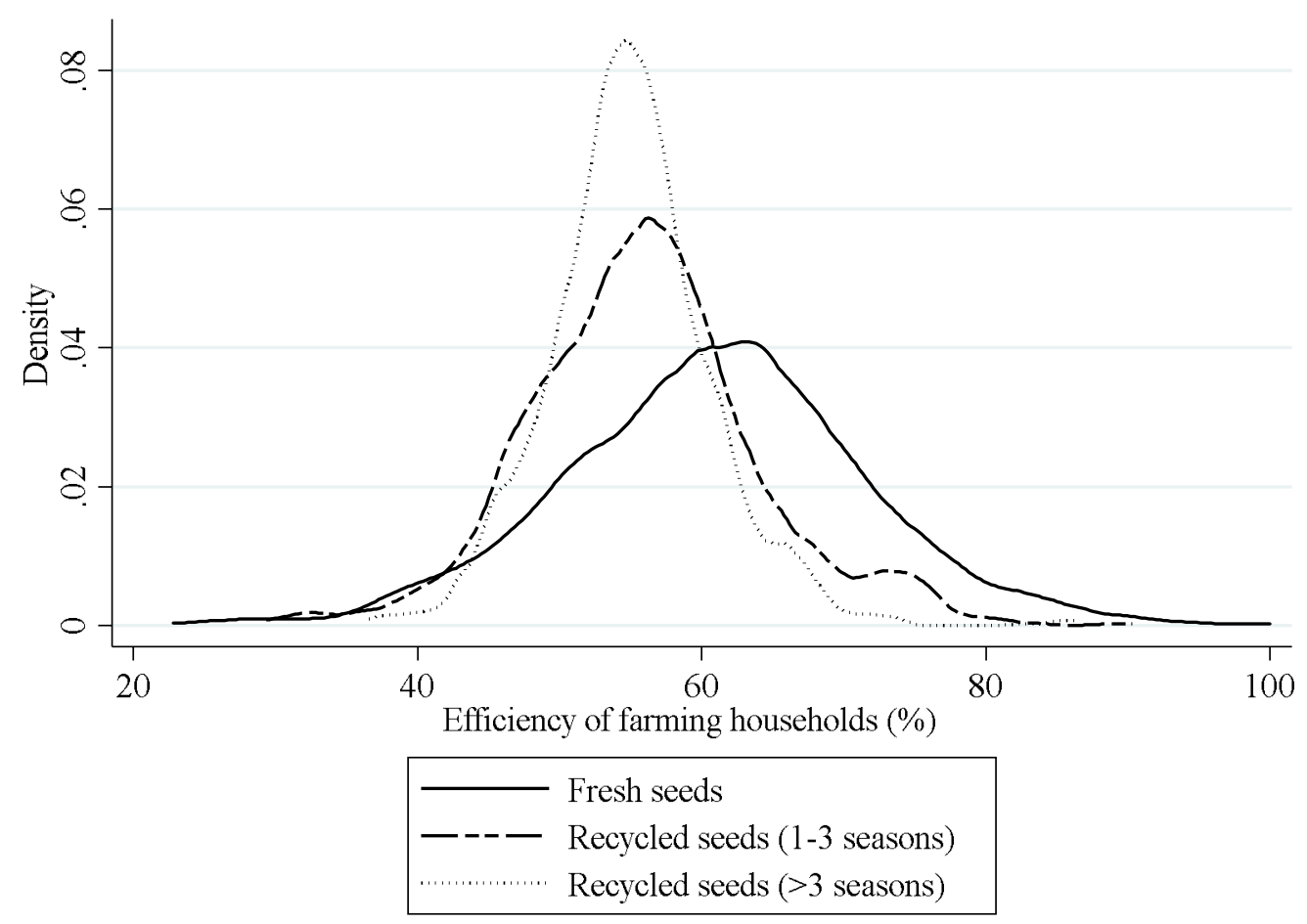

Figure 4.5. Distributions of actual estimated efficiency of farming households by seed type.

In Table 4.6, we show the ATTs and the ATUs for the estimated efficiency. Alike the land productivity estimates discussed above, we estimate the ATTs and ATUs using equations (4.5a4.5d). ATT 1 indicates that using fresh seeds could lead to an approximately $3 \%$ efficiency gains compared to the counterfactual outcome based on recycled seeds (1-3 seasons). In comparison to the counterfactual outcome based on recycled seeds ( $>3$ seasons), $\mathrm{ATT}_{2}$ indicates that using fresh seeds brings nearly $5 \%$ efficiency gains to the farming households. ATU 1 and $\mathrm{ATU}_{2}$ reveal that had farmers chosen to use fresh seeds, their efficiency could have had increased by nearly $3 \%$ and $6 \%$ relative to the counterfactual outcomes based on recycled seeds (1-3 seasons) and recycled seeds (>3 seasons), respectively.

We depict the distributions of efficiency for both the expected and counterfactual outcomes in Figure 4.6. With a small exception at the lower tail of the distribution, Figure 4.6A shows that the distribution of efficiency of using fresh seeds is to the right of the two counterfactual outcomes represented by the broken lines. This indicates that using fresh seeds makes most of the farming households more efficient than using recycled seeds. Similarly, Figures 4.6B-4.6C depict that most of the farming households would have had higher efficiency level had they decided to use fresh seeds. 
Table 4.6. The impact of using fresh seeds on efficiency.

\begin{tabular}{lc}
\hline Expected outcomes & Efficiency (\%) \\
\hline Fresh seeds (A) & 61.27 \\
& $(0.20)$ \\
Recycled seeds (1-3 seasons) (B) & 57.54 \\
& $(0.30)$ \\
Recycled seeds (> 3 seasons) (C) & 55.61 \\
& $0.20)$ \\
Had farmers who used recycled seeds (1-3 seasons) had used fresh seeds (D) & 58.64 \\
& $(0.20)$ \\
Had farmers who used recycled seeds (>3 seasons) had used fresh seeds (E) & 56.69 \\
Had farmers who used fresh seeds had used recycled seeds (1-3 seasons) (F) & $(0.10)$ \\
& 60.08 \\
Had farmers who used fresh seeds had used recycled seeds (>3 seasons) (G) & $(0.40)$ \\
& 61.36 \\
ATT $_{1}$ (A-D) & $(0.40)$ \\
ATT $_{2}$ (A-E) & $2.63 * * *$ \\
ATU $_{1}$ (F-B) & $(0.30)$ \\
ATU $_{2}$ (G-C) & $4.58^{* * * *}$ \\
& $(0.30)$ \\
\hline
\end{tabular}

Notes: (i) *** $\mathrm{p}<0.01$, (ii) standard errors in brackets. 

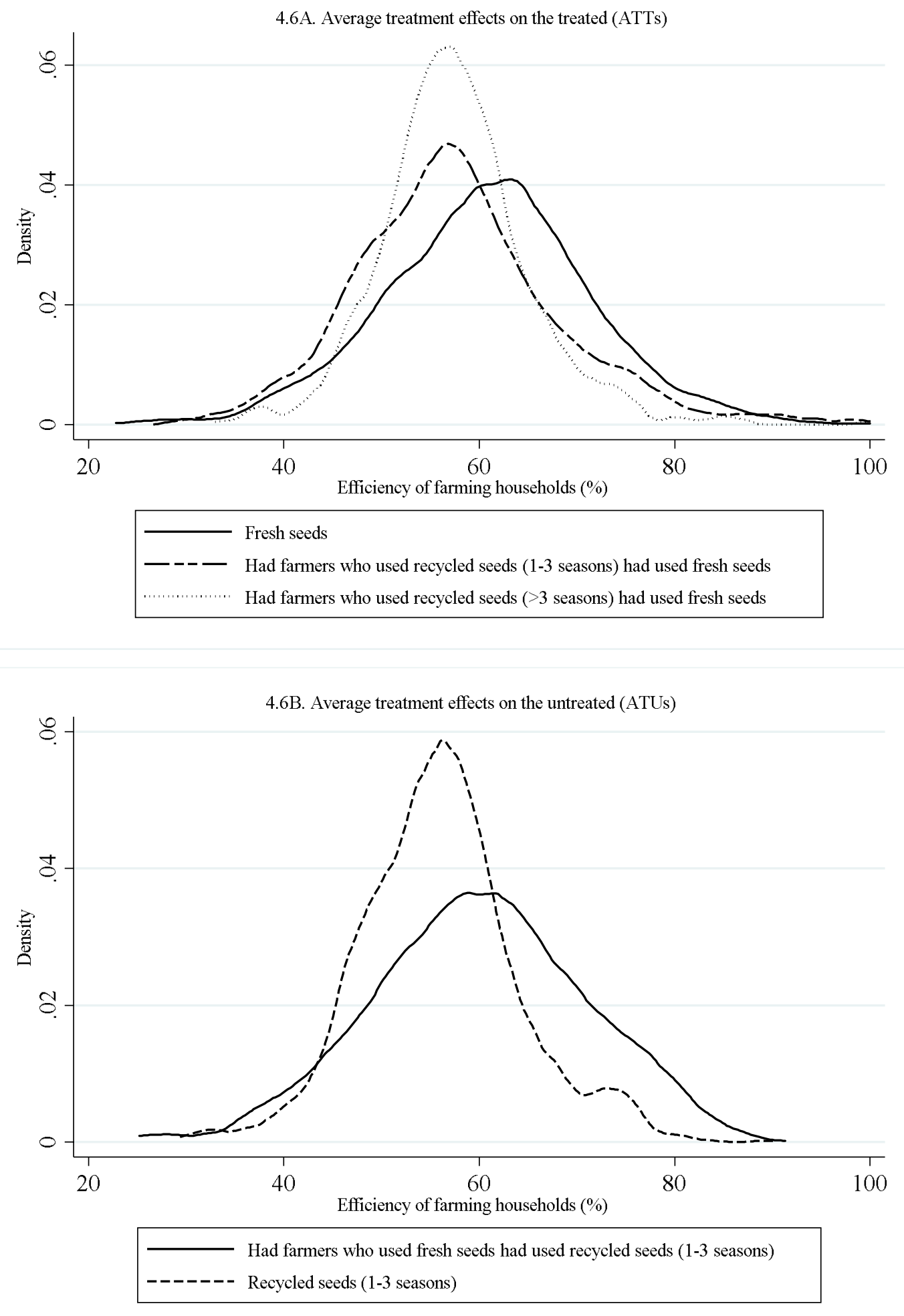


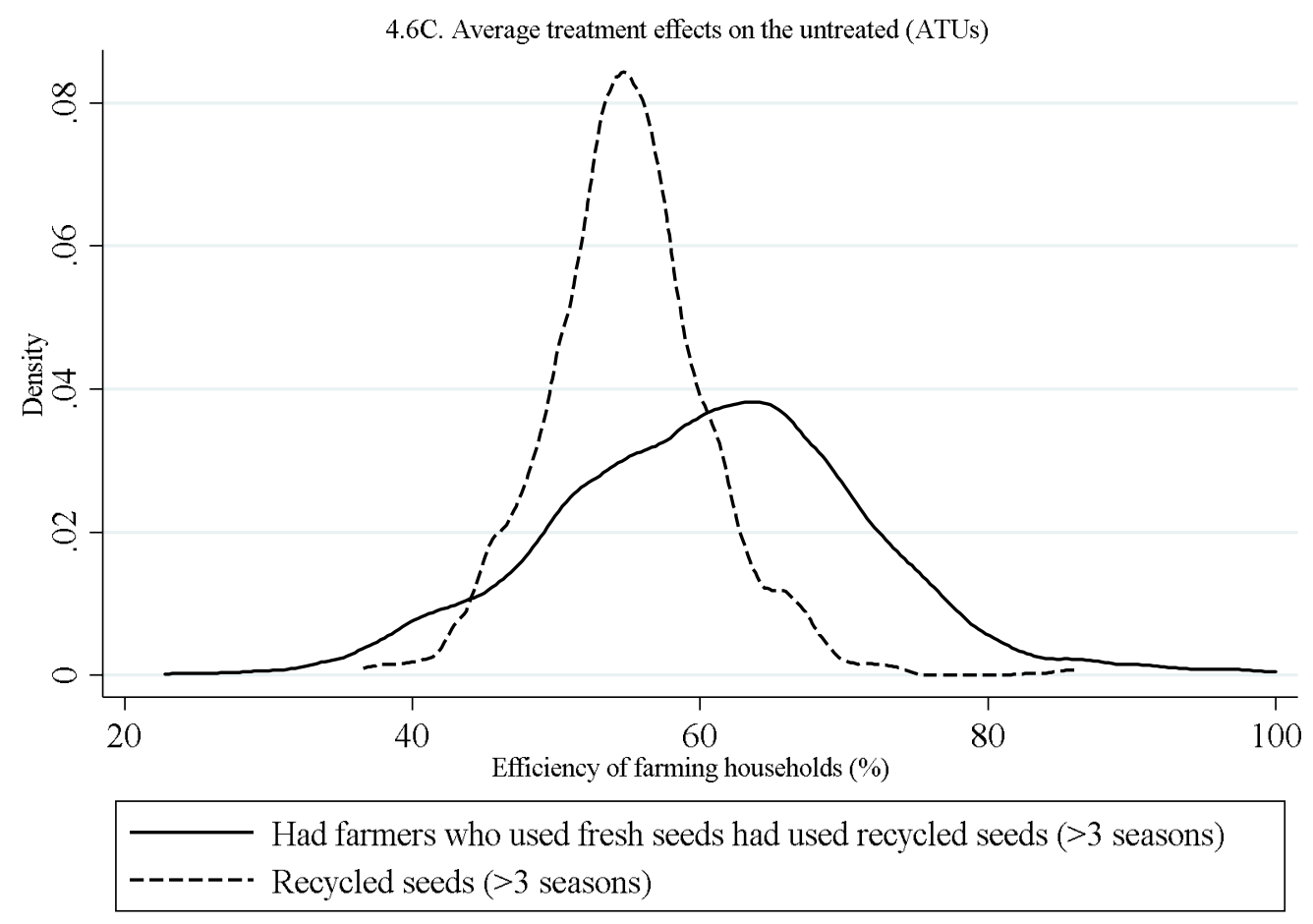

Figure 4.6. Distributions of efficiency of farming households in the actual and counterfactual conditions.

To sum up, the results reveal that using fresh seeds substantially increases not only land productivity but also improve their efficiency. It is also important to ask if the productivity and efficiency gains of using fresh seeds translate to profitability gains. We are not able to calculate the actual profit farmers obtain to each of the plots because we do not have information to all the costs farmers incurred during production. However, we analyze the impact of using fresh seeds on net returns to land, which is the estimated value of maize residue and revenue from quantity of maize produced minus variable costs (seeds, fertilizers, other agrochemicals, and labor). The results are reported in Table 4.12 and Figure 4.8 in appendix 4. Consistent with the findings presented above, using fresh seeds increases net return to land by 1171 and 1193 Birr/kg in compared to the counterfactual outcomes based on recycled seeds (1-3 seasons) and recycled seeds ( $>3$ seasons), respectively. Our results suggest that using fresh seeds increases land productivity and efficiency that might lead to positive net returns to land. 


\subsection{Concluding remarks}

In smallholders agricultural production, choosing the right seeds is one of the most important decisions. Seed choice involves either a decision to varietal replacement of new improved varieties or seed replacement decision, which is using fresh seeds of old varieties or recycled seeds saved from previous harvest. While farmers' varietal replacement decisions are well documented in the literature, little empirical studies exist on smallholder farmers' motivations to use fresh seeds of old improved varieties and recycling seeds.

In this chapter, we study the impact of using fresh seeds on both land productivity and efficiency. To the best of our knowledge, we provide the first rigorous empirical evidence on fresh seeds uses. Second, the previous studies on land productivity estimate the impact of new improved varieties by implicitly assuming that farmers are equally efficient. We take account of the differences in productivity that might arise because of inefficiency. We estimate land productivity and efficiency together in the same econometric model enabling us to understand the joint impact on productivity and efficiency attributed to the use of fresh seeds. Third, unlike previous studies on efficiency that assumed identical seed types, we use a more detailed classification of seed types that might arise because of recycling behavior of farmers. We base our empirical analysis using comprehensive panel household survey data collected from maize producing households in rural Ethiopia. We handle endogeneity problems associated with seed choice by estimating production functions using an endogenous switching regression treatment effects framework.

Findings show that fresh seeds bring a significant increase in land productivity and farmers' efficiency, hence suggesting complementary benefit of using fresh seeds. The productivity and efficiency gains indicate that promoting fresh seeds has a potential for boosting maize production without even introducing new improved varieties. This has an important policy implication in many developing countries where varietal turnover rate is extremely slow. Policy makers may need to stress on the importance of fresh seeds in designing agricultural growth policies to increase agricultural productivity given the available improved seed technologies at most efficiency. Our results further demonstrate that evaluating the impact of improved agricultural technologies using land productivity or efficiency alone may underestimate the potential benefit of improved technologies that may accrue to farmers.

Our results also show the presence of significant inefficiencies in inputs use despite the higher productivity and efficiency gains of using fresh seeds. In tandem with promoting fresh seeds, the development community and the government may need to design complementary policy 
instruments that promote resource use efficiency. Furthermore, many farmers have the perception that seeds are high-priced, of low quality, and not available on time. Such perception of farmers may underscore the importance of improving the efficiency of seed production and distribution system. 


\subsection{Appendix 4}

Table 4.7. The multinomial logit selection model for seeds use.

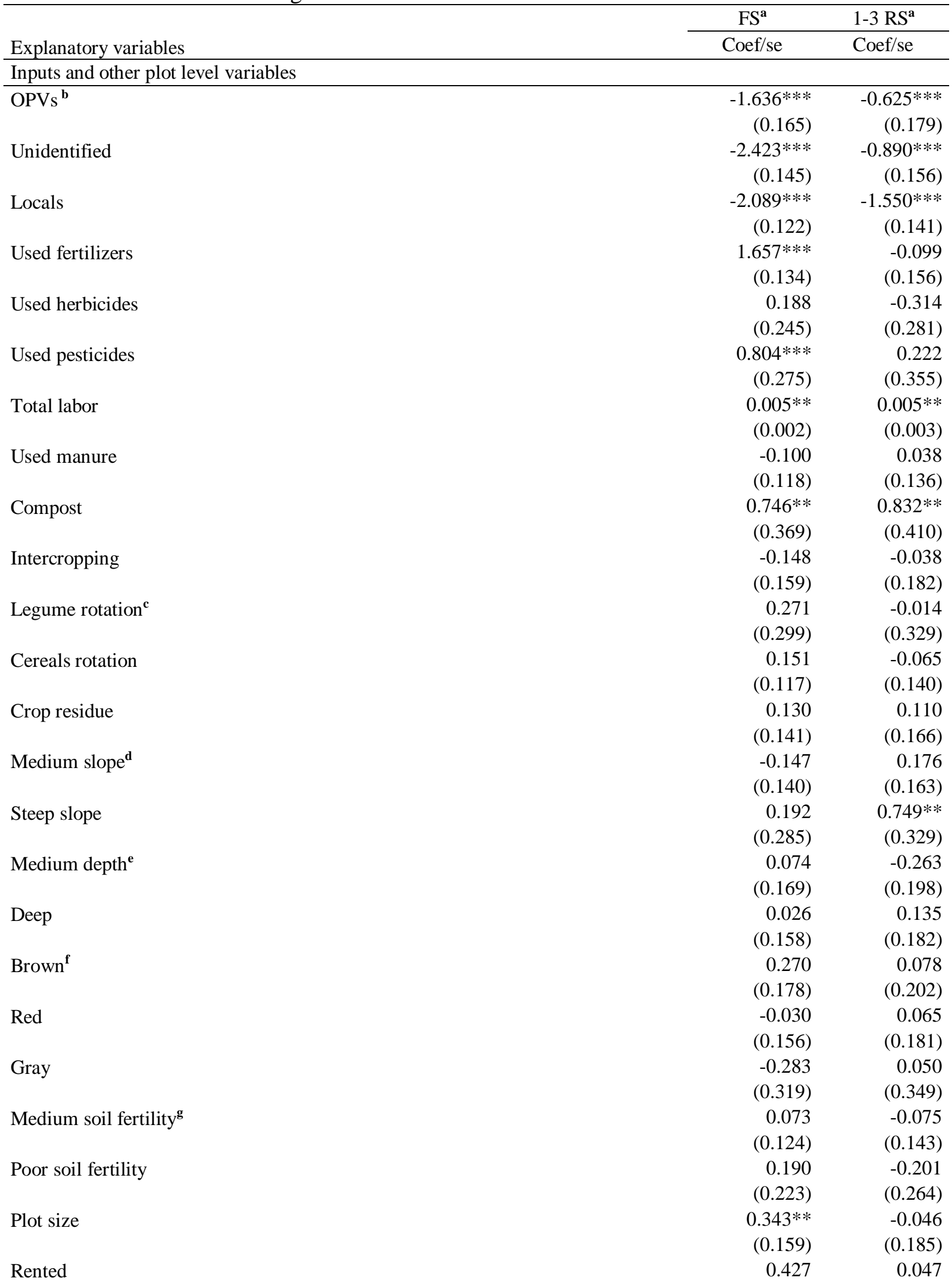




\begin{tabular}{|c|c|c|}
\hline \multirow[b]{2}{*}{ Explanatory variables } & $\mathrm{FS}^{\mathrm{a}}$ & $1-3 R^{a}$ \\
\hline & Coef/se & Coef/se \\
\hline \multirow{3}{*}{ Plot distance } & $(0.313)$ & $(0.376)$ \\
\hline & 0.003 & 0.001 \\
\hline & $(0.003)$ & $(0.004)$ \\
\hline \multicolumn{3}{|l|}{ Production stresses } \\
\hline \multirow[t]{2}{*}{ Drought } & $-1.140^{*}$ & $-1.493 * *$ \\
\hline & $(0.604)$ & $(0.624)$ \\
\hline \multirow[t]{2}{*}{ Waterlogging } & 0.300 & 0.333 \\
\hline & $(0.475)$ & $(0.528)$ \\
\hline \multirow[t]{2}{*}{ Abiotic stress } & -0.109 & 0.257 \\
\hline & $(0.347)$ & $(0.403)$ \\
\hline \multirow[t]{2}{*}{ Pests } & 0.971 & $1.350^{* *}$ \\
\hline & $(0.616)$ & $(0.636)$ \\
\hline \multirow[t]{2}{*}{ Disease } & 0.295 & 0.363 \\
\hline & $(0.382)$ & $(0.442)$ \\
\hline \multicolumn{3}{|l|}{ Household level variables } \\
\hline \multirow[t]{2}{*}{ Male } & -0.247 & -0.162 \\
\hline & $(0.182)$ & (0.199) \\
\hline \multirow[t]{2}{*}{ Age } & $-0.010 * * *$ & $-0.012 * * *$ \\
\hline & $(0.004)$ & $(0.004)$ \\
\hline \multirow[t]{2}{*}{ School $>=2 \&<6^{\mathbf{h}}$} & 0.122 & 0.049 \\
\hline & $(0.097)$ & $(0.112)$ \\
\hline \multirow[t]{2}{*}{ School $>=6$} & $0.323^{* *}$ & 0.104 \\
\hline & $(0.138)$ & $(0.159)$ \\
\hline \multirow[t]{2}{*}{ Training } & $-0.808 * * *$ & $-0.512^{*}$ \\
\hline & $(0.272)$ & $(0.297)$ \\
\hline \multirow[t]{2}{*}{ Low asset ${ }^{\mathrm{i}}$} & -0.419 & -0.534 \\
\hline & (1.138) & $(1.257)$ \\
\hline \multirow[t]{2}{*}{ Middle aseet } & 0.142 & $0.270^{* *}$ \\
\hline & $(0.108)$ & (0.123) \\
\hline \multirow[t]{2}{*}{ Oxen ownership } & $-0.459 * * *$ & $-0.425 * * *$ \\
\hline & $(0.124)$ & (0.136) \\
\hline \multirow[t]{2}{*}{ Survey year } & $2.821^{* *}$ & $2.089 *$ \\
\hline & $(1.143)$ & $(1.261)$ \\
\hline \multicolumn{3}{|c|}{ Variables used as exclusion restrictions } \\
\hline \multirow[t]{2}{*}{ Distance to seed dealers } & 0.002 & 0.000 \\
\hline & $(0.002)$ & $(0.002)$ \\
\hline \multirow[t]{2}{*}{ Distance to main market } & 0.000 & 0.000 \\
\hline & $(0.001)$ & $(0.001)$ \\
\hline Distance to ag ext office & -0.002 & 0.002 \\
\hline & $(0.002)$ & $(0.002)$ \\
\hline Distance to fert dealers & -0.001 & -0.002 \\
\hline & $(0.001)$ & $(0.002)$ \\
\hline Distance to coops & 0.002 & $0.004 * * *$ \\
\hline & $(0.001)$ & $(0.001)$ \\
\hline Leadership & $-0.181 * *$ & -0.006 \\
\hline & $(0.085)$ & $(0.098)$ \\
\hline Kinship & $0.003 * *$ & 0.000 \\
\hline & $(0.001)$ & $(0.002)$ \\
\hline No of traders & -0.000 & -0.003 \\
\hline & $(0.006)$ & $(0.006)$ \\
\hline Confidence & 0.016 & -0.142 \\
\hline & $(0.090)$ & $(0.103)$ \\
\hline
\end{tabular}




\begin{tabular}{lrr}
\hline & \multicolumn{2}{c}{$1-3 \mathrm{RS}^{\mathrm{a}}$} \\
\cline { 2 - 3 } Explanatory variables & \multicolumn{1}{c}{ Coef/se } & \multicolumn{1}{c}{ Coef/se } \\
\hline Seed not available on time & 0.070 & $0.199^{*}$ \\
& $(0.095)$ & $(0.109)$ \\
High seed price & $0.185^{*}$ & 0.190 \\
& $(0.107)$ & $(0.124)$ \\
Low seed quality & $-0.182^{*}$ & 0.024 \\
District fixed effects controlled & $(0.100)$ & $(0.114)$ \\
Mundlak's fixed effects controlled & Yes & Yes \\
Constant & Yes & Yes \\
& $3.941^{* * *}$ & $3.281^{* * *}$ \\
Log likelihood & $(0.667)$ & $(0.699)$ \\
Likelihood ratio (LR) chi-square test & -4282.379 \\
Joint Wald test statistic $\mathrm{H}_{0}:$ the exclusion restrictions are jointly zero) & $4323.26^{* * *}$ \\
Pseudo ${ }^{2}$ & $58.73 * * *$ \\
Number of plots & 0.335 & \\
\hline
\end{tabular}

Notes: (i) $* * * * 0.01, * * \mathrm{p}<0.05$, * $\mathrm{p}<0.1$. (ii) Clustered standard errors at household level in brackets. (iii) ${ }^{\text {a }} \mathrm{FS}$ and $1-3 \mathrm{RS}$ refer fresh seeds and recycled seeds (1-3 seasons), respectively. The base group is recycled seeds ( $>3$ seasons). (iv) $)^{\mathbf{b}, \mathbf{c}, \mathbf{d}, \mathbf{e}, \mathbf{f}, \mathbf{g}, \mathbf{h , i}}$ the base categories hybrids, no rotation, flat slope, shallow depth, black, good soil fertility, illiterate and high asset, respectively. 
Table 4.8. The random effects switching regressions.

\begin{tabular}{|c|c|c|c|c|c|c|c|c|c|}
\hline \multirow[b]{3}{*}{ Explanatory variables } & \multicolumn{9}{|c|}{ Log of land productivity (kg/ha) models with: } \\
\hline & \multicolumn{3}{|c|}{$\begin{array}{l}\text { Exogenous switching regressions } \\
\text { excluding the inverse Mill's ratio }\end{array}$} & \multicolumn{3}{|c|}{$\begin{array}{l}\text { Exogenous switching regressions } \\
\text { excluding the inverse Mill's ratio, but the } \\
\text { exclusion restrictions are used as } \\
\text { explanatory variables }\end{array}$} & \multicolumn{3}{|c|}{ Endogenous switching regressions } \\
\hline & $\begin{array}{c}\mathrm{FS}^{\mathrm{a}} \\
\text { Coef/se }\end{array}$ & $\begin{array}{l}1-3 \mathrm{RS}^{\mathbf{a}} \\
\text { Coef/se }\end{array}$ & $\begin{array}{l}>3 \mathrm{RS}^{\mathrm{a}} \\
\text { Coef/se }\end{array}$ & $\begin{array}{c}\text { FS } \\
\text { Coef/se }\end{array}$ & $\begin{array}{l}1-3 \mathrm{RS} \\
\text { Coef/se }\end{array}$ & $\begin{array}{l}>3 \mathrm{RS} \\
\text { Coef/se }\end{array}$ & $\begin{array}{c}\text { FS } \\
\text { Coef/se }\end{array}$ & $\begin{array}{l}1-3 \mathrm{RS} \\
\text { Coef/se }\end{array}$ & $\begin{array}{c}>3 \mathrm{RS} \\
\text { Coef/se }\end{array}$ \\
\hline \multicolumn{10}{|l|}{ Inputs } \\
\hline Labor & $\begin{array}{l}0.279 * * * \\
(0.056)\end{array}$ & $\begin{array}{l}0.330 * * * \\
(0.121)\end{array}$ & $\begin{array}{c}0.099 \\
(0.121)\end{array}$ & $\begin{array}{l}0.275 * * * \\
(0.056)\end{array}$ & $\begin{array}{l}0.304 * * \\
(0.125)\end{array}$ & $\begin{array}{c}0.098 \\
(0.121)\end{array}$ & $\begin{array}{l}0.279 * * * \\
(0.057)\end{array}$ & $\begin{array}{l}0.332 * \\
(0.171)\end{array}$ & $\begin{array}{c}0.098 \\
(0.143)\end{array}$ \\
\hline Fertilizers $(\log )$ & $\begin{array}{c}0.276 * * * \\
(0.025)\end{array}$ & $\begin{array}{c}0.182 * * * \\
(0.068)\end{array}$ & $\begin{array}{c}0.295 * * * \\
(0.062)\end{array}$ & $\begin{array}{c}0.277 * * * \\
(0.025)\end{array}$ & $\begin{array}{c}0.187 * * * \\
(0.070)\end{array}$ & $\begin{array}{c}0.296 * * * \\
(0.062)\end{array}$ & $\begin{array}{c}0.278 * * * \\
(0.028)\end{array}$ & $\begin{array}{c}0.183 * * \\
(0.076)\end{array}$ & $\begin{array}{c}0.296 * * * \\
(0.084)\end{array}$ \\
\hline Manure (log) & $\begin{array}{l}-0.002 \\
(0.023)\end{array}$ & $\begin{array}{c}0.069 \\
(0.066)\end{array}$ & $\begin{array}{c}0.117 * * \\
(0.056)\end{array}$ & $\begin{array}{l}-0.003 \\
(0.023)\end{array}$ & $\begin{array}{c}0.065 \\
(0.067)\end{array}$ & $\begin{array}{c}0.116^{* *} * \\
(0.056)\end{array}$ & $\begin{array}{l}-0.002 \\
(0.026)\end{array}$ & $\begin{array}{c}0.066 \\
(0.105)\end{array}$ & $\begin{array}{c}0.117 \\
(0.079)\end{array}$ \\
\hline Other agrochemicals (log) & $\begin{array}{c}0.045 \\
(0.047)\end{array}$ & $\begin{array}{c}-0.211 * * \\
(0.090)\end{array}$ & $\begin{array}{c}0.043 \\
(0.140)\end{array}$ & $\begin{array}{c}0.038 \\
(0.047)\end{array}$ & $\begin{array}{c}-0.213^{*} * \\
(0.091)\end{array}$ & $\begin{array}{c}0.058 \\
(0.144)\end{array}$ & $\begin{array}{c}0.045 \\
(0.058)\end{array}$ & $\begin{array}{l}-0.218 \\
(0.151)\end{array}$ & $\begin{array}{c}0.042 \\
(0.132)\end{array}$ \\
\hline $\mathrm{OPVs}^{\mathbf{b}}$ & $\begin{array}{c}-0.203 * * * \\
(0.078)\end{array}$ & $\begin{array}{l}-0.081 \\
(0.099)\end{array}$ & $\begin{array}{l}-0.117 \\
(0.100)\end{array}$ & $\begin{array}{c}-0.199 * * * \\
(0.077)\end{array}$ & $\begin{array}{l}-0.071 \\
(0.097)\end{array}$ & $\begin{array}{l}-0.130 \\
(0.101)\end{array}$ & $\begin{array}{c}-0.191 * * \\
(0.080)\end{array}$ & $\begin{array}{l}-0.052 \\
(0.127)\end{array}$ & $\begin{array}{l}-0.112 \\
(0.122)\end{array}$ \\
\hline Unidentified & $\begin{array}{c}-0.165^{* *} \\
(0.072)\end{array}$ & $\begin{array}{l}-0.151 \\
(0.106)\end{array}$ & $\begin{array}{c}0.014 \\
(0.087)\end{array}$ & $\begin{array}{c}-0.168 * * \\
(0.071)\end{array}$ & $\begin{array}{c}-0.163 \\
(0.107)\end{array}$ & $\begin{array}{l}-0.002 \\
(0.085)\end{array}$ & $\begin{array}{c}-0.131 * \\
(0.074)\end{array}$ & $\begin{array}{c}-0.089 \\
(0.156)\end{array}$ & $\begin{array}{c}0.022 \\
(0.110)\end{array}$ \\
\hline Locals & $\begin{array}{c}-0.175 * * * \\
(0.057)\end{array}$ & $\begin{array}{c}-0.242 * * * \\
(0.089)\end{array}$ & $\begin{array}{c}-0.123 \\
(0.076)\end{array}$ & $\begin{array}{c}-0.174 * * * \\
(0.057)\end{array}$ & $\begin{array}{c}-0.241 * * * \\
(0.087)\end{array}$ & $\begin{array}{c}-0.125^{*} \\
(0.076)\end{array}$ & $\begin{array}{c}-0.164 * * * \\
(0.058)\end{array}$ & $\begin{array}{c}-0.146 \\
(0.154)\end{array}$ & $\begin{array}{l}-0.110 \\
(0.116)\end{array}$ \\
\hline Compost & $\begin{array}{c}0.012 \\
(0.073)\end{array}$ & $\begin{array}{c}0.210 \\
(0.234)\end{array}$ & $\begin{array}{c}0.219 \\
(0.158)\end{array}$ & $\begin{array}{c}0.016 \\
(0.072)\end{array}$ & $\begin{array}{c}0.233 \\
(0.237)\end{array}$ & $\begin{array}{c}0.253 \\
(0.155)\end{array}$ & $\begin{array}{c}0.010 \\
(0.075)\end{array}$ & $\begin{array}{c}0.192 \\
(0.272)\end{array}$ & $\begin{array}{c}0.211 \\
(0.205)\end{array}$ \\
\hline Oxen ownership & $\begin{array}{c}0.097 * * \\
(0.038)\end{array}$ & $\begin{array}{c}0.062 \\
(0.079)\end{array}$ & $\begin{array}{l}0.127 * \\
(0.073)\end{array}$ & $\begin{array}{c}0.094 * * \\
(0.038)\end{array}$ & $\begin{array}{c}0.028 \\
(0.079)\end{array}$ & $\begin{array}{c}0.102 \\
(0.073)\end{array}$ & $\begin{array}{c}0.099 * * \\
(0.042)\end{array}$ & $\begin{array}{c}0.085 \\
(0.113)\end{array}$ & $\begin{array}{c}0.131 \\
(0.086)\end{array}$ \\
\hline Inputs interaction terms & & & & & & & & & \\
\hline Labor squared & $\begin{array}{c}-0.038 \\
(0.028)\end{array}$ & $\begin{array}{c}-0.129 * * \\
(0.057)\end{array}$ & $\begin{array}{c}-0.117 * * * \\
(0.040)\end{array}$ & $\begin{array}{c}-0.038 \\
(0.028)\end{array}$ & $\begin{array}{c}-0.125^{* *} \\
(0.056)\end{array}$ & $\begin{array}{c}-0.106 * * * \\
(0.041)\end{array}$ & $\begin{array}{l}-0.037 \\
(0.030)\end{array}$ & $\begin{array}{l}-0.126 \\
(0.081)\end{array}$ & $\begin{array}{c}-0.117 * * * \\
(0.045)\end{array}$ \\
\hline Labor $(\log ) \mathrm{X}$ fertilizers $(\log )$ & $\begin{array}{c}-0.055^{*} * * \\
(0.009)\end{array}$ & $\begin{array}{l}-0.022 \\
(0.019)\end{array}$ & $\begin{array}{c}-0.025^{*} \\
(0.014)\end{array}$ & $\begin{array}{c}-0.054 * * * \\
(0.009)\end{array}$ & $\begin{array}{l}-0.024 \\
(0.019)\end{array}$ & $\begin{array}{l}-0.023 \\
(0.014)\end{array}$ & $\begin{array}{c}-0.055 * * * \\
(0.009)\end{array}$ & $\begin{array}{l}-0.022 \\
(0.026)\end{array}$ & $\begin{array}{l}-0.025 \\
(0.017)\end{array}$ \\
\hline Labor $(\log ) X$ manure $(\log )$ & $\begin{array}{c}-0.001 \\
(0.010)\end{array}$ & $\begin{array}{c}-0.010 \\
(0.019)\end{array}$ & $\begin{array}{c}-0.023 * \\
(0.013)\end{array}$ & $\begin{array}{c}-0.001 \\
(0.010)\end{array}$ & $\begin{array}{l}-0.009 \\
(0.019)\end{array}$ & $\begin{array}{c}-0.022 * \\
(0.013)\end{array}$ & $\begin{array}{l}-0.001 \\
(0.010)\end{array}$ & $\begin{array}{l}-0.007 \\
(0.027)\end{array}$ & $\begin{array}{c}-0.023 * \\
(0.013)\end{array}$ \\
\hline Labor $(\log ) \mathrm{X}$ other agrochemicals $(\log )$ & $\begin{array}{c}0.007 \\
(0.014)\end{array}$ & $\begin{array}{l}-0.008 \\
(0.044)\end{array}$ & $\begin{array}{l}-0.051 \\
(0.046)\end{array}$ & $\begin{array}{c}0.007 \\
(0.014)\end{array}$ & $\begin{array}{l}-0.016 \\
(0.044)\end{array}$ & $\begin{array}{l}-0.047 \\
(0.046)\end{array}$ & $\begin{array}{c}0.007 \\
(0.016)\end{array}$ & $\begin{array}{l}-0.004 \\
(0.051)\end{array}$ & $\begin{array}{l}-0.051 \\
(0.050)\end{array}$ \\
\hline Fertilizers $(\log )$ squared & $0.047 * * *$ & 0.050 & $0.030 * * *$ & $0.049 * * *$ & 0.053 & $0.028 * *$ & $0.048 * * *$ & 0.050 & 0.031 \\
\hline
\end{tabular}


Log of land productivity (kg/ha) models with:

Exogenous switching regressions

Exogenous switching regressions excluding the inverse Mill's ratio

excluding the inverse Mill's ratio, but the

exclusion restrictions are used as

\begin{tabular}{|c|c|c|c|c|c|c|c|c|c|}
\hline \multirow[b]{2}{*}{ Explanatory variables } & \multicolumn{7}{|c|}{ explanatory varıables } & \multirow[b]{2}{*}{$\begin{array}{c}1-3 \mathrm{RS} \\
\text { Coef/se }\end{array}$} & \multirow[b]{2}{*}{$\begin{array}{c}>3 \mathrm{RS} \\
\text { Coef/se }\end{array}$} \\
\hline & $\begin{array}{c}F^{\mathrm{a}} \\
\text { Coef/se }\end{array}$ & $\begin{array}{l}1-3 \mathrm{RS}^{\mathbf{a}} \\
\text { Coef/se }\end{array}$ & $\begin{array}{l}>3 \mathrm{RS}^{\mathrm{a}} \\
\text { Coef/se }\end{array}$ & $\begin{array}{c}\text { FS } \\
\text { Coef/se }\end{array}$ & $\begin{array}{l}1-3 \mathrm{RS} \\
\text { Coef/se }\end{array}$ & $\begin{array}{c}>3 \mathrm{RS} \\
\text { Coef/se }\end{array}$ & $\begin{array}{c}F S \\
\text { Coef/se }\end{array}$ & & \\
\hline \multirow{3}{*}{ Fertilizers $(\log ) \mathrm{X}$ manure $(\log )$} & $(0.013)$ & $(0.037)$ & $(0.011)$ & $(0.013)$ & $(0.037)$ & $(0.011)$ & $(0.016)$ & $(0.034)$ & $(0.022)$ \\
\hline & 0.002 & -0.002 & $0.008 * *$ & 0.002 & -0.001 & $0.008 * *$ & 0.001 & -0.003 & $0.008 * *$ \\
\hline & $(0.002)$ & $(0.004)$ & $(0.003)$ & $(0.002)$ & $(0.004)$ & $(0.003)$ & $(0.002)$ & $(0.005)$ & $(0.004)$ \\
\hline \multirow[t]{2}{*}{ Fertilizers (log) X other agrochemicals (log) } & -0.003 & $-0.033 * * *$ & -0.007 & -0.004 & $-0.034 * * *$ & -0.005 & -0.003 & $-0.033 * * *$ & -0.007 \\
\hline & $(0.004)$ & $(0.009)$ & $(0.008)$ & $(0.004)$ & $(0.010)$ & $(0.008)$ & $(0.004)$ & $(0.012)$ & $(0.009)$ \\
\hline \multirow[t]{2}{*}{ Manure $(\log )$ squared } & $0.016^{*}$ & -0.000 & 0.022 & $0.016^{*}$ & -0.001 & 0.022 & 0.016 & -0.000 & 0.022 \\
\hline & $(0.009)$ & $(0.025)$ & $(0.020)$ & $(0.009)$ & $(0.025)$ & $(0.020)$ & $(0.010)$ & $(0.045)$ & $(0.029)$ \\
\hline \multirow[t]{2}{*}{ Manure $(\log ) \mathrm{X}$ other agrochemicals $(\log )$} & 0.000 & 0.009 & 0.004 & 0.000 & 0.009 & 0.004 & 0.000 & 0.009 & 0.004 \\
\hline & $(0.003)$ & $(0.010)$ & $(0.008)$ & $(0.003)$ & $(0.010)$ & $(0.008)$ & $(0.004)$ & $(0.011)$ & $(0.010)$ \\
\hline \multirow[t]{2}{*}{ Other agrochemicals (log) squared } & -0.004 & $0.066 * *$ & -0.017 & -0.003 & $0.077 * *$ & -0.017 & -0.004 & 0.070 & -0.016 \\
\hline & $(0.010)$ & $(0.032)$ & $(0.040)$ & $(0.010)$ & $(0.034)$ & $(0.041)$ & $(0.014)$ & $(0.058)$ & $(0.046)$ \\
\hline \multicolumn{10}{|l|}{ Other plot level variables } \\
\hline \multirow{2}{*}{ Intercropping } & $0.094 * *$ & 0.051 & -0.024 & $0.097 * *$ & 0.037 & -0.024 & $0.096^{*}$ & 0.041 & -0.024 \\
\hline & $(0.048)$ & $(0.128)$ & $(0.092)$ & $(0.048)$ & $(0.127)$ & $(0.092)$ & $(0.050)$ & $(0.143)$ & $(0.109)$ \\
\hline \multirow[t]{2}{*}{ Legume rotation ${ }^{\mathbf{c}}$} & 0.054 & 0.073 & 0.208 & 0.052 & 0.077 & 0.221 & 0.052 & 0.067 & 0.208 \\
\hline & $(0.055)$ & $(0.174)$ & $(0.257)$ & $(0.056)$ & $(0.174)$ & $(0.253)$ & $(0.052)$ & $(0.176)$ & $(0.246)$ \\
\hline \multirow[t]{2}{*}{ Cereals rotation } & $0.063 * *$ & $0.202 * * *$ & -0.010 & $0.065 * *$ & $0.192 * *$ & -0.006 & $0.060 * *$ & $0.199 * *$ & -0.010 \\
\hline & $(0.032)$ & $(0.077)$ & $(0.070)$ & $(0.031)$ & $(0.078)$ & $(0.069)$ & $(0.030)$ & $(0.087)$ & $(0.066)$ \\
\hline \multirow[t]{2}{*}{ Crop residue } & 0.033 & -0.082 & 0.084 & 0.036 & -0.088 & 0.084 & 0.035 & -0.087 & 0.083 \\
\hline & $(0.042)$ & $(0.119)$ & $(0.082)$ & $(0.042)$ & $(0.118)$ & $(0.081)$ & $(0.043)$ & $(0.138)$ & $(0.098)$ \\
\hline \multirow[t]{2}{*}{ Own seed } & -0.045 & -0.044 & $0.401 * * *$ & -0.055 & -0.061 & $0.412 * * *$ & -0.048 & -0.037 & $0.400 * * *$ \\
\hline & $(0.053)$ & $(0.091)$ & $(0.147)$ & $(0.054)$ & $(0.091)$ & (0.149) & $(0.057)$ & $(0.111)$ & $(0.150)$ \\
\hline \multirow[t]{2}{*}{ Medium slope $^{\mathbf{d}}$} & 0.009 & 0.065 & 0.093 & 0.008 & 0.049 & 0.109 & 0.010 & 0.051 & 0.091 \\
\hline & $(0.039)$ & (0.109) & $(0.082)$ & $(0.039)$ & $(0.110)$ & $(0.080)$ & $(0.037)$ & $(0.120)$ & $(0.092)$ \\
\hline \multirow[t]{2}{*}{ Steep slope } & $0.197 * *$ & -0.159 & -0.064 & $0.194 * *$ & -0.141 & -0.005 & $0.192 * *$ & -0.219 & -0.071 \\
\hline & $(0.088)$ & $(0.241)$ & $(0.187)$ & $(0.088)$ & $(0.241)$ & $(0.190)$ & $(0.086)$ & $(0.304)$ & $(0.229)$ \\
\hline \multirow[t]{2}{*}{ Medium depth ${ }^{\mathbf{e}}$} & 0.066 & $-0.376^{* *}$ & -0.021 & 0.069 & $-0.366^{* *}$ & -0.027 & 0.064 & $-0.345^{*}$ & -0.020 \\
\hline & $(0.048)$ & $(0.150)$ & (0.109) & $(0.048)$ & $(0.150)$ & $(0.106)$ & $(0.048)$ & $(0.181)$ & $(0.128)$ \\
\hline \multirow[t]{2}{*}{ Deep } & 0.017 & $-0.225^{*}$ & -0.050 & 0.018 & $-0.221 *$ & -0.039 & 0.017 & -0.216 & -0.051 \\
\hline & $(0.049)$ & $(0.131)$ & $(0.094)$ & $(0.050)$ & $(0.133)$ & $(0.092)$ & $(0.049)$ & $(0.168)$ & $(0.104)$ \\
\hline
\end{tabular}


Log of land productivity (kg/ha) models with:

Exogenous switching regressions excluding the inverse Mill's ratio

Exogenous switching regression

excluding the inverse Mill's ratio, but the Endogenous switching regressions exclusion restrictions are used as explanatory variables

\begin{tabular}{|c|c|c|c|c|c|c|c|c|c|}
\hline \multirow[b]{2}{*}{ Explanatory variables } & & \multirow[b]{2}{*}{$\begin{array}{c}1-3 \mathrm{RS} \\
\text { Coef/se }\end{array}$} & \multirow[b]{2}{*}{$\begin{array}{c}>3 \mathrm{RS} \\
\text { Coef/se }\end{array}$} \\
\hline & $\begin{array}{c}\mathrm{FS}^{\mathrm{a}} \\
\text { Coef/se }\end{array}$ & $\begin{array}{l}1-3 \mathrm{RS}^{\mathbf{a}} \\
\text { Coef/se }\end{array}$ & $\begin{array}{l}>3 \mathrm{RS}^{\mathrm{a}} \\
\text { Coef/se }\end{array}$ & $\begin{array}{c}\text { FS } \\
\text { Coef/se }\end{array}$ & $\begin{array}{c}1-3 \mathrm{RS} \\
\text { Coef/se }\end{array}$ & $\begin{array}{c}>3 \mathrm{RS} \\
\text { Coef/se }\end{array}$ & $\begin{array}{c}\text { FS } \\
\text { Coef/se }\end{array}$ & & \\
\hline \multirow[t]{2}{*}{ Brown $^{f}$} & -0.029 & 0.165 & 0.139 & -0.022 & 0.168 & 0.130 & -0.029 & 0.155 & 0.138 \\
\hline & $(0.051)$ & $(0.139)$ & $(0.112)$ & $(0.051)$ & $(0.139)$ & $(0.110)$ & $(0.053)$ & $(0.145)$ & $(0.144)$ \\
\hline \multirow[t]{2}{*}{ Red } & -0.034 & 0.007 & $0.183 * *$ & -0.028 & 0.009 & $0.159 *$ & -0.034 & 0.002 & 0.182 \\
\hline & $(0.053)$ & $(0.116)$ & $(0.091)$ & $(0.053)$ & $(0.116)$ & $(0.090)$ & $(0.053)$ & $(0.124)$ & $(0.116)$ \\
\hline \multirow[t]{2}{*}{ Gray } & 0.041 & 0.022 & -0.139 & 0.052 & 0.066 & -0.113 & 0.043 & 0.051 & -0.139 \\
\hline & $(0.068)$ & $(0.159)$ & $(0.306)$ & $(0.068)$ & $(0.159)$ & $(0.299)$ & $(0.066)$ & $(0.171)$ & $(0.347)$ \\
\hline \multirow{2}{*}{ Medium soil fertility ${ }^{\mathrm{g}}$} & -0.004 & 0.110 & -0.088 & -0.003 & 0.102 & -0.063 & -0.006 & 0.104 & -0.088 \\
\hline & $(0.032)$ & $(0.092)$ & $(0.072)$ & $(0.032)$ & $(0.092)$ & $(0.071)$ & $(0.033)$ & $(0.105)$ & $(0.079)$ \\
\hline \multirow{2}{*}{ Poor soil fertility } & -0.083 & 0.097 & 0.130 & -0.086 & 0.110 & 0.131 & -0.087 & 0.098 & 0.132 \\
\hline & $(0.056)$ & $(0.149)$ & $(0.138)$ & $(0.056)$ & $(0.146)$ & $(0.138)$ & $(0.056)$ & $(0.157)$ & $(0.175)$ \\
\hline \multirow[t]{2}{*}{ Rented } & 0.022 & $0.449 * *$ & -0.005 & 0.023 & $0.436 * *$ & 0.025 & 0.023 & $0.452 * *$ & -0.005 \\
\hline & $(0.049)$ & $(0.176)$ & $(0.171)$ & $(0.049)$ & $(0.175)$ & $(0.167)$ & $(0.053)$ & $(0.217)$ & $(0.193)$ \\
\hline \multirow[t]{2}{*}{ Plot size } & 0.022 & $0.135^{*}$ & $0.167 * *$ & 0.019 & $0.144^{*}$ & $0.172 * *$ & 0.020 & 0.110 & 0.167 \\
\hline & $(0.037)$ & $(0.081)$ & $(0.076)$ & $(0.037)$ & $(0.081)$ & $(0.076)$ & $(0.036)$ & $(0.122)$ & $(0.106)$ \\
\hline \multirow[t]{2}{*}{ Plot distance } & -0.000 & $0.003 *$ & 0.003 & -0.000 & $0.003 *$ & 0.002 & -0.000 & 0.003 & 0.003 \\
\hline & $(0.001)$ & $(0.001)$ & $(0.002)$ & $(0.001)$ & $(0.001)$ & $(0.002)$ & $(0.001)$ & $(0.002)$ & $(0.002)$ \\
\hline \multicolumn{10}{|l|}{ Production stresses } \\
\hline \multirow[t]{2}{*}{ Drought } & 0.108 & $-0.469 * * *$ & -0.158 & 0.109 & $-0.510 * * *$ & -0.311 & 0.109 & $-0.415 * *$ & -0.131 \\
\hline & $(0.157)$ & $(0.162)$ & $(0.682)$ & $(0.155)$ & $(0.157)$ & $(0.636)$ & $(0.146)$ & $(0.200)$ & $(1.020)$ \\
\hline \multirow[t]{2}{*}{ Waterlogging } & $-0.227 * *$ & -0.035 & $-1.019 * * *$ & $-0.233 * *$ & -0.066 & $-1.010 * * *$ & $-0.229 * *$ & -0.064 & $-1.023 * *$ \\
\hline & $(0.111)$ & $(0.222)$ & $(0.368)$ & $(0.110)$ & $(0.215)$ & $(0.360)$ & $(0.104)$ & $(0.308)$ & $(0.407)$ \\
\hline \multirow[t]{2}{*}{ Abiotic stress } & -0.026 & $-0.724 *$ & $-0.474 * *$ & -0.029 & $-0.663^{*}$ & $-0.455^{* *}$ & -0.015 & -0.732 & $-0.477 * *$ \\
\hline & $(0.133)$ & $(0.401)$ & $(0.195)$ & $(0.134)$ & $(0.396)$ & $(0.192)$ & $(0.148)$ & $(0.562)$ & $(0.215)$ \\
\hline \multirow[t]{2}{*}{ Pests } & -0.261 & $0.503 * * *$ & -0.339 & $-0.265^{*}$ & $0.542 * * *$ & -0.194 & $-0.262 *$ & $0.459 * *$ & -0.365 \\
\hline & $(0.159)$ & $(0.177)$ & $(0.695)$ & $(0.158)$ & $(0.177)$ & $(0.649)$ & $(0.147)$ & $(0.230)$ & (1.007) \\
\hline \multirow[t]{2}{*}{ Disease } & $-0.243 * *$ & 0.155 & -0.050 & $-0.240 * *$ & 0.171 & -0.027 & $-0.246 * *$ & 0.130 & -0.054 \\
\hline & $(0.111)$ & $(0.243)$ & $(0.207)$ & $(0.110)$ & $(0.244)$ & $(0.208)$ & $(0.118)$ & $(0.385)$ & $(0.195)$ \\
\hline \multicolumn{10}{|c|}{ Household level variables } \\
\hline Male & $0.119 *$ & 0.182 & -0.102 & $0.111^{*}$ & 0.191 & -0.112 & $0.121 * *$ & 0.195 & -0.100 \\
\hline
\end{tabular}


Log of land productivity (kg/ha) models with:

Exogenous switching regressions excluding the inverse Mill's ratio

Exogenous switching regression

excluding the inverse Mill's ratio, but the Endogenous switching regressions exclusion restrictions are used as explanatory variables

\begin{tabular}{|c|c|c|c|c|c|c|c|c|c|}
\hline \multirow[b]{2}{*}{ Explanatory variables } & & \multirow[b]{2}{*}{$\begin{array}{c}>3 \mathrm{RS} \\
\text { Coef/se }\end{array}$} \\
\hline & $\begin{array}{c}F^{\mathrm{a}} \\
\text { Coef/se }\end{array}$ & $\begin{array}{l}1-3 R^{a} S^{a} \\
\text { Coef/se }\end{array}$ & $\begin{array}{l}>3 \mathrm{RS}^{\mathbf{a}} \\
\text { Coef/se }\end{array}$ & $\begin{array}{c}\text { FS } \\
\text { Coef/se }\end{array}$ & $\begin{array}{l}1-3 \mathrm{RS} \\
\text { Coef/se }\end{array}$ & $\begin{array}{c}>3 \mathrm{RS} \\
\text { Coef/se }\end{array}$ & $\begin{array}{c}\text { FS } \\
\text { Coef/se }\end{array}$ & $\begin{array}{l}1-3 \mathrm{RS} \\
\text { Coef/se }\end{array}$ & \\
\hline & $(0.061)$ & $(0.121)$ & $(0.096)$ & $(0.060)$ & $(0.119)$ & $(0.098)$ & $(0.060)$ & $(0.134)$ & $(0.098)$ \\
\hline \multirow[t]{2}{*}{ Age } & $-0.003 * *$ & $-0.007 * *$ & $-0.004 * *$ & $-0.003 * * *$ & $-0.007 * *$ & $-0.004 *$ & $-0.003 * *$ & $-0.007 * *$ & $-0.004 *$ \\
\hline & $(0.001)$ & $(0.003)$ & $(0.002)$ & $(0.001)$ & $(0.003)$ & $(0.002)$ & $(0.001)$ & $(0.003)$ & $(0.002)$ \\
\hline \multirow[t]{2}{*}{ School $>=2 \&<6^{\mathbf{h}}$} & 0.030 & -0.013 & -0.042 & 0.012 & -0.022 & -0.051 & 0.029 & -0.017 & -0.041 \\
\hline & $(0.030)$ & $(0.070)$ & $(0.055)$ & $(0.030)$ & $(0.072)$ & $(0.055)$ & $(0.032)$ & $(0.090)$ & $(0.061)$ \\
\hline \multirow[t]{2}{*}{ School >=6 } & $0.179 * * *$ & $0.242 * * *$ & $-0.176^{*}$ & $0.153 * * *$ & $0.232 * *$ & $-0.192 * *$ & $0.177 * * *$ & $0.221 * *$ & $-0.177 *$ \\
\hline & $(0.038)$ & $(0.093)$ & $(0.091)$ & $(0.038)$ & $(0.099)$ & $(0.090)$ & $(0.039)$ & $(0.101)$ & $(0.091)$ \\
\hline \multirow[t]{2}{*}{ Training } & 0.067 & -0.238 & -0.084 & 0.060 & -0.265 & -0.066 & 0.070 & -0.201 & -0.079 \\
\hline & $(0.064)$ & $(0.177)$ & $(0.172)$ & $(0.063)$ & $(0.180)$ & $(0.171)$ & $(0.061)$ & $(0.261)$ & $(0.175)$ \\
\hline \multirow[t]{2}{*}{ Low asset ${ }^{\mathrm{i}}$} & $-0.205 *$ & $-0.715 * *$ & $1.517 * * *$ & $-0.241 * *$ & $-0.740 * *$ & $1.550 * * *$ & -0.207 & -0.724 & $1.522 * * *$ \\
\hline & $(0.119)$ & $(0.283)$ & $(0.218)$ & $(0.110)$ & $(0.289)$ & $(0.217)$ & $(0.147)$ & $(0.469)$ & $(0.253)$ \\
\hline \multirow[t]{2}{*}{ Middle asset } & $-0.132 * * *$ & 0.083 & -0.050 & $-0.129 * * *$ & 0.096 & -0.053 & $-0.132 * * *$ & 0.063 & -0.051 \\
\hline & $(0.041)$ & $(0.082)$ & $(0.059)$ & $(0.041)$ & $(0.082)$ & $(0.060)$ & $(0.042)$ & $(0.112)$ & $(0.066)$ \\
\hline \multirow[t]{2}{*}{ Survey year } & 0.028 & $0.784 * * *$ & $-1.538 * * *$ & 0.079 & $0.781 * * *$ & $-1.534 * * *$ & 0.018 & 0.697 & $-1.556 * * *$ \\
\hline & $(0.122)$ & $(0.296)$ & $(0.229)$ & $(0.114)$ & $(0.300)$ & $(0.231)$ & $(0.145)$ & $(0.514)$ & $(0.297)$ \\
\hline \multicolumn{10}{|c|}{ Variables used as instruments } \\
\hline \multirow[t]{2}{*}{ Distance to seed dealers } & & & & $-0.001 * *$ & $-0.002 * * *$ & 0.001 & & & \\
\hline & & & & $(0.000)$ & $(0.001)$ & $(0.001)$ & & & \\
\hline \multirow[t]{2}{*}{ Distance to main market } & & & & -0.000 & 0.001 & $-0.001 *$ & & & \\
\hline & & & & $(0.000)$ & $(0.001)$ & $(0.000)$ & & & \\
\hline \multirow{2}{*}{ Distance to ag ext office } & & & & 0.000 & 0.002 & 0.001 & & & \\
\hline & & & & $(0.001)$ & $(0.001)$ & $(0.001)$ & & & \\
\hline \multirow[t]{2}{*}{ Distance to fert dealers } & & & & 0.000 & $0.001 * *$ & -0.001 & & & \\
\hline & & & & $(0.000)$ & $(0.000)$ & $(0.001)$ & & & \\
\hline \multirow[t]{3}{*}{ Distance to coops } & & & & $-0.001 * *$ & -0.000 & -0.000 & & & \\
\hline & & & & $(0.000)$ & $(0.000)$ & $(0.001)$ & & & \\
\hline & & & & $(0.000)$ & $(0.001)$ & $(0.001)$ & & & \\
\hline \multirow[t]{2}{*}{ Leadership } & & & & $0.082 * * *$ & $0.123 *$ & $0.096 *$ & & & \\
\hline & & & & $(0.027)$ & $(0.068)$ & $(0.050)$ & & & \\
\hline
\end{tabular}


Exogenous switching regressions excluding the inverse Mill's ratio

Exogenous switching regressions

excluding the inverse Mill's ratio, but the Endogenous switching regressions

exclusion restrictions are used as

explanatory variables

\begin{tabular}{|c|c|c|c|c|c|c|c|c|c|}
\hline Explanatory variables & $\begin{array}{c}F^{\mathrm{a}} \\
\text { Coef/se }\end{array}$ & $\begin{array}{l}1-3 \mathrm{RS}^{\mathrm{a}} \\
\text { Coef/se }\end{array}$ & $\begin{array}{l}>3 \mathrm{RS}^{\mathrm{a}} \\
\text { Coef/se }\end{array}$ & $\begin{array}{c}\text { FS } \\
\text { Coef/se }\end{array}$ & $\begin{array}{c}1-3 \mathrm{RS} \\
\text { Coef/se }\end{array}$ & $\begin{array}{c}>3 \mathrm{RS} \\
\text { Coef/se }\end{array}$ & $\begin{array}{c}\text { FS } \\
\text { Coef/se }\end{array}$ & $\begin{array}{l}1-3 \mathrm{RS} \\
\text { Coef/se }\end{array}$ & $\begin{array}{c}>3 \mathrm{RS} \\
\text { Coef/se }\end{array}$ \\
\hline Kinship & & & & $\begin{array}{c}0.000 \\
(0.000)\end{array}$ & $\begin{array}{c}-0.001 \\
(0.001)\end{array}$ & $\begin{array}{l}-0.001 \\
(0.001)\end{array}$ & & & \\
\hline Number of traders & & & & $\begin{array}{l}0.003 * \\
(0.002)\end{array}$ & $\begin{array}{c}0.002 \\
(0.004)\end{array}$ & $\begin{array}{c}0.004 \\
(0.004)\end{array}$ & & & \\
\hline Confidence & & & & $\begin{array}{c}0.001 \\
(0.028)\end{array}$ & $\begin{array}{l}-0.083 \\
(0.066)\end{array}$ & $\begin{array}{l}-0.009 \\
(0.054)\end{array}$ & & & \\
\hline Seed not available on time & & & & $\begin{array}{c}0.038 \\
(0.030)\end{array}$ & $\begin{array}{l}-0.037 \\
(0.069)\end{array}$ & $\begin{array}{c}0.141 * * \\
(0.063)\end{array}$ & & & \\
\hline High seed price & & & & $\begin{array}{l}-0.001 \\
(0.038)\end{array}$ & $\begin{array}{l}-0.003 \\
(0.086)\end{array}$ & $\begin{array}{l}-0.095 \\
(0.065)\end{array}$ & & & \\
\hline Low seed quality & & & & $\begin{array}{c}0.040 \\
(0.029)\end{array}$ & $\begin{array}{c}0.059 \\
(0.067)\end{array}$ & $\begin{array}{l}-0.105 \\
(0.064)\end{array}$ & & & \\
\hline Inverse Mill's ratio & & & & & & & $\begin{array}{l}-0.052 \\
(0.054)\end{array}$ & $\begin{array}{l}-0.152 \\
(0.159)\end{array}$ & $\begin{array}{c}0.023 \\
(0.161)\end{array}$ \\
\hline District fixed effects controlled & Yes & Yes & Yes & Yes & Yes & Yes & Yes & Yes & Yes \\
\hline Mundlak's fixed effects controlled & Yes & Yes & Yes & Yes & Yes & Yes & Yes & Yes & Yes \\
\hline Battese intercept shifting variables controlled & Yes & Yes & Yes & Yes & Yes & Yes & Yes & Yes & Yes \\
\hline Constant & $\begin{array}{l}-0.052 \\
(0.219)\end{array}$ & $\begin{array}{l}-0.061 \\
(0.332)\end{array}$ & $\begin{array}{c}-0.719 * * \\
(0.329)\end{array}$ & $\begin{array}{l}-0.071 \\
(0.222)\end{array}$ & $\begin{array}{l}-0.119 \\
(0.354)\end{array}$ & $\begin{array}{c}-0.603 * \\
(0.346)\end{array}$ & $\begin{array}{l}-0.070 \\
(0.210)\end{array}$ & $\begin{array}{l}-0.162 \\
(0.445)\end{array}$ & $\begin{array}{l}-0.775 \\
(0.517)\end{array}$ \\
\hline Wald test & $2438.42 * * *$ & $2578.99 * * *$ & $6190.82 * * *$ & $2503.87 * * *$ & $2837.93 * * *$ & $6488.71 * * *$ & $3239.11 * * *$ & $3826.50 * * *$ & $3583.16 * * *$ \\
\hline Log likelihood & -6386.383 & -1217.2531 & -1773.9253 & -6368.6711 & -1208.0595 & -1764.1825 & -6385.6841 & -1216.0953 & -1773.909 \\
\hline
\end{tabular}

Di Falco et al. (2011) Falsification test $\left(\mathrm{H}_{0}\right.$ :the instruments are jointly zero)

Cobb Douglas production function $\left(\mathrm{H}_{0}\right.$ : input interaction terms are jointly zero)

Number of plots 5,388

$33.7 * * *$

$32.64 * * *$

$54.38 * * *$

$35.72 * * *$

$28.59 * *$

$35.01 * * *$

11.35

17.84

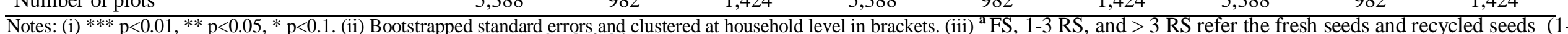

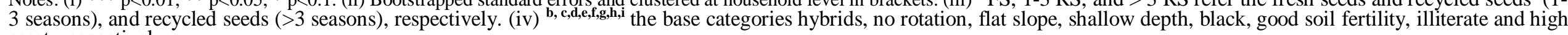
asset, respectively. 
Table 4.9. Average treatment effects on the treated and untreated using the variants of the exogenous switching regressions (land productivity).

\begin{tabular}{|c|c|c|}
\hline \multirow[b]{2}{*}{ Expected outcomes } & \multicolumn{2}{|c|}{ Land productivity (kg/ha) } \\
\hline & $\begin{array}{l}\text { Exogenous } \\
\text { switching } \\
\text { regressions } \\
\text { excluding the } \\
\text { inverse Mill's } \\
\text { ratio }\end{array}$ & $\begin{array}{l}\text { Exogenous } \\
\text { switching } \\
\text { regressions } \\
\text { excluding the } \\
\text { inverse Mill's ratio, } \\
\text { but the exclusion } \\
\text { restrictions used as } \\
\text { explanatory } \\
\text { variables }\end{array}$ \\
\hline Fresh seeds (A) & $\begin{array}{c}2130.32 \\
(13.59)\end{array}$ & $\begin{array}{c}2137.74 \\
(13.78)\end{array}$ \\
\hline Recycled seeds (1-3 seasons) (B) & $\begin{array}{l}1371.12 \\
(27.41)\end{array}$ & $\begin{array}{l}1380.83 \\
(27.83)\end{array}$ \\
\hline Recycled seeds (> 3 seasons) (C) & $\begin{array}{c}1264.63 \\
(19.64)\end{array}$ & $\begin{array}{l}1269.17 \\
(19.80)\end{array}$ \\
\hline Had farmers who used recycled seeds (1-3 seasons) had used fresh seeds (D) & $\begin{array}{c}1949.86 \\
(15.34\end{array}$ & $\begin{array}{l}1958.41 \\
(15.75)\end{array}$ \\
\hline Had farmers who used recycled seeds ( $>3$ seasons) had used fresh seeds (E) & $\begin{array}{l}1545.65 \\
(13.69\end{array}$ & $\begin{array}{l}1521.37 \\
(13.85)\end{array}$ \\
\hline Had farmers who used fresh seeds had used recycled seeds (1-3 seasons) (F) & $\begin{array}{l}1522.36 \\
(26.03)\end{array}$ & $\begin{array}{l}1523.13 \\
(26.14)\end{array}$ \\
\hline Had farmers who used fresh seeds had used recycled seeds ( $>3$ seasons) $(\mathrm{G})$ & $\begin{array}{l}1339.47 \\
(19.30)\end{array}$ & $\begin{array}{c}1338.20 \\
(19.31)\end{array}$ \\
\hline $\mathrm{ATT}_{1}(\mathrm{~A}-\mathrm{D})$ & $\begin{array}{c}180.46 * * * \\
(20.49)\end{array}$ & $\begin{array}{l}179.33 * * * \\
(20.93)\end{array}$ \\
\hline $\mathrm{ATT}_{2}(\mathrm{~A}-\mathrm{E})$ & $\begin{array}{l}584.67 * * * \\
(19.29)\end{array}$ & $\begin{array}{c}616.37 * * * \\
(19.53)\end{array}$ \\
\hline $\mathrm{ATU}_{1}(\mathrm{~F}-\mathrm{B})$ & $\begin{array}{c}151.24 * * * \\
(37.80)\end{array}$ & $\begin{array}{c}142.30 * * * \\
(38.18)\end{array}$ \\
\hline $\mathrm{ATU}_{2}(\mathrm{G}-\mathrm{C})$ & $\begin{array}{l}74.84 * * * \\
(27.54)\end{array}$ & $\begin{array}{l}69.03 * * \\
(27.65)\end{array}$ \\
\hline
\end{tabular}

Notes: (i) $* * \mathrm{p}<0.005, * * * \mathrm{p}<0.01$. (ii) standard errors in brackets. 
Table 4.10. Average treatment effects on the treated and untreated using the variants of the exogenous switching regressions (efficiency).

\begin{tabular}{|c|c|c|}
\hline & \multicolumn{2}{|c|}{ Efficiency $(\%)$} \\
\hline & $\begin{array}{l}\text { Exogenous } \\
\text { switching } \\
\text { regressions } \\
\text { excluding the } \\
\text { inverse Mill's } \\
\text { ratio }\end{array}$ & $\begin{array}{l}\text { Exogenous } \\
\text { switching } \\
\text { regressions } \\
\text { excluding the } \\
\text { inverse Mill's ratio, } \\
\text { but the exclusion } \\
\text { restrictions used as } \\
\text { explanatory } \\
\text { variables }\end{array}$ \\
\hline \multirow[t]{2}{*}{ Fresh seeds (A) } & 61.18 & 62.33 \\
\hline & $(0.20)$ & $(0.20)$ \\
\hline \multirow[t]{2}{*}{ Recycled seeds (1-3 seasons) (B) } & 56.53 & 58.83 \\
\hline & $(0.30)$ & $(0.20)$ \\
\hline \multirow[t]{2}{*}{ Recycled seeds (> 3 seasons) $(\mathrm{C})$} & 55.46 & 54.72 \\
\hline & $(0.20)$ & $(0.20)$ \\
\hline \multirow[t]{2}{*}{ Had farmers who used recycled seeds ( $1-3$ seasons) had used fresh seeds (D) } & 57.61 & 59.58 \\
\hline & $(0.20)$ & $(0.10)$ \\
\hline \multirow[t]{2}{*}{ Had farmers who used recycled seeds ( $>3$ seasons) had used fresh seeds (E) } & 56.59 & 55.93 \\
\hline & $(0.10)$ & $(0.10)$ \\
\hline \multirow[t]{2}{*}{ Had farmers who used fresh seeds had used recycled seeds (1-3 seasons) (F) } & 59.95 & 61.15 \\
\hline & $(0.40)$ & $(0.40)$ \\
\hline \multirow[t]{2}{*}{ Had farmers who used fresh seeds had used recycled seeds ( $>3$ seasons) $(\mathrm{G})$} & 61.04 & 62.15 \\
\hline & $(0.40)$ & $(0.40)$ \\
\hline \multirow[t]{2}{*}{$\mathrm{ATT}_{1}(\mathrm{~A}-\mathrm{D})$} & $3.57 * * *$ & $2.75 * * *$ \\
\hline & $(0.30)$ & $(0.30)$ \\
\hline \multirow[t]{2}{*}{$\mathrm{ATT}_{2}(\mathrm{~A}-\mathrm{E})$} & $4.60^{* * *}$ & $6.40 * * *$ \\
\hline & $(0.30)$ & $(0.30)$ \\
\hline \multirow[t]{2}{*}{$\mathrm{ATU}_{1}(\mathrm{~F}-\mathrm{B})$} & $3.43^{* * *}$ & $2.32 * * *$ \\
\hline & $(0.50)$ & $(0.40)$ \\
\hline \multirow[t]{2}{*}{$\mathrm{ATU}_{2}(\mathrm{G}-\mathrm{C})$} & $5.57 * * *$ & $7.44 * * *$ \\
\hline & $(0.40)$ & $(0.40)$ \\
\hline
\end{tabular}

Notes: (i) $* * * \mathrm{p}<0.01$. (ii) standard errors in brackets. 
Table 4.11. Impact of using fresh seeds on log of land productivity $(\mathrm{kg} / \mathrm{ha})$ based on the endogenous switching regression model.

\begin{tabular}{lc}
\hline Expected outcomes & Log of land productivity (kg/ha) \\
\hline Fresh seeds (A) & 7.55 \\
& $(0.01)$ \\
Recycled seeds (1-3 seasons) (B) & 7.04 \\
& $(0.02)$ \\
Recycled seeds (> 3 seasons) (C) & 6.99 \\
& $(0.02)$ \\
Had farmers who used recycled seeds (1-3 seasons) had used fresh seeds (D) & 7.43 \\
& $(0.01)$ \\
Had farmers who used recycled seeds (>3 seasons) had used fresh seeds (E) & 7.16 \\
& $(0.01)$ \\
Had farmers who used fresh seeds had used recycled seeds (1-3 seasons) (F) & 7.18 \\
& $(0.02)$ \\
Had farmers who used fresh seeds had used recycled seeds (>3 seasons) (G) & 7.03 \\
& $(0.01)$ \\
ATT $_{1}$ (A-D) & $0.12^{* * *}$ \\
ATT $_{2}$ (A-E) & $(0.01)$ \\
& $0.40^{* * *}$ \\
ATU $_{1}$ (F-B) & $(0.01)$ \\
ATU $_{2}$ (G-C) & $0.14^{* * *}$ \\
\end{tabular}

Notes: (i) *** $\mathrm{p}<0.01$. (ii) standard errors in brackets. 


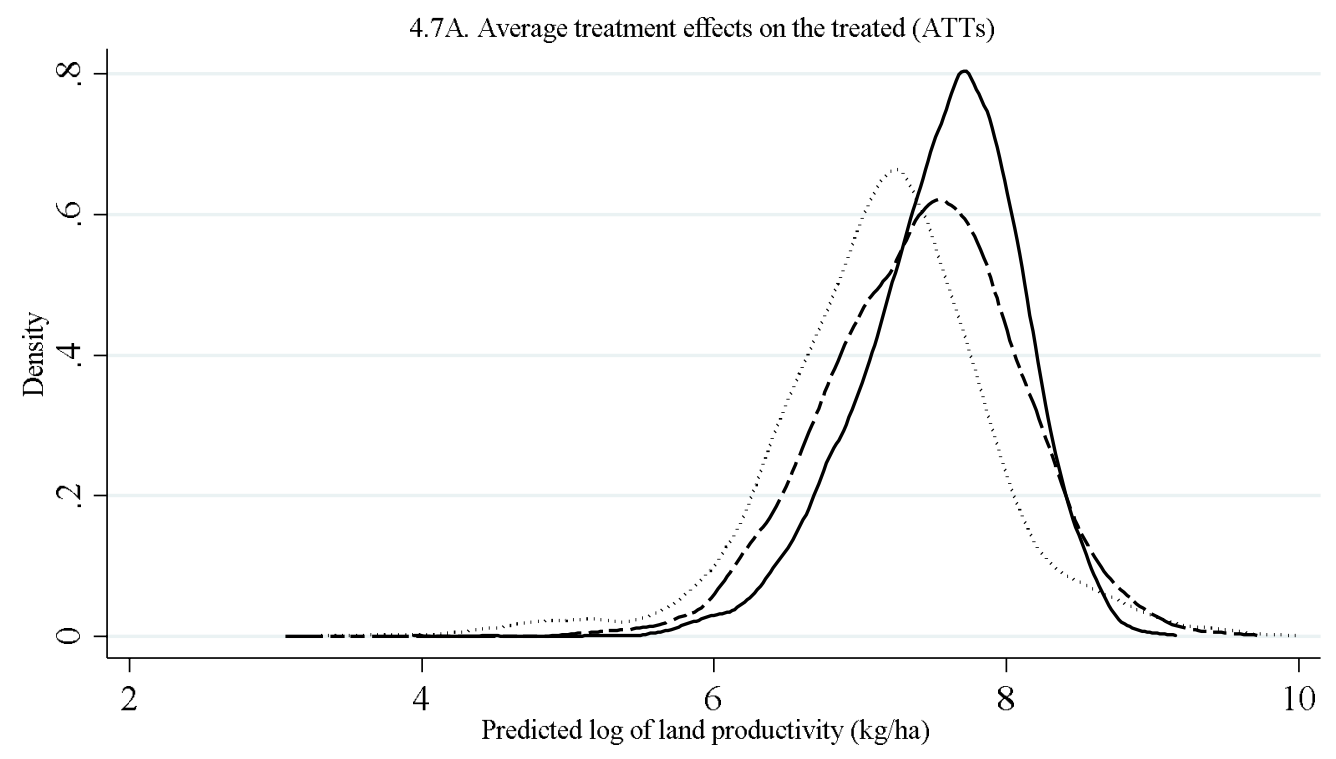

Fresh seeds

- - - Had farmers who used recycled seeds (1-3 seasons) had used fresh seeds Had farmers who used recycled seeds ( $>3$ seasons) had used fresh seeds

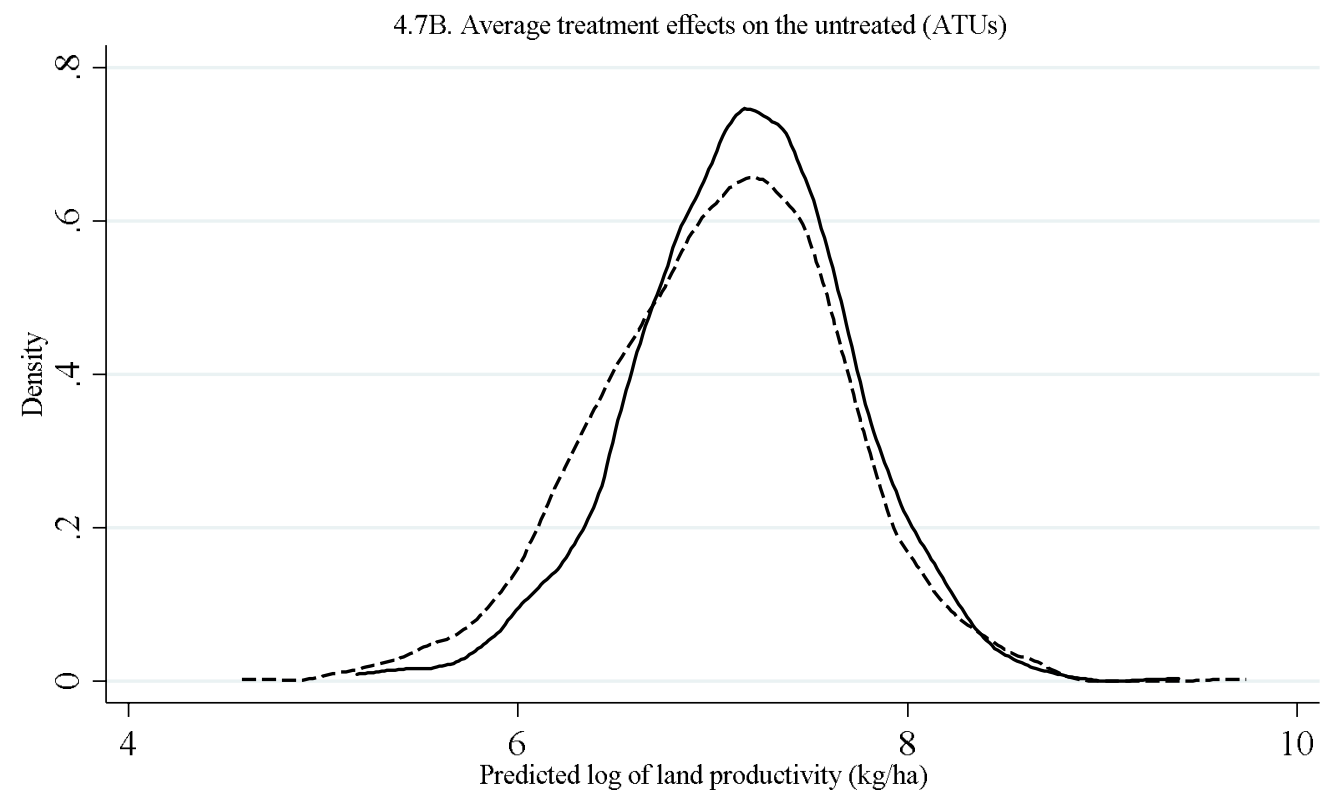

Had farmers who used fresh seeds had used recycled seeds (1-3 seasons) Recycled seeds (1-3 seasons) 


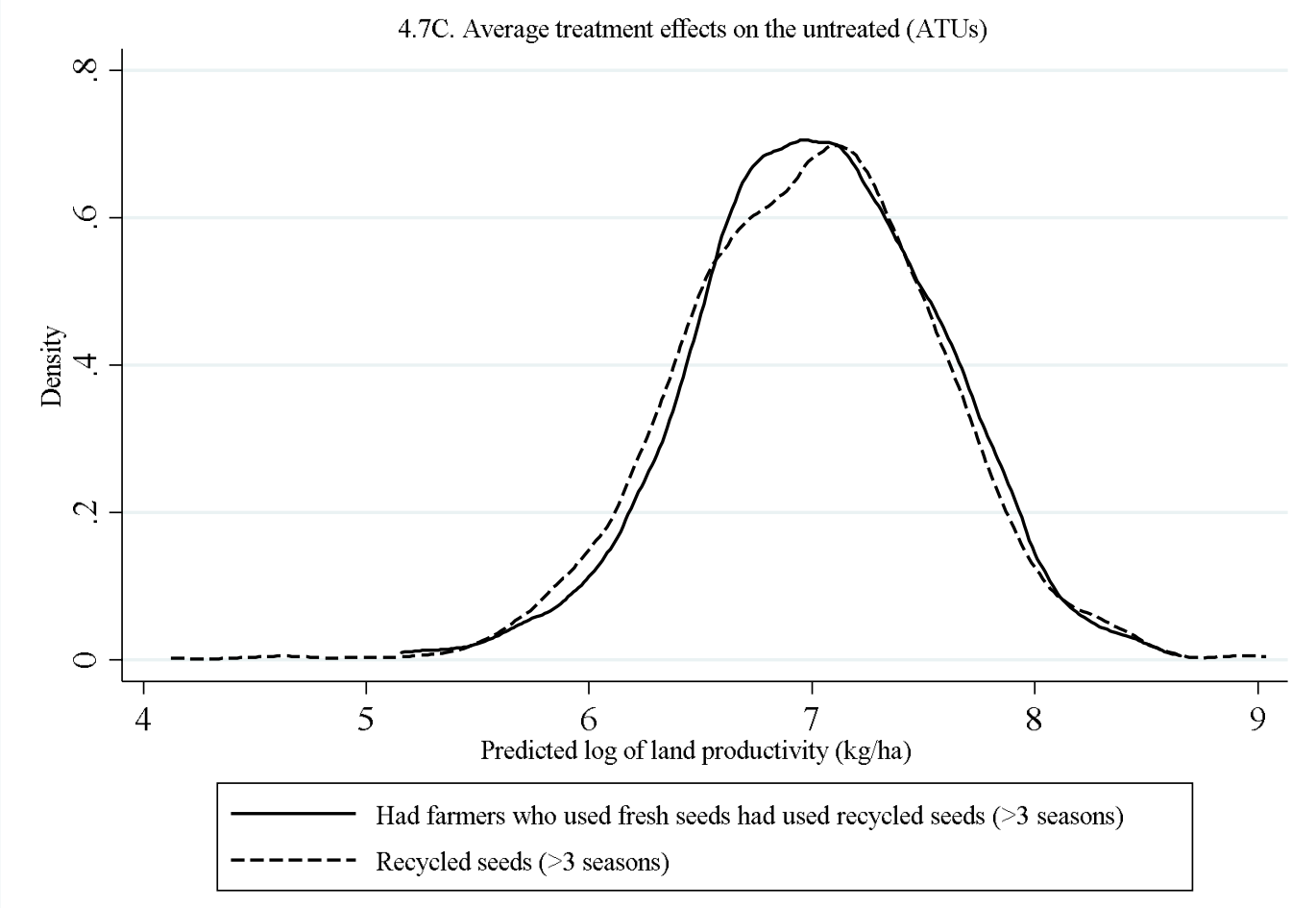

Figure 4.7. Distributions of predicted log of land productivity $(\mathrm{kg} / \mathrm{ha})$ in actual and counterfactual conditions. 
Table 4.12. The impact of fresh seeds on net return to land (Birr/ha).

\begin{tabular}{|c|c|c|c|}
\hline \multirow[b]{2}{*}{ Expected outcomes } & \multicolumn{3}{|c|}{ Net return to land (Birr/ha) models with: } \\
\hline & $\begin{array}{l}\text { Exogenous } \\
\text { switching } \\
\text { regressions } \\
\text { excluding the } \\
\text { inverse Mill's } \\
\text { ratio }\end{array}$ & $\begin{array}{l}\text { Exogenous } \\
\text { switching } \\
\text { regressions } \\
\text { excluding the } \\
\text { inverse Mill's } \\
\text { ratio, but the } \\
\text { exclusion } \\
\text { restrictions used } \\
\text { as explanatory } \\
\text { variables }\end{array}$ & $\begin{array}{c}\text { Endogenous } \\
\text { switching } \\
\text { regression }\end{array}$ \\
\hline Fresh seeds $(\mathrm{A})$ & $\begin{array}{c}7127.038 \\
(51.21)\end{array}$ & $\begin{array}{l}7137.92 \\
(52.13)\end{array}$ & $\begin{array}{c}7126.70 \\
(51.21)\end{array}$ \\
\hline Recycled seeds (1-3 seasons) (B) & $\begin{array}{l}5076.47 \\
(104.72)\end{array}$ & $\begin{array}{l}5081.71 \\
(106.59)\end{array}$ & $\begin{array}{l}5077.38 \\
(104.88)\end{array}$ \\
\hline Recycled seeds (> 3 seasons) (C) & $\begin{array}{c}4391.84 \\
(79.89)\end{array}$ & $\begin{array}{c}4396.40 \\
(81.48)\end{array}$ & $\begin{array}{c}4391.72 \\
(79.89)\end{array}$ \\
\hline Had farmers who used recycled seeds (1-3 seasons) had used fresh seeds (D) & $\begin{array}{c}5933.764 \\
(43.09)\end{array}$ & $\begin{array}{l}5969.57 \\
(44.03)\end{array}$ & $\begin{array}{c}5955.28 \\
(43.09)\end{array}$ \\
\hline Had farmers who used recycled seeds ( $>3$ seasons) had used fresh seeds (E) & $\begin{array}{c}5876.748 \\
(74.23)\end{array}$ & $\begin{array}{c}5842.193 \\
(75.64)\end{array}$ & $\begin{array}{l}5931.45 \\
(74.53)\end{array}$ \\
\hline Had farmers who used fresh seeds had used recycled seeds (1-3 seasons) $(\mathrm{F})$ & $\begin{array}{l}6380.15 \\
(134.75)\end{array}$ & $\begin{array}{l}6362.68 \\
(140.00)\end{array}$ & $\begin{array}{l}6318.80 \\
(135.34)\end{array}$ \\
\hline Had farmers who used fresh seeds had used recycled seeds (>3 seasons) $(\mathrm{G})$ & $\begin{array}{l}5236.15 \\
(121.62)\end{array}$ & $\begin{array}{l}5240.58 \\
(123.13)\end{array}$ & $\begin{array}{l}5063.83 \\
(121.50)\end{array}$ \\
\hline $\mathrm{ATT}_{1}(\mathrm{~A}-\mathrm{D})$ & $\begin{array}{c}1193.27 * * * \\
(66.93)\end{array}$ & $\begin{array}{c}1168.35^{* * * *} \\
(68.23)\end{array}$ & $\begin{array}{c}1171.42 * * * \\
(66.93)\end{array}$ \\
\hline $\mathrm{ATT}_{2}(\mathrm{~A}-\mathrm{E})$ & $\begin{array}{c}1250.29 * * * \\
(90.18)\end{array}$ & $\begin{array}{c}1295.73 * * * \\
(91.86)\end{array}$ & $\begin{array}{c}1195.25 * * * \\
(90.43)\end{array}$ \\
\hline $\mathrm{ATU}_{1}(\mathrm{~F}-\mathrm{B})$ & $\begin{array}{c}1303.67 * * * \\
(170.66)\end{array}$ & $\begin{array}{c}1280.97 * * * \\
(175.96)\end{array}$ & $\begin{array}{c}1241.41 * * * \\
(171.22)\end{array}$ \\
\hline $\mathrm{ATU}_{2}(\mathrm{G}-\mathrm{C})$ & $\begin{array}{c}844.31 * * * \\
(145.51)\end{array}$ & $\begin{array}{c}844.19 * * * \\
(147.65)\end{array}$ & $\begin{array}{c}672.11 * * * \\
(145.41)\end{array}$ \\
\hline
\end{tabular}

Notes. (i) $\mathrm{p}<0.01$. (ii) standard errors in brackets. (ii) The net return to land equals estimated value of maize residue and revenue from quantity of maize produced minus vari 


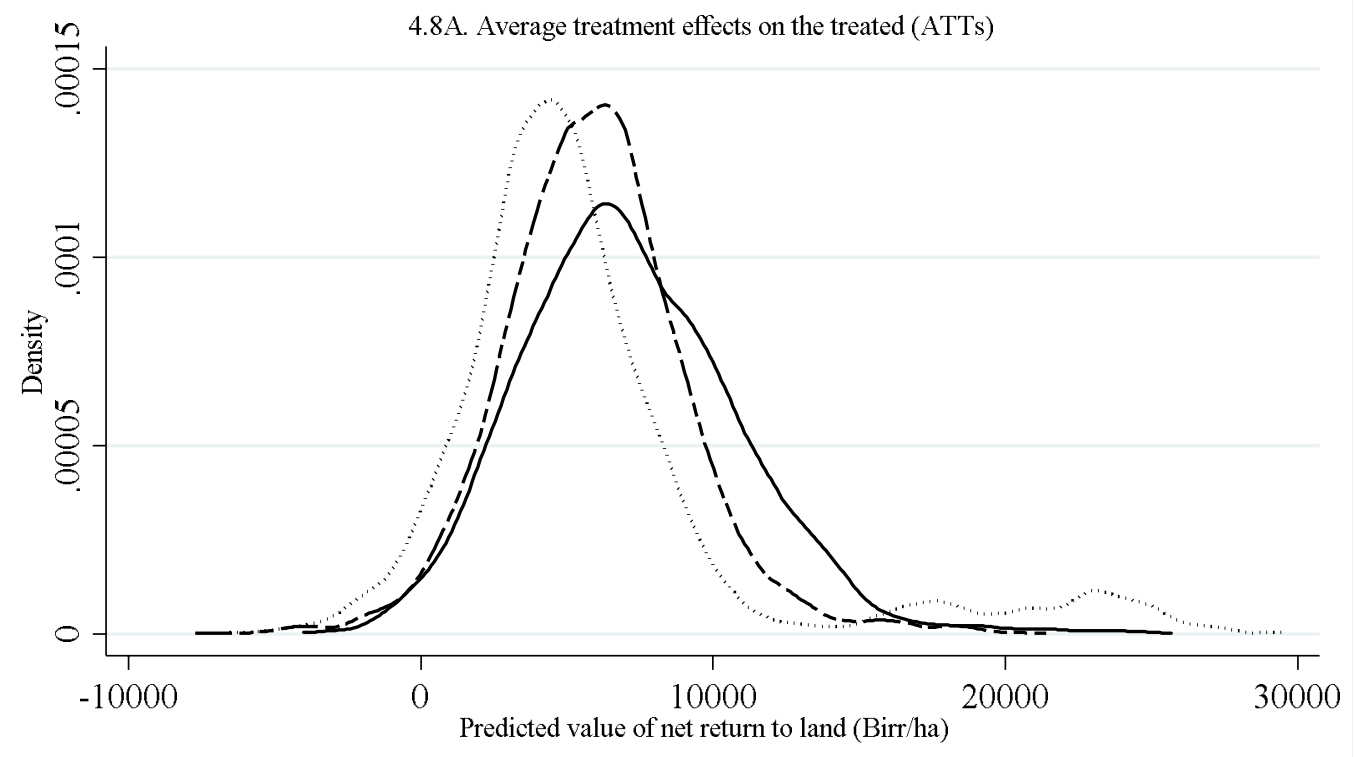

Fresh seeds

- - - Had farmers who used recycled seeds (1-3 seasons) had used fresh seeds Had farmers who used recycled seeds ( $>3$ seasons) had used fresh seeds

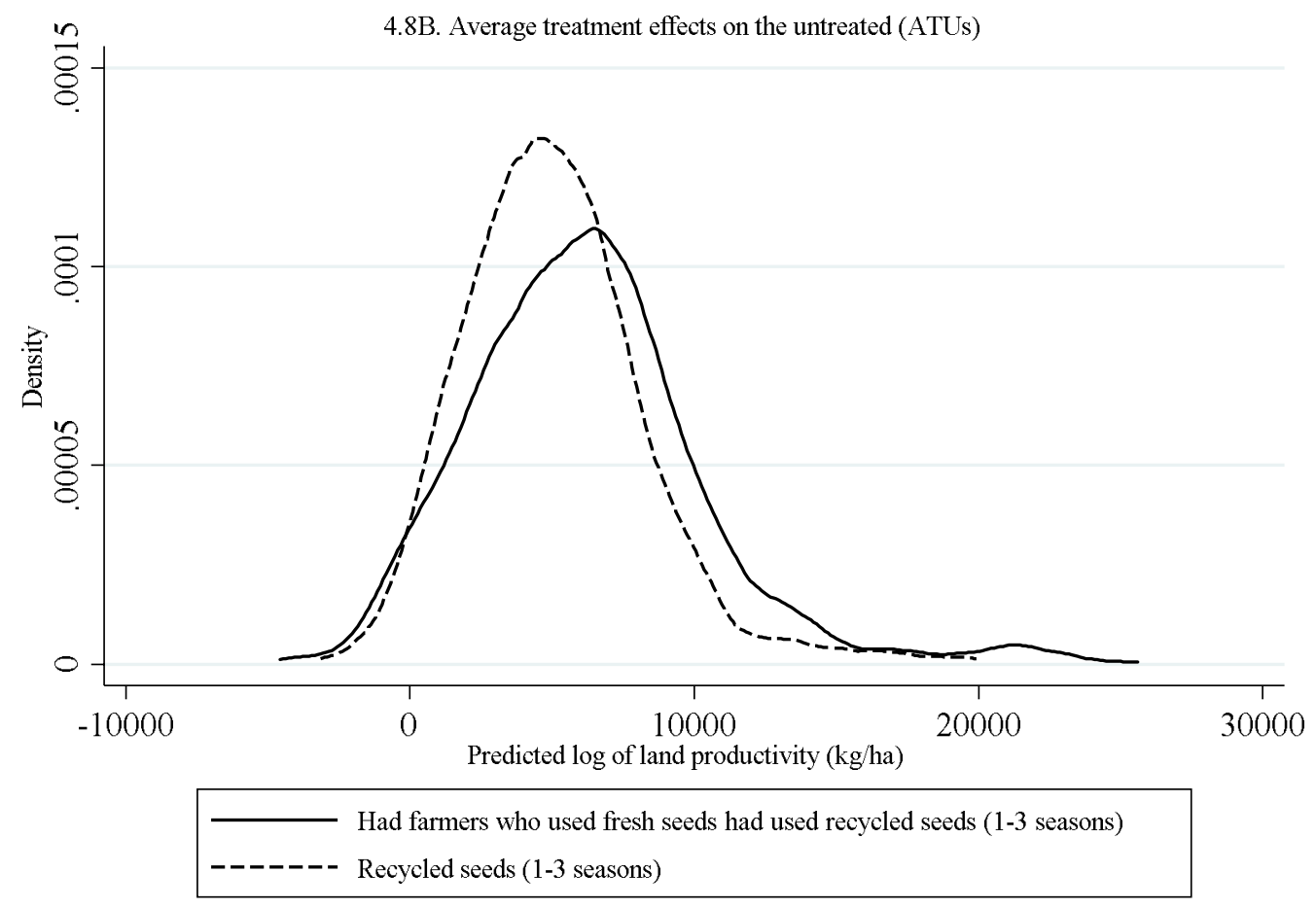




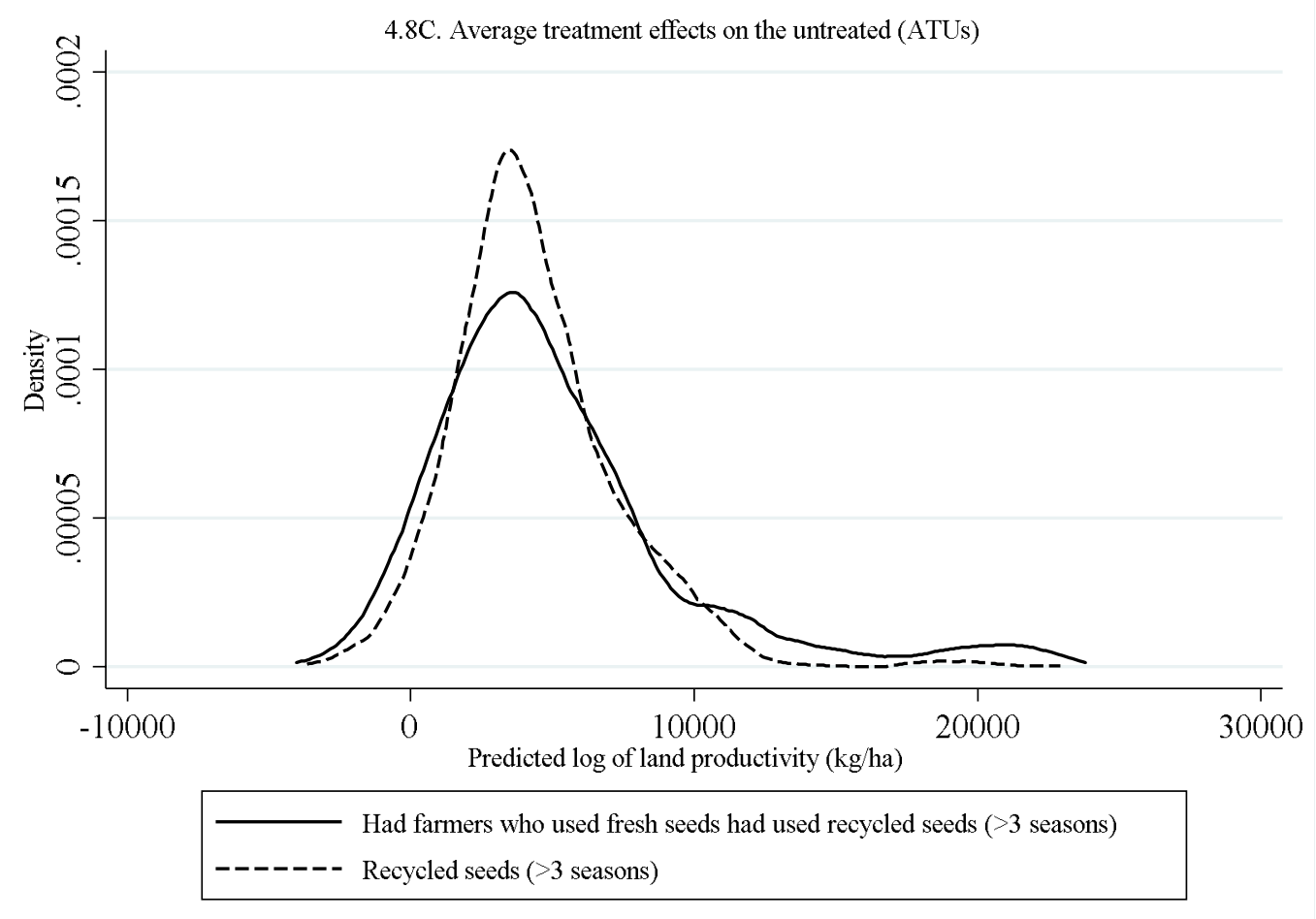

Figure 4.8. Distributions of predicted value of net return to land (Birr/ha) in actual and counterfactual conditions. 


\section{General conclusion}

\subsection{Conclusions}

In order to meet future food demand, reduce poverty, and achieve food and nutrition security, increases in agricultural productivity are urgently required. Meanwhile, the agricultural sector needs to adapt to climate change. As a response, global policy makers have committed to sustainable agricultural intensification by integrating food and nutrition security objectives with climate policies to increase productivity and reduce environmental footprints of agricultural activities. The required technologies and practices, which are being promoted as climate-smart agriculture, often vary across countries and agroecological zones, which calls for more research on the identification of locally suitable production technologies and practices. The three essays presented in this dissertation contribute to this line of literature by focusing on tillage and seed choice practices in the small farm sector in Ethiopia, using two comprehensive household survey panel datasets collected from wheat and maize producing farmers. From the findings of the three essays, important conclusions and policy implications can be drawn.

In Essay 1, we quantify the productivity and risk implications of farmers' intensity of tillage practices. Our results show that higher intensities of tillage are associated with higher productivity and lower risk exposure than lower intensities of tillage. These findings suggest that farmers use tillage in order to increase their productivity, and to reduce potential production risks. These findings should inform ongoing efforts to promote reduced tillage because of its potential to mitigate global warming through increased carbon sequestration and potential long-term productivity gains. Our findings show that farmers may not have sufficient incentives to switch from intensive tillage to reduced tillage because the short-term gains of intensive tillage tend to be high. To increase the adoption of reduced tillage practices, policies may thus require appropriate measures to compensate farmers for potential losses in productivity and increased production risks.

In addition to reduced tillage, high yielding improved varieties are promoted by climate-smart agriculture with the aim of increasing productivity and reducing losses associated with various production stresses. In Essay 2, we study the effects of using improved rust-resistant varieties on wheat productivity in comparison to improved susceptible varieties and traditional susceptible 
varieties. Our findings show that improved resistant varieties have higher productivity gains than improved susceptible varieties, and traditional susceptible varieties. Using improved rust resistant varieties is one of the sustainable technologies to curb the negative effects of production losses due to rust diseases without increasing the use of environmentally polluting agrochemicals. The productivity gains of improved resistant varieties in farmers' fields deliver important evidence for breeders, policy makers and the donor community. However, we find that improved varieties have lower productivity gains than traditional varieties under drought and other abiotic stresses (e.g., waterlogging). Our results suggest that the lack of adaptation of the improved varieties to the local production conditions may induce farmers to switch back to traditional varieties. For sustainable adoption of high yielding varieties, policy makers may need to promote investment in the adaptation of improved varieties to the local soil and climatic conditions before releasing improved varieties.

Using quality seeds is an important part of climate-smart agriculture. However, farmers may suboptimally use improved varieties because of seed recycling practices. In Essay 3, we focus on understanding the implications of using fresh seeds on both land productivity and efficiency by establishing counterfactual outcomes based on the recycled seeds. Our findings show that using fresh seeds increases productivity and farmers' efficiency. This indicates that promoting fresh seeds use could help achieving food security even without introducing new improved varieties. However, farmers are inefficient regardless of the types of seeds used. In addition to promoting fresh seeds, complementary policies to promote more efficient use of inputs should be considered. The complementary policies may need to promote technologies that improve farmers' dexterity on harvesting and threshing activities in times of production stresses such as too much rainfall as it is common in many developing countries.

Our findings in Essays 2 and 3 reveal that seed policies may need to find efficient strategies that balance investment on breeding for new improved varieties and seed multiplication of existing varieties. Investment on breeding for improved varieties that brings improved genetic material that substantially increase productivity and avoid production losses should continue. In the meantime, the production of fresh seeds of existing varieties should be promoted in order to exploit the benefits of past breeding investments. 


\subsection{Overall policy implications}

Overall, the three essays show that heterogeneity in decision making is the main characteristics of small farm sector. The heterogeneity of farmers' decision is shown by their practice of cultivating several varieties of the same crop spreading across plots with varying intensities of tillage. Climatesmart agricultural policies may need to respond to farmers' heterogeneous tillage and seed choice practices. Modern biotechnology, including new tools for genome editing, may help to speeding up the identification of important plant traits, and adaptation of improved varieties to the local soil and climatic conditions. This may in turn facilitate seed multiplication of a portfolio of high yielding improved varieties of adequate quantity and quality. Reduced tillage is also an important practice for sustainable intensification. Exploiting the full potential of reduced tillage as a climate-smart agriculture may need further investment in breeding for improved varieties that are responsive to reduced tillage. The availability of reduced tillage responsive improved seeds may become a good incentive for farmers to switch from high intensive tillage to sustainable reduced tillage systems.

\subsection{Caveats and future research}

The conclusions and policy implications we draw from the three essays should be considered in light of some caveats. A potential estimation issue in our analysis on farmers' choices is endogeneity. When farmers make decisions, it is based on their expectation on productivity, efficiency or risk implications of their choice. Our results are robust to differences in observed variables. We also control for time invariant unobserved factors. However, the findings of Essay 1 should be cautiously interpreted in the sense that if time varying unobserved factors that affect varietal choice are present, estimates might be biased. In Essays 1 and 3, we attempt to use selection correction terms in order to control for potential endogeneity that may arise from time varying factors that affect both farmers' choices and outcome variables. While most of our results are robust to various specifications, justifying the exclusion restrictions might be challenging. Therefore, all our findings should be interpreted taking into account potential endogeneity biases. Finally, the panel structure of our datasets are only at the household level. For this reason, we are unable to analyze plot level variations in tillage practices and seed choice of farmers over time. Future research may need to collect plot level panel datasets in order to understand the productivity, efficiency and risk implications of plot level dynamics of farmers' tillage and seed choice practices. 
In Essay 1, tillage practices and the associated gains from additional tillage may differ across crops and agroecological zones. Additional analysis on other crops and agroecological specific studies are required in order to ascertain the potential benefits of intensive tillage documented by our study. Our research focus is on the comparison of higher intensities of tillage with lower intensities of tillage because zero tillage is not common in Ethiopia. However, it might be important to document differences in productivity and risk exposure of farmers who practice higher intensities of tillage with zero tillage. In addition, other agronomic variables such as the history of tillage in the plot in the previous seasons and sowing dates might improve our understanding of the impact of intensive tillage on productivity and risk. Collecting the history of tillage on each of the plots may help to understand how changes in tillage practices affect productivity and production risk over time. This may contribute towards the burgeoning literature that links agronomic attributes to productivity analysis in agricultural economics.

As Essays 2 and 3 show, all the information on improved varieties of maize and wheat are selfreported by farmers. Maximum care was given to ensure the quality of the data using a well-trained team of enumerators after validating the questionnaires through pretesting. However, a new line of research on varietal information data collection using DNA finger printing is emerging. A comparison of varietal information collected using DNA finger printing and household survey data has shown that the latter may not be the best method of data collection because farmers may not be able to identify the genetic quality of the varieties (Floro IV et al., 2017; Kilic, 2018). We do not have DNA finger printing of the varieties used by farmers and hence cannot test the sensitivity of our results to differences in data collection methodology. We suggest that future data collection and research on varietal and seed choices could exploit the potential role of new methodological innovations such as DNA finger printing.

Throughout the three essays, we focus on the consequences of farmers' key decisions on tillage, crop varieties, and seed types. Understanding the key factors that determine farmers' choices are as important as understanding the consequences of farmers' choices. A host of behavioral, technical and economic factors may affect adoption and dis-adoption of technologies and practices. As the determinants of tillage and seed choice may differ across agroecological zones or even across crops, a holistic approach that integrates both quantitative and qualitative analysis may help to identify and prioritize the most important determinants and dynamics of technology adoption. This is especially important to better understand those choices that are associated with lower productivity or efficiency, such as the use of recycled seeds. Findings from such studies may facilitate tailoring policies and strategies towards important factors in various production contexts. 


\section{References}

Abate, T., Fisher, M., Abdoulaye, T., Kassie, G. T., Lunduka, R., Marenya, P. and Asnake, W. 'Characteristics of maize cultivars in Africa: How modern are they and how many do smallholder farmers grow?'. Agriculture and Food Security, vol. 6(1) (2017) PP. 1-17.

Abate, T., Shiferaw, B., Menkir, A., Wegary, D., and Kebede, Y. 'Factors that transformed maize productivity in Ethiopia'. Food Security, vol. 7 (2015) PP. 965-981.

Abdul-Salam, Y. and Phimister, E. 'Efficiency effects of access to information on small-scale agriculture: empirical evidence from Uganda using stochastic frontier and IRT models'. Journal of Agricultural Economics, vol. 68(2) (2016) PP. 494-517.

Abro, Z. A., Jaleta, M., and Teklewold, H. 'Does intensive tillage enhance productivity and reduce risk exposure? Panel data evidence from smallholders' agriculture in Ethiopia'. Journal of Agricultural Economics, (2018). https://doi.org/10.1111/1477-9552.12262.

Aguilar, A., Carranza, E., Goldstein, M., Kilic, T., and Oseni, G. 'Decomposition of gender differentials in agricultural productivity in Ethiopia'. Agricultural Economics, vol. 46(3) (2015) PP. 311-334.

Alemu, D. and Bishaw, Z. 'Commercial behaviours of smallholder farmers in wheat seed use and its implication for demand assessment in Ethiopia'. Development in Practice, vol. 25(6) (2015) PP. 798-814.

Alemu, W., Fininsa, C., and Hundie, B. 'Effects of environment on epidemics of yellow rust (Puccinia striiformis West.) of bread wheat (Triticum aestivum L.) in Bale highlands, SouthEastern Ethiopia'. Global Journal of Pests, Diseases and Crop Protection, vol. 3(2) (2015) PP. 96-107.

Alene, A. D. and Hassan, R. M. 'The efficiency of traditional and hybrid maize production in Eastern Ethiopia: an extended efficiency decomposition approach'. Journal of African Economies, vol. 15(1) (2006) PP. 91-116. 
Alene, A. D. and Manyong, V. M. 'Farmer-to-farmer technology diffusion and yield variation among adopters: the case of improved cowpea in northern Nigeria'. Agricultural Economics, vol. 35(2) (2006) PP. 203-211.

Alene, A. D. and Manyong, V. M. 'The effects of education on agricultural productivity under traditional and improved technology in northern Nigeria : an endogenous switching regression analysis'. Empirical Economics, vol. 32 (2007) PP. 141-159.

Amare, M., Asfaw, S., and Shiferaw, B. 'Welfare impacts of maize-pigeonpea intensification in Tanzania'. Agricultural Economics, vol. 43(1) (2012) PP. 27-43.

Andersson, J. A. and D’Souza, S. 'From adoption claims to understanding farmers and contexts : a literature review of conservation agriculture (CA ) adoption among smallholder farmers in southern Africa'. Agriculture, Ecosystems and Environment, vol. 187 (2014) PP. 116-132.

Angrist, J. D. 'The perils of peer effects'. Labour Economics, vol. 30 (2014) PP. 98-108.

Antle, J. M. 'Testing the stochastic structure of poduction : a flexible moment-based approach' Journal of Business \& Economic Statistics, vol. 1(3) (1983) PP. 192-201.

Aryal, J. P., Sapkota, T. B., Stirling, C. M., Jat, M. L., Jat, S. H., Rai, M., Mittal, S. and Suta-liya, J. M. 'Conservation agriculture-based wheat production better copes with extreme climate events than conventional tillage-based systems: a case of untimely excess rainfall in Haryana, India'. Agriculture, Ecosystems and Environment, vol. 233 (2016) PP. 325-335.

Asche, F. and Tveterås, R. 'Modeling production risk with a two-step procedure'. Journal of Agricultural and Resource Economics, vol. 24(2) (1999) PP. 424-439.

Aune, J. B., Bussa, M. T., Asfaw, F. G., and Ayele, A. A. 'The ox ploughing system in Ethiopia: Can it be sustained?'. Outlook on Agriculture, vol. 30(4) (2001) PP. 275-280.

Bailey, K. L. 'Diseases under conservation tillage systems'. Canadian Journal of Plant Science, vol. 76(4) (1996) PP. 635-639.

Barrett, C. B., Bellemare, M. F., and Hou, J. Y. 'Reconsidering conventional explanations of the inverse productivity-size relationship'. World Development, vol. 38(1) (2010) PP. 88-97.

Barrett, C. B., Christian, P., and Shiferaw, B. A. 'The structural transformation of african agriculture and rural spaces: introduction to a special section'. Agricultural Economics, vol. 48 (2017) PP. 
Barrett, C. B., Moser, C. M., McHugh, O. V, and Barison, J. 'Better technology, better plots, or better farmers? Identifying changes in productivity and risk among Malagasy rice farmers'. American Journal of Agricultural Economics, vol. 86(4) (2004) PP. 869-888.

Battese, G. E. 'A note on the estimation of Cobb-Douglas production functions when some explanatory variables have zero values'. Journal of Agricultural Economics, vol. 48(2) (1997) PP. 250-252.

Battese, G. E., Nazli, H., and Smale, M. 'Factors influencing the productivity and efficiency of wheat farmers in Punjab, Pakistan'. Journal of Agribusiness in Developing and Emerging Economies, vol. 7(2) (2017) PP. 82-98.

Bellon, M. R. 'Crop research to benefit poor farmers in marginal areas of the developing world: a review of technical challenges and tools'. CAB Reviews: Perspectives in Agriculture, Veterinary Science, Nutrition and Natural Resources, vol. 1(70) (2006) PP. 1-11.

Bezu, S., Kassie, G. T., Shiferaw, B., and Ricker-Gilbert, J. 'Impact of improved maize adoption on welfare of farm households in Malawi: a panel data analysis'. World Development, vol. 59 (2014) PP. 120-131.

Bishaw, Z., Struik, P. C., and Van Gastel, A. J. G. 'Assessment of on-farm diversity of wheat varieties and landraces: evidence from farmer's fields in Ethiopia'. African Journal of Agricultural Research, vol. 9(38) (2014) PP. 2948-2963.

Blevins, R. L. and Frye, W. W. 'Conservation tillage: an ecological approach to soil management'. Advances in Agronomy, vol. 51 (1993) PP. 33-78.

Bockus, W. W. and Shroyer, J. P. 'The impact of reduced tillage on soilborne plant pathogens'. Annual Review of Phytopathology, vol. 36(1) (1998) PP. 485-500.

Bold, T., Kaizza, K. C., Stevensson, J., and Yanagizawa-Drott, D. 'Lemon technologies and adoption: measurement, theory, and evidence from agricultural markets in Uganda'. Quarterly Journal of Economics, vol. 132(3) (2017) PP. 1055-1100.

Boomsma, C. R., Santini, J. B., West, T. D., Brewer, J. C., McIntyre, L. M. and Vyn, T. J. 'Maize grain yield responses to plant height variability resulting from crop rotation and tillage system 
in a long-term experiment'. Soil and Tillage Research, vol. 106(2) (2010) PP. 227-240.

Boserup, E. 'Woman's Role in Economic Development. New Introduction by Nazneen Kanji, Su Fei Tan and Camilla Toulmin.'. (London: Earthscan, 2007).

Bourguignon, F., Fournier, M., and Gurgand, M. 'Selection bias corrections based on the multinomial logit model : Monte Carlo comparisons'. Journal of Economic Surveys, vol. 21(1) (2006) PP. 174-205.

Brown, B., Nuberg, I., and Llewellyn, R. 'Negative evaluation of conservation agriculture: perspectives from African smallholder farmers'. International Journal of Agricultural Sustainability, vol. 0(0) (2017) PP. 1-15.

Byerlee, D. 'Modem Varieties , Productivity, and Sustainability : Recent Experience and Emerging Challenges'. World Development, vol. 24(4) (1996) PP. 697-718.

Carey, K. 'A Multilevel modelling approach to analysis of patient costs under managed care'. Health Economics, vol. 4 (2000) PP. 435-446.

Carletto, C., Savastano, S., and Zezza, A. 'Fact or artifact: The impact of measurement errors on the farm size-productivity relationship'. Journal of Development Economics, vol. 103 (2013) PP. 254-261.

Chaves, M. S., Martinelli, J. A., Wesp-Guterres, C., Graichen, F. A. S., Brammer, S. P., Scagliusi, S. M., da Silva, P., Wiethölter, P., Torres, G., Lau, E., Consoli, L., and Chaves, A. 'The importance for food security of maintaining rust resistance in wheat'. Food Security, vol. 5(2) (2013) PP. 157-176.

Chen, W., Wellings, C., Chen, X., Kang, Z., and Liu, T. 'Wheat stripe (yellow) rust caused by Puccinia striiformis f. sp. tritici.'. Molecular Plant Pathology, vol. 15(5) (2014) PP. 433-446.

Claassen, R., Cattaneo, A., and Johansson, R. 'Cost-effective design of agri-environmental payment programs : U.S. experience in theory and practice'. Ecological Economics, vol. 65 (2008) PP. $737-752$.

Coelli, T. J., Rao, D. S. P., O’Donnell, C. J., and Battese, G. E. 'An Introduction to Efficiency and Productivity Analysis'. 2nd ed. (New York: Springer, 2005).

Conforti, P. 'Looking Ahead in World Food and Agriculture. Perspectives in 2050'. Food and 
Agricultural Organization (FAO). (Rome, 2011).

Cooke, B. M., Jones, D. G., and Kaye, B. 'The Epidemiology of Plant Diseases'. 2nd ed. (Dordrecht: Springer, 2006).

Denbel, W., Badebo, A., and Alemu, T. 'Evaluation of Ethiopian commecial wheat cultivars for resistance to stem rust of wheat rust race 'UG99'. International Journal of Agronomy and Plant Protection, vol. 4(1) (2013) PP. 15-24.

Dhungana, B. R., Nuthall, P. L., and Nartea, G. V. 'Measuring the economic inefficiency of Nepalese rice farms using data envelopment analysis'. The Australian Journal of Agricultural and Resource Economics, vol. 48(2) (2004) PP. 347-369.

Di Falco, S. and Chavas, J.-P. 'On crop biodiversity, risk exposure, and food security in the highlands of Ethiopia'. American Journal of Agricultural Economics, vol. 91(3) (2009) PP. 599-611.

Di Falco, S., Chavas, J., and Smale, M. 'Farmer management of production risk on degraded lands : the role of wheat variety diversity in the Tigray region, Ethiopia'. Agricultural Economics, vol. 36 (2007) PP. 147-156.

Di Falco, S. and Veronesi, M. 'Managing environmental risk in presence of climate change: the role of adaptation in the Nile Basin of Ethiopia'. Environmental \& Resource Economics, vol. 57(4) (2014) PP. 553-577.

Di Falco, S., Veronesi, M., and Yesuf, M. 'Does adaptation to climate change provide food security? A micro-perspective from Ethiopia'. American Journal of Agricultural Economics, vol. 93(3) (2011) PP. 825-842.

Dixon, J., Nalley, L., Kosina, P., La Rovere, R., Hellin, J., \& Aquino, P. 'Adoption and economic impact of improved wheat varieties in the developing world'. The Journal of Agricultural Science, vol. 144(6) (2006) PP. 489-502.

Dubin, J. A. and McFadden, D. L. 'An econometric analysis of residential electric appliance holdings and consumption'. Econometrica, vol. 52(2) (1984) PP. 345-362.

ECSA. Agricultural sample survey 2014/2015 (2007 E.C.) Report on area and production of major crops (private peasant holdings, Meher season) (Vol. I). Addis Ababa: Statistical bulletin 578. 
Ethiopian Central statistical agency (ECSA), (Addis Ababa, 2015).

El-Shater, T., Yigezu, Y. A., Mugera, A., Piggin, C., Haddad, A., Khalil, Y., Loss, S. and AwHassan, A. 'Does zero tillage improve the livelihoods of smallholder cropping farmers?'. Journal of Agricultural Economics, vol. 67(1) (2016) PP. 154-172.

Erenstein, O., Farooq, U., Malik, R. K., and Sharif, M. 'On-farm impacts of zero tillage wheat in South Asia's rice-wheat systems'. Field Crops Research, vol. 105(3) (2008) PP. 240-252.

Erkossa, T., Stahr, K., and Gaiser, T. 'Soil tillage and crop productivity on a vertisol in Ethiopian highlands'. Soil and Tillage Research, vol. 85(1-2) (2006) PP. 200-211.

Evenson, R. E. and Gollin, D. 'Crop Variety Improvement and Its Effect on Productivity: The Impact of International Agricultural Research'. (Wallingford (UK): Cabi publishing, 2003).

FAO. 'Climate-smart agriculture sourcebook'. (Food and Agricultural Organization (FAO) Rome, 2013) .

FAO. 'Strengthening Capacities and Promoting Collaboration to Prevent Wheat Rust Epidemics: Wheat Rust Diseases Global Program 2014-2017.' Food and Agricultural Organization (FAO). (Rome, 2014).

FAO. 'Building resilience for peace and food security the state of food security and nutrition in the world'. Food and Agricultural Organization (FAO). (Rome, 2017).

FAO. 'Climate-Smart Agriculture: Building Resilience to Climate Change', L. Lipper, N. McCarthy, D. Zilberman, S. Asfaw, and G. Branca (eds). Food and Agriculture Organization of the United Nations ( FAO) (Cham, Switzerland: Springer, 2018).

Feder, G., Just, R. E., and Zilberman, D. 'Adoption of agricultural innovations in developing countries : a survey'. Economic Development and Cultural Change, vol. 33(2) (1985) PP. 255298.

Fick, S. E. and Hijmans, R. J. 'Worldclim 2: new 1-km spatial resolution climate surfaces for global land areas'. International Journal of Climatology, (2017). https://doi.org/10.1002/joc.5086.

Fisher, M. Abate, T., Lunduka , R. W., Asnake, W. Alemayehu, Y. and Madulu, R. B. 'Drought tolerant maize for farmer adaptation to drought in sub-Saharan Africa: Determinants of adoption in eastern and southern Africa'. Climatic Change, vol. 133(2) (2015) PP. 283-299. 
Floro IV, V. O., Labarta, R. A., Becerra López-Lavalle, L. A., Martinez, J. M., and Ovalle, T. M. 'Household Determinants of the Adoption of Improved Cassava Varieties using DNA Fingerprinting to Identify Varieties in Farmer Fields: A Case Study in Colombia'. Journal of Agricultural Economics, (2017) .

Gandorfer, M., Pannell, D., and Meyer-aurich, A. 'Analyzing the effects of risk and uncertainty on optimal tillage and nitrogen fertilizer intensity for field crops in Germany'. Agricultural Systems, vol. 104(8) (2011) PP. 615-622.

Gebre-Mariam, H., Tanner, D. G., and Hulluka, M. 'Wheat Research in Ethiopia: A Historical Perspective'. (Addis Ababa: Ethiopian Institute of Agricultural Research and CIMMYT, 1991).

Getnet, M., Van Ittersum, M., Hengsdijk, H., and Descheemaeker, K. 'Yield Gaps and Resource Use Across Farming Zones in the Central Rift Valley of Ethiopia'. Experimental Agriculture, vol. 52(4) (2016) PP. 493-517.

Giller, K. E., Corbeels, M., Nyamangara, J., Triomphe, B., Affholder, F., Scopel, E. and Tit-tonell, $\mathrm{P}$ 'A research agenda to explore the role of conservation agriculture in African smallholder farming systems'. Field Crops Research, vol. 124(3) (2011) PP. 468-472.

Giller, K. E., Witter, E., Corbeels, M., and Tittonell, P. 'Field Crops Research Conservation agriculture and smallholder farming in Africa: the heretics' view'. Field Crops Researh, vol. 114 (2009) PP. 23-34.

Glover, D., Sumberg, J., and Andersson, J. A. 'The adoption problem; or why we still understand so little about technological change in African agriculture'. Outlook on Agriculture, vol. 45(1) (2016) PP. 3-6.

Gollin, D., Morris, M., and Byerlee, D. 'Technology adoption in intensive post-green revolution systems'. American Journal of Agricultural Economics, vol. 87(5) (2005) PP. 1310-1316.

Grabowski, P. P., Kerr, J. M., Haggblade, S., and Kabwe, S. 'Determinants of adoption and disadoption of minimum tillage by cotton farmers in eastern Zambia'. Agriculture, Ecosystems and Environment, vol. 231 (2016) PP. 54-67.

Greene, W. 'Fixed and random effects in stochastic frontier models'. Journal of Productivity Analysis, vol. 23(1) (2005a) PP. 7-32. 
Greene, W. 'Reconsidering heterogeneity in panel data estimators of the stochastic frontier model'. Journal of Econometrics, vol. 126(2) (2005b) PP. 269-303.

Greene, W. H. 'Econometric Analysis'. 7th ed. (New York: Pearson, 2012).

Guan, D., Zhang, Y., Al-kaisi, M. M., Wang, Q., and Zhang, M. 'Tillage practices effect on root distribution and water use efficiency of winter wheat under rain-fed condition in the North China Plain'. Soil \& Tillage Research, vol. 146 (2015) PP. 286-295.

Hailu, D. and Fininsa, C. 'Relationship between stripe rust (Puccinia striiformis) and common wheat (Triticum aestivum) yield loss in the highlands of Bale, southeastern Ethiopia'. Journal of Food, Agriculture \& Environment, vol. 5(2) (2007) PP. 24-30.

Halbrendt, J., Gray, S. G, Crow, S., Radovich, T., Kimura, A. H., and Tamang, B. B. 'Differences in farmer and expert beliefs and the perceived impacts of conservation agriculture'. Global Environmental Change, vol. 28 (2014) PP. 50-62.

Heisey, P. W. and Brennan, J. P. 'An analytical model of farmers' demand for replacement seed'. American Journal of Agricultural Economics, vol. 73(4) (1991) PP. 1044-1052.

Hertel, T. W. 'The challenges of sustainably feeding a growing planet'. Food Security, vol. 7 (2015) PP. 185-198.

Hobbs, P. R., Sayre, K., and Gupta, R. 'The role of conservation agriculture in sustainable agriculture'. Philosophical Transactions of the Royal Society of London B: Biological Sciences, vol. 363(1491) (2008) PP. 543-555.

Husmann, C. 'Transaction costs on the Ethiopian formal seed market and innovations for encouraging private sector investments'. Quarterly Journal of International Agriculture, vol. 54(1) (2015) PP. 59-76.

ICARDA. 'Research to Action: Strategies to Reduce the Emerging Wheat Stripe Rust Disease: Synthesis of a Dialog between Policy Makers and Scientists from 31 Countries. International Center for Agricultural Research in the Dry Areas (ICARDA).'. (Aleppo, 2011).

ICARDA. 'Tackling Stripe Rust Disease. Science Impact. A12-2013'. (Amman, 2013).

IFAD. 'Rural development report 2016: fostering inclusive rural transformation'. International Fund for Agricultural Development (IFAD). (Rome, 2016) . 
IFPRI. 'Green revolution: curse or blessing?'. International Food Policy Research Institute (IFPRI) Policy Brief. (Washington DC, 2002) .

Jaggard, K. W., Qi, A. \& Ober, E. S. Possible changes to arable crop yields by 2050. Philosophical Transactions of the Royal Society of London B: Biological Sciences, vol. 365 (2016) PP. 28352851.

Jaleta, M., Kassie, M., Tesfaye, K., Teklewold, T., Jena, P. R., Marenya, P. and Ernstein, O. 'Resource saving and productivity enhancing impacts of crop management innovation packages in Ethiopia'. Agricultural Economics, vol. 47 (2016) PP. 513-522.

Jaleta, M., Kassie, M., and Erenstein, O. 'Determinants of maize stover utilization as feed, fuel and soil amendment in mixed crop-livestock systems, Ethiopia'. Agricultural Systems, vol. 134 (2015) PP. 17-23.

James, W. C. 'Assessment of plant diseases and losses'. Annual Review of Phytopathology, vol. 12(370) (1974) PP. 27-48.

Japhether, W., Groote, H. D. E., Lawrence, M., Kengo, D., and Mohammed, L. 'Recycling hybrid maize varieties :is it backward practice or innovative response to adverse conditions in Kenya?', in Proceedings of the 26th International Association of Agricultural Economists Conference, Gold Coast, Australia. 12-18 Aug. 2006. IAAE, Milwaukee, WI. (2006).

Johnes, J. 'Measuring efficiency: a comparison of multilevel modelling and data envelopment analysis in the context of higher education'. Bulletin of Economic Research, vol. 58(2) (2006) PP. 75-104.

Just, R. E. and Pope, R. D. 'Stochastic specification of production functions and economic implications'. Journal of Econometrics, vol. 7(488) (1978) PP. 67-86.

Kabunga, N. S., Dubois, T., and Qaim, M. 'Yield effects of tissue culture Bananas in Kenya: accounting for selection bias and the role of complementary inputs'. Journal of Agricultural Economics, vol. 63(2) (2012) PP. 444-464.

Kalirajan, K. P. 'The importance of efficient use in the adoption of technology: a micro panel data analysis'. Journal of Productivity Analysis, vol. 2(2) (1991) PP. 113-126.

Kalirajan, K. P. and Shand, R. T. 'Technology and farm performance: paths of productive 
efficiencies over time'. Agricultural Economics, vol. 24(3) (2001) PP. 297-306.

Kassam, A., Friedrich, T., Shaxson, F., and Pretty, J. 'The spread of conservation agriculture: justification, sustainability and uptake'. International Journal of Agricultural Sustainability, vol. 7(4) (2009) PP. 292-320.

Kassie, M., Teklewold, H., Jaleta, M., Marenya, P., and Ernstein, O. 'Understanding the adoption of a portfolio of sustainable intensification practices in eastern and southern Africa'. Land Use Policy, vol. 42 (2015a) PP. 400-411.

Kassie, M., Teklewold, H., Marenya, P., Jaleta, M., and Erenstein, O. 'Production risks and food security under alternative technology choices in Malawi: application of a multinomial endogenous switching regression'. Journal of Agricultural Economics, vol. 66(3) (2015b) PP. 640-659.

Kassie, M., Zikhali, P., Pender, J., and Köhlin, G. 'The economics of sustainable land management practices in the Ethiopian highlands'. Journal of Agricultural Economics, vol. 61(3) (2010) PP. $605-627$.

Kertész, Á. and Madarász, B. 'Conservation agriculture in Europe'. International Soil and Water Conservation Research, vol. 2(1) (2014) PP. 91-96.

Khonje, M., Manda, J., Alene, A. D., and Kassie, M. 'Analysis of adoption and impacts of improved maize varieties in Eastern Zambia'. World Development, vol. 66 (2015) PP. 695-706.

Kilic, T. 'Blowing in the wind: zhe quest for accurate crop variety identification in field research, with an application to maize in Uganda. A paper presented at the CSAE Conference 2018 Economic Development in Africa. Oxford, 18-20 March 2018'. (Oxford, 2018).

Kilic, T., Zezza, A., Carletto, C., and Savastano, S. 'Missing(ness) in Action: Selectivity Bias in GPS-Based Land Area Measurements'. World Development, vol. 92 (2017) PP. 143-157.

Kim, K., Chavas, J. P., Barham, B., and Foltz, J. 'Rice, irrigation and downsiderisk: aquantile analysis of risk exposure and mitigation on Korean farms'. European Review of Agricultural Economics, vol. 41(5) (2014) PP. 775-815.

Krishna, V., Keil, A., and Aravindakshan, S. 'Conservation tillage for sustainable wheat intensifi cation in South Asia', in P. Langridge (ed.), Achieving Sustainable Cultivation of Wheat. 
Volume 2. Cultivation Techniques (Cambridge, UK: Burleigh Dodds Science Publishing Limited, 2016a).

Krishna, V., Qaim, M., and Zilberman, D. ‘Transgenic crops, production risk and agrobiodiversity'. European Review of Agricultural Economics, vol. 43(1) (2016b) PP. 137-164.

Krishna, V. V. and Veettil, P. C. 'Productivity and efficiency impacts of conservation tillage in northwest Indo-Gangetic Plains'. Agricultural Systems, vol. 127 (2014) PP. 126-138.

Krupinsky, J. M., Halvorson, A. D., Tanaka, D. L., and Merrill, S. D. 'Nitrogen and tillage effects on wheat leaf spot diseases in the northern Great Plains'. Agronomy Journal, vol. 99(2) (2007) PP. 562-569.

Kumbhakar, S. C., Wang, H.-J., and Horncastle, A. P. 'A Practitioner's Guid to Stochastic Frontier Analysis Using Stata'. (New York, USA: Cambridge University Press, 2015).

Lal, R. 'Managing world soils for food security and environmental quality'. Advances in Agronomy, vol. 74 (2001) PP. 155-192.

Lalani, B., Dorward, P., Holloway, G., and Wauters, E. 'Smallholder farmers' motivations for using conservation agriculture and the roles of yield, labour and soil fertility in decision making'. Agricultural Systems, vol. 146 (2016) PP. 80-90.

Lantican, M. A., Braun, H. J., Payne, T. S., Singh, R. P., Sonder, K., Baum, M., Ginkel, M. and Erenstein, O. 'Impacts of International Wheat Improvement Research, 1994-2014' CIMMYT. (Mexico, D.F., 2016).

Lee, D. R., Barrett, C. B., and McPeak, J. G. 'Policy, technology, and management strategies for achieving sustainable agricultural intensification'. Agricultural Economics, vol. 34(2) (2006) PP. 123-127.

Loss, S., Haddad, A., Khalil, Y., Alrijabo, A., Feindel, D. and Piggin, C. 'Evolution and adoption of conservation agriculture in the Middle East', in: M. Farooq and K. H. M. Siddique (eds.), Conservation Agriculture (Cham: Springer, 2015).

Macharia, C. N., Njeru, C. M., Ombakho, G. A., and Shiluli, M. S. 'Comparative performance of advanced generations of maize hybrids with a local maize variety: agronomic and financial implications for smallholder farmers.'. Journal of Animal and Plant Sciences (JAPS), vol. 7(2) 
(2010) PP. 801-809.

Magnan, N., Lybbert, T. J., Mrabet, R., and Fadlaoui, A. 'The quasi-option value of delayed input use under catastrophic drought risk: the case of no-till in Morocco'. American Journal of Agricultural Economics, vol. 93(2) (2011) PP. 498-504.

Manda, J., Alene, A. D., Gardebroek, C., Kassie, M., and Tembo, G. 'Adoption and impacts of sustainable agricultural practices on maize yields and incomes: evidence from Rural Zambia'. Journal of Agricultural Economics, vol. 67(1) (2016) PP. 130-153.

Manski, C. F. 'Identification of endogenous social effects: the reflection problem'. The Review of Economic Studies, vol. 60(3) (1993) PP. 531-542.

Marasas, C. N., Smale, M., and Singh, R. P. 'The economic impact of productivity maintenance research: Breeding for leaf rust resistance in modern wheat'. Agricultural Economics, vol. 29(3) (2003) PP. 253-263.

Marasas, C. N., Smale, M., and Singh, R. P. 'The Economic Impact in Developing Countries of Leaf Rust Resistance Breeding in CIMMYT-Related Spring Bread Wheat. Economics Program Paper 04-01'. (Mexico, D.F., 2004).

Mather, D. L., Bernsten, R., Rosas, J. C., Viana Ruano, A., and Escoto, D. 'The economic impact of bean disease resistance research in Honduras'. Agricultural Economics, vol. 29 (2003) PP. $343-352$.

Matuschke, I., Mishra, R. R., and Qaim, M. 'Adoption and impact of hybrid wheat in India'. World Development, vol. 35(8) (2007) PP. 1422-1435.

Mazid, A., Keser, M., Amegbeto, K. N., Morgounov, A., Bagci, A., Peker, K., Akin, M. Kucukcongar, M., Kan, M., Semerci, A., Karabak, S., Altikat, A., and Yaktubay, S. 'Measuring the impact of agricultural research: the case of new wheat varieties in Turkey'. Experimental Agriculture, vol. 51(2) (2015) PP. 161-178.

McCann, J. C. 'People of the Plough. An Agricultural History of Ethiopia, 1800-1990'. (Madison: The University of Wisconsin Press, 1995).

Meyer-Aurich, A., Gandorferb, M., Gerld, G., and Kainz, M. 'Tillage and fertilizer effects on yield, profitability, and risk in a corn-wheat-potato-wheat rotation'. Agronomy Journal, vol. 101(6) 
(2009) PP. 1538-1547.

MOA. 'Wheat Production Extension Manual (in Amharic)'. Ethiopia's Ministry of Agriculture (MOA), Ethiopian Institute of Agricultural Research and Agricultural Transformation Agency. (Addis Ababa, 2014).

Morgounov, A., Tufan, H. A., Sharma, R., Akin, B., Bagci, A., Braun, H.-J., Kaya, Y., Keser, M.,Payne, T., Sonder, K., and Mcintosh, R. 'Global incidence of wheat rusts and powdery mildew during 1969 - 2010 and durability of resistance of winter wheat variety Bezostaya 1'. European Journal of Plant Pathology, vol. 132(3) (2012) PP. 323-340.

Morris, M. L., Risopoulos, J., and Beck, D. 'Genetic change in farmer-recycled maize seed: a review of the evidence'. Working Paper - CIMMYT Economics Program, (No. 99/07) (1999) .

Mundlak, Y. 'On the pooling of time series and cross section data'. Econometrica, vol. 46(1) (1978) PP. 69-85.

Ngwira, A. R., Thierfelder, C., Eash, N., and Lambert, D. M. 'Risk and maize-based cropping systems for smallholder Malawi farmers using conservation agriculture technologies'. Experimental Agriculture, vol. 49(4) (2013) PP. 483-503.

Nkonya, E. and Mwangi, W. 'The economic rational of recycling hybrid seeds in Northern Tanzania'. East Africa Journal of Rural Development, vol. 40 (2004) PP. 113-124.

Oerke, E.-C. 'Crop losses to pests'. The Journal of Agricultural Science, vol. 144(1) (2006) PP. 3143.

Ogundari, K. 'The paradigm of agricultural efficiency and its implication on food security in Africa: what does Meta-analysis reveal?'. World Development, vol. 64(1920) (2014) PP. 690-702.

Olivera, P., Newcomb, M., Szabo, L. J., Rouse, M., Johnson, J., Gale, S., Luster, D., Hodson, D., Cox, J., Burgin, L., Hort, M., Gilligan, C., Patpour, M., Justesen, A., Hovmøller, M., Woldeab, G., Hailu, E., Hundie, B., Tadesse, K., Pumphrey, M., Singh, R., and Jin, Y. 'Phenotypic and genotypic characterization of race TKTTF of Puccinia graminis f. sp. tritici that caused a wheat stem rust epidemic in southern Ethiopia in 2013-14'. Ecology and Epidemiology, vol. 105(7) (2015) PP. 917-928.

Pardey, Ph. G., Alston, J. M., Chan-Kang, C., Magalhes, E. C., and Vosti, S. A. 'International and 
institutional R\&D Spillovers: attribution of benefits among sources for Brazil's new crop variteties'. American Journal of Agricultural Economics, vol. 88(1) (2006) PP. 104-123.

Pedzisa, T., Rugube, L., Winter-Nelson, A., Baylis, K., and Mazvimavi, K. 'Abandonment of conservation agriculture by smallholder farmers in Zimbabwe'. Journal of Sustainable Development, vol. 8(1) (2015) PP. 69-82.

Piggin, C., Haddad, A., Khalil, Y., Loss, S., and Pala, M. 'Effects of tillage and time of sowing on bread wheat, chickpea, barley and lentil grown in rotation in rainfed systems in Syria'. Field Crops Research, vol. 173 (2015) PP. 57-67.

Pingali, P. 'Green revolution:impacts, limits, and the path ahead'. Proceedings of the National Academy of Science, vol. 109(31) (2012) PP. 12302-12308.

Pixley, K. and Bänziger, M. 'Open-pollinated maize varieties: a backward step or valuable option for farmers?, in: D. K. Friesen and A. F. E. Palmer (eds). Inntegrated approaches to higher maize productivity in the new millennium. Proc. of the Eastern and Southern Africa Regional Maize Conf., 7th, Nairobi, Kenya. 5-11 Feb. 2002, 2004).

Power, A. G. 'Ecosystem services and agriculture: tradeoffs and synergies.'. Philosophical Transactions of the Royal Society of London. Series B, Biological Sciences, vol. 365(1554) (2010) PP. 2959-2971.

Qaim, M. 'Genetically Modified Crops and Agricultural Development'. (New York,: Palgrave Macmillan, 2016).

Qaim, M., Subramanian, A., Naik, G., and Zilberman, D. 'Adoption of Bt cotton and impact variability: Insights from India'. Review of Agricultural Economics, vol. 28(1) (2006) PP. 4858.

Rabe-Hesketh, S. and Skrondal, A. 'Multilevel and Longitudinal Modeling Using Stata Volume I: Continuous Responses'. 3rd ed. (Texas: Stata Press, 2012).

Ramirez, O. A., Misra, S., and Field, J. 'Crop-yield distributions revisited'. American Journal of Agricultural Economics, vol. 85(1) (2003) PP. 108-120.

Ribaudo, M., Greene, C., Hansen, L., and Hellerstein, D. 'Ecosystem services from agriculture : steps for expanding markets'. Ecological Economics, vol. 69(11) (2010) PP. 2085-2092. 
Savary, S., Bregaglio, S., Willocquet, L., Gustafson, D., Mason D’Croz,D., Sparks, A., Castilla, N.,Djurle, A., Allinne, C., Sharma, M., Rossi, V., Amorim, L., Bergamin, A.,Yuen, J.,Esker, P., McRoberts, N., Avelino, J., Duveiller, E., Koo, J., and Garrett, K. 'Crop health and its global impacts on the components of food security'. Food Security, (2017) PP. 311-327.

Savary, S., Ficke, A., Aubertot, J. N., and Hollier, C. 'Crop losses due to diseases and their implications for global food production losses and food security'. Food Security, vol. 4(4) (2012) PP. 519-537.

Savary, S., Teng, P. S., Willocquet, L., and Nutter, F. W. 'Quantification and modeling of crop losses: a review of purposes'. Annual Review of Phytopathology, vol. 44 (2006) PP. 89-112.

Sen, A. K. 'Peasants and dualism with or without surplus labor'. Journal of Political Economy, vol. 74(5) (1966) PP. 425-450.

Shiferaw, B., Smale, M., Braun, H. J., Duveiller, E., Reynolds, M., and Muricho, G. 'Crops that feed the world 10. Past successes and future challenges to the role played by wheat in global food security'. Food Security, vol. 5(3) (2013) PP. 291-317.

Shiferaw, B., Tesfaye, K., Kassie, M., Abate, T., Prasanna, B. M. and Mekir, A. 'Managing vulnerability to drought and enhancing livelihood resilience in sub-Saharan Africa: technological, institutional and policy options'. Weather and Climate Extremes, vol. 3 (2014a) PP. 67-79.

Shiferaw, B., Kassie, M., Jaleta, M., and Yirga, C. 'Adoption of improved wheat varieties and impacts on household food security in Ethiopia'. Food Policy, vol. 44 (2014b) PP. 272-284.

Shiferaw, B., Prasanna, B. M., Hellin, J., and Bänziger, M. 'Crops that feed the world 6. Past successes and future challenges to the role played by maize in global food security'. Food Security, vol. 3(3) (2011) PP. 307-327.

Sime, G., Aune, J. B., and Mohammed, H. 'Agronomic and economic response of tillage and water conservation management in maize, central rift valley in Ethiopia'. Soil and Tillage Research, vol. 148 (2015) PP. 20-30.

Sisay, D. T., Verhees, F. J. H. M., and van Trijp, H. C. M. 'Seed producer cooperatives in the Ethiopian seed sector and their role in seed supply improvement: A review'. Journal of Crop Improvement, vol. 31(3) (2017) PP. 323-355. 
Smale, M., Singh, R. P., Sayre, K., Pingali, P., Rajaram, S., and Dubin, H. J. 'Estimating the economic impact of breeding nonspecific resistance to Leaf Rust in modern bread wheats' Plant Disease, vol. 82(9) (1998) PP. 1055-1061.

Smale, M., Byerlee, D., and Jayne, and T. 'Maize Revolutions in Sub-Saharan Africa', in K. Otsuka and D. F. Larson (eds), An African Green Revolution: Finding Ways to Boost Productivity on Small Farms (New York: 2013, PP. 165-196).

Sommer, R., Ryan, J., Masri, S., Singh, M., and Diekmann, J. 'Effect of shallow tillage, moldboard plowing, straw management and compost addition on soil organic matter and nitrogen in a dryland barley/wheat-vetch rotation'. Soil and Tillage Research, vol. 115-116 (2011) PP. 3946.

Spielman, D. J. and Smale, M. 'Policy options to accelerate variety change among smallholder farmers in South Asia and Africa south of the Sahara. International Food Policy Research Institute (IFPRI)'. IFPRI Discussion Paper, vol. 1666 (2017) .

Stevenson, J. R., Serraj, R., and Cassman, K. G. 'Evaluating conservation agriculture for smallscale farmers in Sub-Saharan Africa and South Asia'. Agriculture, Ecosystems and Environment, vol. 187 (2014) PP. 1-10.

Stuthman, D. D., Leonard, K. J., and Miller-Garvin, J. 'Breeding crops for durable resistance to disease'. Advances in Agronomy, vol. 95 (2007) PP. 319-367.

Sumberg, J. 'Opinion: the effects of technology adoption on food security: linking methods, concepts and data'. Food Security, vol. 8(6) (2016) PP. 1037-1038.

Suri, T. 'Selection and Comparative Advantage in Technology Adoption'. Econometrica, vol. 79(1) (2011) PP. 159-209.

Tadesse, K., Ayalew, A., and Badebo, A. 'Effect of fungicide on the development of wheat stem rust and yield'. African Crop Science Journal, vol. 18(1) (2010) PP. 23-33.

Teklewold, H., Kassie, M., and Shiferaw, B. 'Adoption of Multiple Sustainable Agricultural Practices in Rural Ethiopia'. Journal of Agricultural Economics, vol. 64(3) (2013a) PP. 597623.

Teklewold, H., Kassie, M., Shiferaw, B., and Köhlin, G. 'Cropping system diversification, 
conservation tillage and modern seed adoption in Ethiopia: impacts on household income, agrochemical use and demand for labor'. Ecological Economics, vol. 93 (2013b) PP. 85-93.

Teklewold, H. and Mekonnen, A. 'The tilling of land in a changing climate: panel data evidence from the Nile Basin of Ethiopia'. Land Use Policy, vol. 67 (2017) PP. 449-459.

Temesgen, M., Rockstrom, J., Savenije, H. H. G., Hoogmoed, W. B., and Alemu, D. 'Determinants of tillage frequency among smallholder farmers in two semi-arid areas in Ethiopia'. Physics and Chemistry of the Earth, vol. 33(1-2) (2008) PP. 183-191.

Tessema, Y., Asafu-Adjaye, J., Rodriguez, D., Mallawaarachchi, T., and Shiferaw, B. 'A bioeconomic analysis of the benefits of conservation agriculture: the case of smallholder farmers in Adami Tulu district, Ethiopia'. Ecological Economics, vol. 120 (2015) PP. 164-174.

Tew, B. V, Rafsnider, G. T., Lybecker, D. W., and Chapman, P. L. 'The relative risk efficiencies of alternative tillage practices for irrigated corn production'. North Central Journal of Agricultural Economics, vol. 8(1) (1986) PP. 83-191.

Tilman, D., Cassman, K. G., Matson, P. A., Naylor, R., and Polasky, S. 'Agricultural sustainability and intensive production practices'. Nature, vol. 418(6898) (2002) PP. 671-677.

Tolemariam, A., Jaleta, M., Hodson, D., Alemayehu, Y., Yirga, C. and Abeyo, B. 'Wheat Varietal Change and Adoption of Rust Resistant Wheat Varieties in Ethiopia 2009/10-2013/14. CIMMYT. (Addis Ababa, 2016).

UN. 'United Nations' draft outcome document of the United Nations summit for the adoption of the post-2015 development agenda. Sixty-ninth session, A/69/L.85'. (2015) .

Velu, G. and Singh, R. P. 'Phenotyping in Wheat Breeding', in S. K. Panguluri and A. A. Kumar (eds), Phenotyping for plant breeding: applications of phenotyping methods fro crop improvement (New York: Springer, 2013 pp. 42-71).

Wainaina, P., Tongruksawattana, S., and Qaim, M. 'Tradeoffs and complementarities in the adoption of improved seeds, fertilizer, and natural resource management technologies in Kenya'. Agricultural Economics, vol. 47 (2016) PP. 1-12.

Wainaina, P., Tongruksawattana, S., and Qaim, M. 'Synergies between different types of agricultural technologies: insights from the Kenyan small farm sector'. The Journal of 
Development Studies, (2017) PP. 1-17.

Walker, T. S. and Alwang, J. 'Crop Improvement, Adoption and Impact of Improved Varieties in Food Crops in Sub-Saharan Africa'. (Wallingford: CABI, 2015).

Wang, H., Liu, C., and Zhang, L. 'Water-saving agriculture in China: an overview'. Advances in Agronomy, vol. 75 (2002) PP. 135-171.

Wanyama, J.M., Mose, L.O., De Groote, H., Mutoko, M.C., Kigen, W.M., De Groote, H. Economics of recycling late maturing hybrid maize seed in North West Kenya, In Wasilwa, L., et al. (eds), Agricultural Research for Improved Productivity and Livelihoods. Proceedings of the 9th KARI Biennial Scientific Conference, Nairobi, 8-12 November. KARI. (Nairobi, 2006, PP. 638-643).

Weiner, J., Griepentrog, H., and Kristensen, L. 'Suppression of weeds by spring wheat Triticum aestivum'. Journal of Applied Ecoology, vol. 38 (2001) PP. 784-790.

Williams, J. R., Llewelyn, R. V, and Barnaby, G. A. 'Risk analysis of tillage alternatives with government programs'. American Journal of Agricultural Economics, vol. 72(1) (1990) PP. $172-181$.

World Bank. 'Sustainable agricultural productivity growth and bridging the gap for small-family farms (English). Interagency Report to the Mexican G20 Presidency'.(Washington, DC, 2012).

World Bank. 'The 2017 global poverty update from the World Bank. Let's talk development'. (2017) . http://blogs.worldbank.org/developmenttalk/2017-global-poverty-update-world-bank (accessed April 30, 2018).

$\mathrm{Xu}, \mathrm{X}$. and Jeffrey, S. 'Efficiency and technical progress in traditional and modern agriculture: evidence from rice production in China'. Agricultural Economics, vol. 18 (1998) PP. 157-165.

Yami, M., Benga, B., Terefe, G., Solomon, T., Tilahun, W., Eticha, F. and others 'Enhancing Adoption of Rust Tolerant Wheat Varieties: Experience of EAAPP in Ethiopia'. Ethiopian Institute of Agricultural Research. (Addis Ababa, 2012).

Zeng, D., Alwang, J.,Norton, G.W., Shiferaw, B., Jaleta, M., and Yirga, C. 'Maize technologies and rural poverty reduction in Ethiopia', in Walker, T. S. and Alwang, J. (eds), Crop Improvement, Adoption and Impact of Improved Varieties in Food Crops in Sub-Saharan Africa 
(Oxfordshire: CABI, 2015, pp. 294-313).

Zerihun, T., Firdissa, E., Fekadu, F., Kebede, T., Mathewos, A., Mohamed, A. and others 'Exploiting yield potential of Ethiopian commercial bread wheat (Triticum aestivum L.) varieties outside their original recommended domains'. Wheat for Food Security in Africa Conference. (Addis Ababa, 2012). 